

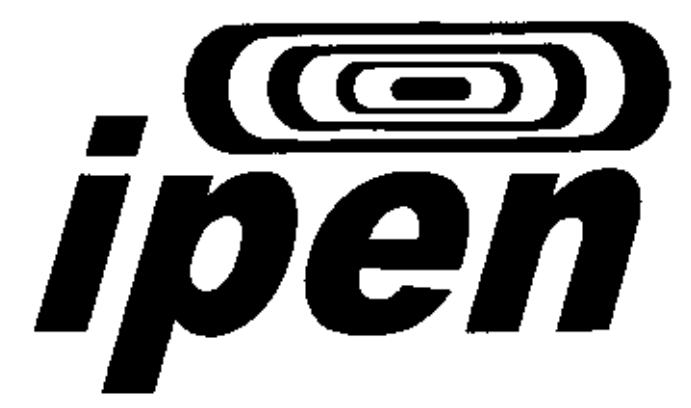

AUTARQUIA ASSOCIADA À UNIVERSIDADE DE SÃO PAULO

\title{
ESTUDO DA APLICAÇÃO DE ARGILAS NANOESTRUTURADAS EM RESINAS RESTAURADORAS FOTOATIVADAS, UTILIZADAS EM ODONTOLOGIA
}

\section{LUIZA MELLO DE PAIVA CAMPOS}

\author{
Tese apresentada como parte \\ dos requisitos para obtenção do Grau \\ de Doutor em Ciências na Área de \\ Tecnologia Nuclear - Materiais \\ Orientadora: \\ Prof?. Dra. Duclerc Fernandes Parra \\ Co-Orientador \\ Prof. Dr. Mário Ramalho de \\ Vasconcelos
}

São Paulo 
"Valeu a pena? Tudo vale a pena

Se a alma não é pequena.

Quem quer passar além do Bojador

Tem que passar além da dor.

Deus ao mar o perigo e o abismo deu,

Mas nele é que espelhou o céu."

Fernando Pessoa

Dedico esse trabalho aos meus pais Jorge e Sueli e às minhas irmãs Carolina e Mariana, meus maiores incentivadores, meus verdadeiros amores e a razão de eu existir. 


\section{AGRADECIMENTOS}

À Profo. Dra . Duclerc Fernandes Parra, pela generosa orientação, dedicação à realização desse trabalho e por acreditar em mim e no meu potencial. Du, você que para mim é um grande exemplo profissional e pessoal, minha eterna gratidão!

Ao Profo. Dro‥ Mário Ramalho Vasconcelos, por me co-orientar, me receber em Portugal de maneira tão prestativa e me apoiar na realização desse trabalho.

À CAPES pela bolsa de Doutorado no exterior (Processo: 0253-10-3).

À FGM do Brasil e a Southern Clay Products, pela doação dos materiais.

Ao Prof $^{\circ}$ Dro Fernando Moreira, ao Profo $^{\circ}$ Dro $^{\circ}$ José Carlos Bressiani, ao Profo $^{\circ}$ Dro Roberto Frajndlich, a Ana Cláudia Feher e a Magali Silva, por me ajudarem a enfrentar todos os obstáculos e burocracia na realização do doutorado co-tutela. Muito obrigada por tudo!

Ao colega Eleosmar Gasparin, técnico do Laboratório de Polímeros e Nanotecnologia, por toda a ajuda na realização das análises, pelos momentos de convívio e por ser sempre tão prestativo e paciente comigo. Muito obrigada por tudo!

À Maria José Alves e Henrique Perez, por todas as palavras de incentivo, pela torcida, por toda a ajuda prestada, pela paciência, pela amizade, pelos momentos de alegria, por me levantarem nos momentos de tristeza, por me fazerem companhia até mais tarde no laboratório, por me ensinarem a plotar os gráficos e formatar os textos com tanta paciência, por estarem sempre ao meu lado e por serem meus grandes companheiros nessa jornada. Saibam que sempre podem contar comigo e eu nunca vou esquecer da generosidade de vocês!

Ao querido amigo Luis Martins, por sua ajuda ter sido fundamental para minha aprovação nos créditos obrigatórios e por entender que física nuclear, reatores nucleares, proteção radiológica e tecnologia de materiais, não são 
conteúdos simples de serem absorvidos por uma cirurgiã dentista recém-formada. Lu, um dia espero ser uma professora tão competente quanto você. Obrigada por ser esse grande exemplo de humildade e humanidade.

À amiga Letícia Boaro, por sempre me apoiar, me lembrar que esse desafio vale a pena e por ser sempre tão compreensiva e humilde comigo. Obrigada Le!

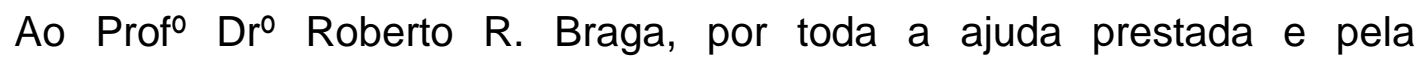
colaboração.

A todos os Professores da Faculdade de Medicina Dentária da Universidade do Porto, em especial ao Prof ${ }^{\circ}$ Dro - Mário Jorge Silva e Prof ${ }^{\underline{a}}$ Ana Portela, pela amizade, colaboração e por serem grandes exemplos de profissionas a serem seguidos.

Às funcionárias da Faculdade de Medicina Dentária da Universidade do Porto Carla Pinto e Eugênia (Geninha), por serem tão prestativas comigo!

Aos Professores da Faculdade de Engenharia da Universidade do Porto, Profo Dro Mário Vaz, Profo Dro Jaime Monteiro e ao Engenheiro Nuno, por toda a colaboração.

Aos meus queridos amigos da faculdade, especialmente a Dra. Renata Menezes, Dra. Letícia Oliveira, Dra. Vanessa Kaspinski, Dr. Pedro Quintela, Dr. Vinícius Silva e Dr. Pedro Jorge, por sempre torcerem pelo meu crescimento. Não importa o tempo e a distância, trago comigo todas as maravilhosas recordações dos tempos de faculdade. Obrigada por fazerem parte da minha história!

À Janaína Reis, Bárbara Monteiro e Milena di Gioia, pelo incondicional apoio e colaboração. Obrigada por estarem sempre ao meu lado no consultório e por torcerem tanto por mim! Vocês são meninas talentosíssimas e eu admiro muito vocês!

Aos amigos Luciano Rota, Ricardo da Silveira, Edson Goto, Celene Luiza, Laise Zenly, Maria Anita, Hilton Mariano e Rodrigo Rolim, por levarem um pouco do 
calor brasileiro ao inverno de Portugal. A visita de vocês me emocionou muito, obrigada!

Ao Rui Pina, Suzana Gonçalves, Daniela Maia, David Almeida, José Ruy, José Sousa, Nuno, e toda Família do Breyner 85. Obrigada por tornar minha estadia no Porto inesquecível!

À "Levadas da Broca" (que é formada pelas gajas mais giras de Portugal), à "Tuna da Engenharia da Universidade do Porto" (os melhores pandeiretas) e à "Tuna da Faculdade de Medicina Dentária da Universidade do Porto" (a Tuna mais Tuna), que por tantas vezes me emocionaram com vossos talentos. Minha eterna admiração e gratidão por todos os maravilhosos momentos que tivemos juntos!

Aos meus queridos alunos da Faculdade de Medicina Dentária da Universidade do Porto pela importantíssima troca de conhecimento. Ensinar e aprender com vocês, foi sem dúvida a melhor experiência profissional que já tive.

À minha "Família Clandestina", especialmente a Dra. Carolina Gaspar e Dra. Naliane Zenly, pelo incondicional apoio e torcida. Corações, me orgulho muito de fazer parte desse clã de amigos e por ter a oportunidade de passar momentos tão marcantes de nossas vidas juntos! Obrigada por tudo! Levo sempre vocês em meu coração!

Aos amigos da árvore Klaus Siperek, Fernando, Daniel e Adressa Farah, Rose Tonizo, Marcelo Ferreira, Paula Ikematsu, Natália Maia, Maria Fernanda Moraes, Denise Fernandes, João Paulo, Milene Scaranalle, Aluísio Godoy e Rafael Melo, por sempre me incentivarem com gestos tão carinhosos e por serem meus "irmãos mais velhos"!

Aos queridíssimos amigos, Carlos Eduardo Pinto, Mariana Dias, Carlos Eduardo Campos, Guilherme Andrada, Juliana Moreno, Davi Andrada, Rafael Ferreira, Eduardo Rezende, Leandro Bertoni, Jonathan Andres e a todos os amiguinhos do Tatuapé, por fazerem parte da minha vida e por torcerem tanto por $\operatorname{mim!}$

À Mafalda Moreira e família, ao Pedro Lhorca, Luis Miguel Gaio, Luís e Mariana Barros, Mariana e Sofia Golstraw, João Silva (Foto), Álvaro Vaz, Maria 
João, Rita Duro, Antônio Ferreira, Alex Roda e Ana Carolina Novo, pelos maravilhosos momentos que passamos juntos!

Aos meus queridos pacientes clínicos, pela fidelidade, compreesão e apoio!

Ao meu querido primo e padrinho Dr. Ariovaldo Stefani, por ser o maior exemplo no árduo ofício de cirurgião dentista. Obrigada por toda ajuda, por todas as críticas construtivas, por acreditar no meu potencial e por me ensinar que somente com muito trabalho e disciplina, é que chegamos a excelência. Você para mim é o melhor dentista do mundo! Obrigada por tudo, Ari!

Ao Profo Dro Joaquim Morgado (Quim), Ana Paula Morgado, João Pedro Morgado, Ricardo Jorge Morgado, Athaíde Travanca (Pires), Maria Natália Travanca (Mimas), Margarida Travanca (Guida), João Paulo Travanca, Pedro Travanca e aos miúdos André e Sofia, por me receberem como parte da família e por serem sempre tão maravilhosos comigo! Eu nunca vou esquecer de todo o carinho, ajuda, torcida e apoio que vocês me deram! Minha eterna gratidão!

Às amigas Anaíde Sunamita Cohen, Lys Junia Alonso e Luciana Figueiredo por serem amigas tão maravilhosas! Aonde quer que eu vá, eu levo vocês junto comigo! Obrigada pelas risadas, pelas viagens, pelos concertos, pelas "Jam Sessions", por nossas tardes na praia, por nossos jantares incríveis, pelas noites no Piolho, pelos colóquios de literatura, pelos festivais de música e por sempre me fazerem chorar quando lembro desses momentos. Obrigada por me ensinar que a amizade verdadeira vence a distância e o tempo. Eu amo muito vocês! E nunca se esqueçam: sempre vai haver uma próxima viagem!

Às amigas Diva do Nascimento, Denise Tavares, Andréia Garibaldi, Carolina Guimalhães, Karen di Stefano e Bianca Zucarato, pela lealdade, amizade, confiança, carinho, torcida e pelo total apoio! Você estão comigo para o que der vier e eu fico muito grata de poder contar com vocês. Obrigada por serem a verdadeira tradução do que a amizade significa. Amo e admiro muito vocês, minhas incondicionais amigas! 
Aos meus segundos pais, Tereza Machado, Maria José Ângelo, Carlos Ângelo, Cremilde Stefani, Zulmira Nascimento, Mathilde Casagrande, João Carlos Casagrande, Regina Alencar, Ana Lúcia Soares, Andréia Augusto, Bernardo Carvalho, Maria do Carmo e Marcelo Ricardo de Mello, por fazeram parte da minha vida desde o dia que nasci. Amo vocês!

À toda família Paiva Campos, especialmente aos meus avós Neuza e José.

Aos meus primos Michele, Érica, Vinícius, Bárbara, Ramon, Lucas, João, Pedro, Maria Eduarda, Natália, André, Aruan, Gabriela, Felipe, Anderson, Denise, Ana Paula, Clara e Júlia. Foi uma honra crescer ao lado de vocês!

Aos meus irmãos do coração, Alexandre Ângelo da Silva e Paulo Alexandre Pontes, por serem meu porto seguro, meus melhores amigos e por sempre estarem ao meu lado! Agradeço muito a Deus por ter me dado os melhores irmãos que alguém poderia ter!

Aos meus avós, Leonor e Euclides, por serem as melhores pessoas com que eu já convivi na vida! Vocês são a minha maior preciosidade. Obrigada por serem tão maravilhosos. Amo vocês eternamente!

E à Deus, por ter me presenteado com a minha maravilhosa família. Pai e Mãe, obrigada por serem o meu maior exemplo de honestidade, caráter, integridade e por todo o incentivo, compreensão e amor. Carol e Mari, obrigada por sempre estarem ao meu lado, por fazerem parte da minha vida e por eu ser tão feliz. A vocês, dedico minha vida e todo meu amor! 


\title{
ESTUDO DA APLICAÇÃO DE ARGILAS NANOESTRUTURADAS EM RESINAS RESTAURADORAS FOTOATIVADAS, UTILIZADAS EM ODONTOLOGIA
}

\author{
Luiza Mello de Paiva Campos
}

\section{RESUMO}

O problema ocasionado pela contração de polimerização é crítico, pois a resina composta deve conservar-se intimamente ligada à cavidade dentária enquanto ganha rigidez e diminui suas dimensões. Forçando-se o material restaurador a se distanciar, ou se separar das paredes da cavidade, a consequente ruptura levaria a uma microinfiltração marginal responsável por outros problemas tais como a cárie secundária, sensibilidade dolorosa pós-operatória, podendo até provocar alterações pulpares. Este processo induz a alteração volumétrica do composto, dado pela união de radicais na formação da macromolécula (polímero), causando uma diminuição em seu volume. Esse estudo teve como objetivo desenvolver novos compósitos experimentais, por meio da adição de nanocomponentes argilominerais em uma matriz polimérica a base de BisGMA/TEGDMA, para que assim se avalie a possibilidade de ocorrer um comportamento dimensional diferenciado no decorrer da polimerização. Foram utilizados nesse estudo matrizes poliméricas adicionadas com nanopartículas argilominerais MMT Cloisite $10 A^{\circledR}$ (nas concentrações de 50, 55, 60, 65 e 70\% em massa) e Cloisite $30 \mathrm{~B}^{\circledR}$ (nas concentrações de 50, 55, 60 e 65\% em massa), que posteriormente foram comparados com 0 desempenho de compósitos experimentais adicionados com partículas micro-híbridas de Sílica Silanizada Aerosil $^{\circledR}$ OX-50 ( nas concentrações de 50, 60, 65 e 70\% em massa). Foram utilizados os métodos de caracterização: Microscopia Eletrônica de Varredura 
(MEV), Análise Térmica-Mecânica (TMA), Análise de Termogravimetria (TGA), Calorimetria Exploratória Diferencial (DSC), Espectroscopia de Absorção na Região do Infravermelho (FTIR), Difração de Raio-X (DRX), Micro Dureza Knoop, Técnica de Interferometria Holográfica (TIH), Holografia Digital (HD), Correlação de Imagem (Cl) e Termografia. Foi observado que os compósitos experimentais adicionados com as nanopartículas argilominerais Cloisite $10 \mathrm{~A}^{\circledR}$ e Cloisite $30 \mathrm{~B}^{\circledR}$, apresentaram um melhor desempenho nos ensaios que mensuraram a contração de polimerização (TMA, TIH/HD/Cl) e a micro dureza (Knoop), em relação aos compósitos adicionados com a Sílica Aerosil ${ }^{\circledR}$ OX-50. Esses resultados podem estar relacionados pela interação polímero /argila e pela formação de nanocompósitos, observados pela análise de DRX. Entre as nanopartículas estudadas, a Cloisite $30 \mathrm{~B}^{\circledR}$ apresentou os resultados mais expressivos em relação a nanopartícula Cloisite $10 \mathrm{~A}^{\circledR}$ e isso pode ser atribuído a afinidade química e a natureza polar da referida nanopartícula. 


\title{
STUDY OF NANOSTRUCTURED CLAY'S APPLICATION IN PHOTOACTIVATED RESTORATIVE RESINS, USED IN DENTISTRY
}

\section{Luiza Mello de Paiva Campos}

\begin{abstract}
The problem caused by polymerization shrinkage is critical, because the resin must to remain closely in the tooth cavity while gaining rigidity and decrease its dimensions. Forcing the restorative material to distance or to separate the walls of the cavity, the resulting disruption would lead to microleakage, responsible for other problems such as secondary caries, postoperative soreness and may even cause pulpal changes. This process induces the volumetric change of the compound, given by the union of radicals in the formation of the macromolecule (polymer), causing a decrease in volume. This study aimed to develop new experimental composites through the addition of nano components clay minerals in a polymer matrix-based BisGMA / TEGDMA, to evaluate the possibility of a different dimensional behavior during the polymerization. Were used in this study, experimental composites added nanoparticle clay MMT Cloisite \& 10A (at concentrations of $50,55,60,65$ and 70 wt\%) and Cloisite $\AA 30 \mathrm{~B}$ (at concentrations of 50,55, 60 and $65 \mathrm{wt} \%$ ), which were then compared with the performance of the experimental composites added with micro-particles of silanized silica hybrid Aerosil OX-50 $\AA$ (at concentrations of 50, 60, 65 and 70 wt\%). Was used the methods of characterization: Scanning Electron Microscopy (SEM), Thermal-Mechanical Analysis (TMA), Thermogravimetric Analysis (TGA), Differential Scanning Calorimetry (DSC), Absorption Spectroscopy in the Region of the Infrared (FTIR), X-ray Diffraction (XRD), Micro Hardness Knoop, Holographic Interferometry Technique (HIT), Digital Holography (DH), Correlation
\end{abstract}


Image $(\mathrm{Cl})$ and Thermography. It was observed that the experimental composites with nanoparticles added clay Cloisite $\AA 10 \mathrm{~A}$ and Cloisite $\AA 30 \mathrm{~B}$, performed better on tests that measured the polymerization shrinkage (TMA, HIT / HD / IC) and the micro hardness (Knoop), in relation to composites added with Silica Aerosil OX-50 $\AA$. These results may be related to the interaction polymer / clay and the nanocomposites formation, observed by XRD analysis. Among the nanoparticles studied, the Cloisite ${ }^{\circledR} 30 \mathrm{~B}$ showed the most significant results in relation to the nanoparticle Cloisite $\AA 10 A$ and this can be attributed to chemical affinity and polar nature of that nanoparticle. 


\section{SUMÁRIO}

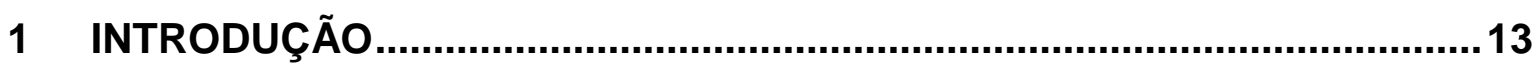

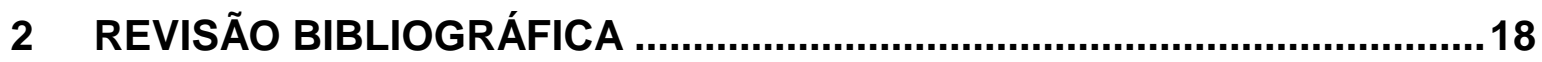

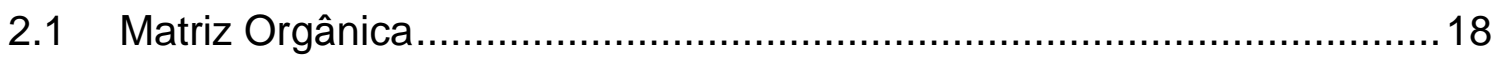

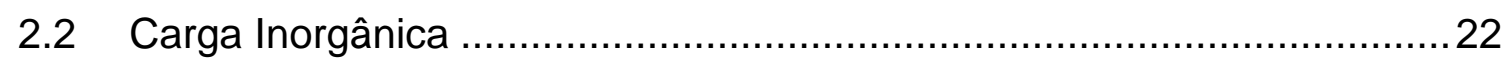

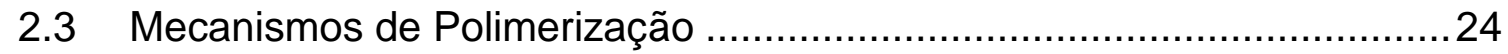

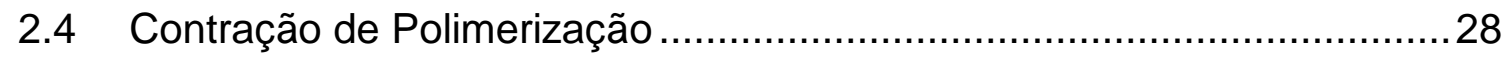

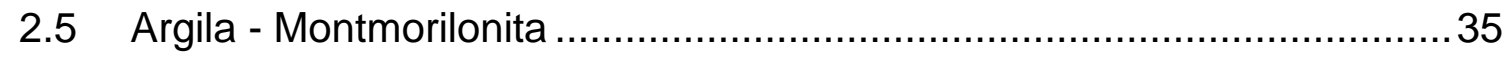

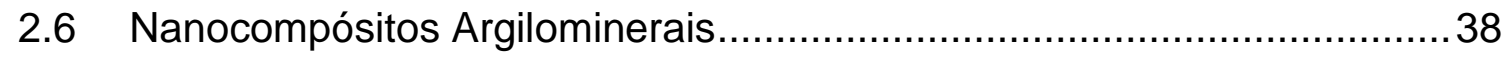

2.6.1 Técnica de Interferometria Holográfica $(\mathrm{TIH})$.................................44

3 OBJETIVO

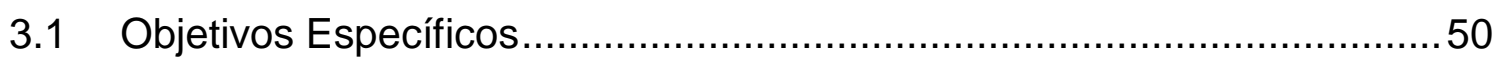

4 MATERIAIS

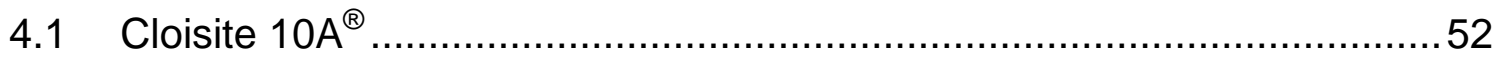

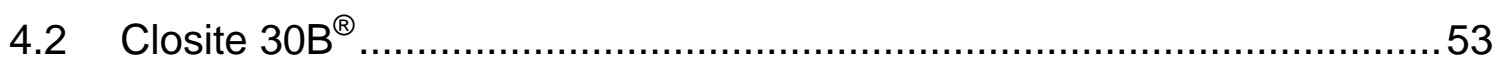

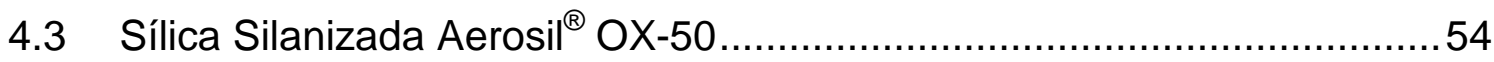

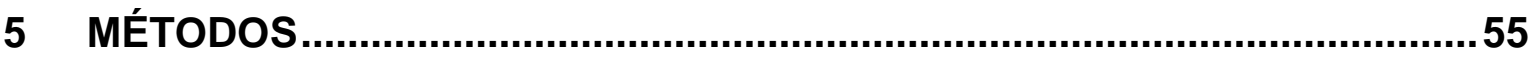

5.1 Confecção dos Compósitos Experimentais...........................................55

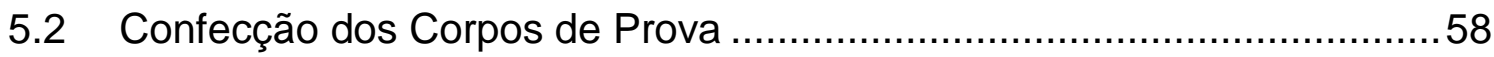

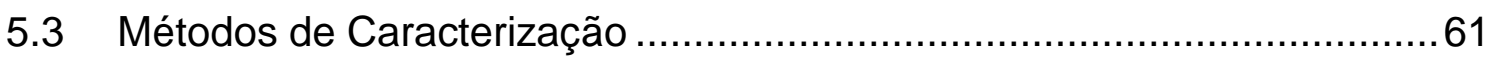

5.3.1 Microscopia Eletrônica de Varredura - (MEV) .................................61

5.3.2 Análise Térmica-Mecânica - (TMA) ................................................62

5.3.3 Análise de Termogravimetria - (TGA) ………............................64

5.3.4 Calorimetria Exploratória Diferencial - (DSC) …............................64

5.3.5 Espectroscopia de Absorção na Região do Infravermelho - (FTIR) .. 65 


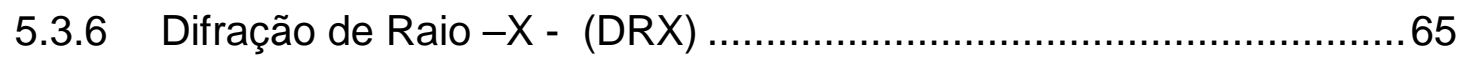

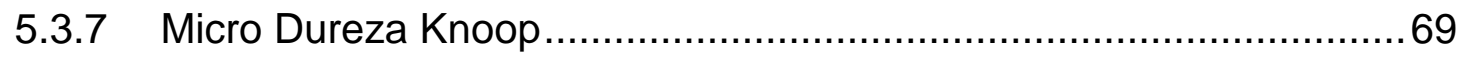

5.3.8 Técnica de Interferometria Holográfica $(\mathrm{TIH})$................................70

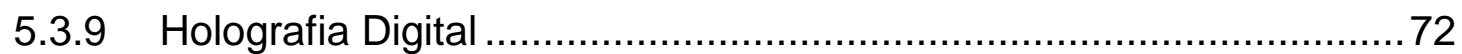

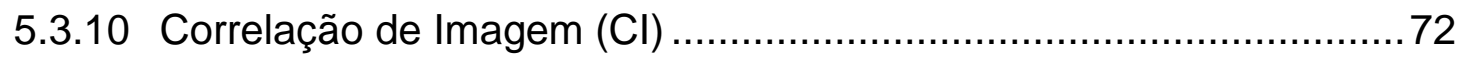

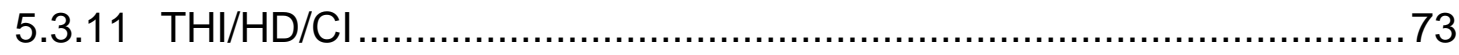

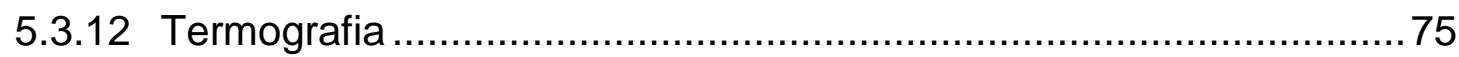

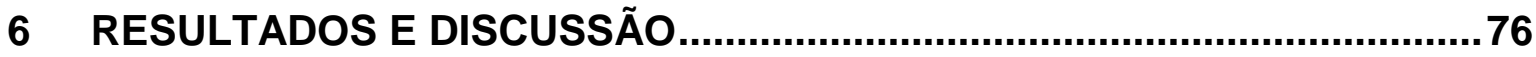

6.1 Microscopia Eletrônica de Varredura - (MEV) …………………..........76

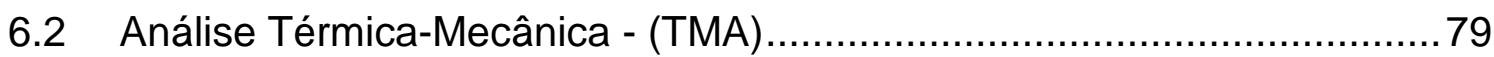

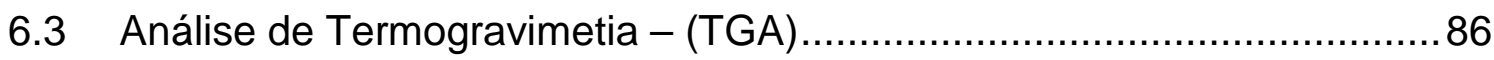

6.4 Calorimetria Exploratória Diferencial - (DSC) ......................................92

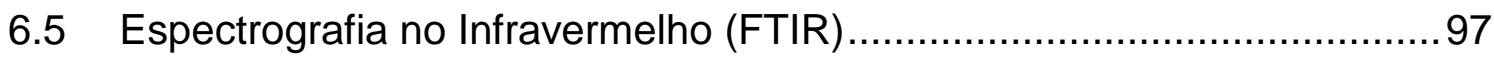

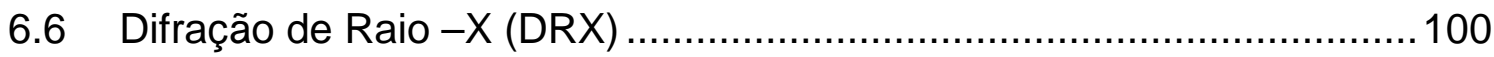

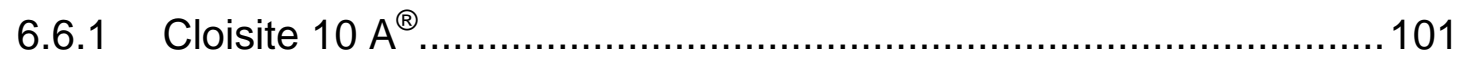

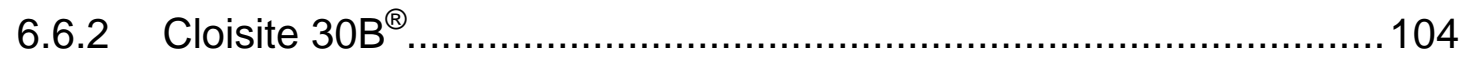

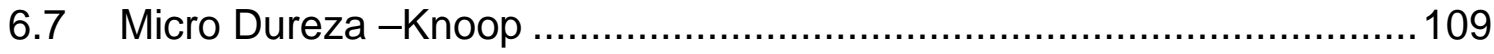

$6.8 \mathrm{THI} / \mathrm{HD} / \mathrm{Cl}$

6.8.1 Dentes Artificiais...............................................................112

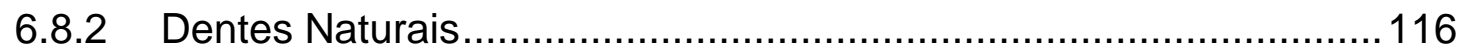

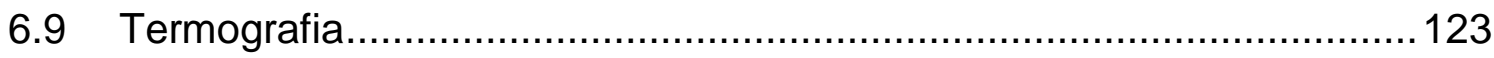

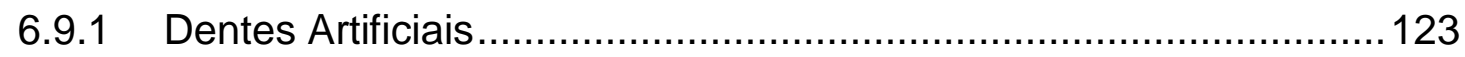

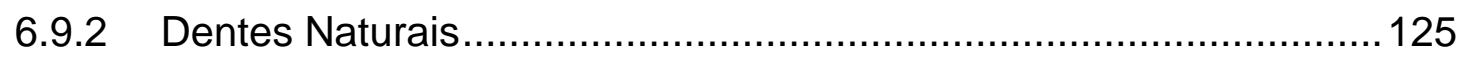

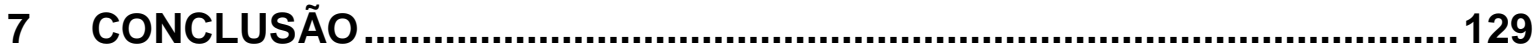

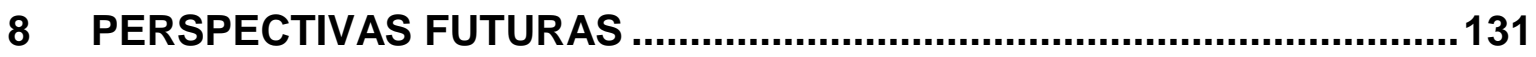

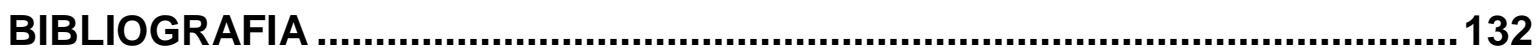




\section{LISTA DE FIGURAS}

FIGURA 1: Estrutura, classificação e fórmula geral da montmorilonita (Zanetti e Costa, 2004).

FIGURA 2: Estrutura da galeria (espaçamento basal) da Montmorilonita (Paiva et al.,2008)

FIGURA 3: Dispersão do sistema matriz polimérica/MMT (Vaia et al,.1995)

FIGURA 4: Tipos de estruturas que podem ocorrer quando uma argila é dispersa em uma matriz polimérica (Alexandre e Dubois, 2000). .43

FIGURA 5: Visualização de um padrão de "speckle" típico (a) e um "speckle" com franjas de interferência (b), associado com o deslocamento molecular, decorrente da contração de polimerização sofrida pela amostra. .46

FIGURA 6: Dimetil Di“tallow" hidrogenado de amônio quaternário (2MBHT) ......52 FIGURA 7: Metil "tallow" bis-2-hidroxetil amônio quaternário (MT2EtOH).

FIGURA 8: Etapas da confecção das amostras: pesagem na balança digital de precisão (a), verificação da espessura por meio de um paquímetro digital (b) e vista superior dos corpos de prova prontos (c).

FIGURA 9: Vista lateral e superior de um corpo de prova de dente artificial (a-b) e a vista superior de um corpo de prova de dente natural (c) 61

FIGURA 10: Imagens do aparelho de Análise Térmica Mecânica (TMA). 62

FIGURA 11: Sequência da inserção do corpo de prova no aparelho TMA. (a) Levantamento da haste. (b) Ajuste do posicionamento do sensor sobre o corpo de prova. (c) Ajuste da abertura do forno. (d) Fotopolimerizador acoplado.

FIGURA 12: Aparelho utilizado para as análises de DRX. 66

FIGURA 13: Os diferentes estados da dispersão da argila em relação ao polímero, pela análise de DRX: (a) sem interação argila/polímero, (b) argila intercalada em relação ao polímero e (c) argila esfoliada em relação ao polímero.

FIGURA 14: Corpos de provas prontos para a análise de DRX. 68 
FIGURA 15: llustração da área de análise da micro dureza Knoop. .70

FIGURA 16: Dispositivo experimental de um sistema de TIH. .71

FIGURA 17: Dispositivo experimental de um sistema de HD. .72

FIGURA 18: Plano cartesiano do princípio básico de funcionamento da $\mathrm{Cl}$.........73

FIGURA 19: Visão lateral da metodologia THI/HD/Cl........................................74

FIGURA 20: Visão frontal da metodologia THI/HD/Cl. ....................................74

FIGURA 21: Micrografia de MEV: Cloisite $10 A^{\circledR}$ (a) e Cloisite $30 B^{\circledR}$ (b) puras......76

FIGURA 22: (a-b) Micrografia de MEV Grupo 1 (50A) com oito e doze mil vezes de aumento. (c-d) Micrografia de MEV Grupo 3 (60A) com oito e doze mil vezes de aumento.

FIGURA 23: (a-b) Micrografia de MEV Grupo 5 (70A) com oito e doze mil vezes de aumento. (c-d) Micrografia de MEV Grupo 6 (50B) com oito e doze mil vezes de aumento.

FIGURA 24: (a-b) Micrigrafia de MEV Grupo 8 (60B) com oito e doze mil vezes de aumento. (c-d) Micrografia de MEV Grupo 9 (65B) com oito e doze mil vezes de aumento.

FIGURA 25: Comparação do desempenho de contração de polimerização em relação ao tipo e concentração das cargas inorgânicas: Sílica Aerosil OX-50, Cloisite $10 \mathrm{~A}^{\circledR}$ e Cloisite 30B $\mathrm{B}^{\circledR}$.

FIGURA 26: Curvas de contração de polimerização registradas pela metodologia TMA. (a) Grupo1(50A). (b) Grupo 2(55A). (c) Grupo 3(60A). (d) Grupo 4(65A). (e) Grupo 5(70A). .82

FIGURA 27: Curvas de contração de polimerização registradas pela metodologia TMA. (a) Grupo 6(50B). (b) Grupo 7(55B). (c) Grupo 8(60B). (d) Grupo 9(65B)...83 FIGURA 28: Curvas referentes a decomposição térmica pela metodologia TGA. (a) Grupo 1(50A). (b) Grupo 2(55A). (c) Grupo 3(60A). (d) Grupo 4 (65A). (e) Grupo 5(70A).

FIGURA 29: Curvas referentes a decomposição térmica pela metodologia TGA.

(a) Grupo 6(50B). (b) Grupo 7(55B). (c) Grupo 8(60B). (d) Grupo 9 (65B). .88 
FIGURA 30: Curvas referentes a decomposição térmica pela metodologia TGA.

(a) Grupo 10(50S). (b) Grupo 11(60S). (c) Grupo 12(65S). (d) Grupo 13 (70S). ..89

FIGURA 31: Comparação por meio da análise DSC de uma amostra não polimerizada (A) e uma amostra previamente polimerizada pela metodologia TMA (B), do Grupo 1(50A) .93

FIGURA 32: Comparação por meio da análise DSC de uma amostra não polimerizada (A) e uma amostra previamente polimerizada pela metodologia TMA (B), do Grupo 2(55A)

FIGURA 33: Comparação por meio da análise DSC de uma amostra não polimerizada da (A) e uma amostra previamente polimerizada pela metodologia TMA (B), do Grupo 3(60A).

FIGURA 34: Comparação por meio da análise DSC de uma amostra não polimerizada (A) e uma amostra previamente polimerizada pela metodologia TMA (B), do Grupo 5(70A).

FIGURA 35: : Comparação por meio da análise DSC de uma amostra não polimerizada (A) e uma amostra previamente polimerizada pela metodologia TMA (B), do Grupo 6(50B) .95

FIGURA 36: Comparação por meio da análise DSC de uma amostra não polimerizada (A) e uma amostra previamente polimerizada pela metodologia TMA (B), do Grupo 7(55B).

FIGURA 37: Comparação por meio da análise DSC de uma amostra não polimerizada (A) e uma amostra previamente polimerizada pela metodologia TMA (B), do Grupo 8(60A).

FIGURA 38: Comparação por meio da análise DSC de uma amostra não polimerizada (A) e uma amostra previamente polimerizada pela metodologia TMA (B), do Grupo 9(65B)

FIGURA 39: Comparação por meio da análise DSC de uma amostra não polimerizada (A) e uma amostra previamente polimerizada pela metodologia TMA (B), do Grupo 10(50S).

FIGURA 40: Espectrografia por infravermelho das nanopartículas argilominerais Cloisite $10 A^{\circledR}$ e $30 B^{\circledR}$ puras. 
FIGURA 41: Espectrografia no infravermelho da matriz polimérica a base de BisGMA e TEGDMA, sem nenhum tipo de carga.

FIGURA 42: Espectrografia no infravermelho dos Grupos de compósitos experimentais adicionados com a nanopartícula argilomineral Cloisite $10 A^{\circledR}$. 99

FIGURA 43: Espectrografia no infravermelho dos Grupos de compósitos experimentais adicionados com a nanopartícula argilomineral Cloisite $30 \mathrm{~B}^{\circledR} \ldots . .100$ FIGURA 44: Difratograma da nanopartícula argilomineral Cloisite 10A ${ }^{\circledR}$ pura para obtenção do "d" inicial. 101

FIGURA 45: Difratograma dos Grupos de compósitos experimentais adicionados com a nanopartícula argilomineral Cloisite $10 A^{\circledR}$. (Grupo 1(50A), 2(55A), $3(60 \mathrm{~A})$, 4 (65)A e 5(70A)). 102

FIGURA 46: Difratograma dos compósitos experimentais de baixa concentração $(0,5 \%, 1 \%, 2 \%$ e $10 \%)$ adicionados com a nanopartícula argilomineral Cloisite $10 A^{\circledR}$ 103

FIGURA 47: Difratograma da nanopartícula argilomineral Cloisite $30 \mathrm{~B}^{\circledR}$ pura para obtenção do "do01". 105

FIGURA 48: Difratograma dos Grupos de compósitos experimentais adicionados com a nanopartícula argilomineral Cloisite $30 \mathrm{~B}^{\circledR}$. (Grupo 6(50B), 7(55B), 8 (60B), $9(65 \mathrm{~B}))$. 106

FIGURA 49: Difratograma dos grupos de compósitos experimentais de baixa concentração $(0,5 \%, 1 \%, 2 \%$ e $10 \%)$, adicionados com a nanopartícula argilomineral Cloisite $30 \mathrm{~B}^{\circledR}$.

FIGURA 50: (a) Imagem captada de uma amostra do Grupo 6 (50B), onde foi possível observar as "franjas" de deslocamento. (b) Escala de cores indicando as áreas de maior e menor deslocamento. (c) Imagem captada no término da análise, com uma escala indicando os valores finais de deslocamento. (d) Valores de deslocamento registrados na análise. 113

FIGURA 51: Resultados de THI/HD/Cl em dentes artificiais: (a) Imagem captada de uma amostra do Grupo 7 (55B), onde foi possível observar as "franjas" de deslocamento. (b) Escala de cores indicando as áreas de maior e menor deslocamento. (c) Imagem captada no término da análise, com uma escala 
indicando os valores finais de deslocamento. (d) Valores de deslocamento registrados na análises.

FIGURA 52: Resultados de $\mathrm{THI} / \mathrm{HD} / \mathrm{Cl}$ em dentes artificiais (a) Imagem captada de uma amostra do Grupo 9 (65B), onde foi possível observar as "franjas" de deslocamento. (b) Escala de cores indicando as áreas de maior e menor deslocamento. (c) Imagem captada no término da análise, com uma escala indicando os valores finais de deslocamento. (d) Valores de deslocamento registrados na análise.

FIGURA 53: Resultados de $\mathrm{THI} / \mathrm{HD} / \mathrm{Cl}$ em dentes naturais: (a) Imagem captada de uma amostra do Grupo 1 (50A), onde foi possível observar as "franjas" de deslocamento. (b) Escala de cores indicando as áreas de maior e menor deslocamento. (c) Imagem captada no término da análise com uma escala indicando os valores finais de deslocamento.

FIGURA 54: Resultados de THI/HD/Cl em dentes naturais: (a) Imagem captada de uma amostra do Grupo 3 (60A), onde foi possível observar as "franjas" de deslocamento. (b) Escala de cores indicando as áreas de maior e menor deslocamento. (c) Imagem captada no término da análise, com uma escala indicando os valores finais de deslocamento.

FIGURA 55: Resultados de THI/HD/Cl em dentes naturais: (a) Imagem captada de uma amostra do Grupo 5 (70A), onde foi possível observar as "franjas" de deslocamento. (b) Escala de cores indicando as áreas de maior e menor deslocamento. (c) Imagem captada no término da análise, com uma escala indicando os valores finais de deslocamento.

FIGURA 56: Resultados de THI/HD/Cl em dentes naturais: (a) Imagem captada de uma amostra do Grupo 7 (55B), onde foi possível observar as "franjas" de deslocamento. (b) Escala de cores indicando as áreas de maior e menor deslocamento. (c) Imagem captada no término da análise, com uma escala indicando os valores finais de deslocamento.

FIGURA 57: Resultados de THI/HD/Cl em dentes naturais: (a) Imagem captada de uma amostra do Grupo 9 (65B), onde foi possível observar as "franjas" de deslocamento. (b) Escala de cores indicando as áreas de maior e menor 
deslocamento. (c) Imagem captada no término da análise, com uma escala indicando os valores finais de deslocamento.

FIGURA 58: Resultados da Termografia dos Grupos 1(50A), 3(60A), 5(70A), 6(50B), 7(60B) e 9(65B).

FIGURA 59: Resultado da Termografia realizada em dentes naturais. Grupos 3(60A), 5(70A), 6(50B), 7(60B) e 9(65B).

FIGURA 60: Imagens da análise de Termografia do Grupo 1. (a) Dente artificial e (b) natural. 128 


\section{LISTA DE TABELAS}

TABELA 1: Tamanho das partículas correspondentes a MMT Cloisite $10 \mathrm{~A}^{\circledR}$, segundo informações do fabricante

TABELA 2: Tamanho das partículas correspondentes a MMT Cloisite $30 \mathrm{~B}^{\circledR}$, segundo informações do fabricante.

TABELA 3: Identificação dos Grupos de compósitos experimentais:

TABELA 4: Formulações dos Grupos 1(50A), 2(55A), 3(60A), 4(65A) e 5(70A)..57

TABELA 5: Formulações Grupo 6(50B), 7(55B), 8(60B) e 9 (65B). .57

TABELA 6: Formulações dos Grupo 10(50S), 11(60S), 12(65S) e 13(70S). .58

TABELA 7: Resultados da contração de polimerização pela metodologia TMA dos Grupos de compósitos adicionados com Cloisite $10 \mathrm{~A}^{\circledR}$ e Cloisite $30 \mathrm{~B}^{\circledR}$. 80

TABELA 8: Resultados da contração de polimerização pela metodologia TMA. Sílica Silanizada Aerosii ${ }^{\circledR}$ OX-50. 80

TABELA 9: Resultados em porcentagem do resíduo (carga inorgânica) após decomposição das amostras pela análise do TGA.

TABELA 10: Distância interlamelar "d" dos Grupos de compósitos experimentais adicionados com a nanopartícula Cloisite $10 \mathrm{~A}^{\circledR}$ e a comparação ao " $\mathrm{d}_{001}$ ". 104

TABELA 11:Distância interlamelar "d" dos Grupos de compósitos experimentais adicionados com a nanopartícula Cloisite $10 \mathrm{~A}^{\circledR}$ e a comparação ao "d $\mathrm{d}_{001}$ ".........108

TABELA 12: Valores da micro dureza dos compósitos experimentais. 109

TABELA 13: Total do deslocamento pela metodologia $\mathrm{THI} / \mathrm{HD} / \mathrm{Cl}$ dos corpos de prova de dentes artificiais adicionados com Closite $30 \mathrm{~B}^{\circledR}$. Grupos 6, 7 e 9 .

TABELA 14: Total do deslocamento pela metodologia $\mathrm{THI} / \mathrm{HD} / \mathrm{Cl}$ com corpos de prova de dentes naturais. Grupos 1(50A), 3(60A), 5(70A), 7(60B) e 9(65B). .....122

TABELA 15: Resultados da Termografia do Grupos 1(50A), 3(60A), 5(70A), 6(50B), 7(60B) e 9(65B)

TABELA 16: Resultados da Termografia com corpos de prova de dentes de naturais. Grupos 1(50A), 3(60A), 5(70A), 6(50B), 7(60B) e 9(65B). 


\section{LISTA DE ABREVIAÇÕES E SÍMBOLOS}

\begin{tabular}{|c|c|}
\hline BisGMA & Metacrilato de glicidila do Bisfenol A \\
\hline BET & Técnica de Brunauer, Emmett e Teller \\
\hline CCD & Charge-Coupled Device \\
\hline $\mathrm{Cl}$ & Correlação de Imagem \\
\hline “d” & Distância ou Espaçamento Interplanar da Estrutura Cristalina \\
\hline "d $d_{001} "$ & Distância Interlamelar Inicial \\
\hline DMAEMA & metacrilato de 2-dimetilaminoetila \\
\hline DRX & Difração de Raio-X \\
\hline DSC & Calorimetria Exploratória Diferencial \\
\hline ESPI & Interferometria Eletronica de Padrão Speckle \\
\hline FTIR & Espectroscopia de Absorção na Região do Infravermelho \\
\hline HD & Holografia Digital \\
\hline meq & Miliequivalente \\
\hline MEV & Microscopia Eletrônica de Varredura \\
\hline $\min$ & Minuto \\
\hline MMT & Argila Montmorilonita \\
\hline Cloisite $^{\circledR} 10 \mathrm{~A}$ & Argila Montmorilonita Natural Cloisite ${ }^{\circledR} 10 \mathrm{~A}$ \\
\hline Cloisite ${ }^{\circledR}$ 30B & Argila Montmorilonita Natural Cloisite ${ }^{\circledR} 30 \mathrm{~B}$ \\
\hline $\mathrm{mJ}$ & Milijoules \\
\hline
\end{tabular}


(MT2EtOH)

Sal Quaternário de Amônio Quaternário de Metil "tallow" bis-

2- hidroxetila

$\mathrm{mW} \mathrm{cm}^{-2}$

Miliwatt por Centímetro Quadrado

$\mathrm{mW} \mathrm{mg}^{-1}$

Miliwatt por Miligrama

$\mathrm{nm}$

Nanômetro

$\mathrm{S}$

Segundo

Tallow

Grupo Alquila (65\% de $\mathrm{C}_{18} ; 30 \%$ de $\mathrm{C}_{16}$ e $5 \%$ de $\mathrm{C}_{14}$ )

TEGDMA

Dimetacrilato de Trietilenoglicol

$\mathrm{T}_{\mathrm{g}}$

Temperatura de Transição Vítrea

TGA

Análise de Termogravimetria

$\mathrm{TIH}$

Técnica de Interferometria Holográfica

TMA

Análise Térmica-Mecânica

u.a.

Unidade Arbitrária

$(2 \mathrm{MBHT})$

Sal Quaternário de Amônio de Dimetil Di "tallow" Hidrogenado

$\AA$

Angstron

$\Delta \mathrm{H}$

Entalpia

$\lambda$

Comprimento de Onda da Radiação Incidente

$\stackrel{\circ}{C}$

Graus Celsius

$\Theta$

Ângulo de Incidência do Raio-X

$\mu \mathrm{m}$

Micrômetro 


\section{INTRODUÇÃo}

A evolução da ciência aplica-se a vários ramos. Um deles é a odontologia, que paulatinamente adquiriu uma enorme variedade de materiais restauradores. A resina composta, que aprimora a prática dos cirurgiões dentistas e contribui para a técnica adesiva, é um exemplo deste avanço.

Segundo Sun-Hong (2010) uma das vantagens recorrentes do material mencionado é uma estética superior e a possibilidade de preparos cavitários mínimos. Entretanto, os compostos sofrem uma alteração volumétrica, devido à aproximação das moléculas monoméricas, no processo de polimerização. Esta reação acontece quando há a quebra das duplas ligações em ligações simples dos metacrilatos, componentes base.

As ligações covalentes entre os monômeros, fator que diminui a distância interatômica de $4 \AA$ (relativo a interações secundárias do tipo Van der Walls) para $1,5 \AA ̊$ (Peutzfeldt, 1997) é causa do movimento de contração volumétrica apresentada pela matriz resinosa. $\mathrm{O}$ aumento da rigidez do material, a contração de polimerização e a reticulação ocorrem à medida que as cadeias poliméricas se constituem (Ferracane, 2005). A trinca do esmalte, o deslocamento da interface, a deflexão cuspídea e as microfraturas de esmalte são alguns dos possíveis acontecimentos, decorrentes da junção dos monômeros, que resultam no desencadeamento de tensões de polimerização. Além de possibilitar o surgimento de sensibilidade pós-operatória e cáries secundárias, de acordo com Braga (2004) e Calheiros (2005).

As resinas compostas normalmente sofrem contração. Sua polimerização é iniciada a partir da fotoativação na faixa espectral de 300 a $500 \mathrm{~nm}$. A alteração volumétrica do composto, dado pela união de radicais na formação da macromolécula (polímero), causa uma diminuição em seu volume. (Rueggerbeg, 1999). Considerando-se cura induzida por radiação ao processo de formação da rede tridimensional polimérica, esta ocorrerá em virtude da combinação de radicais livres com monômeros ou de macroradicais entre si. 
O sistema de radicais livres consiste em uma molécula de fotoiniciador e de uma amina ativadora que quando expostos à luz com o correto comprimento de onda (aproximadamente $468 \mathrm{~nm}$ ), produz um estado excitado do fotoiniciador que propicia o inicio da polimerização. Normalmente utiliza-se como iniciadores da reação de fotopolimerização, a canforoquinona (ativada por luz em comprimentos de onda que variam entre 400-500 nm) e um agente redutor, como uma amina terciária (Fan et al.,1985).

A resina composta quando inserida em uma cavidade, estabelece uma competição entre as forças de contração de polimerização e a resistência de união à estrutura dentária (Carvalho et al.,1996). Como resultado pode ocorrer formação de fendas marginais e subsequente infiltração marginal. Se a união dente-restauração for resistente para suportar as tensões da contração de polimerização pode haver fraturas coesivas na estrutura dentária (Lu et al., 2005).

Alguns dos prejuízos provenientes das tensões que implicam o processo de polimerização são: surgimento de fendas entre o dente e a restauração, dor pósoperatória, desprendimento da resina depositada, deflexão de cúspides, entre outros. O problema ocasionado pela contração de polimerização é crítico, pois a resina composta deve conservar-se intimamente ligada à cavidade dentária enquanto ganha rigidez e diminui suas dimensões. Porém, forçando-se o material restaurador a se distanciar, ou se separar das paredes da cavidade, a consequente ruptura levaria a uma microinfiltração marginal responsável por outros problemas tais como a cárie secundária, sensibilidade dolorosa pós-operatória, podendo até provocar alterações pulpares (Kleverlaan et al.,2005; Venhoven, 1993).

A sensibilidade dolorosa pode ser provocada pelo preenchimento dos espaços vazios, com fluídos, o que ocasiona pressão hidráulica sobre os túbulos dentinários. Estes espaços são formados através da tensão de contração, já que a adesão à dentina do assoalho do preparo cavitário ou à dentina ou ao cemento das paredes e margens gengivais que se encontram além dos limites da junção amelocementária, podem não suportar a tensão (Lutz et al.,1991; Carvalho et al.,1996).

Todos os problemas acima descritos estão relacionados com as tensões de polimerização que, por sua vez, relacionam-se com a composição da resina. De 
acordo com a carga inorgânica ou orgânica, há uma interação diretamente ligada à contração de polimerização e ao comportamento viscoelástico (Braga e Ferracane, 2004; Stansbury et al., 2005). Ainda de acordo com Condon e Ferracane (2000), o conteúdo da carga inorgânica está intimamente ligado às tensões de polimerização.

Consoante à Vandewalle (et al., 2004), a contração volumétrica também é um fator decisivo no aumento das tensões, de acordo com os estudos feitos comparando os valores de tensão entre os compósitos de baixa viscosidade e compósitos de consistência regular.

A perda de integridade marginal é uma das principais causas de fracasso de restaurações utilizando compósitos resinosos. O procedimento adesivo deficiente ou tensões relacionadas ao dente e à restauração são algumas das causas de um "possível" rompimento da união entre o material restaurador e o substrato dentário. Conforme explicitam alguns autores (Davidson-Kaban, 2000; Ferracane, 2005), 0 deslocamento interfacial é decorrente, principalmente, das tensões geradas pela polimerização dos compósitos resinosos.

Para compreender o desenvolvimento das tensões de polimerização em compostos resinosos, é necessário conhecer a estrutura química da matriz polimérica, sendo que a mesma é determinante para a sua rigidez e contração, somada ao conteúdo inorgânico. De acordo com Gonçalvez (et al.,2007), é preciso pesquisar mais a fundo a questão da polimerização com baixos níveis de tensão combinada com boas propriedades mecânicas.

Com o passar do tempo, houve um grande avanço no que diz respeito à área desses compósitos. Mudanças estruturais advindas da junção de maiores valores de carga inorgânica, além da adição de monômeros metacrilatos multifuncionais contribuíram para a produção de materiais mais resistentes ao desgaste e com maior elasticidade. (Hirata et. al.;2003; Marchini et al.,2000; Gonçalvez et.al., 2011).

Os polímeros reforçados com pequenas quantidades de argilominerais, como a Montmorilonita (MMT) foram intensamente estudados, mas inicialmente seu uso chamou a atenção da indústria de plásticos, por causa do aprimoramento nas propriedades ópticas, térmicas e mecânicas (Fournaris et al.,2001). A possibilidade de incorporação dessas argilas e compósitos, para utilização odontológica, tem 
intuito de reduzir a contração de polimerização e de tensão residual (Liu et al.,1990; Salahuddin e Sherata, 2001; Discacciati et al.,2003, Discacciati e Oréfice, 2004).

Novas características são obtidas através da interface entre a nanopartícula inorgânica e a matriz polimérica, devido ao aumento de superfície. Por isso, grande tem sido a valorização tecnológica desses materiais, sendo atrativos para a indústria e para a pesquisa. Segundo Fournaris (et al.,2001), são incorporados aos polímeros, as partículas inorgânicas, com o intuito de maximizar o módulo de elasticidade mecânica, bem como reduzir os custos e melhorar as propriedades.

Algumas argilas têm a capacidade de absorção das moléculas orgânicas, dentre estas, a MMT. Este processo de absorção interfere no aumento do volume do material, uma vez que suas lamelas se distanciam ou se dispersam ao longo da matriz. De acordo com alguns autores (Kelly et al.,1994; Salahuddin e Sherata, 2001), essa expansão poderia minimizar a contração de polimerização e a tensão residual desses compósitos. Outros autores afirmam que houve a redução na contração de polimerização (de um sistema de base de BisGMA) quando foram incorporados os silicatos lamelados. O volume adicional livre dentro das argilas pode ter contribuído para o resultado (Discacciati e Oréfice, 2004).

A adição dessas argilas podem aprimorar as propriedades dos polímeros, isso por causa de sua geometria específica (forma de "prato fino") e pela ocorrência de uma dispersão em nível molecular. A interface entre a matriz polimérica e a partícula inorgânica é maximizada, pois há um aumento na área superficial (Fournaris et al.,2001).

Pesquisas para descobrir se as forças tensionais advindas da polimerização dentro das galerias da argila seriam causadoras na intercalação e na esfoliação lamelar, foram feitas para testar a teoria do enovelamento do polímero. De acordo com Park e Jana (2003), com o aumento do peso molecular, cadeias poliméricas com ligações cruzadas armazenam muita energia para se enovelar. As forças elásticas superariam as forças atrativas e as camadas adjacentes se distanciariam uma das outras, ou seja, lamelas adjacentes à polimerização impedem o enovelamento devido a forças atrativas eletrostáticas entre íons do amônio 
quaternário e sua carga negativa e também devido a forças de van der Waals entre os fragmentos orgânicos dos íons do amônio quaternário.

A argila por apresentar baixo custo (tanto no processamento, quanto na matéria prima), um processo de preparação simples, uma redução à susceptibilidade a água, um aumento das propriedades mecânicas, ser biodegradável e biocompatível, torna-se um excelente componente às resinas.

O objetivo é que tais tecnologias, como a de nanocomponentes empregada aos compósitos odontológicos, sejam mais investigadas a fim de criar ou aprimorar materiais, que possibilitem a inexistência de contrações de polimerização (Liu et al.,1990; Salahuddin e Sherata, 2001; Discacciati et. al.,2004; Discacciati e Oréfice, 2005). É necessário enfrentar toda e qualquer dificuldade para superar o desprendimento da resina depositada na cavidade do dente. Assim, um avanço nesse aspecto faz com que as empresas do ramo procurem e pesquisem novos materiais em resposta a essa necessidade. 


\section{REVISÃo BIBLIOGRÁFICA}

\subsection{Matriz Orgânica}

Em 1963, Bowen desenvolveu um monômero resinoso, nomeado de BisGMA (metacrilato de glicidila do Bisfenol A). A esse novo composto químico foram adicionadas partículas de quartzo silanizadas com o intuito de diminuir o efeito da contração de polimerização, minimizar a expansão térmica e o fluxo de água, e aumentar a dureza de superfície e o módulo de elasticidade.

Por apresentar um extenso comprimento da cadeia molecular e uma estrutura aromática no centro da molécula, o BisGMA confere menor contração de polimerização e maior rigidez à massa resultante. As resinas produzidas a partir do monômero BisGMA são mais resistentes, pois ele é superior ao metacrilato de metila por seu tamanho molecular e estrutura química serem maiores, o que o torna menos volátil e com menor contração de polimerização. Como o BisGMA tem uma alta viscosidade ( $\eta$ = 1369 Pa.s) uma forma de reduzi-la é misturando-o com monômeros de dimetacrilato, que têm baixo peso molecular. A diminuição da viscosidade permite a integração das partículas de preenchimento (iniciadores, inibidores e partículas de carga), mas também causa o aumento da contração de polimerização (Peutzfeld, 1997; Rueggeberg, 2002).

O TEGDMA (dimetacrilato de trietilenoglicol; $\eta=0,05$ Pa.s) é o diluente mais comumente utilizado (Dickens et al.,2003). Apresenta-se como uma molécula linear relativamente flexível, e funciona como um agente de ligações cruzadas, melhorando a polimerização do monômero e as propriedades físicas do compósito (Peutzfeldt, 1997). Seu baixo peso molecular é o responsável por aumentar a contração de polimerização da mistura (Atai e Watts, 2006).

A reação de polimerização de dimetacrilatos é uma reação difuso-controlada, pois sua taxa de propagação, terminação e grau de conversão final são definidos pela capacidade dos monômeros se movimentarem no meio em que ocorre a 
reação. A partir da ativação dos iniciadores, ocorre a formação de uma rede polimérica tridimensional, que causa o aumento da viscosidade do sistema, e que restringe a movimentação de microradicais. $O$ resultado deste processo está na taxa de terminação da reação e em um aumento da velocidade de propagação (autoaceleração), mais conhecido como "efeito gel". A medida que a reação ocorre a mobilidade do meio diminui e a propagação passa a ser difuso-controlada, levando a autodesaceleração. Misturas com grande quantidades de BisGMA apresentam fases pré-gel e pré-vitrificação curtas (Dauvillier et al., 2003), podendo levar à diminuição no grau de conversão (Asmussen, 1985; Ruyter e Svendsen, 1978; Ruyter e Oysaed, 1987). A relação entre a velocidade de propagação e a terminação define a velocidade de polimerização do sistema. (Dickens et al.,2003).

Dois momentos importantes durante a reação de polimerização no desenvolvimento das tensões são o ponto-gel e o ponto de vitrificação. O ponto-gel, correspondente ao grau de conversão, no qual uma rede densa de ligações cruzadas é formada, interferindo no aumento da viscosidade (o ponto-gel ocorre antes dos 5\% da conversão, em monômeros multifuncionais) (Stansbury et al.,2005). Enquanto ocorre a fase pré-gel, o material apresenta baixo módulo de elasticidade, permitindo ao compósito uma alteração permanente devido ao deslizamento das cadeias poliméricas que não estão em formação e dissipando a tensão no interior do material. Depois de atingir o ponto-gel, aumenta-se o módulo de elasticidade do compósito, diminuindo a mobilidade molecular e a rigidez do polímero, o que impede a ocorrência de uma deformação plástica, suficiente para compensar a contração, (Davidson e Feilzer,1997) e o crescimento de tensões que são transmitidas às estruturas dentais circunvizinhas e à interface adesiva entre a estrutura dentária e o material restaurador (Braga e Ferracane, 2004; Kinomoto e Torii, 1998). O ponto de vitrificação representa o estágio de constituição do polímero, que alcançou uma temperatura de transição vítrea $(\mathrm{Tg})$ maior que a temperatura da reação (o ponto de vitrificação é sucessor do gel). Nesse processo, o polímero muda de estado, passando de borrachoso para um estado vítreo no qual os monômeros residuais, duplas ligações pendentes e radicais livres, ficam imobilizados (Sideridou et al., 2002). 
Algumas características destas fases são: as tensões advindas da fase prégel são minimizadas pela deformação plástica do compósito (Rueggeberg, 2000). ponto gel é atingido rapidamente e a diminuição das tensões deve ser atribuída principalmente à relaxação das cadeias poliméricas, passível de ocorrer até que seja atingido o ponto de vitrificação (Lu et al., 2004). O escoamento e a relaxação de cadeias são fenômenos tempo-dependentes, materiais com velocidade de reação menores desenvolvem valores de tensão mais baixos. (Davidson, 1998).

A velocidade de polimerização é influenciada pela qualidade e concentração dos monômeros presentes no sistema. O BisGMA, devido ao seu alto peso molecular $(512 \mathrm{~g} / \mathrm{mol})$, sua rigidez estrutural e principalmente pela presença de radicais hidroxilas, é um composto altamente viscoso (Dickens, 2003). A sua capacidade de formar pontes de hidrogênio leva-o a atingir o estágio de autoaceleração muito rapidamente, uma vez que em sistemas com maior viscosidade a limitação da movimentação dos macroradicais ocorre em menor tempo (Sideridou et al., 2002). Da mesma maneira, rapidamente se forma uma densa rede polimérica que limita a propagação da reação, iniciando a sua desaceleração.

Misturas com grande quantidade de BisGMA apresentam fases pré-gel e prévitrificação curtas (Feilzer e Dauvillier, 2003) e menor grau de conversão final (Sideridou et al., 2002). Isso porque o BisGMA é um composto altamente viscoso (devido seu alto peso molecular: $512 \mathrm{~g} / \mathrm{mol}$ ), sua rigidez estrutural e especialmente pela presença de radicais hidroxilas. Sua facilidade de formar pontes de hidrogênio faz com que o mesmo atinja o estágio de autoaceleração quase instantaneamente já que em sistemas com maior viscosidade a limitação da movimentação dos macroradicais ocorre em menor tempo (Sideridou et al., 2002) assim, rapidamente se forma uma densa rede polimérica, que restringe a propagação da reação, iniciando a sua desaceleração.

Resinas com grandes quantidades de TEGDMA tendem a apresentar maior escoamento devido às fases pré-gel e pré-vitrificação prolongadas, além de atingirem graus de conversão mais elevados (Feilzer e Dauvillier, 2003; Atai e Watts, 2006). Como o TEGDMA tem uma menor viscosidade e peso molecular menor $(286 \mathrm{~g} / \mathrm{mol})$, consegue alcançar os estágios de autoaceleração em graus de conversão relativamente altos. Em compósitos comerciais, a contração é 
sensivelmente reduzida pela incorporação de partículas de carga, atingindo valores entre 1,5 e 5\% (Labella et al.,1998). Enquanto o BisGMA apresenta contração volumétrica de 5,2\% (65으, grau de conversão de 76\%) O TEGDMA apresenta contração de polimerização volumétrica de $19,9 \%$ (60ำ, grau de conversão de $68 \%)$ (Stansbury, 1992).

O módulo de elasticidade é a propriedade que demonstra a rigidez do material. Assim, quanto maior o módulo, menor a capacidade do sistema sofrer deformações elásticas que proporcionariam o alívio de tensões. Em um estudo, foi observado que os copolímeros que continham misturas com TEGDMA mostraram módulo de elasticidade superior aos demais. Tal resultado é atribuído ao efeito antiplastificante do TEGDMA (Davidson Kaban, 2000).

Enquanto ocorre o processo de polimerização, o módulo de elasticidade se desenvolve. Quando atinge o estágio de vitrificação, a partir de então, o módulo se mantém quase em total constância (Navarrete et al.,2005). Em um estudo feito a respeito da dose empregada na fotoativação de uma mistura de BisGMA/TEGDMA, observou-se a correlação não linear do grau de conversão e a tensão de polimerização, sendo a maior parte da tensão desenvolvida nos estágios finais da reação de polimerização. (Braga e Ferracane, 2002)

Em estudo que avaliou misturas de BisGMA e TEGDMA em concentrações de 30, 50 e 70\% em peso, constatou-se a redução da tensão de polimerização de 7 para 3,5MPa com o aumento da concentração de BisGMA, devido à redução da contração volumétrica de 5,7 para 3,5\% (Feilzer e Dauvillier, 2003).

Sendo a matriz orgânica responsável pela polimerização do material e, por consequência contração de polimerização, quanto menor a porcentagem de carga em uma resina, maior será a contração de polimerização (Lambrechts et al.,1987). 


\subsection{Carga Inorgânica}

Os compósitos resinosos são utilizados como materiais restauradores porque são insolúveis em fluídos da cavidade oral, estéticos, de baixo custo e de fácil manipulação (Phillips, 1993).

As primeiras resinas apresentavam elevado índice de contração de polimerização e alto coeficiente de expansão térmica, dois fatores que resultam em deficiências clínicas como: infiltração marginal e uma inadequada resistência ao desgaste, sob o atrito mastigatório (Anusavice, 1996). A fim de minimizar os problemas, partículas de preenchimento inertes foram adicionadas para reduzir 0 volume do componente resinoso.

São partículas de preenchimento: o quartzo, a sílica, o silicato de alumínio e lítio, o vidro de bário, o vidro de estrôncio, ou uma mistura destes. Outros componentes que melhoram a efetividade e a durabilidade do material são: os agentes de adesão (silano), necessário para promover uma união entre as partículas de preenchimento inorgânicas e a matriz da resina (BisGMA e Trietilenoglicol dimetacrilato - TEGDMA), e um ativador-iniciador, necessário para polimerizar a resina. Outros aditivos em pequenas quantidades também melhoram a estabilidade da cor e previnem a polimerização prematura (inibidores como hidroquinona) (Anusavice, 1996). Fatores como a composição, tamanho, quantidade e distribuição das partículas de carga dos materiais utilizados podem auxiliar na compreensão de algumas limitações clínicas (Venhoven et. al. 1996; Condon et al.,1997; Taylor et al., 1998).

Autores de distintos estudos concordaram que os compósitos possuem uma relação direta entre a resistência à compressão e desgaste, módulo de elasticidade, e dureza Knoop (Liu et al.,1990; Van Nort, 2005). Também se verificou uma correlação positiva entre o conteúdo de carga e a resistência à tração diametral e dureza, porém o mesmo não se repetiu nos ensaios de resistência à compressão (Chung et al.,1990). A resistência mecânica de um compósito está diretamente relacionada ao seu conteúdo de partículas por volume (Willems et al.,1993).

As partículas de cargas de três resinas compostas comerciais foram estudadas para se determinar a sorção de água (SA) e a solubilidade (SO). As 
resinas foram selecionadas de acordo com o tamanho das partículas de carga, sendo elas: Filtek Supreme Nanoparticulado (3mESPE), Esthet-X Micro-híbrido (Dentsply Caulk) e Renamel Microparticulado (Cosmedent Inc.). Foram selecionados e armazenados em dessecador, até obtenção de massa constante, dez amostras em formato de disco. As amostras foram em seguida, armazenadas em água por sete dias e sua massa mensurada. Após uma nova desidratação a massa final foi mensurada. A SO e a SA foram calculadas a partir dessas medidas. Os dados foram analisados por ANOVA e teste de Tukey $(\alpha=0.05)$. As três resinas testadas demonstraram valores similares em relação a $S A$, mas em relação a $S O$, a resina nanoparticulada (Filtek Supreme) apresentou um valor menor. Em relação ao estudo das partículas de carga, observaram-se partículas irregulares (Esthetic-X e Remanel) e esféricas (Filtek Supreme). Os materiais demonstraram conter distintos conteúdos de carga, de acordo com o formato e o tamanho das partículas (Berger et al., 2009).

Em um estudo feito por Karabela e Sideridou em 2011, utilizando resinas compostas com partículas nanométricas, objetivou-se detalhar as características de sorção de água ou saliva artificial, determinar a resitência à flexão e o módulo de flexão e avaliar a estabilidade térmica. Dentre os compósitos estudados, a encontrou resina comercil com menor valor de contração volumétrica e absorção de água, maior resistência à flexão e módulo de flexão após imersão em água ou saliva artificial por 30 dias, a qual apresenta o menor teor de matriz polimérica e consiste principalmente de BisGMA.

Em outro estudo feito por Gonçalvez et al. em 2010, foram avaliados o conteúdo inorgânico e a proporção de BisGMA:TEGDMA em relação à tensão de polimerização (TP), grau de conversão (GC), taxa máxima de reação de polimerização (Rpmax), contração volumétrica (CV), módulo de elasticidade (E) e a tangente de delta (tan $\delta$ ) objetivando verificar as possíveis relações entre a TP e as demais variáveis. Prepararam-se vinte formulações, com concentrações de carga de 40, 50, 60 ou $70 \%$ em peso de vidro de bário e proporções molares de BisGMA:TEGDMA. A formulação de compósitos com baixa tensão de polimerização (TP) deve observar criteriosamente a fração inorgânica e o conteúdo monomérico, sendo o principal desafio encontrar formulações com baixa contração volumétrica, 
uma vez que os demais fatores demonstraram não ter influência significativa e o grau de conversão do material não deve ser sacrificado com o propósito de reduzir a TP.

\subsection{Mecanismos de Polimerização}

As primeiras resinas compostas apresentavam ativação química pela combinação de uma pasta base e uma base catalisadora. O iniciador da reação de polimerização era o peróxido de benzoíla. Este sistema estabelecia a conversão uniforme do material, mas o tempo de trabalho limitado e a incorporação de bolhas durante sua manipulação eram empecilhos que prejudicavam as propriedades do material.

Foi então desenvolvido o sistema de fotoativação por luz ultravioleta, para indução da polimerização das resinas compostas. Esse sistema incorporou ao material um agente fotossensível, que inicia o processo de polimerização a partir do contato com uma energia luminosa, polimerizando-se. A partir de então pesquisas tem sido feitas para determinar a fonte de luz e a melhor técnica que fotoative 0 material restaurador. A fotopolimerização obtém alta conversão do material de maneira uniforme e em profundidade, tem baixo estresse de contração e garante a longevidade da restauração (Davidson, 2000).

As resinas compostas possuem um mecanismo de polimerização por radicais livres, que são gerados pela reação química do peróxido de benzoíla com uma amina terciária, dando início à polimerização dos grupos metacrílicos, formando-se assim, uma matriz polimérica tridimensional. As resinas compostas, ativadas por luz visível, iniciam o processo de polimerização por absorção de luz numa faixa específica de comprimento de onda, isso devido à canforoquinona que uma vez ativada, reage com a amina alifática para reduzir os radicais livres (Baratieri et al.,1995).

A ativação da canforoquinona é de suma importância para o início da reação de polimerização do compósito (por volta das $470 \mathrm{~nm}$ ). A conversão completa pode não ser possível nas áreas mais profundas da restauração e está diretamente relacionada à contração do material. As tensões provenientes da própria conversão 
podem ser amenizadas com a fotoativação a baixa intensidade de luz (Davidson; De Gee, 2000).

O grau de conversão não depende apenas da formulação química do material, mas também da quantidade de luz apropriada que ativa o catalisador. Nas resinas compostas autopolimerizáveis, a polimerização ocorre de forma uniforme desde que a mistura seja eficiente, mas as resinas fotopolimerizáveis polimerizam-se somente onde a luz alcança. Isso significa dizer que estes efeitos fazem com que as superfícies mais próximas à fonte de irradiação de luz, sejam polimerizadas mais efetivamente do que as áreas mais profundas. Criam-se com isso, camadas não polimerizadas ou parcialmente polimerizadas, acarretando inúmeros prejuízos à restauração, principalmente nas suas propriedades mecânicas (Baratieri et al.,1995).

A reação de polimerização apresenta alguns estágios definidos pela cinética da reação, a autoaceleração e a desaceleração. Inicialmente a oferta de monômeros livres ao redor dos centros de iniciação da polimerização é grande, favorecendo a propagação e a terminação das cadeias. Conforme a reação progride, a viscosidade do material aumenta, e uma grande quantidade de monômeros livres se acumula próximo aos radicais ainda disponíveis para reagir, reduzindo a possibilidade de terminação das cadeias e favorecendo a propagação, esta fase é denominada autoaceleração. Com o aumento da viscosidade do material, devido à polimerização, a capacidade de difusão das moléculas no meio diminui. A menor oferta de monômeros próximos à extremidade reativa do radical livre corresponde à fase de desaceleração. A partir de então, as taxas de polimerização declinam até aproximadamente de zero e os radicais livres ficam aprisionados na rede polimérica até decaírem para um estado de menor energia e tornarem-se inativos (Dickens et al.,2003; Lovell et al.,1999; Burtscher, 1993).

Os aparelhos utilizados para a fotoativação de materiais resinosos tem se aperfeiçoado. Os mais utilizados são os que contêm lâmpadas de quartzo-tungstênio (QHT) ou diodos emissores de luz (LED). A tecnologia LED apresenta vantagens em relação às lâmpadas QTH, pois emitem comprimentos de onda na faixa de absorção da canforoquinona, dispensa o uso de filtros, apresenta baixo consumo de energia e mínima geração de calor, é resistente ao manuseio e possui maior vida útil. 
Um aparelho de fotopolimerização consiste de uma fonte de luz (bulbo de luz halógena, de Tungstênio), um filtro (selecionar o comprimento de onda específico), e um tubo (transmitir o feixe de luz para a área de aplicação). A luz branca gerada pelo bulbo passa através de um filtro que remove o espectro visível e o infravermelho para comprimentos de onda maiores do que 500nm. As fontes de luz geram diferentes intensidades com o decorrer dos anos, por fatores como a qualidade e idade da lâmpada e a contaminação por resíduos de material compósito. Consequentemente, a fonte de luz deve ser aferida regularmente e o operador deve sempre posicionar a ponta da luz o mais próximo possível do material restaurador (Anusavice, 1996).

Existem diferenças na distribuição espectral na intensidade luminosa e na intensidade da radiação entre os diversos tipos de aparelhos. Para avaliar a eficiência dos aparelhos fotopolimerizadores, autores analisaram o grau de conversão e a dureza das resinas compostas, proporcionadas pelas fontes de luz halógena (Soares, 2002).

Importantes fatores que alteram as propriedades físicas dos materiais são: a, a intensidade de luz e a densidade de potência (mensurados pela quantidade de fótons emitidos em $\mathrm{mW} / \mathrm{cm}^{2}$ (Franco e Lopes, 2003), sendo que a energia de um fóton isolado está relacionada com a sua localização no espectro eletromagnético, que se refere ao comprimento de onda) (Nagel, 1999). O comprimento de onda é definido como a distância percorrida por uma energia emitida por luz em um período cíclico. Como toda a energia do espectro eletromagnético se encontra na velocidade da luz, a frequência pode alterar o valor de energia. Para a fotoativação das resinas compostas, as faixas de energia correspondentes à faixa de luz azul do espectro visível estão entre 400 e 500nm. O processo de polimerização tem relação direta com a intensidade de luz, sendo que quanto maior a quantidade de fótons atingindo a resina composta, maior o número de radicais livres que iniciarão a reação. $A$ densidade de potência é o fator chave para a porcentagem de conversão dos monômeros e para a velocidade em que ocorre a conversão. (Rueggeberg, 1999).

A aplicação de altas densidades de potência melhora as propriedades mecânicas do material. Deve se considerar ainda, o efeito negativo da alta intensidade de luz, no desenvolvimento das tensões da contração e na limitação do 
relaxamento das tensões. A aplicação de baixa densidade de potência permite um prolongamento da fase pré-gel (a reação ocorre mais lentamente e há o rearranjo das moléculas), visando um melhor escoamento das tensões provindas da contração de polimerização, mas também pode resultar em materiais subpolimerizados, o que implicaria em propriedades físicas e mecânicas insatisfatórias (Mehl et al. 1997; Unterbrink e Muessneer, 1995). A intensidade de luz emitida pelos aparelhos fotopolimerizadores, tem sido considerada primordial na determinação do desempenho dessas unidades, uma vez que as variações dos valores de intensidade podem resultar em alterações significativas na profundidade de polimerização das resinas (Pereira et al. 2008).

Com relação à intensidade da luz da ativação, Rueggeberg em 1993, investigou a interdependência do tempo de exposição e da intensidade de uma fonte de luz halógena. Foi observado o grau de polimerização das resinas compostas quando empregadas com espessuras de camadas de 1, 2, e $3 \mathrm{~mm}$ e fotopolimerizadas por $20,40,60$, e 80 segundos. Os resultados mostraram que 0 tempo de exposição de 60 segundos é ideal para uma intensidade de luz de pelo menos $400 \mathrm{~mW} / \mathrm{cm}^{2}$. As camadas incrementais de material não devem exceder a espessura de $2 \mathrm{~mm}$, com $1 \mathrm{~mm}$ sendo considerado o ideal e fontes de luz com intensidades menores do que $233 \mathrm{~mW} / \mathrm{cm}^{2}$, não devem ser utilizadas por terem características de cura inadequadas (Rueggeberg, 1993).

Em outro estudo, Halvorson e Davidson (2002) estudaram a relação entre a extensão de polimerização e energia/dose, aplicada durante a fotoativação da resina composta por meio da espectografia FTIR. O perfil de polimerização $(\%$ de conversão $x$ energia aplicada) mostrou uma gradual diminuição na conversão com 0 decréscimo da dose de energia. Mesmo com diferenças entre o grau de conversão obtido para as diferentes resinas, a conversão em 24 horas e em 5 minutos foi bastante idêntica às mesmas. Observou-se ainda que os graus de conversão são semelhantes quando a densidade de energia é mantida, e a relação entre a intensidade e o tempo de exposição é alterada. Mesmo com a máxima intensidade, há uma limitação na conversão, devido ao grande número de ligações cruzadas do polímero, que restringem a mobilidade dos dois constituintes da rede. Foi encontrada conversão similar quando utilizadas energias equivalentes, mostrando evidências 
para a relação recíproca entre intensidade e tempo de exposição, com significante importância no estudo de conversão em função do total de doses aplicadas. Esse relacionamento estabelece o perfil de polimerização do compósito como uma correlação universal entre tempo de exposição e intensidade.

\subsection{Contração de Polimerização}

Um dos fatores que mais contribui para o insucesso das resinas compostas é a contração de polimerização devido a sensibilidade pós-operatória e a perda da integridade marginal (Sakaguchi,1998).

A grande maioria das resinas compostas tem como base de constituição o metacrilato de glicidila, que sofre contração à medida que se polimeriza. A contração é resultado da movimentação e aproximação dos monômeros entre si, durante a formação da cadeia polimérica. Quanto maior for o grau de conversão do monômero em polímero, maior será a contração de polimerização. Com a incorporação das partículas de carga, esta contração reduziu para 1,5 a 3,0\%. A adição de monômeros multifuncionais e monômeros com alto peso molecular permitiu a formação de uma estrutura em rede, na qual necessita de um número menor de duplas ligações convertidas, diminuindo o potencial de contração. A conversão máxima de monômeros em polímeros nas resinas atuais é de 60 a 70\%, onde as duplas ligações de carbono não convertidas ficam presas na rede polimérica (Rueggeberg, 1999).

A formulação da resina é um fator fundamental e muito mais relevante que a fotoativação no que se refere à contração. O volume envolvido na contração depende do peso molecular e da funcionalidade dos monômeros. Quando monômeros de pesos moleculares similares são comparados observa-se um aumento da contração à medida que a funcionalidade aumenta; e comparando monômeros de funcionalidades parecidas, a contração aumenta quando o peso molecular diminui, um exemplo disso é a diluição do BisGMA, que aumenta a contração de polimerização (Lovell et al.,1999). As resinas fotopolimerizáveis possuem polimerização mais rápida e com menor capacidade de escoamento, o que 
gera maior estresse de contração, decisivo para a falha do sistema adesivo. (Carvalho et al.,1996; Bouschlicher et al.,1997).

A contração de polimerização sofrida por um material pode ser determinada de forma volumétrica (De Gee et al.,1981; Watts e Cash, 1991; Pucket e Smith, 1992) ou linear (Feilzer et al.,1993).

Vários métodos foram propostos para mensurar a contração de polimerização de compósitos. O dilatômetro modificado já foi utilizado para determinar a contração de polimerização volumétrica de compósitos odontológicos (De Gee et al.,1981), no entanto, a maioria utiliza dilatômetros de mercúrio ou de água (Davidson e De Gee, 1984).

Hansen et al. (1985), atentos à possibilidade de uma relação direta entre forma cavitária e selamento marginal, relacionaram a forma da cavidade com a contração de polimerização, avaliando a adaptação de restaurações de resina com o volume, a profundidade da cavidade, a área livre e a área aderida. Observou-se que o volume por si só é importante na adaptação marginal de resinas compostas e que o aumento do raio das paredes unidas gera o aumento de fenda marginal.

Lambrechts et al. (1987) relataram que embora as resinas híbridas possuíssem alta quantidade de partículas de carga, sua contração volumétrica era alta, isso devido à adição do TEGDMA para controlar a viscosidade.

Ainda em 1987, Feilzer et al. investigaram o papel do fator de configuração cavitária no desenvolvimento e relaxamento das tensões resultantes da contração de polimerização, para assim, possibilitar o sucesso dos adesivos dentinários. Dois discos de aço foram utilizados, dos quais um foi conectado a célula de carga e outro ao dispositivo medidor de tensões. Dessa maneira conseguiu-se registrar as tensões de contração de uma resina comercial em restaurações com fator de configuração cavitária (fator $\mathrm{C}$ ). Após a obtenção dos dados, observou-se que quanto maior o fator de configuração, maiores foram as tensões geradas durante a contração de polimerização devido à redução da capacidade de escoamento.

Em outro estudo de Feilzer (et al.,1989) analisaram o desenvolvimento da contração livre de polimerização de uma série de resinas compostas e de cimentos 
ionoméricos. Utilizaram um dilatômetro que registrou a contração de 26 materiais durante 24 horas. Foi observado que os cimentos ionoméricos convencionais estudados apresentavam um baixo valor de contração quando comparados às resinas compostas e que a razão de contração tem relação com a quantidade, o tamanho e o tipo de partícula de carga.

A contração, por ser consequência da formação de ligações covalentes curtas entre as unidades monoméricas da resina, tomou a atenção de Rees (1989) que avaliou o valor de contração de cinco resinas comerciais. Observou-se que a contração ocorre principalmente entre os primeiros 60 minutos, os baixos valores encontrados foram atribuídos às resinas de dentes posteriores, ao baixo conteúdo de matriz orgânica e alta concentração de carga. Os autores ainda consideraram que o peso molecular e a configuração dos diferentes monômeros, podem afetar a contração.

Em 1989, Sakaguchi desenvolveu um sistema para medir as mudanças dimensionais em compósitos durante sua polimerização. Extensômetros elétricos foram colocados com as amostras de resinas para mensurar a contração linear e os sinais foram amplificados por um condicionador de sinais para serem analisados digitalmente. Observou-se que o valor da contração diminuiu com o aumento da espessura da amostra e com o afastamento da fonte de luz.

Em 1990, Feilzer et al., descreveram o mecanismo de contração de polimerização em relação às tensões produzidas ressaltando que as tensões produzidas são diminuídas pelo escoamento do material, e se houver uma transposição do limite elástico pode-se então decorrer uma deformação plástica. Observou-se também que durante a fase inicial da reação de polimerização, a rede polimérica é fraca e as tensões ocorridas neste momento não promovem prejuízos à estrutura interna da resina ou à união adesiva, uma vez que as moléculas ainda tem a possibilidade de se movimentarem para novas posições. Essa movimentação caracteriza-se pelo escoamento do material, que é reduzido na fase pós gel, especialmente pela rigidez. Segundo os autores, isto implicaria em problemas para a manutenção da interface adesiva, por causa do aumento das tensões com o tempo e do material não poder compensá-lo pelo escoamento. Propuseram então a determinação e quantificação da redução das tensões pelo escoamento em várias 
configurações cavitárias $(C)$ de quatro compósitos comerciais. Observou-se que a redução das tensões e a capacidade de escoamento estão em função do material e da configuração cavitária e que este escoamento contribui significantemente para a redução das tensões de contração em restaurações com baixo fator $C$, além de ser insuficiente em restaurações com alto fator $\mathrm{C}$.

Watts e Cash (1991) estudaram a contração de polimerização de materiais curados por luz visível, utilizando a técnica "deflexão de disco", onde uma lamínula de vidro é suportada por um anel espaçador metálico, permanecendo em contato com o material que é fotoativado. A lamínula de vidro se deflete em função da contração do material, e a leitura é feita por um transdutor acoplado a um computador.

Em 1992, Puckett e Smith determinaram a contração volumétrica relacionando as densidades específicas, medidas por meio de picnometria, à água do material curado e não curado. Concluíram então, que o método utilizado provê uma forma precisa e conveniente de medir a contração, sem uso de instrumentos sofisticados.

Com base nas vantagens das resinas ativadas quimicamente, Fusayama (1990) propôs que essas resinas deveriam ser utilizadas em restaurações de dentes posteriores, pois as resinas fotoativadas contraem em direção à camada superficial irradiada, conduzindo à formação de uma fenda entre a parede cavitária e a restauração. Em estudo, o autor relatou que as resinas de ativação química não proporcionam separação na interface adesiva, indicando assim que as resinas quimicamente ativadas devem ser utilizadas para restauração de cavidades profundas e com margens em dentina.

Sakaguchi (et al.,1992) avaliaram a contração de polimerização, por meio de extensômetros elétricos. Este método apresentava dados ou resultados com valores numéricos muito baixos, isso porque o método media apenas a fase pós-gel, fase em que o fluxo molecular compensaria a contração de polimerização.

Com a afirmação de que tensões criadas na interface adesiva não estarem somente em função da contração volumétrica, mas de uma interação multifatorial, Unterbrink (1995) avaliou o efeito da variação de intensidade de luz empregada em 
duas resinas comerciais, enfatizando a adaptação marginal de cada uma. Nesse estudo utilizaram-se quarenta e oito incisivos bovinos. O exame de verificação e quantificação das fendas foi realizado por meio de fotomicrografias eletrônicas. Concluiu que as restaurações de resinas compostas polimerizadas com alta intensidade de luz empregada podem levar a uma pobre adaptação marginal. Além do que o desenvolvimento do módulo elástico foi influenciado pela intensidade de luz, representando um fator importante em termos de contribuição para a alteração das tensões da contração de polimerização.

Alguns autores revisaram os métodos determinantes das tensões provenientes da contração e de seu efeito clínico na interface adesiva, objetivando facilitar a compreensão do mecanismo da contração de polimerização. Relatou-se que as consequências da contração de polimerização são dependentes do escoamento do material, e que as tensões provenientes deste mecanismo podem ser as responsáveis pela falha do sistema adesivo. Estas tensões, segundo os autores, ocorrem quando a contração é impedida e o material é rígido o bastante para resistir ao escoamento plástico, a fim de compensar o volume original. Relatouse também que a magnitude deste não depende apenas das características das estruturas circunvizinhas, mas também da natureza do material, especialmente das propriedades visco-elásticas. O estudo também descreveu os mecanismos de alívio das tensões provenientes da contração sobre a configuração cavitária e afirmou que quanto menor a quantidade de paredes opostas unidas, menor obstrução, existirá para a contração. A utilização de bases cavitárias com baixo módulo de elasticidade, que teriam a função de absorver as tensões da contração, melhoram a manutenção da união adesiva. Concluiu ainda que o entendimento do mecanismo que causa estes problemas, como a infiltração marginal, a sensibilidade pós-operatória e a aplicação de uma técnica correta podem auxiliar na redução de seus efeitos e aumentar a longevidade clínica destas restaurações (Davidson e Feilzer,1997).

Em 1998, Condon e Ferracane, utilizaram uma máquina de testes mecânicos para avaliar a tensão de contração de treze marcas comerciais de resinas de uso odontológico, onde o material era colocado entre dois suportes de vidro, sendo fotoativado pelos dois lados. Observaram-se valores variando entre 4,5 e 10,5 MPa. 
Em 1999, Whitters et al.,compararam a contração de polimerização e a dureza superficial, em um aparelho convencional com luz halógena e em um aparelho com sistema LED. Observou-se que os valores de dureza Knoop para amostras polimerizadas por sessenta segundos foram semelhantes para os dois aparelhos, assim como a contração linear. Concluiu-se que o LED proporciona características à resina composta semelhante ao aparelho convencional de luz halógena.

Kinomoto et al. em 2000, determinou as tensões geradas durante as contrações pelo método de fotoelasticidade. As tensões geradas foram avaliadas por resinas fotoativadas e quimicamente ativadas nas paredes da cavidade. Relatou-se que a magnitude das tensões foi maior nas resinas fotoativadas do que nas quimicamente ativadas. Isso devido à alta velocidade de reação de polimerização das resinas fotoativadas. As resinas fotoativadas não se contraem em direção à fonte de luz, pois grande parte das tensões ocorre nas camadas mais profundas da cavidade.

Baseados na hipótese, de que com o aumento da concentração de partículas de carga a contração de polimerização é reduzida Aw (et al., 2001) avaliaram a contração linear de seis resinas comerciais condensáveis e de duas híbridas. Para avaliar a contração de polimerização, uma medida inicial foi tomada por meio de um microscópio óptico. Depois de polimerizadas, outra medida era obtida e assim a contração linear foi determinada. Observou-se que quanto menor a porcentagem de carga por volume, maior a contração de polimerização.

Braga (et al.,2002), para aumentar a concentração do inibidor (butilato de hidroxitolueno) e reduzir a velocidade da reação de polimerização, avaliaram o grau de conversão e geração de tensões provenientes da contração de polimerização de uma resina experimental, com diferentes concentrações de substância inibidora. Segundo os autores, cada molécula inibidora pode inativar temporariamente duas ou mais cadeias poliméricas, levando a uma reação lenta inicial até que o inibidor seja completamente consumido. Dessa maneira aumenta-se a fase pré-gel do compósito proporcionando um maior alívio das tensões iniciais de contração de polimerização. 
Objetivando avaliar a contração de polimerização de resinas com diferentes cargas orgânicas, Weinmann (et al., 2005), comparou um compósito resinoso à base de silorano, que polimeriza pelo processo de abertura do anel catiônico, com diferentes resinas a base de metacrilato. Os métodos de Arquimedes e do disco aderido, foram utilizados para mensurar a contração volumétrica. O compósito a base de silorano apresentou a menor porcentagem de contração de polimerização em ambos os métodos, 0,94\% em volume. A estabilidade em luz ambiente do silorano foi de 10 minutos, maior que a encontrada nas resinas a base de metacrilato, que variou de 55 a 90 segundos. Concluiu-se que a reação química de polimerização obtida pela abertura do anel encontrada nos siloranos, permitiu a obtenção de valores de contração menores que $1 \%$ em volume e propriedades mecânicas semelhantes aos compósitos convencionais.

Em 2006, Bouillaguet (et al., 2006) estudaram a deformação do dente em resposta à polimerização de cinco compósitos resinosos, avaliados pela técnica de interferometria eletrônica (ESPI). Os autores utilizaram dentes molares humanos em cavidades MOD $(2 \mathrm{~mm} \times 2,5 \mathrm{~mm} \times 11 \mathrm{~mm})$. Uma ponta termoelétrica foi fixada na face interna da cúspide lingual, para monitorar alterações térmicas sofridas pelas amostras durante o processo de polimerização. As cavidades dos dentes eram preenchidas em incremento único. As resinas foram ativadas por 40 segundos com $100 \mathrm{~mW} . \mathrm{cm}^{-2} .0$ deslocamento da cúspide lingual do dente durante a polimerização do compósito foi mensurado com a técnica ESPI. A microdureza Vickers foi utilizada como um método indireto para avaliar o grau de conversão do material. Concluiu-se que o ESPI foi um método viável para avaliar a deformação das cúspides, porém os dados obtidos de contração de polimerização podem superestimar a deformação do dente induzida pela contração.

Gonçalvez (et al., 2010) avaliaram o papel do conteúdo de carga inorgânica em relação à tensão de polimerização, contração volumétrica, módulo de elasticidade e grau de conversão. Foram utilizados oito compósitos experimentais contendo 01:01 BisGMA:TEGDMA e concentrações de carga inorgânica (vidro de bário) em concentrações crescentes de 25 a $60 \%$ em volume, com intervalos de $5 \%$. A tensão de polimerização foi mensurada por uma máquina universal de ensaios. A contração volumétrica foi avaliada por um picnômetro à água. O módulo de 
elasticidade foi observado por um teste de flexão por três pontos. O grau de conversão foi determinado por uma espectroscopia FT-Raman. A tensão e a contração de polimerização apresentaram relação inversa ao conteúdo de carga inorgânica $\left(R^{2}=0,965\right.$ e $R^{2}=0,966$, respectivamente). O módulo de elasticidade apresentou uma correlação direta com o conteúdo inorgânico $\left(R^{2}=0,984\right)$. O grau de conversão não variou significativamente. A tensão de polimerização apresentou uma forte correlação direta com a contração $\left(R^{2}=0,982\right)$ e uma correlação inversa ao módulo de elasticidade $\left(R^{2}=0,966\right)$. Concluiu-se que os baixos valores de tensão de polimerização foram diretamente associados com a redução da contração volumétrica, devido ao alto teor de conteúdo inorgânico.

Alguns métodos utilizados para mensurar a contração de polimerização são: o dilatômetro de mercúrio (De Gee et al.,1981; Reed et al.,1996), o picnômetro a gás (Amore et al.,2003), o uso de extensômetros (Puckett et al.,1993; Rosin et. al, 2002; Vandewalle et al., 2004), deslocamento linear (De Gee et al.,1993; Park et al., 2002), contração linear livre (Pereira, et al.,2008), discos aderidos (Watts et al.,1991; 1999), entre outros. Todos os métodos tem em comum a dependência da mensuração de um princípio físico.

Dos métodos estudados na tentativa de se reduzir a contração volumétrica durante a polimerização, a tensão residual de compósitos odontológicos e consequentemente seus efeitos, se destacam: o uso da técnica incremental (Lutz et al.,1991), o desenvolvimento de monômeros que não se contraem (Chung et al., 2002), de compósitos com uma menor velocidade de reação (Braga, Ferracane, 2002), de agentes de união que absorvem a tensão (Kemp-Scholte e Davidson, 1990), o aumento na concentração de carga inorgânica (Bowen et al.,1991), a inserção estratégica do compósito nas cavidades (Verluis et al.,1996), uso de fontes de baixa intensidade (Neves et al., 2005), e a incorporação de nanocomponentes minerais na matriz orgânica (Liu et al.,1990; Discacciati e Oréfice, 2004).

\subsection{Argila - Montmorilonita}

A argila é o termo usado para designar materiais encontrados no solo com tamanhos de partículas inferiores a $2 \mu \mathrm{m}$, considera-se que a argila seja constituída 
essencialmente por argilominerais, constituintes minerais quimicamente compostos por silicatos de alumínio hidratados, podendo conter outros elementos como magnésio, ferro, cálcio, sódio, potássio e lítio (Santos, 1989).

A Montmorilonita (MMT, encontrada em Montmotillon, região de Poitou na França) conhecida também como esmectita foi identificada por Knigth em 1896, é formada pelo empilhamento regular de camadas de duas folhas tetraédricas $\mathrm{SiO}_{4} \mathrm{e}$ entre elas uma folha de octaedros $\left(\mathrm{Al}_{2}(\mathrm{OH})_{6}\right)$ e $\left.\mathrm{Mg}_{3}(\mathrm{OH})_{6}\right)$ ligadas entre si pelos átomos de oxigênio, formando uma única camada, chamada de lamela. As folhas apresentam continuidade nos eixos e geralmente possuem orientação paralela nos planos (001) dos cristais, que the confere a estrutura laminada (Santos, 1989; Bharadwaj, 2001; Utracki, 2009). As lamelas da Montmorilonita apresentam perfil irregular, são finas, tendem a se agregar no processo de secagem e possuem boa capacidade de delaminação. O diâmetro é de aproximadamente $100 \mathrm{~nm}$, a espessura pode chegar até $1 \mathrm{~nm}$ e as dimensões laterais podem variar em torno de $30 \mathrm{~nm}$. O empilhamento dessas placas é regido por forças polares fracas e por forças de van der Waals, caracterizando as lacunas existentes entre essas placas, as galerias. Cerca de $80 \%$ dos cátions trocáveis na Montmorilonita estão presentes nas galerias e $20 \%$ se encontram nas superfícies laterais (Santos, 1989; Merinska et al.,2002; Alexandre et al.,2000).

A MMT, principalmente a sódica, é utilizada no desenvolvimento de nanocompósitos poliméricos. Possui uma estrutura lamelar cristalina que consiste em camadas, sendo uma lâmina central octaédrica de alumina fundida em duas lâminas tetraédricas externas de sílica. As lamelas se organizam formando pilhas mantidas pelas forças de van der Waals e entre as lamelas, formam-se espaços regulares chamados espaçamento basal "d", ou espaço interlamelar. (Alexandre, 2000).

Na Figura 1, observa-se a estrutura, a classificação e a fórmula geral da montomorilonita e na Figura 2, a estrutura da galeria (espaçamento basal). 

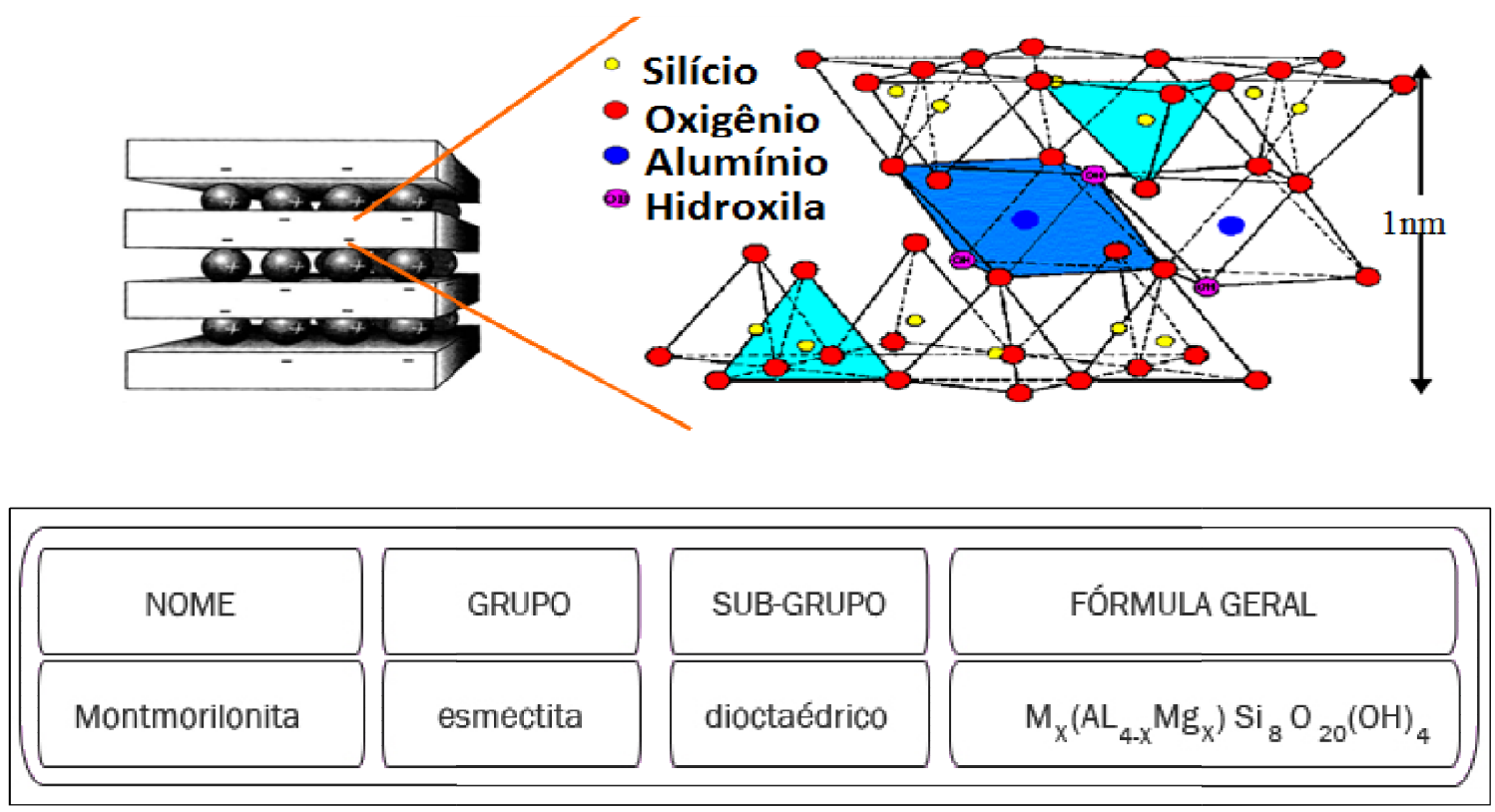

FIGURA 1: Estrutura, classificação e fórmula geral da montmorilonita (Zanetti e Costa, 2004).

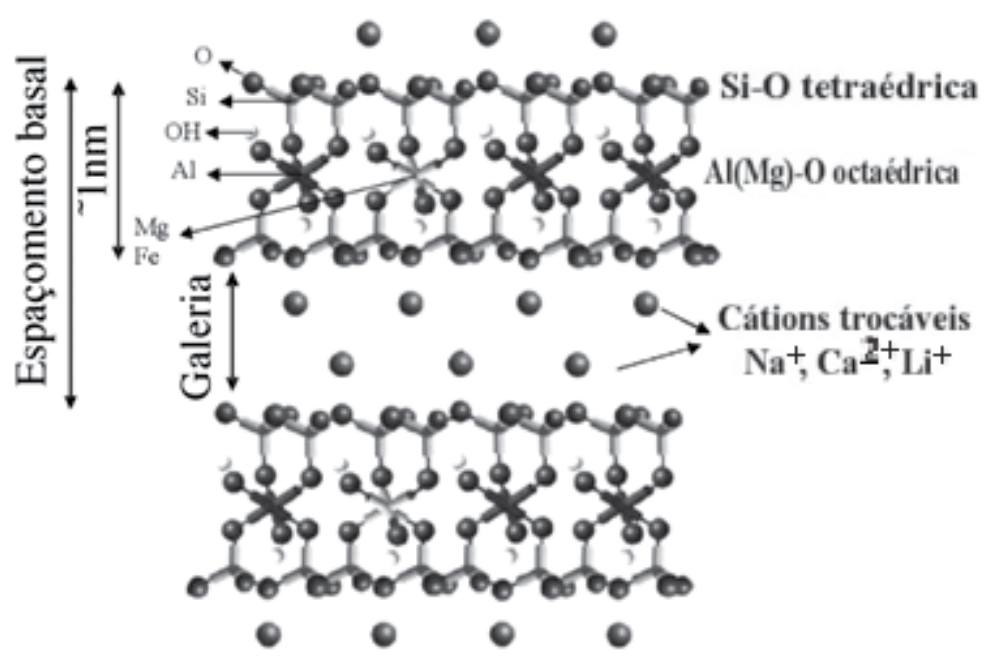

FIGURA 2: Estrutura da galeria (espaçamento basal) da Montmorilonita (Paiva et al.,2008)

As montmorilonitas são muito utilizadas na preparação de argilas organofílicas, devido às pequenas dimensões dos cristais, a elevada capacidade de troca de cátions e a capacidade de inchamento, que fazem com que a intercalação de compostos orgânicos utilizados na síntese seja rápida e 100\% completa. As 
argilas organofílicas são aplicadas na área de nanocompósitos poliméricos, sendo cerca $70 \%$ do material utilizado na preparação dos nanocompósitos. A popularização e a eficácia comprovadas se devem ao fato de serem de origem natural, terem baixo custo, elevada razão de aspecto, boa capacidade de delaminação (separação das camadas de argila na matriz polimérica), resistência das partículas a solventes e às temperaturas empregadas à polimerização (Markarian, 2005)

O procedimento de organifilização da argila é a etapa chave para que ocorra uma dispersão e esfoliação bem sucedida das partículas da argila na matriz polimérica. A natureza organofílica reduz a energia superficial, torna a argila mais compatível com os polímeros orgânicos e o aumento no espaçamento basal facilita a intercalação das cadeias poliméricas entre as camadas da argila. A adição de argilas organofílicas em matrizes poliméricas para preparação de nanocompósitos, melhora as propriedades mecânicas, físicas e químicas das matrizes poliméricas e reduz o peso e o custo. Tipicamente, as argilas organofílicas substituem cargas convencionais como talco ou fibras de vidro a uma proporção de 3:1. Por exemplo, $5 \%$ de uma argila organofílica pode substituir $15-50 \%$ de uma carga como carbonato de cálcio, melhorando propriedades de impacto e reduzindo custo (Markarian, 2005)

\subsection{Nanocompósitos Argilominerais}

Com o avanço da tecnologia, muitas áreas se beneficiaram e inovaram a utilização materiais. Os nanocompósitos são um exemplo disso, já que chamou atenção das indústrias e, principalmente dos pesquisadores, por apresentarem características importantes, como suas excelentes propriedades mecânicas, térmicas, além das propriedades para barreira a gases. O nanocompósito polímero/argila apresenta-se com forte participação, e a cada dia desempenha papel fundamental nas indústrias automobilísticas, de embalagens, de biomateriais e aeroespacial (Touati et al., 2007; Gu et al., 2004; Zhou et al., 2005; Duran, 2006)

Como a nanotecnologia está restrita entre 0,1 e 100nm, e está ainda em desenvolvimento, há muito que pesquisar a respeito da nanoescala. Vários campos de pesquisa interdisciplinar se debruçam sobre a tarefa de ampliar e melhorar o uso da mesma, além de englobar os mais diferenciados tipos de materiais, como os 
semicondutores, os compósitos e os biomateriais, os polímeros, as cerâmicas, os metais, e vários outros, sempre estruturados em escalas nanométricas (nanoestruturados). Segundo Duran (2006), a síntese e o controle nanométrico possibilitam a fabricação e o controle da estrutura da matéria em um nível molecular. Isso permitirá aplicar novas propriedades e observar nos materiais comportamentos diferentes.

Para esclarecimento, entende-se por compósito a junção de dois materiais diferentes. Porém, tal mistura faz com que o compósito apresente mudanças nas propriedades, como no módulo de elasticidade e na resistência mecânica de polímeros. A inserção de partículas inorgânicas pode melhorar tais mudanças. Por isso, a combinação entre polímeros e materiais inorgânicos tem aumentado cada vez mais.

Os materiais em sua origem, isoladamente, não possuem propriedades superiores aos dos compósitos, estes são fabricados com maior facilidade, pois apresentam baixa densidade e processamento de diversos polímeros (Alexandre, 2000; Murray, 2000).

Ao menos uma das dimensões das partículas dispersas dos nanocompósitos está em escala nanométrica. Os nanocompósitos são diferenciados em pelo menos três tipos, a depender do material e de quantas dimensões estão de acordo com a escala nanométrica, segundo Suprakas (2003). São estes: quando as três dimensões se encontram na escala nanométrica, temos as nanopartículas que são isodimensionais, como por exemplo as sílicas esféricas; quando duas dimensões estão na escala nanométrica e a terceira é a maior, temos estruturas alongadas unidimensionais, por exemplo os nanotubos de carbono e quando apenas uma dimensão está na escala nanométrica formando estruturas lamelares, como por exemplo as argilas esmectitas, conhecidas como silicatos lamelados.

As argilas têm sua estrutura composta por camadas, ou lamelas, por isso apresentam somente uma dimensão na escala nanométrica, cuja espessura é de aproximadamente $1 \mathrm{~nm}$ e seu comprimento e sua largura podem variar de $100 \mathrm{a}$ $1000 \mathrm{~nm}$. 
Há uma diferenciação dos nanocompósitos e dos materiais convencionais. Suas dimensões nanométricas são determinantes em suas propriedades, e não o fato das partículas apresentarem dimensões nanométricas. Por isso, faz-se importante o uso das argilas, para esclarecimento deste fato (Yiu et al., 2006). A argila dispersa em uma matriz polimérica irá atuar como carga convencional, mesmo se as partículas tiverem dimensões nanométricas. Entretanto, se a argila for esfoliada durante o processamento, pode atuar como um nanocompósito, promovendo características de reforço ou retardamento de chama, que não são obtidas com a argila simplesmente dispersa. A vantagem adicional é que essas propriedades são obtidas com concentrações abaixo de 5\% em massa (Yiu et al., 2006).

Para melhorar as características mecânicas (rigidez, tenacidade e resistência nas condições de temperatura ambiente e altas temperaturas) (Callister, 2003) dos materiais é que se desenvolveram os nanocompósitos. Com a adição de argilas, outras propriedades também podem ser aprimoradas, a exemplo, as propriedades térmicas, de flamabilidade, de resistência a solventes e ópticas. Com a diminuição da presença de oxigênio, o nanocompósito é mais resistente à degradação oxidativa (Barbosa, 2006; Ray et al., 2003), ou seja, a maior estabilidade térmica liga-se à diminuição da difusão das moléculas de oxigênio para o interior do nanocompósito devido à barreira formada pelas partículas da argila.

Há várias etapas envolvendo a nanotecnologia. A primeira, importante para o desenvolvimento de polímeros nanoestruturados, envolve o tamanho e a forma controlada dessas nanopartículas. Em seguida, para atingir a dispersão uniforme das nanopartículas em um polímero é necessário efetuar a seleção do processamento e a forma de fabricação e depois a caracterização das nanopartículas. Por último, a determinação do desempenho desses polímeros nanoestruturados, utilizando métodos de ensaio estabelecidos para aplicações específicas (Koo, 2006).

Os compósitos tradicionais são diferenciados dos polímeros nanoestruturados por causa da área interfacial localizada entre as nanopartículas e a matriz polimérica, esta é gerada pela dispersão uniforme das cargas nanométricas. 
Com isso, mostra-se que as regras aplicadas aos compósitos poliméricos tradicionais não podem ser utilizadas para os nanocompósitos. Porém, o contrário é aplicável, ou seja, as propriedades provenientes da estrutura em nanoescala dos nanocompósitos mostraram resultados favoráveis no desempenho dos compósitos tradicionais (Koo et al., 2006).

As argilas, adicionadas ao polímero, desempenham a função de reforço, já que apresentam limitações no que concerne à mobilidade das cadeias poliméricas quando em proximidade com as partículas da mesma. A dispersão da argila, sua forma, o grau de delaminação e as interações interfaciais polímero/argila relacionamse com o crescimento das propriedades dos nanocompósitos (resistência à compressão, fratura, impacto, tração e a flexão, além do módulo de Young) (Barbosa, 2006; Kornmann, 1999).

As argilas da classe da montmorilonita têm sido usadas com os nanocompósitos. Estas são obtidas diretamente da natureza e sua estrutura lamelar permite o esfoliamento (tanto em processos físicos como químicos). De acordo com alguns autores, a adição de níveis pequenos (menores que 10\%) de argilas organofílicas, melhora as propriedades (mecânicas, térmicas, de barreira) e estabilidade dimensional dos nanocompósitos (Barbosa, 2006; Wang, 2002; Gilman, 1999).

Para que ocorra uma boa dispersão no sistema monômero/argila é necessário que haja uma boa afinidade química entre a argila e o monômero. Passando esta etapa inicia-se o processo de polimerização. A argila é normalmente tratada com cátions funcionais que podem reagir com um monômero durante a polimerização. Através deste método, obtêm-se nanocompósitos esfoliados com maior incidência. $O$ sucesso no resultado de nanocompósitos esfoliados explica-se ao fato de que é possível escolher os reagentes e rotas de polimerização mais capazes a fim da melhor afinidade química entre a argila e o polímero (Fu et al., 2005). 


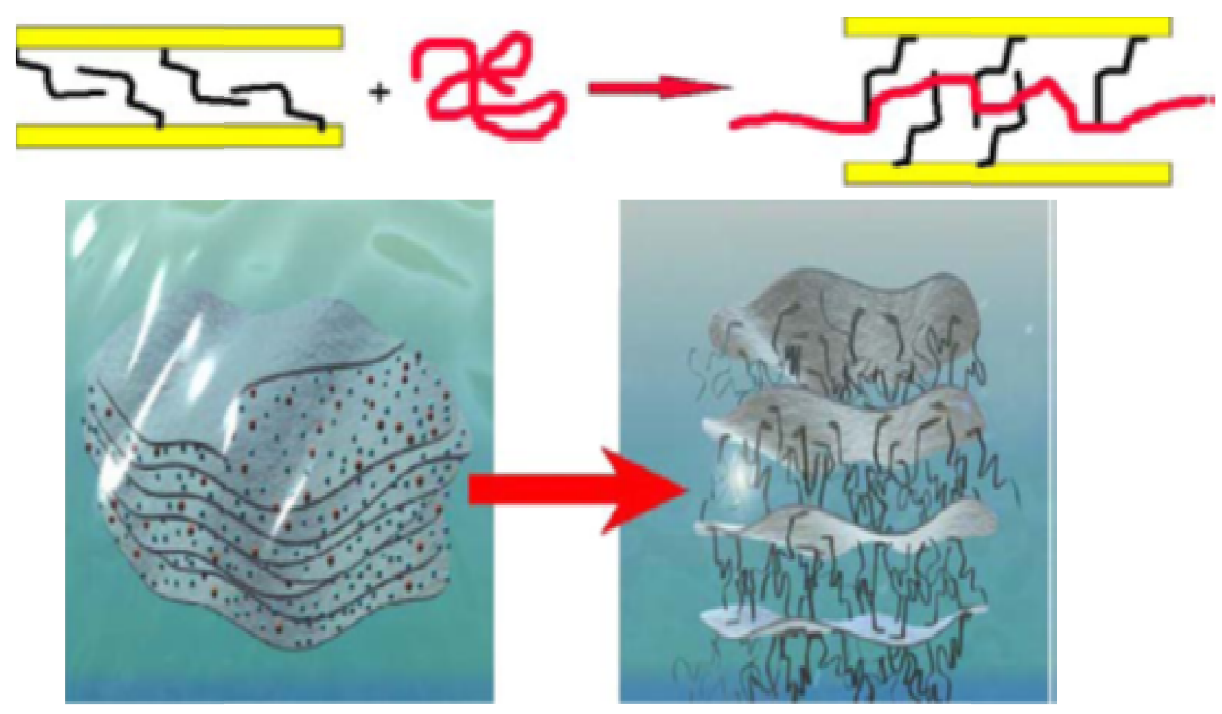

FIGURA 3: Dispersão do sistema matriz polimérica/MMT (Vaia et al,.1995).

Segundo Guimarães (et al.,2006), a estrutura dos nanocompósitos pode apresentar diferenças. São estas, a estrutura intercalada (separadas por cadeias poliméricas, mas tem certa ordem estrutural, o que possibilita ao nonocompósito adquirir propriedades superiores às de um compósito tradicional), a estrutura esfoliada (também chamada de delaminada, apresenta camadas estruturais totalmente desorientadas na matriz, o que aumenta as interações entre polímero/argila e traz melhoras nas propriedades mecânicas e físicas do compósito) e a estrutura aglomerada (semelhante a um compósito convencional). Na figura 4 são apresentados os três tipos de estruturas que podem ocorrer quando uma argila é dispersa em uma matriz polimérica: (a) estrutura de fase separada - propriedades iguais a um compósito convencional; (b) estrutura intercalada - cadeias poliméricas estão intercaladas entre as camadas da argila e as propriedades seriam superiores aos compósitos convencionais; (c) estrutura esfoliada - a argila está uniformemente dispersa na matriz polimérica e melhores propriedades físicas e mecânicas seriam esperadas em relação aos outros tipos de estruturas. (Paiva et al.,2006). 


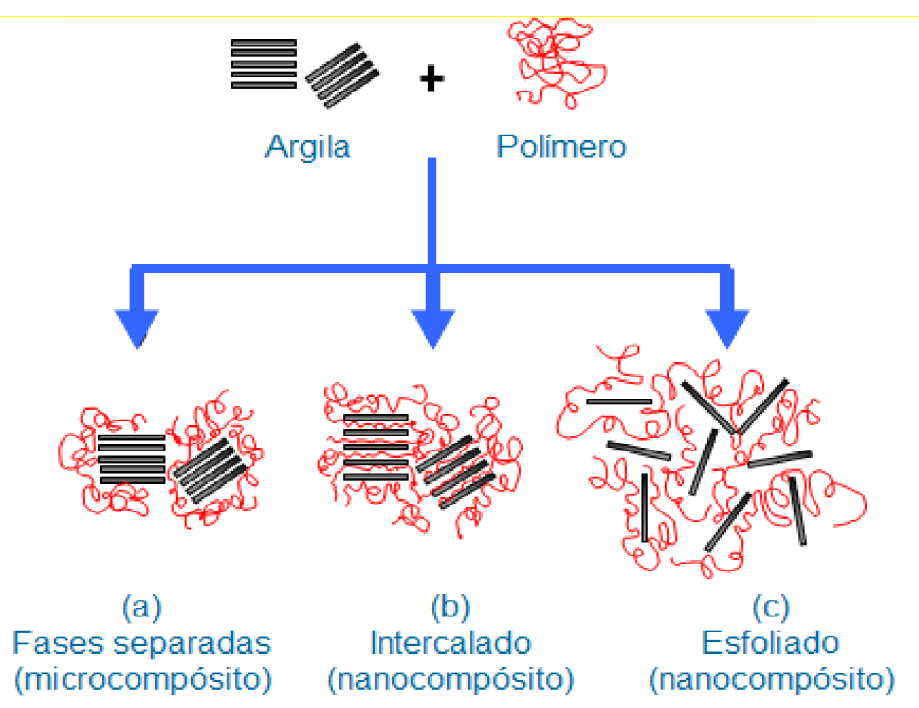

FIGURA 4: Tipos de estruturas que podem ocorrer quando uma argila é dispersa em uma matriz polimérica (Alexandre e Dubois, 2000).

As argilas esmectitas são hidrofílicas, ou seja, se dispersam em água e são incompatíveis com meios hidrofóbicos. Para que haja transformação das argilas esmectitas sódicas em organofílicas são utilizados sais quaternários de amônio que mudam a natureza hidrofílica para hidrofóbica ou organofóbica proporcionando diversas possibilidades de aplicações para essas argilas. Quando há a conversão da superfície dos silicatos hidrofílica em organofílica torna-se possível transformar solúvel a camada de silicato em matrizes poliméricas. Normalmente, isto pode ser feito pela reação de troca iônica com surfactantes catiônicos (cátions alquilamônio ou alquilfosfônico primários, secundários, terciários ou quaternários). A estrutura destes surfactantes (definido como um material tensoativo, que age na superfície limite entre fases e altera a tensão interfacial) é fundamental, assim é possível dar início a intercalação do polímero ou do monômero (Jackson, 1985). Esses surfactates catiônicos incorporados entre as lamelas da argila minimizam as interações entre elas e aumentam a afinidade com a matriz polimérica, além de aumentar o espaçamento interlamelar. Além disto, eles podem prover grupos funcionais de diferente polaridade capazes de reagir com o polímero ou, em alguns casos, iniciar a polimerização de monômeros (Suprakas, 2003).

Para que a argila possa se intercalar com a matriz polimérica, é necessário torná-la organofílica ou hidrofóbica. Este processo de intercalação é usado para 
demonstrar quando uma pequena quantidade de polímero move-se para o interior das galerias do organosilicato, causando menos que $20 \AA ̊$ ou $30 \AA$ de separação entre as lamelas. A esfoliação (delaminação) ocorre quando as moléculas poliméricas separam as estruturas lamelares em mais que $80 \AA$ ou $100 \AA$. Para a formação de um nanocompósito é necessário que os aglomerados sejam quebrados até uma escala de partículas individuais, formando estruturas intercaladas ou esfoliadas, distribuídas homogeneamente ao longo do material, o que é esperado a fim de alcançar melhora nas propriedades dos materiais. Aglomerados de lamelas não separadas após a introdução no polímero são chamados de tactóides (Fornes et al.,2003).

\subsubsection{Técnica de Interferometria Holográfica (TIH)}

Segundo Kobayashi (1989), a TIH ou ESPI (Eletronic Speckle Pattern Interferometry) é um método que utiliza a interferometria óptica de uma luz originada de um laser, para medir deslocamentos e deformações de superfícies de objetos em estudo, por meio da análise de franjas de interferência. A partir da criação do laser, que é uma fonte de luz coerente (Cloud, 1998) houve um grande avanço no desenvolvimento e aplicação prática da Holografia na mecânica experimental. Eram utilizados filmes fotográficos (hologramas) inicialmente, para registrar as deformações nas peças analisadas. Depois desse período passou-se a utilizar um monitor de TV convencional acoplado a uma câmera de vídeo. Com a evolução da técnica, a imagem tornou-se digital e passou a ser transferida para computadores que, com seu poder de processamento, permitiram que a análise fosse mais efetiva e rápida, eliminando assim os antigos filmes fotográficos, conforme exposto em alguns estudos (Cloud, 1998; Hecht, 1987; Willemann, 2002; Kapp, 1998; Robinson, 1993; Brug, 2000; Burke, 1999).

A palavra "speckle" representa a textura granular (pontos claros e escuros) quando uma peça é iluminada pela luz do laser. Estes pontos podem ser vistos através de instrumentos ópticos, como também pelo olho humano. A imagem visualizada inicialmente sofrerá uma variação de intensidade do padrão "speckle" se a superfície do objeto mudar de posição, ou seja, se houver deslocamentos. 
Segundo Brozeit (2000), essa mudança de intensidade está relacionada ao deslocamento.

A base de comparação das franjas associada ao campo de deslocamento é originada pela superposição óptica de dois padrões de "speckle" distintos (por exemplo: objeto em repouso e objeto deformado), que interferem entre si e dão origem a um novo padrão de "speckle". Os padrões de franjas originados em ESPI são parecidos com os obtidos através da holografia interferométrica clássica, porém apresentam mais ruído óptico. O ruído é causado pela modulação aleatória de alguns pontos do padrão de "speckle" e também por pontos que perderam correlação entre o estado inicial e o final. Os campos de deslocamento da superfície medida são responsáveis pela mudança deste novo padrão. Assim a imagem produzida tem relação com o deslocamento sofrido pelo objeto, apresentando um novo padrão de franjas.

De acordo com Hecth (1987), a superposição de duas ou mais ondas luminosas que se encontraram no mesmo lugar no espaço é chamada de interferência óptica. A distribuição de amplitude e fase é única de cada onda, além disso, são instáveis. A partir do momento que for constante no tempo a diferença de fase estabilizam-se os efeitos da interferência e estes poderão ser acompanhados pelas franjas de interferência. Na Figura $5(\mathrm{~A})$ pode-se observar um padrão de "speckle" inicial típico de uma superfície iluminada com luz laser e na Figura 5(B), pode-se observar um padrão "speckle" visualizado por meio de uma câmera CCD, com o padrão de franjas de interferência associado ao deslocamento molecular decorrente da contração de polimerização sofrida pela amostra. 


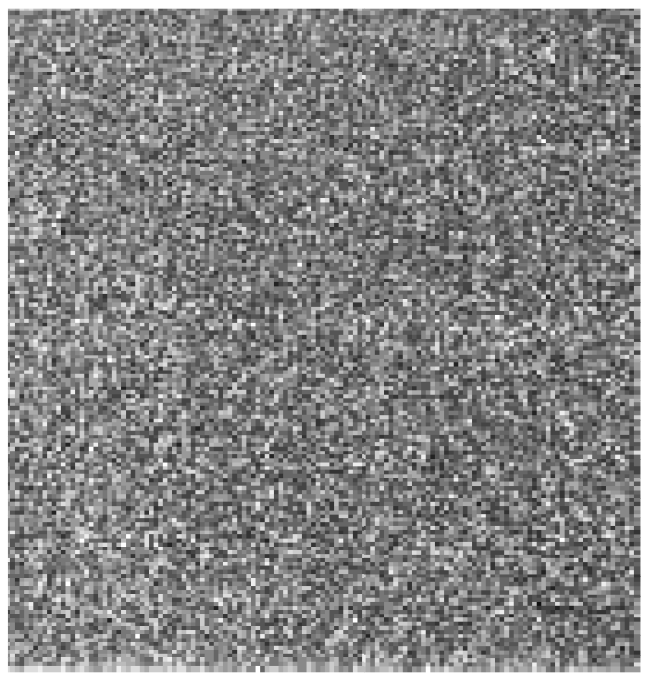

a)

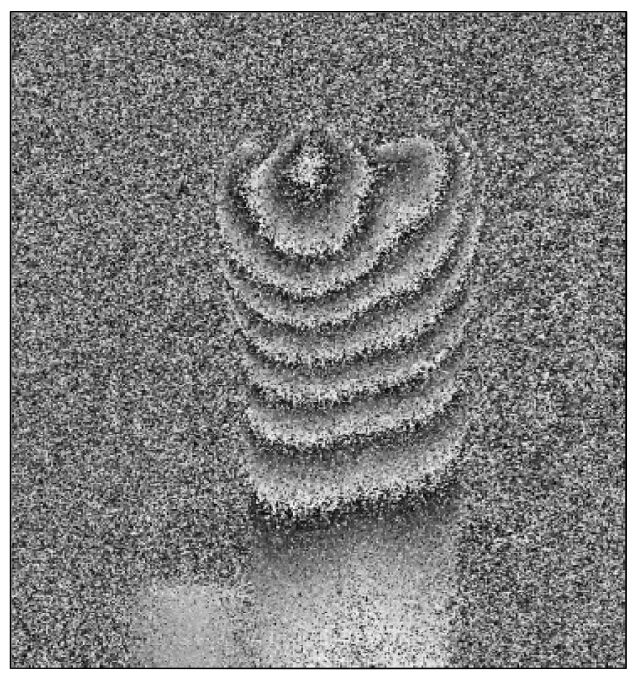

b)

FIGURA 5: Visualização de um padrão de "speckle" típico (a) e um "speckle" com franjas de interferência (b), associado com o deslocamento molecular, decorrente da contração de polimerização sofrida pela amostra.

Baseada na variação do caminho óptico que a luz percorre, é que é feita a medição do deslocamento (deformação). A alteração do caminho óptico ocorre por causa das variações mecânicas na superfície do objeto. Obtém-se a imagem em dois momentos: antes e depois de haver alguma alteração na superfície. As franjas de interferência serão resultado da subtração dessas imagens. Analisando essas franjas, quantificam-se os deslocamentos ocorridos na área observada. Entretanto, durante a execução do teste, é possível observar a formação das franjas em tempo real. O resultado é exposto num monitor na mesma taxa de aquisição. Se a imagem for exatamente igual à imagem de referência, a imagem ao vivo será completamente escura, sem franjas. Se houver alguma deformação dentro do campo de medição, as franjas ao vivo deixam de ser completamente escuras, mostrando um conjunto de franjas que representa as deformações (Troncoso, 1998).

Procura-se encaixar o tamanho do "speckle" dentro de um pixel pela variação da abertura da câmera de vídeo, pois o tamanho do pixel no sensor de imagem é definido pelo fabricante e não pode ser mudado. Se o tamanho do "speckle" é menor do que o tamanho do pixel, então o contraste das franjas cai. Se for muito maior, a resolução espacial piora (Kolenovic, 2000; Joenathan et.al.,1999). É importante que os elementos ópticos do interferômetro não resultem em intensidades desiguais nos 
diferentes caminhos ópticos. Padrões de interferências mostram um maior contraste quando há igualdade das intensidades das ondas que interferem entre si, mas também dependem da coerência e da polarização da luz. Também é fundamental que seja elevada a intensidade da luz que chega ao sensor, porém que esteja um pouco abaixo do nível da saturação, permitindo que o sensor de imagem receba 0 máximo de luz. Segundo Hecht (1987), valores baixos de intensidade de luz se confundem com o ruído produzido pela "corrente escura", característico dos sensores de imagens digitais, piorando a relação sinal-ruído.

Os níveis de energia dos átomos que formam o meio ativo são determinantes na frequência da luz do laser, causando uma largura de banda muito estreita. Tendo variação na temperatura, se houver um elemento de reflexão da luz que oscile numa frequência tal que produza o efeito Doppler, a distribuição de probabilidade de emissão/absorção da luz se dilui num espectro mais amplo, produzindo uma variação na frequência do laser (Sesselmann, 2000). Na presença de perturbações em função do movimento instável das franjas durante o tempo de integração da câmera, a imagem das franjas tende a apresentar um aspecto "borrado", com perda de definição em função da superposição das franjas claras e escuras. Em termos quantitativos, esse efeito representa uma diminuição do contraste (Ochoa et al., 1997). Se uma câmera está integrando uma imagem que está variando a posição das franjas durante a aquisição (por estar sendo perturbada), então o valor final da amplitude de modulação $\left(I_{m}\right)$ será menor do que poderia ser, caso não houvesse nenhuma perturbação (Troncoso, 1998).

Um sistema de THI ou ESPI também foi utilizado em um outro estudo, para mensurar a resposta da dentina de dentes naturais à cargas térmicas em tempo real. Um sistema sensível ao deslocamento foi configurado e utilizado com a técnica de processamento de franjas. Os corpos de prova foram preparados a partir de incisivos centrais inferiores naturais, os quais foram submetidos a temperaturas de $25^{\circ} \mathrm{C}$ a $60^{\circ} \mathrm{C}$. O "speckle", ou seja, a estrutura granulosa observada na superfície do corpo de prova iluminado pela luz do laser, foi formado devido à interferência aleatória de ondas coerentes espalhadas pela superfície áspera do corpo de prova. Pela técnica de interferometria, foi possível comparar os padrões de "speckle" para os dois diferentes estados, não deformado e deformado. Por esse método, as informações 
de deslocamentos e a aspereza dos corpos de prova, quando submetidos a cargas térmicas, foram obtidos. Os padrões de franjas foram visualizados utilizando uma câmera digital e foram submetidos a um processamento de imagem para aumentar a qualidade das franjas decorrente dos deslocamentos sofridos pelos corpos de prova. As imagens resultantes, foram posteriormente analisadas para avaliar 0 deslocamento da dentina. Foram observados deslocamentos no plano perpendicular e paralelo ao longo do eixo do dente. A metodologia ESPI revelou todo o campo de resposta térmica da dentina dos dentes naturais (Kishen, et al., 2001).

A TIH ou ESPI, também foi utilizada para avaliar os impactos mastigatórios sobre diferentes tipos de materiais de restauração em corpos de prova de dentes naturais. Os autores selecionaram dentes pré-molares e fizeram preparos cavitários classe II (MOD) pequenos e grandes. Os dentes foram restaurados com o seguintes materiais: incrustações de ouro, inlays em cerâmica, inlays de resina composta, resina composta e amálgama. As restaurações e as cúspides dentárias foram submetidas a uma carga de $90 \mathrm{~N}$ e a deformação foi avaliada pela TIH ou ESPI. Os dentes com pequenas restaurações apresentaram ligeiras deformações e a diferença entre os materiais, foi mínima $(P>0,05)$. Entretanto, os dentes com grandes restaurações indicaram padrões específicos de deformação, de acordo com cada tipo de material. Os autores concluíram que os materiais utilizados para restaurar os dentes com grandes cavidades, influenciam significativamente o grau e tipo de deformação que ocorre em resposta às forças mastigatórias. O potencial dos materiais adesivos e elásticos para reduzir a deformação (isto é, para estabilizar os dentes) é maior do que o potencial correspondente de materiais não-adesivos e rígidos. A deformação de dentes com pequenas cavidades foi independente do tipo de material utilizado, no entanto os resultados indicaram que o remanescente dentário é o principal fator que define a deformação do dente ao sofrer forças mastigatórias. (Lang et al., 2004).

Com o objetivo de obter o comportamento biomecânico de uma mandíbula humana parcialmente edêntula, em função das diferentes densidades do osso trabecular, autores utilizaram a metodologia ESPI ou TIH para realizar a análise do estresse da mandíbula, quando submetido a forças de mastigação. A simulação foi realizada através de uma extensão distal de uma prótese parcial removível. Duas 
situações foram analisadas após o carregamento: sobre a crista óssea e sob a prótese. Técnicas de Interferometria Holográfica foram utilizadas para obter-se os dados da deformação da mandíbula. Os resultados indicaram que a adaptação correta da base da prótese, foi fundamental para reduzir as tensões na mandíbula e a alta tensão obtida na região do segundo molar inferior, fez com que os autores sugerissem a sua não-inclusão nas reabilitações protéticas (Campos et al., 2009). 


\section{OBJETIVO}

Esse estudo tem como objetivo avaliar a influência da adição de nano partículas argilomineirais em uma matriz polimérica a base de BisGMA e TEGDMA, visando atribuir melhores propriedades mecânicas, redução da contração de polimerização e aprimoramento de uma nova tecnologia para aplicações futuras.

\subsection{Objetivos Específicos}

Estudar o tipo de interação matriz polimérica/carga inorgânica de compósitos experimentais contendo nanopartículas argilominerais Cloisite $10 \mathrm{~A}^{\circledR}$, Cloisite $30 \mathrm{~B}^{\circledR} \mathrm{e}$ comparar com compósitos micro-híbridos contendo sílica silanizada.

Avaliar a influência do processo de organifilização e a concentração das nanopartículas argilominerais sobre a contração de polimerização dos compósitos experimentais.

Observar as alterações na morfologia e analisar a interação do compomente argilomineral com a matriz polimérica à base de BisGMA/TEGDMA, pela determinação do espaçamento interlamelar "d" após a cura.

Determinar a influência da concentração e do tipo de interação matriz polimérica/carga inorgânica nas propriedades mecânicas. 


\section{MATERIAIS}

No presente trabalho foram utilizados compósitos experimentais confeccionados pela técnica de mistura e incorporação manual da carga inorgânica na matriz polimérica. Como parte constituinte da matriz polimérica foram utilizados os seguintes materiais:

- BisGMA: (Bisphenol A Bis(2-hydroxy-3-methacryloxypropyl)Ether). Lote: 688-51, Esstech, Essington, Pennsylvania, USA.

- TEGDMA: (Triethyleneglycol Dimethacrylate). Lote: PA02700018, Esstech, Essington, Pennsylvania, USA.

- Canforoquinona: (camphorquinone, 97\%). Lote: S12442-127, Sigma-Aldrich Chemie, GmBH, Steinheim, Germany.

- DMAEMA: (2-(Dimethylamino)ethyl methacrylate), 98\%. Lote: 21608009, SigmaAldrich Chemie, GmBH, Steinheim, Germany.

Como parte constituinte da carga inorgânica foram utilizados os seguintes materiais:

- Cloisite 10A: MMT natural Cloisite ${ }^{\circledR}$ 10A. Lote: 09K22AGX004, Southern Clay Products, Inc. 1212 Church Street Gonzalez, Texas 78629, USA.

- Cloisite 30B: MMT natural Cloisite ${ }^{\circledR}$ 30B. Lote: 09C02AAX015, Southern Clay Products, Inc. 1212 Church Street Gonzalez, Texas 78629, USA.

- Sílica: Aerosil ${ }^{\circledR}$ OX-50 Silanizado. Lote: 091111. FGM, 89219-501, Joinville, SC, Brasil. 


\subsection{Cloisite 10A ${ }^{\circledR}$}

A nanopartícula argilomineral utilizada nesse estudo, MMT Cloisite $10 A^{\circledR}$ foi previamente organifilizada pelo fabricante e de acordo com suas informações possui a superfície modificada pelo Dimetil Di“tallow" hidrogenado de amônio quaternário (2MBHT), na concentração de 125 meq $100 \mathrm{~g}^{-1}$ de argila, ânion de cloreto e onde "Tallow" hidrogenado, representa um grupo alquila com aproximadamente $65 \%$ de $\mathrm{C}_{18} ; 30 \%$ de $\mathrm{C}_{16}$ e $5 \%$ de $\mathrm{C}_{14}$, conforme demonstra a Figura 6 :

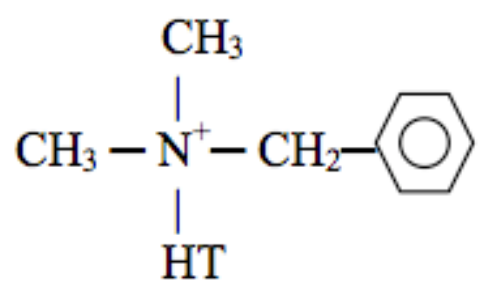

FIGURA 6: Dimetil Di“tallow" hidrogenado de amônio quaternário (2MBHT).

O tamanho das partículas, segundo informações do fabricante, estão descritas na Tabela 1:

TABELA 1: Tamanho das partículas correspondentes a MMT Cloisite $10 A^{\circledR}$, segundo informações do fabricante

10\% menor que: $\quad 50 \%$ menor que: $\quad 90 \%$ menor que:

$2 \mu \mathrm{m} \quad 6 \mu \mathrm{m} \quad 13 \mu \mathrm{m}$

Ainda segundo o fabricante, a MMT Cloisite $10 A^{\circledR}$ possui $\mathrm{d}_{001}=19.2 \AA$, correspondente ao pico inicial da Difração de Raio- $X$, valor que também indica 0 espaçamento interlamelar inicial. O fabricante também afirma que a área superficial da nanopartícula é de $750 \mathrm{~m}^{2} \mathrm{~g}^{-1}$. 


\subsection{Closite $30 \mathrm{~B}^{\circledR}$}

A nanopartícula argilomineral utilizada nesse estudo, MMT Closite $30 \mathrm{~B}^{\circledR}$ foi previamente organifilizada pelo fabricante e de acordo com suas informações possui a superfície modificada pelo Metil "tallow" bis-2-hidroxetil amônio quaternário (MT2EtOH), na concentração de $90 \mathrm{meq} 100 \mathrm{~g}^{-1}$ de argila, ânion de cloreto e onde "Tallow" representa um grupo alquila com aproximadamente $65 \%$ de $\mathrm{C}_{18} ; 30 \%$ de $\mathrm{C}_{16}$; e $5 \%$ de $\mathrm{C}_{14}$ ), conforme demonstra a Figura 7 :

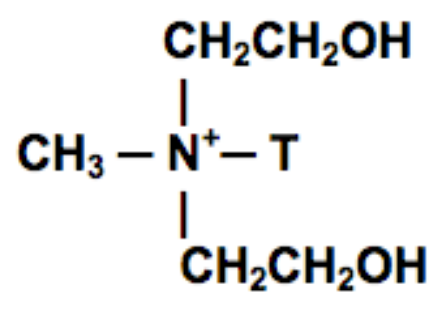

FIGURA 7: Metil "tallow" bis-2-hidroxetil amônio quaternário (MT2EtOH).

O tamanho das partículas, segundo informações do fabricante, estão descritas na Tabela 2:

TABELA 2: Tamanho das partículas correspondentes a MMT Cloisite $30 \mathrm{~B}^{\circledR}$, segundo informações do fabricante.

$10 \%$ menor que:

$50 \%$ menor que:

$90 \%$ menor que:

$2 \mu \mathrm{m}$

$6 \mu \mathrm{m}$

$13 \mu \mathrm{m}$

Ainda segundo o fabricante, a MMT Cloisite $30 \mathrm{~B}^{\circledR}$ possui $\mathrm{d}_{001}=18.5 \AA$, correspondente ao pico principal da Difração de Raio- $X$, valor que também indica o espaçamento interlamelar inicial. $O$ fabricante também afirma que a área superficial da nanopartícula é de $750 \mathrm{~m}^{2} \mathrm{~g}^{-1}$. 


\subsection{Sílica Silanizada Aerosil ${ }^{\circledR}$ OX-50}

A sílica utilizada nesse estudo possui partículas de $0,04 \mu \mathrm{m}$ ou $40 \mathrm{~nm}$. Sua área superficial, segundo a técnica de BET foi determinada pelo fabricante em $48,279 \mathrm{~m}^{2} \mathrm{~g}^{-1}$ quando sua superfície não está silanizada e $26,190 \mathrm{~m}^{2} \mathrm{~g}^{-1}$, após a silanização. 


\section{MÉTODOS}

\subsection{Confecção dos Compósitos Experimentais}

Os compósitos experimentais foram elaborados apresentando uma variação de acordo com o tipo e a concentração em porcentagem de carga inorgânica, compondo 13 diferentes grupos. Os materiais foram pesados individualmente em uma balança eletrônica digital de precisão, marca Shimadzu/ modelo AY220 . O objetivo era que cada grupo de compósito experimental tivesse 1 grama na sua massa final. Após a pesagem dos materiais iniciou-se a mistura pela matriz polimérica, com o auxílio de uma espátula de resina em um pote "dappen". O BisGMA foi incorporado ao TEGDMA em proporções iguais, em todos os grupos. Após essa mistura inicial, adicionou-se a canforoquinona e a amina terciária DMAEMA e em seguida da manipulação adicionou-se a carga inorgânica em pequenas proporções até a inteira incorporação da carga na matriz .

Para uma correta homogeinização da mistura, o compósito experimental era removido do pote "dappen" e levado a um almofariz para ser manipulado com um pistilo. Para a finalização da mistura, o compósito foi manipulado por 5 minutos.

$\mathrm{Na}$ Tabela 3, observa-se a identificação de todos os Grupos de compósitos experimentais. Na tabela 4 estão as formulações e as concentrações de carga inorgânica de cada um dos grupos experimentais adicionados com a nanopartícula argilomineral Cloisite $10 \mathrm{~A}^{\circledR}$, na Tabela 5 estão os grupos adicionados com a nanopartícula argilomineral Cloisite $30 \mathrm{~B}^{\circledR}$ e na Tabela 6 observam-se os grupos adicionados com a Sílica Aerosil ${ }^{\circledR}$ OX-50. 
TABELA 3: Identificação dos Grupos de compósitos experimentais:

\begin{tabular}{|c|c|c|}
\hline Grupo & \% Carga inorgânica e Tipo & Identificação \\
\hline Grupo 1 & $50 \%$ - Cloisite $10 A^{\circledR}$ & $50 \mathrm{~A}$ \\
\hline Grupo 2 & $55 \%$ - Closite $10 A^{\circledR}$ & $55 \mathrm{~A}$ \\
\hline Grupo 3 & $60 \%$ - Cloisite $10 A^{\circledR}$ & $60 \mathrm{~A}$ \\
\hline Grupo 4 & $65 \%$ - Cloisite $10 A^{\circledast}$ & $65 \mathrm{~A}$ \\
\hline Grupo 5 & $70 \%$ - Cloisite $10 A^{\circledR}$ & $70 \mathrm{~A}$ \\
\hline Grupo 6 & $50 \%$ - Cloisite $30 \mathrm{~B}^{\circledR}$ & $50 \mathrm{~B}$ \\
\hline Grupo 7 & $55 \%$ - Cloisite $30 \mathrm{~B}^{\circledR}$ & $55 \mathrm{~B}$ \\
\hline Grupo 8 & $60 \%$ - Cloisite $30 \mathrm{~B}^{\circledR}$ & $60 \mathrm{~B}$ \\
\hline Grupo 9 & $65 \%$ - Cloisite $30 \mathrm{~B}^{\circledR}$ & $65 \mathrm{~B}$ \\
\hline Grupo 10 & $50 \%$ - Sílica Aerosil ${ }^{\circledR}$ OX-50 & $50 S$ \\
\hline Grupo 11 & $60 \%$ - Sílica Aerosil ${ }^{\circledR}$ OX-50 & $60 S$ \\
\hline Grupo 12 & $65 \%$ - Sílica Aerosil ${ }^{\circledR}$ OX-50 & $65 S$ \\
\hline Grupo 13 & $70 \%$ - Sílica Aerosil ${ }^{\circledR}$ OX-50 & $70 S$ \\
\hline
\end{tabular}


TABELA 4: Formulações dos Grupos 1(50A), 2(55A), 3(60A), 4(65A) e 5(70A).

\begin{tabular}{lccccc}
\hline & \multicolumn{5}{c}{ Quantidade em massa (mg) } \\
\hline & Grupo 1 & Grupo 2 & Grupo 3 & Grupo 4 & Grupo 5 \\
BisGMA & 248 & 223 & 198 & 173 & 148 \\
TEGDMA & 248 & 223 & 198 & 173 & 148 \\
Canforoquinona & 2 & 2 & 2 & 2 & 2 \\
DMAEMA & 2 & 2 & 2 & 2 & 2 \\
Cloisite 10A & 500 & 550 & 600 & 650 & 700 \\
Massa Total & 1000 & 1000 & 1000 & 1000 & 1000 \\
\hline
\end{tabular}

TABELA 5: Formulações Grupo 6(50B), 7(55B), 8(60B) e 9 (65B).

Quantidade em massa (mg)

\begin{tabular}{lcccc}
\hline & Grupo 6 & Grupo 7 & Grupo 8 & Grupo 9 \\
BisGMA & 248 & 223 & 198 & 173 \\
TEGDMA & 248 & 223 & 198 & 173 \\
Canforoquinona & 2 & 2 & 2 & 2 \\
DMAEMA & 2 & 2 & 2 & 2 \\
Cloisite 30B & 500 & 550 & 600 & 650 \\
Massa Total & 1000 & 1000 & 1000 & 1000 \\
\hline
\end{tabular}


TABELA 6: Formulações dos Grupo 10(50S), 11(60S), 12(65S) e 13(70S).

\begin{tabular}{lcccc}
\hline & \multicolumn{4}{c}{ Quantidade em massa (mg) } \\
\hline & Grupo 10 & Grupo 11 & Grupo 12 & Grupo 13 \\
& 248 & 198 & 173 & 148 \\
BisGMA & 248 & 198 & 173 & 148 \\
TEGDMA & 2 & 2 & 2 & 2 \\
Canforoquinona & 2 & 2 & 2 & 2 \\
DMAEMA & 500 & 600 & 650 & 700 \\
$\begin{array}{l}\text { Sílica Aerosil } \\
\text { OX-50 }\end{array}$ & 1000 & 1000 & 1000 & 1000 \\
Massa Total & & & & \\
\hline
\end{tabular}

Os compósitos experimentais adicionados com a nanopartícula argilomineral Cloisite $30 \mathrm{~B}^{\circledR}$, tiveram a concentração de carga inorgância definida entre 50 e $65 \%$. Não foi possível obter o compósito experimental com $70 \%$ de concentração de carga inorgânica, devido a limitação da técnica manual de manipulação, pois com essa elevada concentração, o compósito experimental não apresentava a viscosidade adequada para ser submetido a avaliação da contração de polimerização pela Análise Térmica-Mecânica (TMA). No entanto, foi possível obter essa alta concentração de carga inorgânica tanto nos compósitos experimentais adicionados com a nanopartícula Cloisite $10 \mathrm{~A}^{\circledR}$, quanto nos compósitos adicionados com a Sílica Aerosil ${ }^{\circledR}$ OX-50.

\subsection{Confecção dos Corpos de Prova}

Para a realização desse trabalho, foram desenvolvidos dois tipos de corpos de prova. O primeiro tipo foi feito para a avaliação da contração de polimerização pela Análise Térmica Mecânica (TMA). O mesmo corpo de prova, após a polimerização pela metodologia TMA, foi utilizado também para a caracterização 
dos compósitos experimentais pelas técnicas de Microscopia Eletrônica de Varredura (MEV), Calorimetria Exploratória Diferencial (DSC), Análise de Termogravimetria (TGA), Espectroscopia de Absorção na Região do Infravermelho (FTIR) e Micro Dureza Knoop .

Após a confecção de todos os grupos de compósitos experimentais, um grupo foi selecionado de cada vez para o início da confecção dos corpos de prova. Iniciou-se a confecção por uma pesagem. Cada corpo de prova teve seu peso estabelecido em 0,0150g. Após a pesagem foi determinada a espessura dos mesmos. Cada corpo de prova foi colocado sobre uma lâmina de vidro de microscópio. Dessa maneira, com o auxílio de uma outra lâmina de vidro e de um marcador pré determinado de espessura, o corpo de prova foi pressionado entre as duas lâminas e conseguiu-se assim, obter a espessura desejada. Para a verificação da espessura, um paquímetro digital da marca Digital Caliper, modelo Digital 6" (0-150mm) foi utilizado. A espessura foi determinada em 0,50 mm. Na Figura 8, observam-se algumas etapas da confecção das amostras: pesagem na balança digital de precisão (a), verificação da espessura por meio de um paquímetro digital (b) e vista superior dos corpos de prova prontos (c).

Para a realização do segundo tipo de corpo de prova, inicialmente foram utilizados dentes de resina acrílica artificial (ou dentes de frasaco) e posteriormente, dentes naturais. Foram selecionados dentes correspondentes aos primeiros prémolares inferiores esquerdo, tanto nos dentes artificiais, quanto nos dentes naturais. Após a seleção dos dentes artificiais e naturais, foram realizados preparos cavitários do tipo Classe I de Black. Todos os preparos foram realizados com brocas esféricas diamantadas número 1012, marca KG-Sorensen e de uma caneta de alta rotação marca Kavo, modelo 506C Extra Torque, seguindo as marcações e a profundidade padronizadas, sendo $2,5 \mathrm{~mm}$ de profundidade, $3 \mathrm{~mm}$ de distância mésio-distal, e 2,5mm de distância vestíbulo-lingual.

Um grupo de compósito experimental foi selecionado de cada vez. Cada grupo selecionado foi submetido a uma pesagem em uma balança digital de precisão, com o objetivo de que cada amostra tivesse 100mg. Os dentes foram fixados pela base em um suporte para que o laser, ao incidir sobre a superfície dentária, pudesse fazer a mensuração do deslocamento molecular e da contração de polimerização sem interferências. Após a fixação dos dentes no suporte, as luzes 
do laboratório foram apagadas e a amostra do compósito experimental previamente pesada, foi inserida na cavidade dentária preparada em um só incremento. Esse mesmo procedimento foi refeito para cada grupo testado.

Esse tipo de corpo de prova foi utilizado para a avaliação da contração de polimerização pelas metodologias de Técnica de Interferometria Holográfica $(T I H)$, Holografia Digital (HD), Correlação de Imagem (Cl) e para a avaliação da exotermia durante a polimerização pela metodologia da Termografia.

Na Figura 8, observar-se a vista lateral e superior de um corpo de prova de dente artificial (a-b) e a vista superior de um corpo de prova de dente natural (c), ambos com o preparo cavitário tipo Classe I de Black realizados.

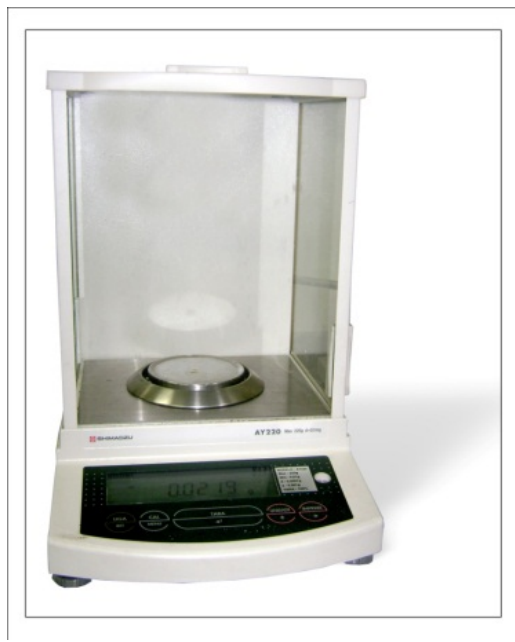

a)

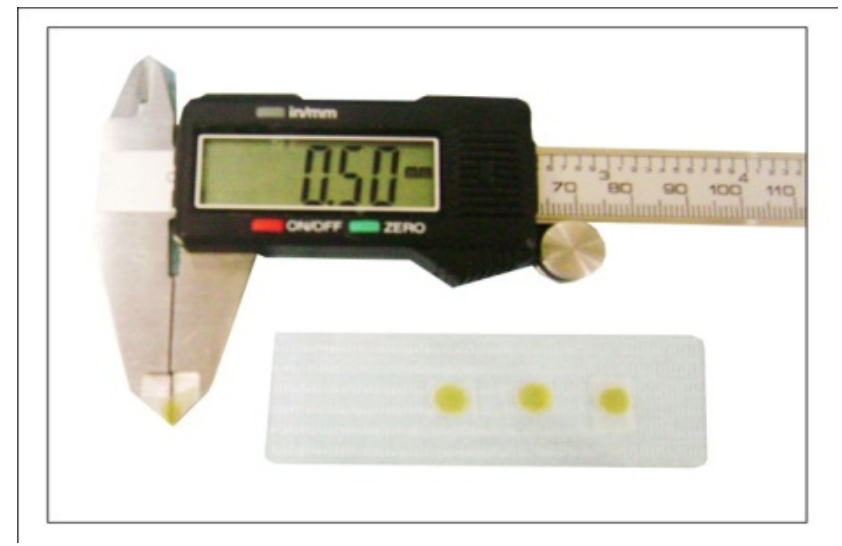

b)

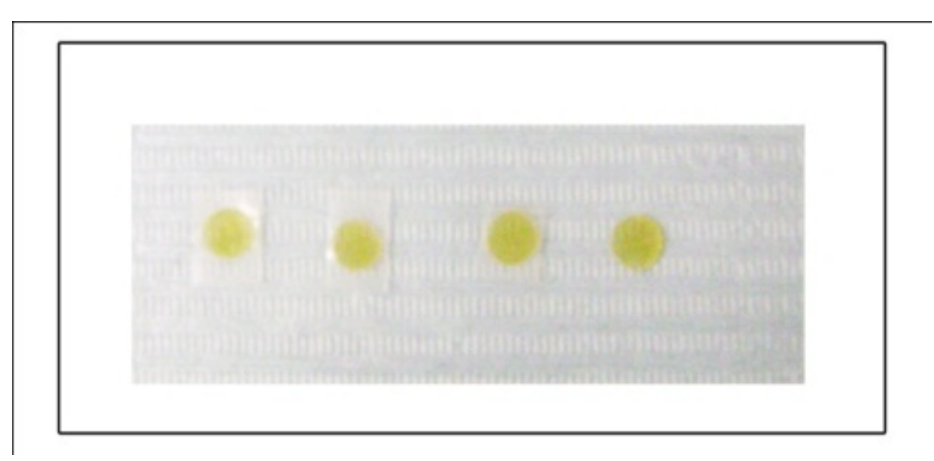

c)

FIGURA 8: Etapas da confecção das amostras: pesagem na balança digital de precisão (a), verificação da espessura por meio de um paquímetro digital (b) e vista superior dos corpos de prova prontos (c). 


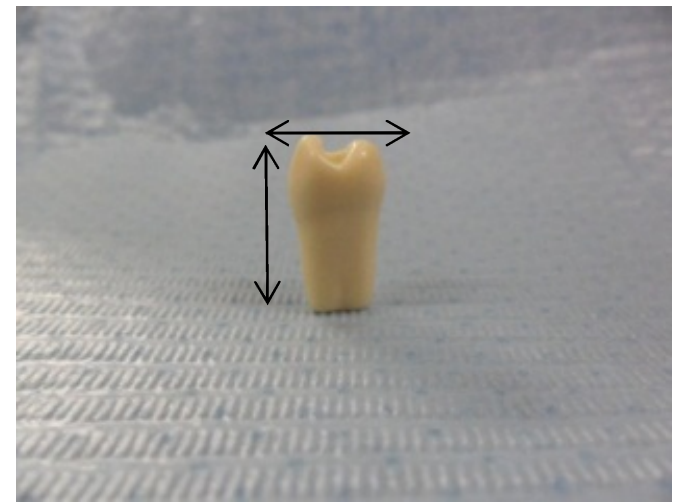

a)

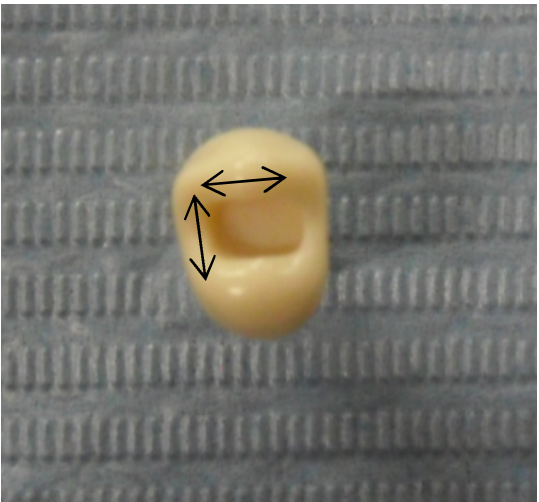

b)

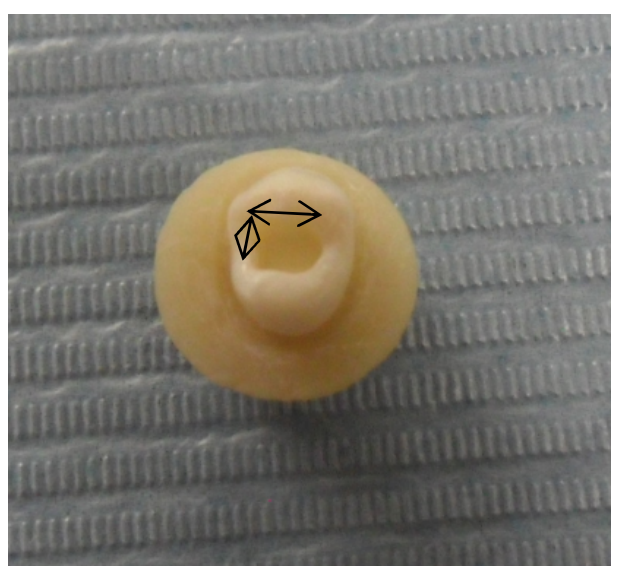

c)

FIGURA 9: Vista lateral e superior de um corpo de prova de dente artificial (a-b) e a vista superior de um corpo de prova de dente natural (c).

\subsection{Métodos de Caracterização}

\subsubsection{Microscopia Eletrônica de Varredura - (MEV)}

A microscopia eletrônica de varredura (MEV) permitiu a observação da morfologia dos compósitos experimentais adicionados com carga inorgânica argilomineral. É uma análise comumente utilizada para o estudo de estruturas superficiais de materiais, pela formação de imagens tridimensionais de alta resolução e profundidade de foco, sem a perda de nitidez. As análises foram realizadas em amostras do corpo de prova recobertas em ouro e analisadas no 
Microscópio Eletrônico de Varredura da marca PHILIPS, modelo XR-30 no Centro de Ciências e Tecnologia de Materiais (CCTM) do IPEN.

\subsubsection{Análise Térmica-Mecânica - (TMA)}

Por meio dessa análise, foi realizada a mensuração da contração de polimerização dos compósitos experimentais durante a cura. Essa metodologia foi realizada com um sistema de fotopolimerização acoplado. Foi utilizado o aparelho fotopolimerizador LED Curing Light, marca Kondodteck, modelo Aigh-7A, número de série Al8100281, o qual emite luz com comprimento de onda de $468 \mathrm{~nm}$, próprio para a cura de compósitos odontológicos.

As análises foram realizadas no equipamento Metter Toledo TMA/STDA 840, no Laboratório de Polímeros do Centro de Química e Meio Ambiente (Lab Pol/ CQMA) do IPEN. Na Figura 10, observar-se o aparelho TMA e na Figura 11, a sequência da inserção do corpo de prova no equipamento TMA para mensurar a contração de polimerização.
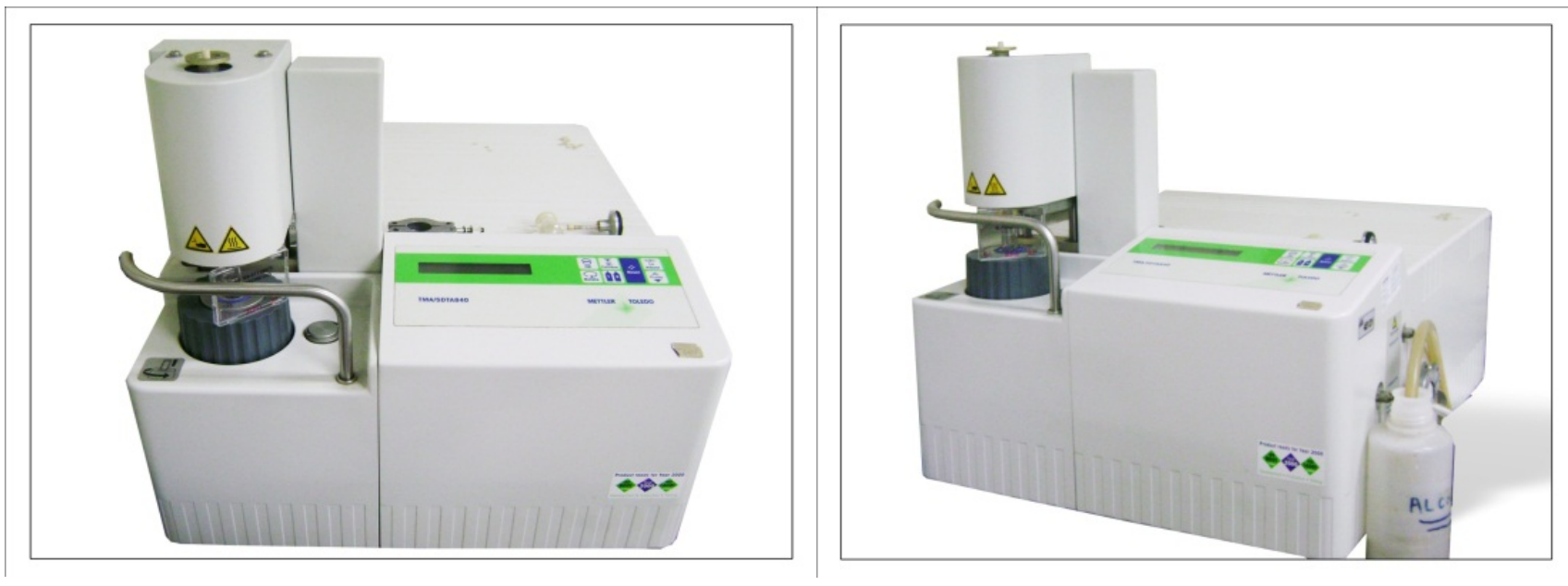

FIGURA 10: Imagens do aparelho de Análise Térmica Mecânica (TMA). 


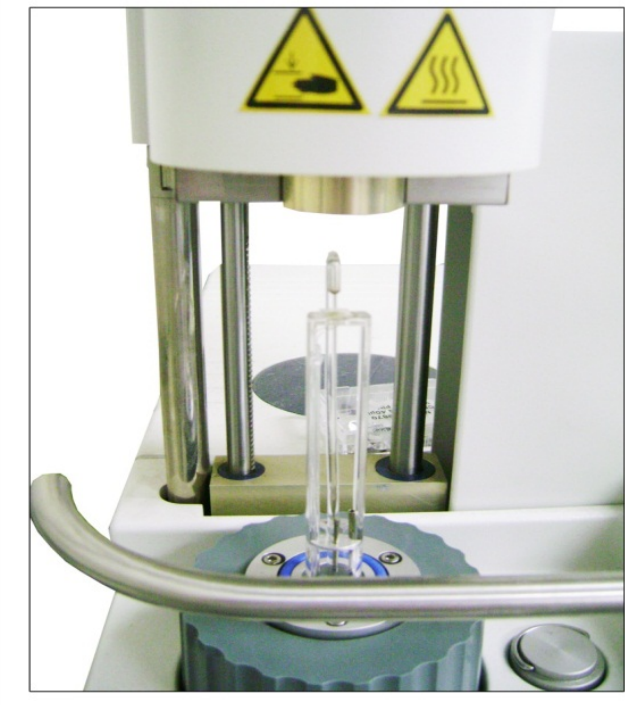

a)

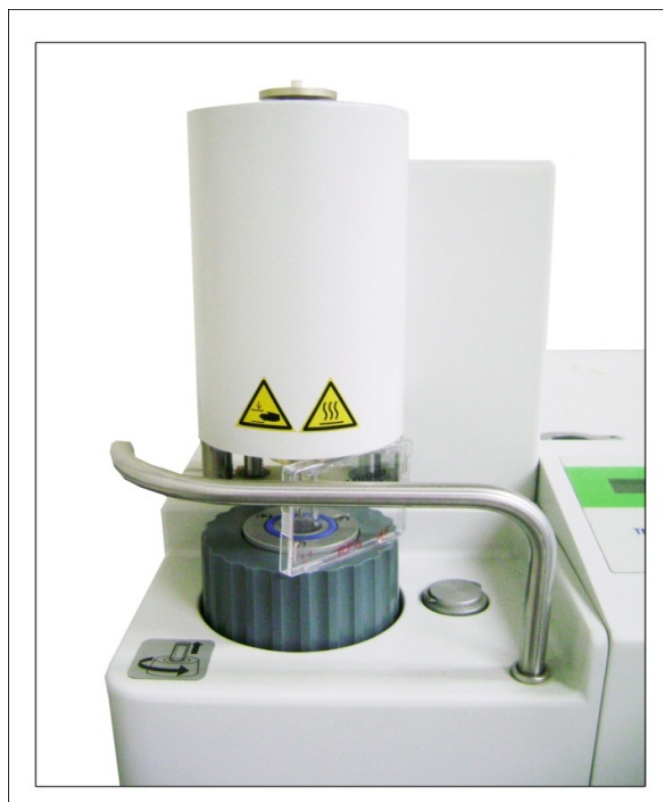

c)

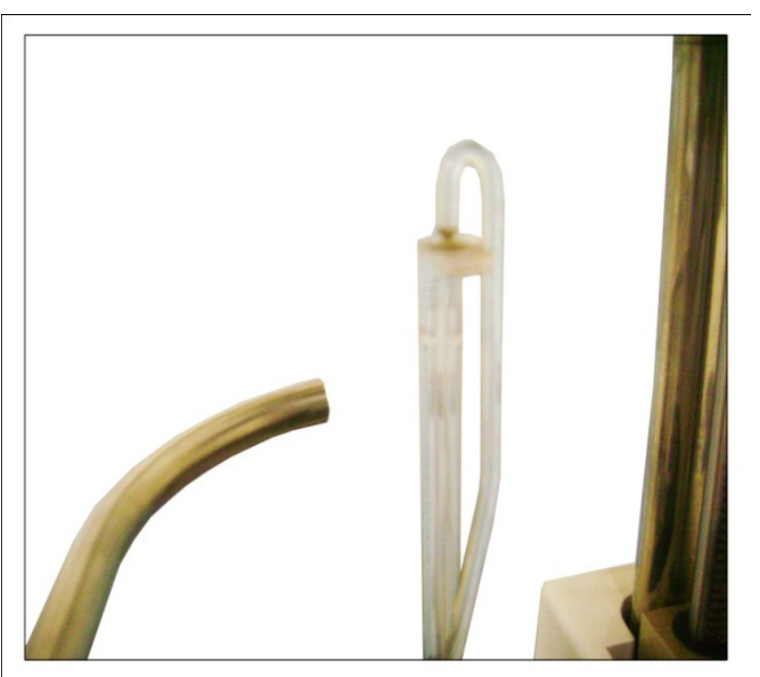

b)

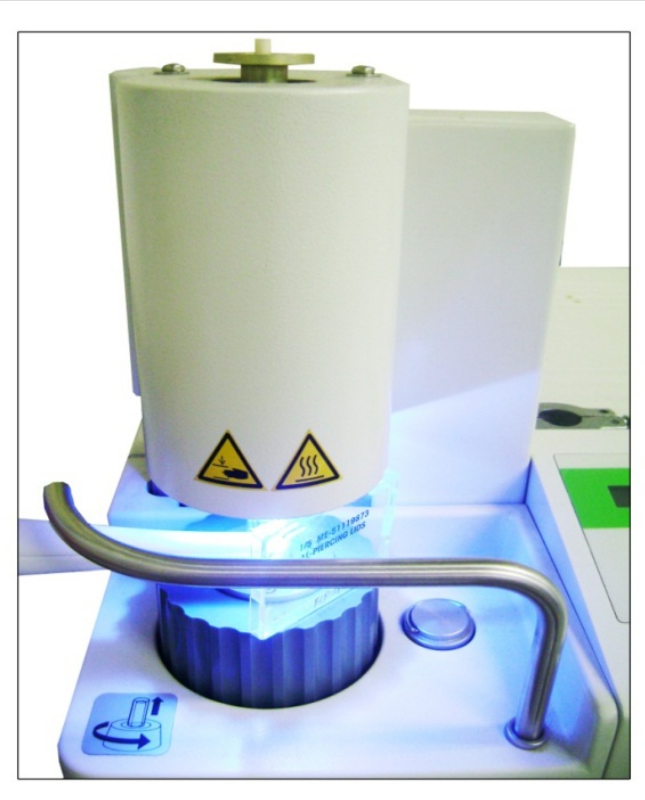

d)

FIGURA 11: Sequência da inserção do corpo de prova no aparelho TMA. (a) Levantamento da haste. (b) Ajuste do posicionamento do sensor sobre o corpo de prova. (c) Ajuste da abertura do forno. (d) Fotopolimerizador acoplado.

Para a mensuração da contração de polimerização, um grupo foi selecionado de cada vez. Foram realizadas dez análises para cada grupo, de onde foi obtida a média da contração volumétrica. Também foram calculados o desvio padrão e a variância. 
O tempo de análise de cada corpo de prova foi determinando em 5 minutos de duração, com temperatura média de $25^{\circ} \mathrm{C}$. Nos segundos iniciais, identificados até $0,5 \mathrm{~min}$, o fotopolimerizador não foi ativado, dessa maneira nenhuma alteração volumétrica foi observada nas análises realizadas. De 0,5 a 2,5 min, o fotopolimerizador foi ativado, assim toda a alteração volumétrica resultante da fotopolimerização pode ser registrada. A partir de $2,5 \mathrm{~min}$, o fotopolimerizador foi desligado e apenas observou-se a reação de pós-cura da amostra.

Os resultados foram baseados em toda a alteração volumétrica em porcentagem sofrida pela amostra nesse período. Esta metodologia mensurou a contração de polimerização em tempo real durante o processo de cura com uma precisão manométrica.

\subsubsection{Análise de Termogravimetria - (TGA)}

Com a análise de termogravimetria pode-se determinar a proporção de conteúdo orgânico/inorgânico das cargas e compósitos utilizados e observar a estabilidade térmica pela observação do perfil de decomposição das amostras elaboradas, quando submetidas a um programa de aquecimento em atmosfera inerte ou oxidativa. As amostras foram pesadas e acondicionadas em cadinhos de alumina. As análises foram realizadas no equipamento Metter Toledo TGA/SDT851 sob atmosfera de nitrogênio, no Lab Pol/CQMA do IPEN.

As amostras utilizadas para essa análise foram previamente fotopolimerizadas pela metodologia TMA.

\subsubsection{Calorimetria Exploratória Diferencial - (DSC)}

Por meio dessa metodologia pode-se monitorar os perfis de cura e pós-cura dos compósitos experimentais e a temperatura de transição vítrea. Esse método também permitiu analisar em tempo real a cura da matriz polimérica por meio do calor desprendido, pois quase todos os processos de polimerização são exotérmicos (Costa et al.,1999). 
Foi pela metodologia DSC que se observou também a eficácia de polimerização e conversão das amostras submetidas a metodologia TMA, comparando-se amostras polimerizadas e não polimerizadas do mesmo grupo. Foram realizadas dez análises para cada grupo de compósitos experimental.

Para a realização das análises, as amostras foram pesadas e acondicionadas sobre cadinhos de alumínio. A duração foi de 28 minutos e a temperatura variou entre $25^{\circ} \mathrm{C}$ e $300^{\circ} \mathrm{C}$. O aparelho utilizado foi DCS822 ${ }^{\mathrm{e}}$ Mettler Toledo, no Lab Pol/CQMA do IPEN.

\subsubsection{Espectroscopia de Absorção na Região do Infravermelho - (FTIR)}

As análises foram realizadas pela metodologia de espectroscopia de absorção na região do infravermelho por transformada de Fourrier, utilizando a técnica de reflectância total (ATR) e teve como objetivo identificar a estrutura dos compósitos experimentais por meio do espectro de absorbância, avaliar as bandas de absorção referentes às ligações da matriz polimérica e a carga inorgânica argilomineral, além de identificar os monômeros livres.

Foi utilizado para essas análises o aparelho ThermoNicolet 6700 - FTIR Espectrometer, com varredura utilizada de $4000 \mathrm{~cm}^{-1}$ a $500 \mathrm{~cm}^{-1}$, no Lab.Pol./CQMA do IPEN.

\subsubsection{Difração de Raio -X - (DRX)}

Esta análise teve como objetivo determinar a distância interlamelar e o espaçamento basal "d" da montmorilonita dispersa na fase orgânica do composto experimental, a fim de avaliar a ocorrência de intercalação, definida como uma estrutura morfológica com espaçamentos lamelares acima de $80 \AA$ (Salahudin et al., 2001).

Pela Difração de Raio-X obtiveram-se os difratogramas que avaliaram a intercalação ou esfoliação da argila no composto polimérico, pelo método do pó, 
mediante o emprego de difratômetro de raios X, marca PANalytical, modelo X'Pert PRO com detector X'Celerator. As condições de análise foram: Fonte geradora de

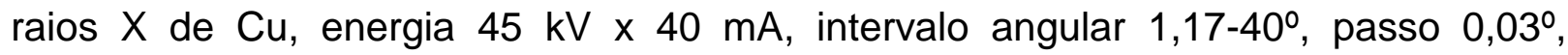
tempo/passo 100s. A Figuras 12, mostra o aparelho de DRX utilizado para a realização das análises.
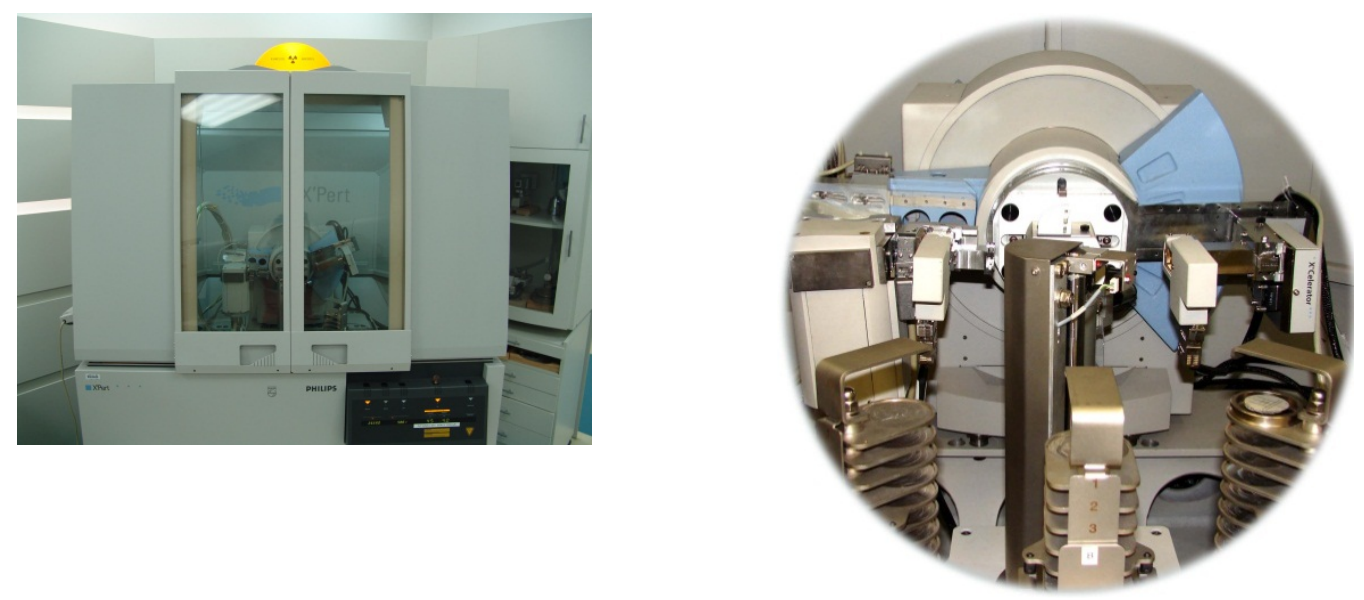

FIGURA 12: Aparelho utilizado para as análises de DRX.

A Difração de Raio-X é caracterizada pelo fenômeno de interação entre um feixe incidente de raio-X e os elétrons dos átomos componentes de um material, sendo posteriormente detectados por fótons difratados, que constituem o feixe difratado. Os raios- $X$ ao atingirem a superfície de um material podem ser espalhados elasticamente sem perda de energia pelos elétrons dos átomos. O fóton de raio-X após a colisão com o elétron da amostra, muda sua trajetória, mas, mantém o mesmo comprimento de onda da radiação incidente. Dessa forma, cada elétron atuante é instantaneamente um novo centro de emissão de raio-X (Jenkins et al.,1996). Se os átomos que geram este espalhamento estiverem arranjados sistematicamente, como uma estrutura cristalina pode-se observar que as relações de fase entre os espalhamentos tornam-se periódicas e que a Difração de Raio-X é observada em vários ângulos de incidência do feixe. Quando esse feixe de raio-X atinge a superfície de uma amostra cristalina sob uma determinada angulação, uma porção é retroespalhada pela camada de átomos superficiais e outra porção penetra em direção à segunda camada de átomos, onde novamente uma fração é retroespalhada e a 
restante passa a atingir a terceira camada. $O$ efeito cumulativo deste retroespalhamento constitui a Difração de Raio-X, entretanto o seu comprimento de onda " $\lambda$ " deve ser da ordem de grandeza das distâncias entre os centros espalhadores "d", como o resultado de uma interferência construtiva e ocorrendo nas direções de espalhamento que satisfazem a Lei de Bragg (Skoog et al.,1992; Cullity, 1978).

O espaçamento interplanar basal "d" dos compósitos experimentais com carga inorgânica argilomineral, foram determinados pela Lei de Bragg expressa da seguinte forma: $\mathbf{n} \boldsymbol{\lambda}=\mathbf{2 d}$ sen $\boldsymbol{\Theta}$, onde:

$\mathrm{n}$ = um número inteiro;

$\lambda=$ comprimento de onda da radiação incidente;

$d=$ a distância ou espaçamento interplanar para o conjunto de planos "hkl" (índice de Miller) da estrutura cristalina;

$\Theta=$ ângulo de incidência de raios- $X$ (medido entre o feixe incidente e $\circ$ plano cristalino).

Pela observação do pico referente ao plano $d_{001}$ da argila pode-se analisar a estrutura do nanocompósito, ou seja, o estado da dispersão da argila em relação a matriz polimérica. Se houver um aumento no espaço interlamelar, o que caracteriza a entrada do polímero entre as camadas da argila, haverá um deslocamento do pico do plano $d_{001}$ para ângulos menores. Entretanto se houver a ausência desse pico indicará a formação de uma estrutura esfoliada e se não houver nenhuma alteração do pico do01 indicará que não houve qualquer tipo de interação entre a argila e o polímero. Na Figura 13 pode-se observar os diferentes estados de dispersão da argila em relação ao polímero pela caracterização de DRX. 


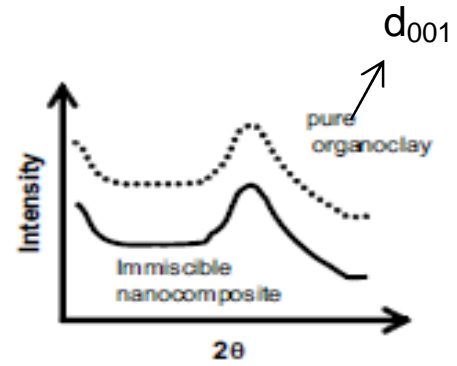

a)

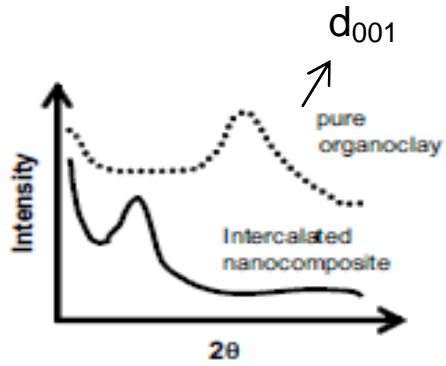

b)

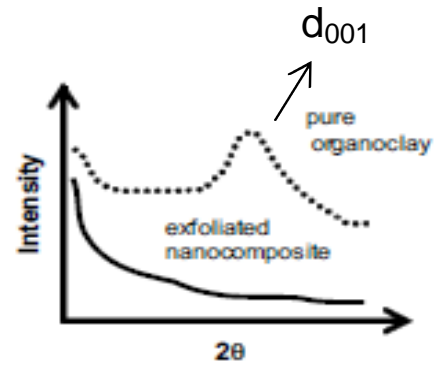

c)

FIGURA 13: Os diferentes estados da dispersão da argila em relação ao polímero, pela análise de DRX: (a) sem interação argila/polímero, (b) argila intercalada em relação ao polímero e (c) argila esfoliada em relação ao polímero.

Na confecção das amostras para a análise de DRX, todos os grupos testados seguiram o mesmo padrão. As amostras foram pesadas incialmente por uma balança digital de precisão, marca Shimadzu/ modelo AY220 e seu peso foi determinado em $0,5 \mathrm{~g}( \pm 0,0001 \mathrm{~g})$. Foi determinada a espessura da amostra em 0,5 $\mathrm{mm}( \pm 0,01 \mathrm{~mm})$ e por meio de um paquímetro digital da marca Digital Caliper, modelo Digital 6" (0-150mm), a espessura das amostras foram confirmadas. As amostras foram confeccionadas com o objetivo de obter uma superfície lisa e plana. Nessa análise, os pós puros da Cloisite $10 A^{\circledR}$ e Cloisite $30 B^{\circledR}$ também foram analisados. $\mathrm{O}$ aparelho dispõe de um recipiente próprio para a análise de materiais nesse estado. Na Figura 14 (a) observa-se uma amostra do Grupo 1 (50A) pronta para ser analisada e na Figura 14 (b) observa-se pó da Closite $10 \mathrm{~A}^{\circledR}$ no recipiente próprio da análise para materiais nesse estado.

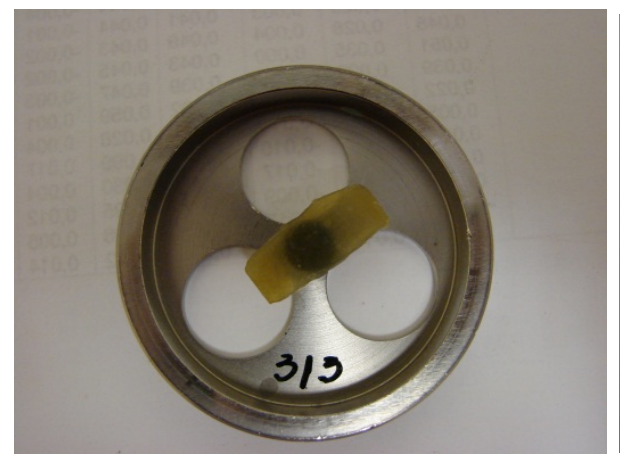

a)

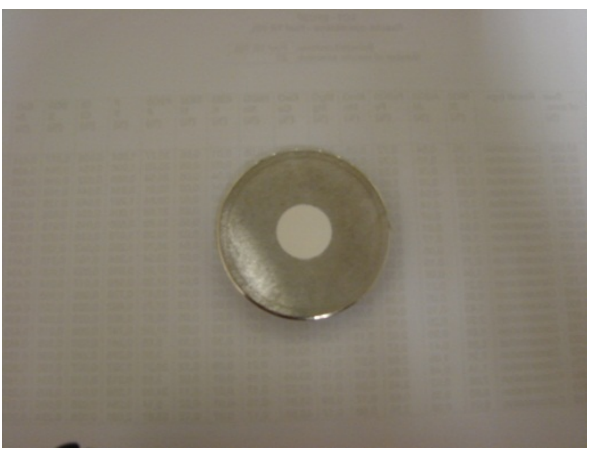

b)

FIGURA 14: Corpos de provas prontos para a análise de DRX. 
As análises foram realizadas no Laboratório de Caracterização Tecnológica (LCT) do Departamento de Engenharia de Minas e de Petróleo, da Escola Politécnica da Universidade de São Paulo.

\subsubsection{Micro Dureza Knoop}

A Micro Dureza com a impressão Knoop é comumente utilizada devido ao seu formato estreito, o que o possibilita analisar materiais com pouca espessura. Foi desenvolvido em 1939 pela National Bureau of Standards (NBS-USA) e é utilizado como indentador, uma pirâmide alongada que possui uma relação entre comprimento-largura-profundidade de 30:4:1 (Purdell-Lewis et al.,1976). A marca deixada pelo penetrador nas amostras é mensurada e convertida para valores de dureza expressando assim, a propriedade do material na resistência à deformação plástica (Callister, 2000; Estrela, 2003).

Para a realização das análises de micro dureza Knoop, a carga aplicada foi definida em 25 gramas durante 10 segundos. A área analisada limitou-se ao comprimento da maior diagonal da marca deixada pelo penetrador Knoop nos corpos de prova testados, conforme mostra a Figura 15.

Foram selecionadas para a análise, 3 corpos de prova de cada grupo de compósito experimental. Em cada corpo de prova foram realizadas 5 identações. Dessa maneira, foi obtida a média de cada corpo de prova e posteriormente, esses valores foram somados e divididos pelo número de corpos de prova testados de cada grupo. Obtiveram-se assim, as médias gerais para cada um dos diferentes Grupos de compósitos experimetais testados. 


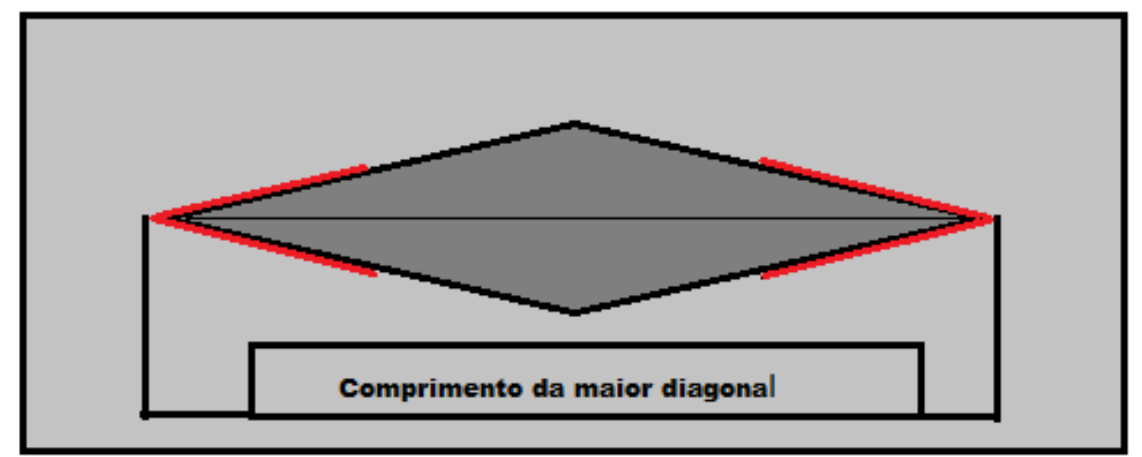

FIGURA 15: llustração da área de análise da micro dureza Knoop.

As análises foram realizadas no microdurômetro Shimadzu, modelo HMV 2000, no Departamento de Materiais Dentários da Faculdade de Odontologia da Universidade de São Paulo (FOUSP).

\subsubsection{Técnica de Interferometria Holográfica (TIH)}

A TIH, conhecida também como Eletronic Specke Pattern Interferometry (ESPI) utiliza uma fonte de luz coerente permitindo obter sem contato e com elevada resolução, a distribuição de deslocamentos associada à deformação da superfície de um objeto. O sistema de TIH utilizado consiste num interferômetro onde um feixe de luz coerente é dividido para gerar os dois braços do interferômetro, feixe referência e feixe objeto. Um dos feixes é filtrado e utilizado como feixe de referência, enquanto o outro ilumina o objeto em análise. A luz difundida pela superfície do objeto é captada pelas lentes do sistema óptico e combinada com o feixe de referência. $O$ padrão resultante da interferência dos dois feixes é captado por uma câmera CCD e armazenado num sistema de processamento de imagem (Monteiro et al., 2011).

Este padrão contém a informação que codifica a superfície do objeto em análise. Após a solicitação do objeto é gravado um segundo padrão que apresenta as modificações correspondentes às eventuais alterações da superfície. Correlacionando os dois padrões de informações é obtida a distribuição espacial dos deslocamentos com uma resolução da ordem de metade do comprimento de onda da luz utilizada (Monteiro, 1998). 
A imagem de uma peça iluminada pela luz do laser aparenta ter uma textura granular, composta por pontos claros e escuros denominados "speckle", que podem ser vistos tanto a olho nu quanto por instrumentos ópticos. O "speckle" resulta da interferência construtiva e destrutiva das múltiplas frentes de onda que são aleatoriamente refletidas por uma superfície opticamente rugosa. A luz que forma cada "speckle" é totalmente coerente, de forma que padrões de interferência podem ser observados possuindo além de intensidade luminosa mensurável, também uma fase bem definida (Suterio, 1998).

Com a montagem de TIH são registados hologramas em tempo real e obtidos padrões de franjas, resultantes da correlação entre padrões de "speckle" antes e após a alteração ocorrida na superfície do objeto.

A câmara captura o padrão de interferência "speckle" de ambas as imagens. O conjunto de lentes e abertura da câmara permite que o tamanho dos "speckles" seja do mesmo tamanho de "pixeis" da câmara (Kapp, 1998). A Figura 16, mostra esquematicamente uma montagem convencional de $\mathrm{TIH}$ com sensibilidade aos deslocamentos fora do plano.

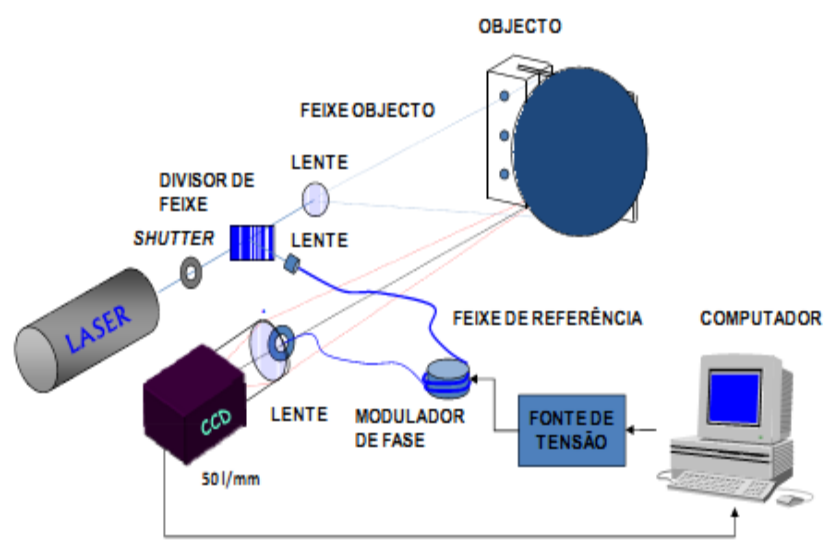

FIGURA 16: Dispositivo experimental de um sistema de TIH.

Para a realização das análises, foi utilizado uma fonte de Laser, marca Coherent, modelo Verdi, potência de 2 Watts, comprimento de onda de $532 \mathrm{~nm}$. As análises de TIH foram realizadas no Instituto de Engenharia Mecânica e Gestão Industrial da Faculdade de Engenharia da Universidade do Porto, Portugal (INEGI/FEUP). 


\subsubsection{Holografia Digital}

A HD tal como o TIH é também uma técnica de interferometria holográfica. Estas técnicas são muito semelhantes, no entanto na HD não existe sistema óptico de formação de imagem, sendo gravado um holograma com um CCD o qual é posteriormente reconstruído numericamente. A reconstrução digital da onda complexa (amplitude e fase) é baseada na transformação de Fresnel, uma aproximação da integral de difração. (Monteiro et al., 2011).

Na Figura 17, observa-se um dispositivo experimental da HD. O feixe de referência e o feixe do objeto interferem na superfície do CCD. Comparativamente ao THI é um sistema mais fácil de implementar e de custo mais baixo, mas só permite medir objetos de pequenas dimensões.

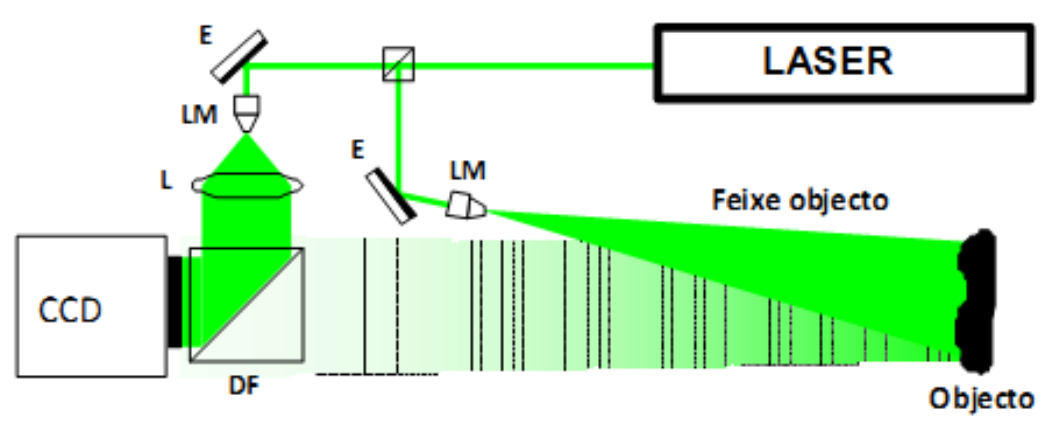

FIGURA 17: Dispositivo experimental de um sistema de HD.

As análises de HD foram realizadas no INEGI/FEUP.

\subsubsection{Correlação de Imagem (Cl)}

$\mathrm{A} \mathrm{Cl}$ é uma técnica que nos últimos anos tem sido cada vez mais utilizada e as principais razões deste avanço se dá pela versatilidade e facilidade de implementação. $\mathrm{Em} \mathrm{Cl}$, contrariamente ao $\mathrm{TIH}$ e a $\mathrm{HD}$, o objeto é iluminado por um padrão de luz não coerente. Neste caso os padrões de intensidade resultam da textura da superfície do objeto. Estes padrões, que deverão ter uma distribuição aleatória são divididos em pequenas áreas. Cada subdivisão da imagem é inicialmente registrada e comparada, por correlação, com as imagens obtidas para 
os diferentes estados de deformação do objeto. Este princípio está esquematicamente representado em plano cartesiano na Figura 18.

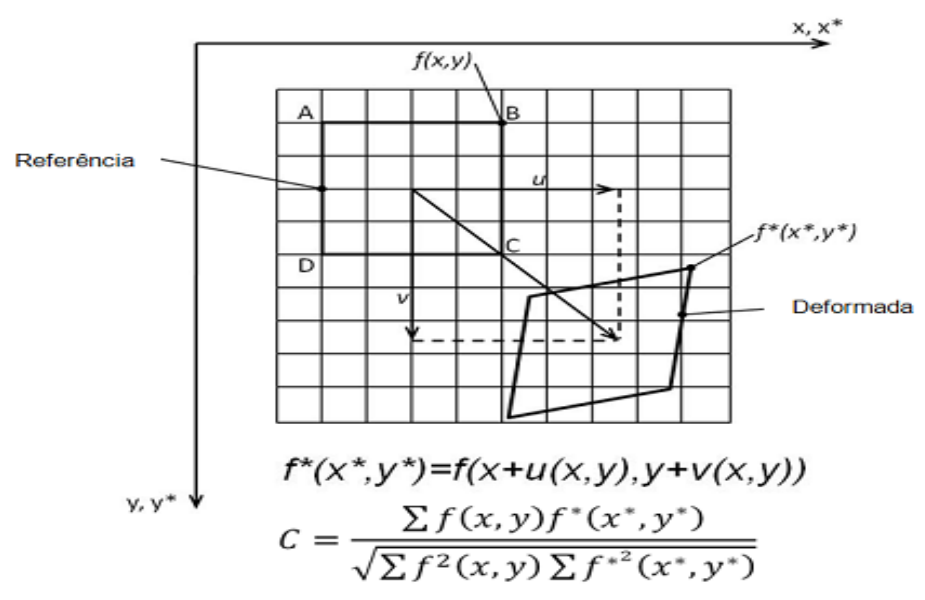

FIGURA 18: Plano cartesiano do princípio básico de funcionamento da $\mathrm{Cl}$.

As análises de $\mathrm{Cl}$ foram realizadas no INEGI/FEUP.

\subsubsection{THI/HD/Cl}

A contração de polimerização foi medida pelas metodologias THI, HD e Cl por meio do deslocamento molecular sofrido pela amostra durante e após a polimerização, dessa forma foram avaliadas a cura e a pós cura. Após o corpo de prova ser fixado no suporte, as luzes do laboratório foram apagadas e o compósito experimental foi inserido na cavidade previamente preparada em um só incremento. A análise se iniciou pelo registro do primeiro padrão do "speckle". Imediatamente o fotopolimerizador foi ativado permanecendo assim por 30 segundos. A mensuração continuou por mais 30 segundos, para que a reação de pós cura pudesse ser também analisada. O tempo total de cada análise foi de 1 minuto.

A Figura 19, mostra uma visão lateral da metodologia $\mathrm{THI} / \mathrm{HD} / \mathrm{Cl}$ esquematicamente pronta para iniciar uma análise e a Figura 20 mostra uma visão frontal da metodologia. Essas imagens foram feitas no laboratório do INEGI/FEUP. 


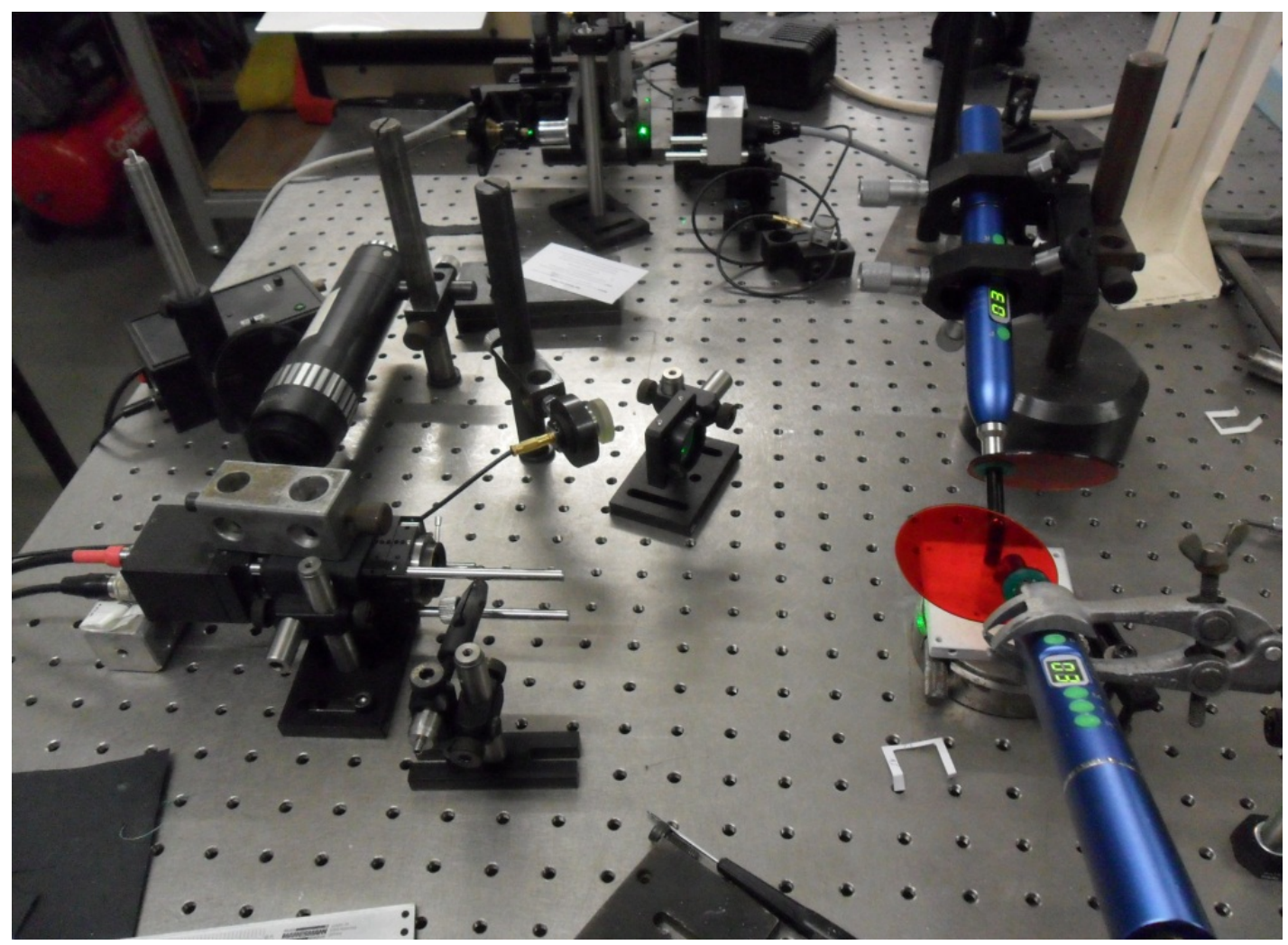

FIGURA 19: Visão lateral da metodologia THI/HD/CI.

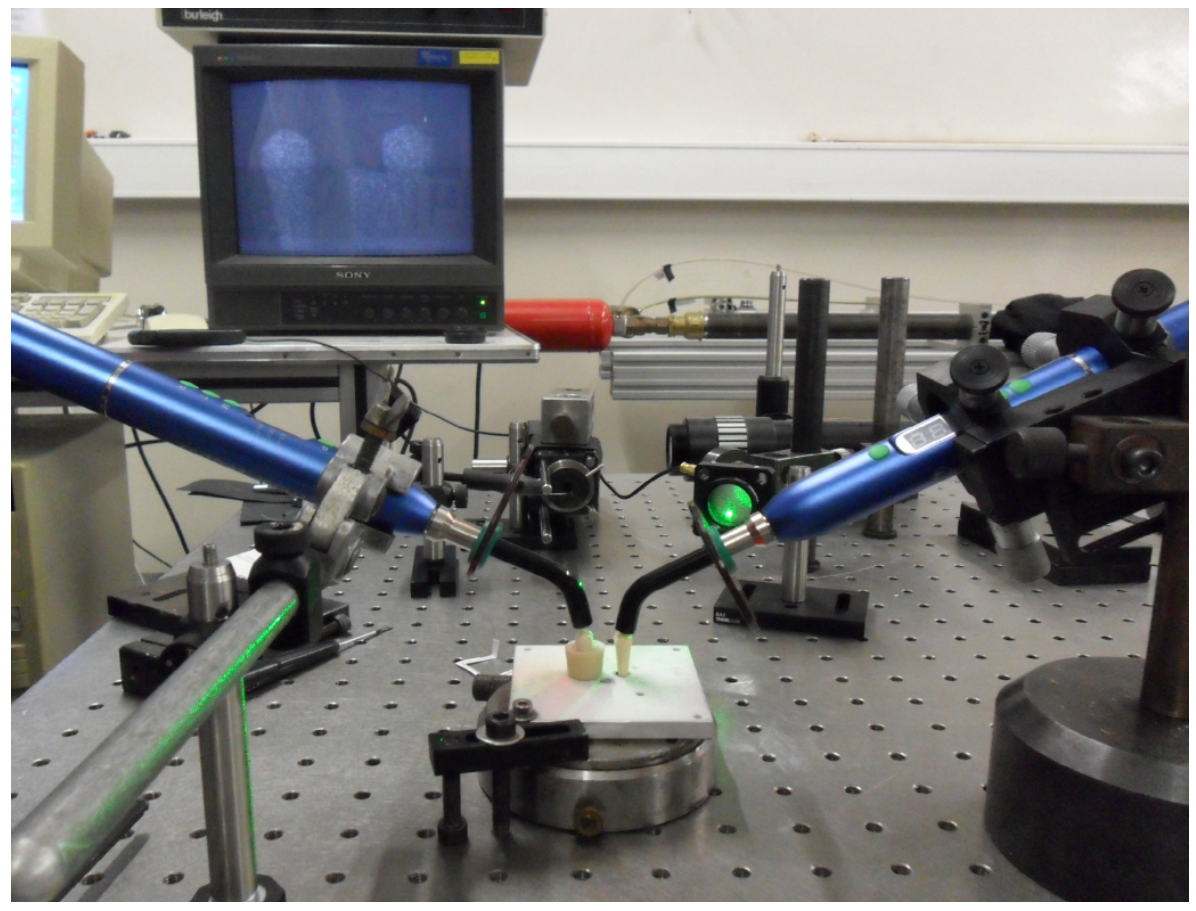

FIGURA 20: Visão frontal da metodologia THI/HD/CI. 


\subsubsection{Termografia}

A termografia teve como objetivo mensurar a temperatura das amostras quando submetidas ao processo de cura. Por meio dessa análise foi possível justificar os deslocamentos dos compósitos experimentais (expansão e contração) quando são ocasionados por alterações térmicas. As análises foram realizadas através da Camera - FLIR A325. Os vídeos exportados para AVI partiram dos arquivos base com uma velocidade 4 vezes superior aos acontecimentos. $A$ análise da Termografia foi realizada no INEGI/FEUP. 


\section{RESULTADOS E DISCUSSÃO}

\subsection{Microscopia Eletrônica de Varredura - (MEV)}

O objetivo dessa análise foi avaliar as características e a morfologia das nanopartículas argilominerais em uma matriz polimérica a base de BisGMA/TEGDMA. Apesar das limitações da técnica manual de mistura e manipulação dos compósitos experimentais, a dispersão das nanopartículas foi clara em todos os grupos testados, mas foi possível observar pequenos aglomerados de nanopartículas, fato que mostra a característica da MMT em se aglomerar. Observou-se também, com maior aumento, uma característica de empilhamento, como se houvesse uma camada sobreposta a outra. Esse comportamento mostra a organização lamelar, em forma de lamelas sobrepostas e espaços interlamelares "d".

$\mathrm{Na}$ Figura 21, observa-se a microscopia das nanopartículas argilominerais Cloisite $10 \mathrm{~A}^{\circledR}$ e Cloisite $30 \mathrm{~B}^{\circledR}$ puras.

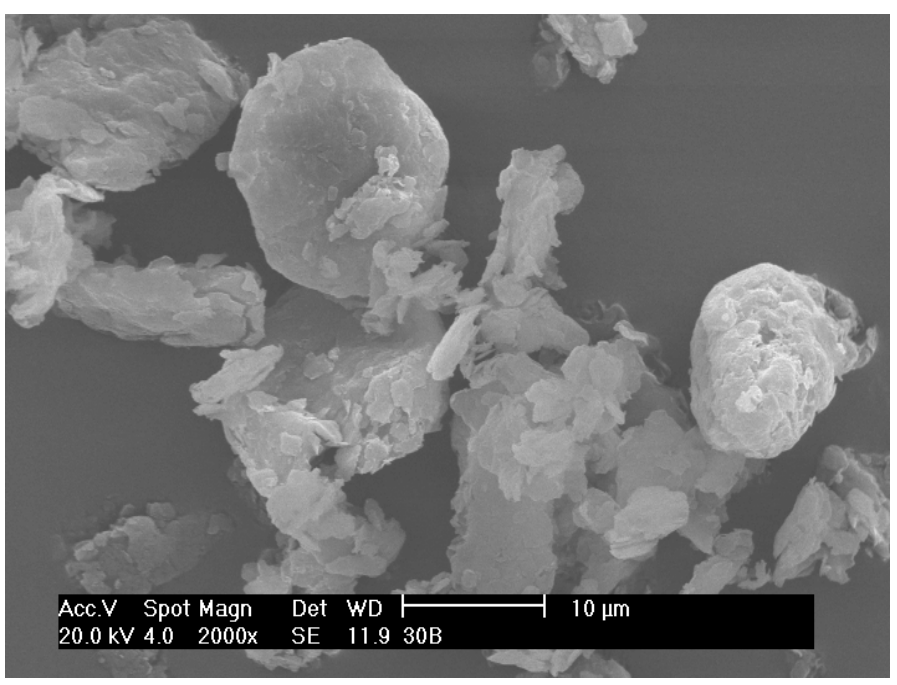

a)

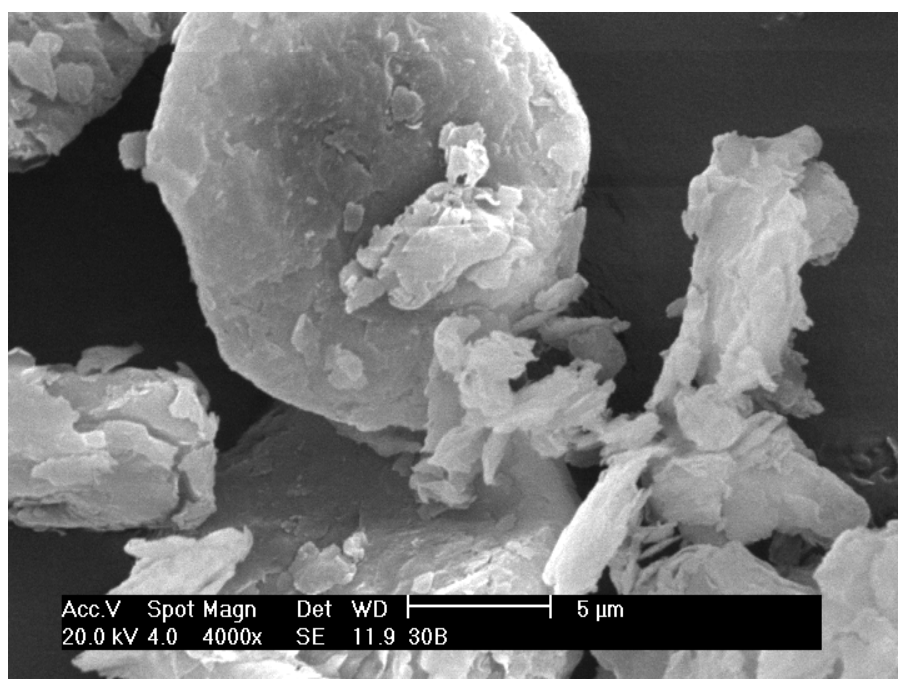

b)

FIGURA 21: Micrografia de MEV: Cloisite $10 A^{\circledR}$ (a) e Cloisite $30 B^{\circledR}$ (b) puras.

Na Figura 22, observa-se a microscopia dos Grupo 1 (50A) e 3 (60A). 


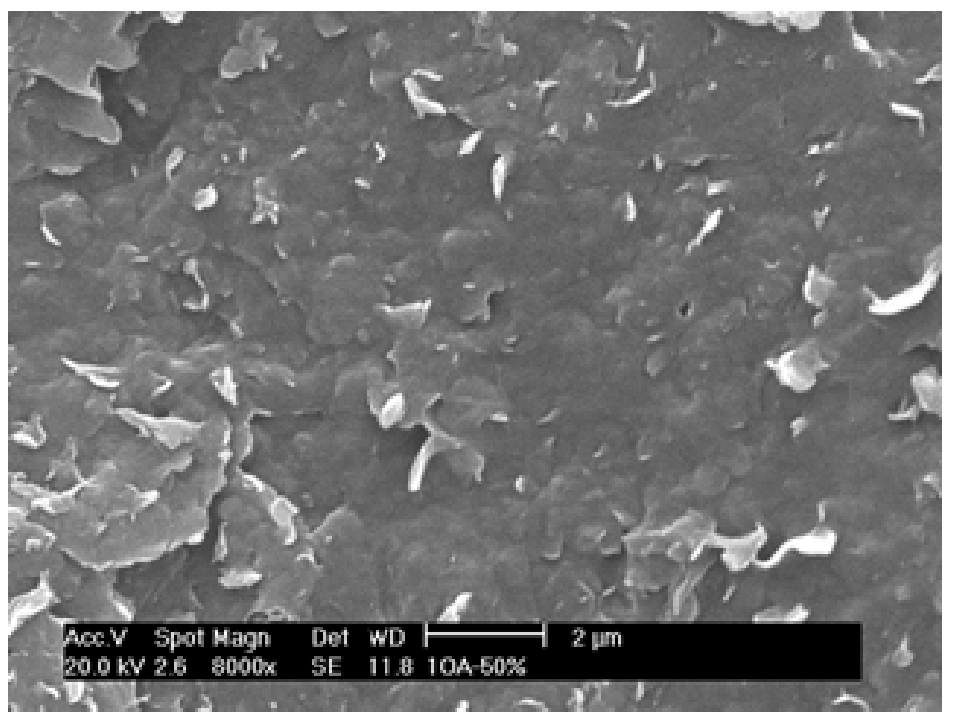

a)

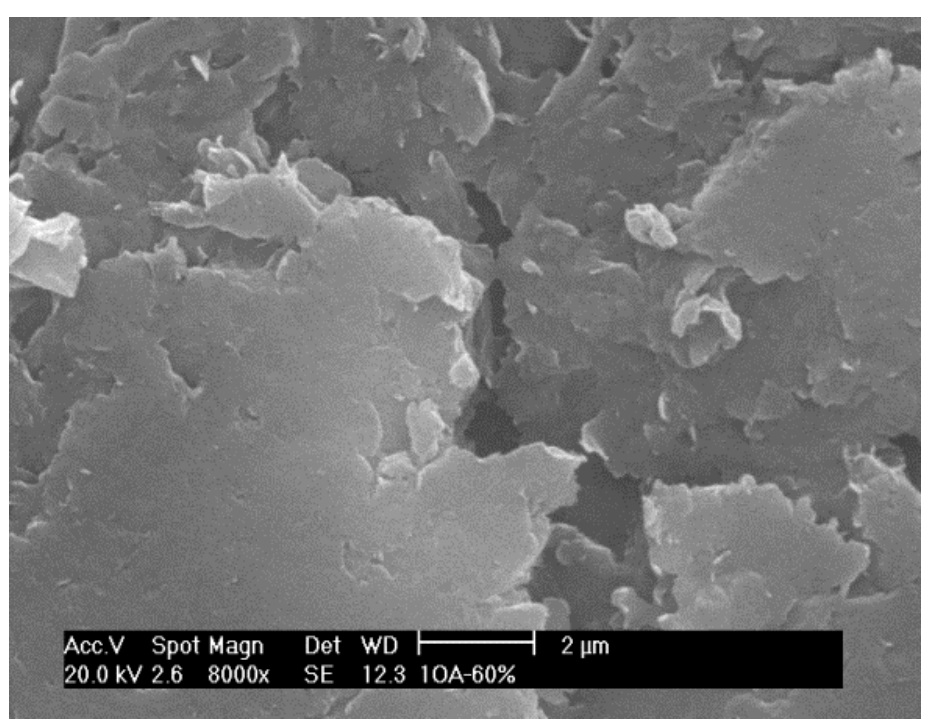

c)

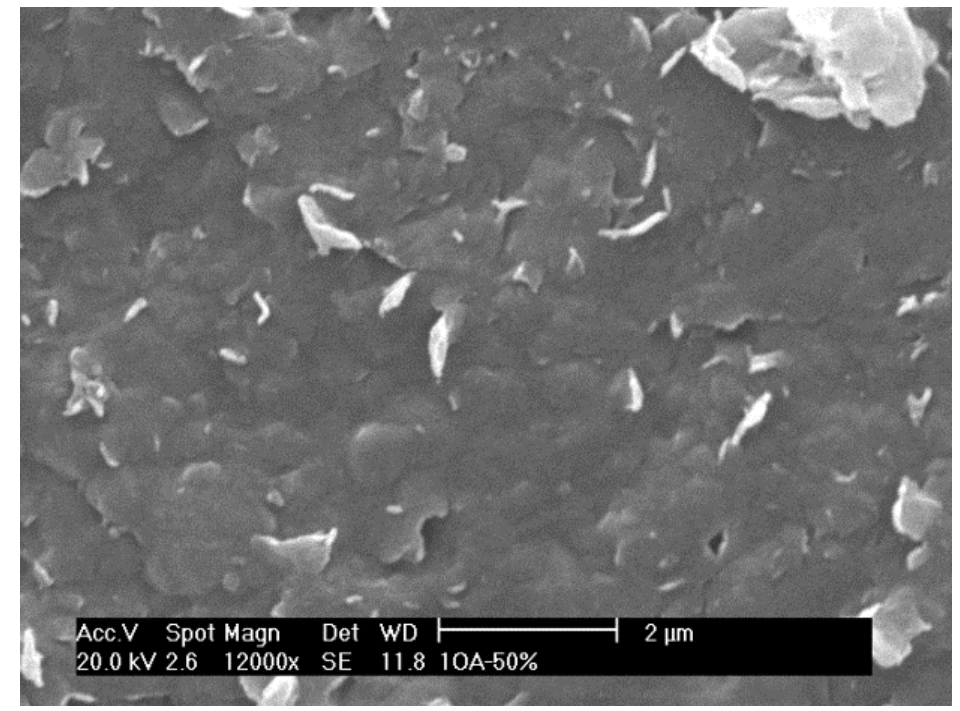

b)

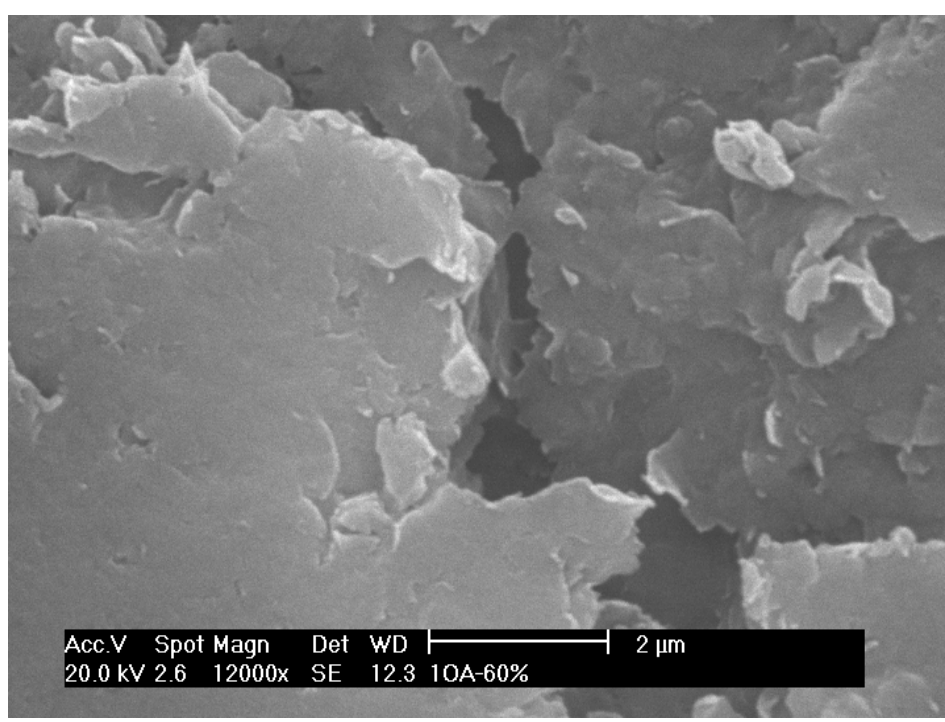

d)

FIGURA 22: (a-b) Micrografia de MEV Grupo 1 (50A) com oito e doze mil vezes de aumento. (c-d) Micrografia de MEV Grupo $3(60 \mathrm{~A})$ com oito e doze mil vezes de aumento.

Na Figura 23, observa-se a microscopia dos Grupos 5 (70A) e 6 (50B). As micrografias indicam total dispersão da argila, com ausência de aglomerados em todas as amostras. 


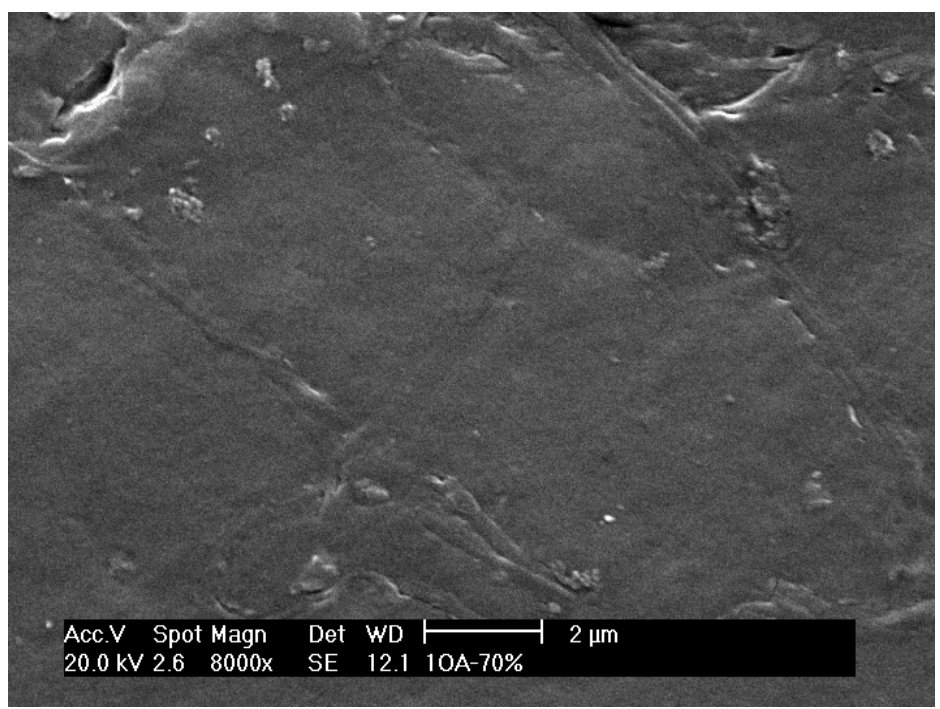

a)

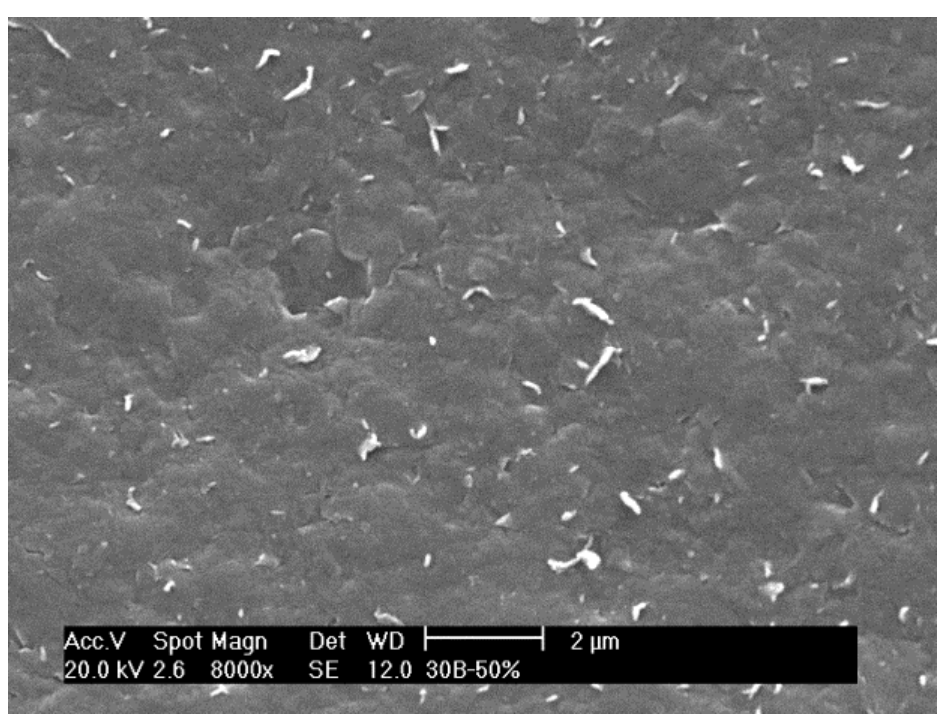

c)

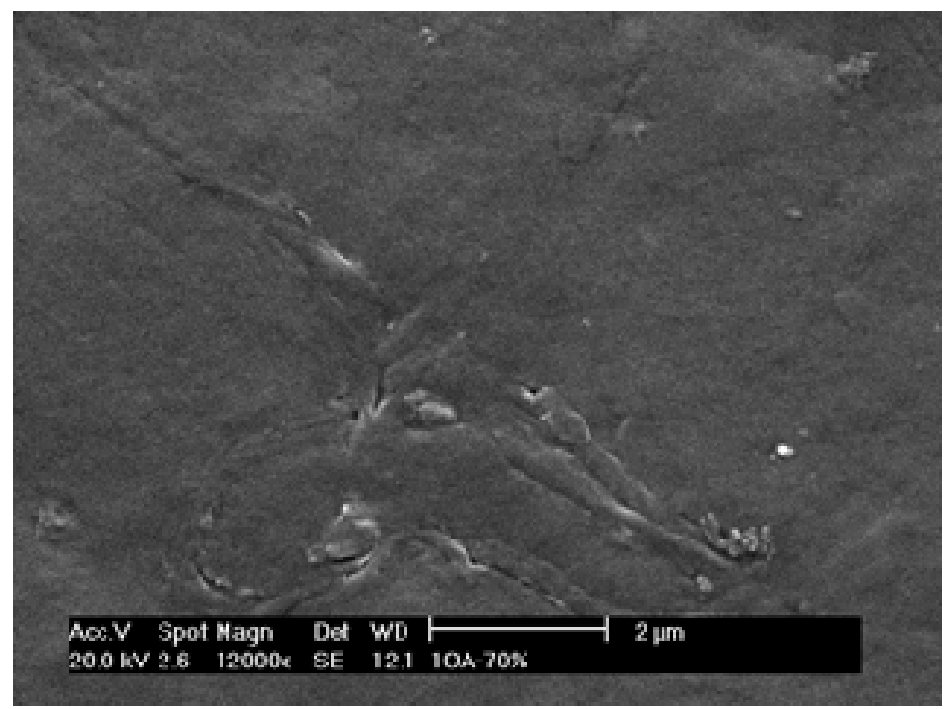

b)

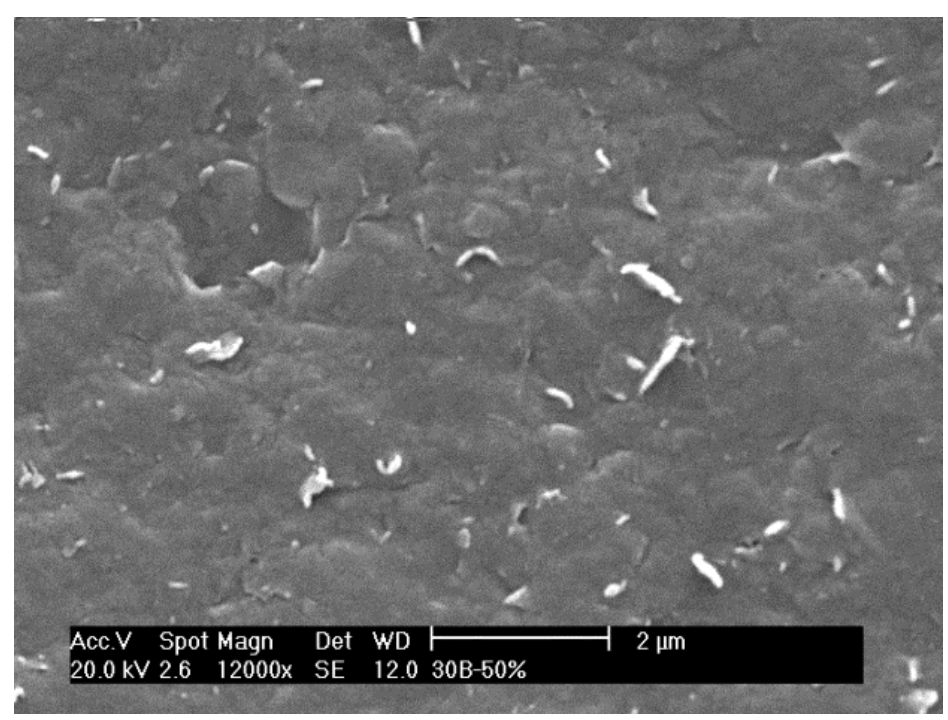

d)

FIGURA 23: (a-b) Micrografia de MEV Grupo 5 (70A) com oito e doze mil vezes de aumento. (c-d) Micrografia de MEV Grupo 6 (50B) com oito e doze mil vezes de aumento.

Na Figura 24, observa-e a microscopia dos Grupos 8 (60B) e 9 (65B). 


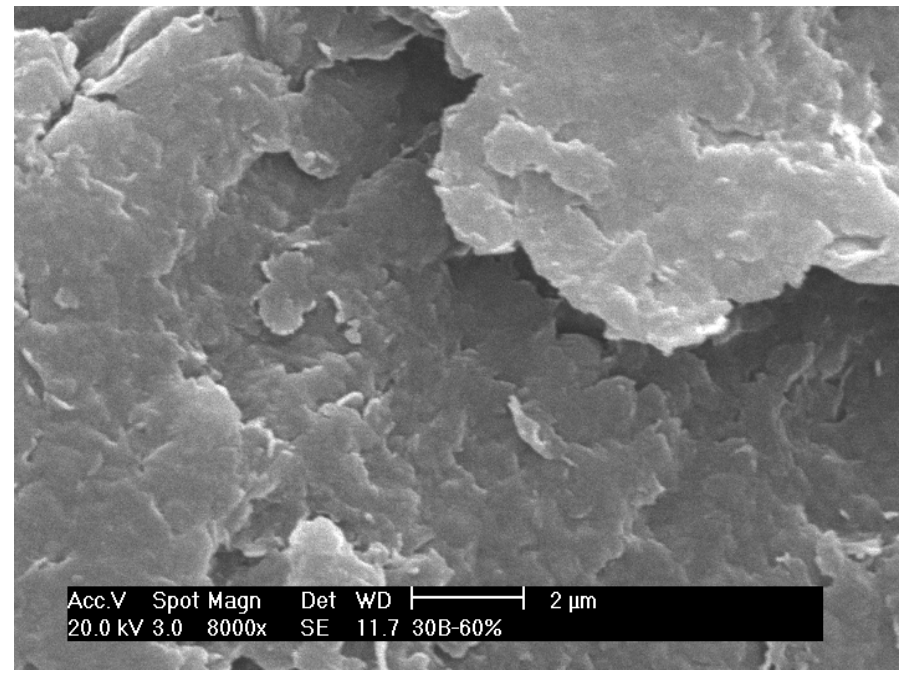

a)

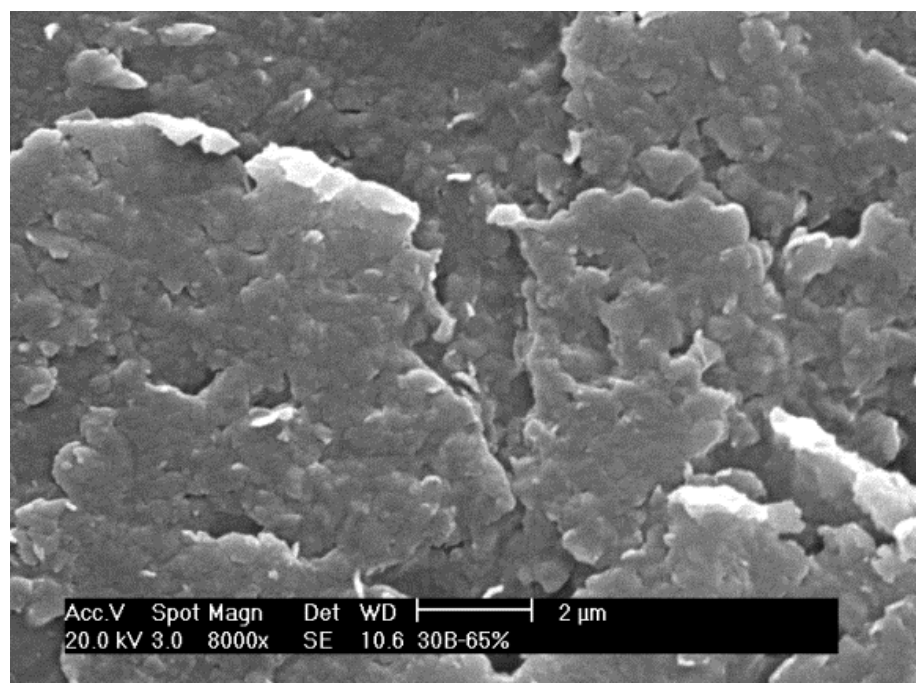

c)

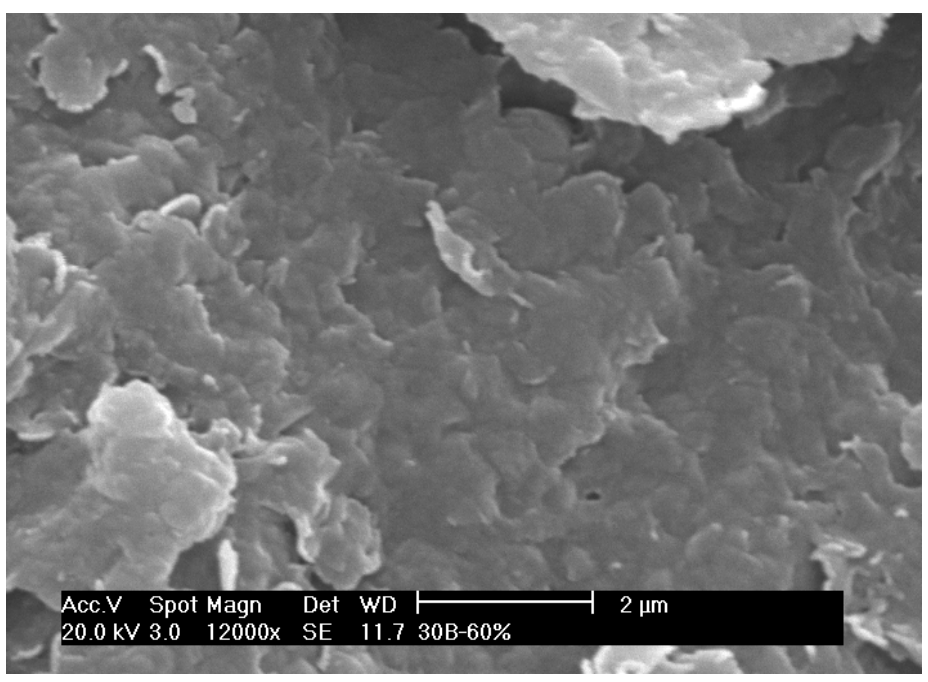

b)

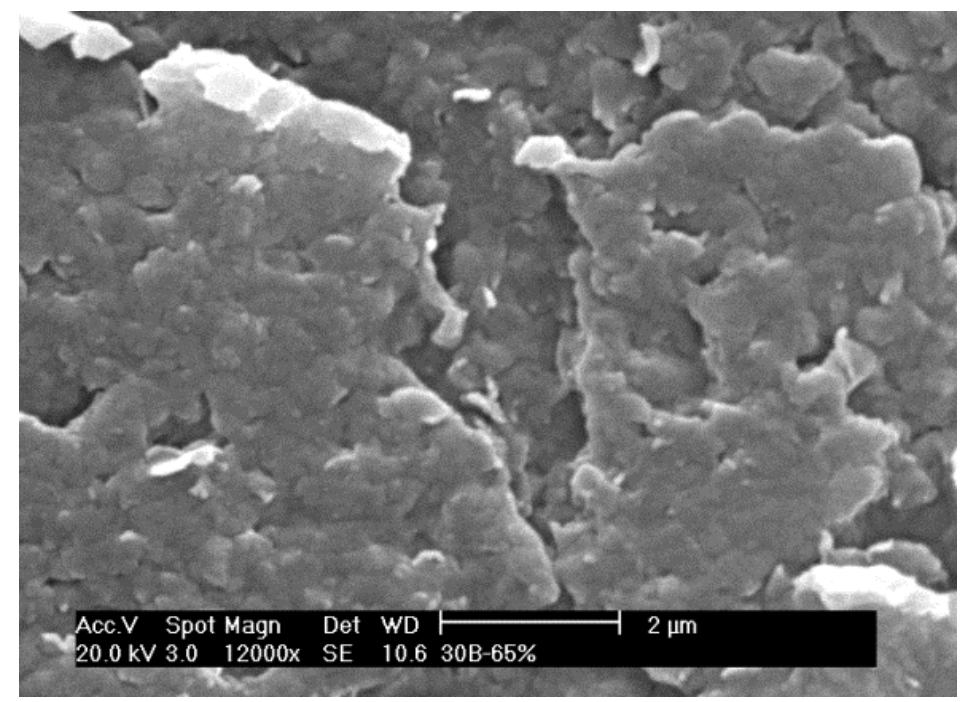

d)

FIGURA 24: (a-b) Micrigrafia de MEV Grupo 8 (60B) com oito e doze mil vezes de aumento. (c-d) Micrografia de MEV Grupo 9 (65B) com oito e doze mil vezes de aumento.

\subsection{Análise Térmica-Mecânica - (TMA)}

Os resultados da contração de polimerização, obtidos pela metodologia TMA, dos compósitos experimentais adicionados com nanopartículas argilominerais Cloisite $10 A^{\circledR}$ e Cloisite $30 B^{\circledR}$ estão descritos na Tabela 7. 
TABELA 7: Resultados da contração de polimerização pela metodologia TMA dos Grupos de compósitos adicionados com Cloisite $10 \mathrm{~A}^{\circledR}$ e Cloisite 30B ${ }^{\circledR}$.

\begin{tabular}{cccc}
\hline Grupo & Contração \% & Variância & Desvio Padrão \\
\hline Grupo 1 (50A) & 2,77 & 0,104 & 0,322 \\
Grupo $2(55 \mathrm{~A})$ & 2,26 & 0,507 & 0,712 \\
Grupo 3 (60A) & 1,90 & 0,132 & 0,363 \\
Grupo $4(65 \mathrm{~A})$ & 0,52 & 0,031 & 0,176 \\
Grupo 5 (70A) & 0,17 & 0,006 & 0,080 \\
Grupo 6 (50B) & 0,98 & 0,167 & 0,409 \\
Grupo 7 (55B) & 0,66 & 0,076 & 0,276 \\
Grupo 8 (60B) & 0,62 & 0,125 & 0,354 \\
Grupo 9 (65B) & 0,22 & 0,059 & 0,003 \\
\hline
\end{tabular}

Os resultados da contração de polimerização, obtidos pela metodologia TMA, dos compósitos experimentais adicionados com Sílica Silanizada, estão descritos na Tabela 8.

TABELA 8: Resultados da contração de polimerização pela metodologia TMA. Sílica Silanizada Aerosil ${ }^{\circledR}$ OX-50.

\begin{tabular}{cccc}
\hline Grupos & Contração (\%) & Variância & Desvio Padrão \\
\hline Grupo 10 (50S) & $\mathbf{2 , 7 3}$ & $\mathbf{0 , 2 6 2}$ & $\mathbf{0 , 6 9 0}$ \\
Grupo 11 (55S) & $\mathbf{1 , 5 1}$ & $\mathbf{0 , 0 3 4}$ & $\mathbf{0 , 1 8 5}$ \\
Grupo 12 (65S) & $\mathbf{1 , 0 1}$ & $\mathbf{0 , 1 2 0}$ & $\mathbf{0 , 3 4 6}$ \\
Grupo 13 (70S) & $\mathbf{0 , 4 9}$ & $\mathbf{0 , 0 2 4}$ & $\mathbf{0 , 1 5 5}$ \\
\hline
\end{tabular}

$\mathrm{Na}$ figura 25, observa-se a comparação do desempenho de contração de polimerização dos Grupos de compósitos experimentais adicionados com Cloisite 
$10 A^{\circledast}$, que apresentou uma linha de tendência $R^{2}=0,9319$, não linear; Cloisite $30 B^{\circledR}$ que apresentou uma linha de tendência $R^{2}=0,915$, não linear; e Sílica Aerosil ${ }^{\circledR}$ OX50 que apresentou uma linha de tendência $=0,9972$, linear.

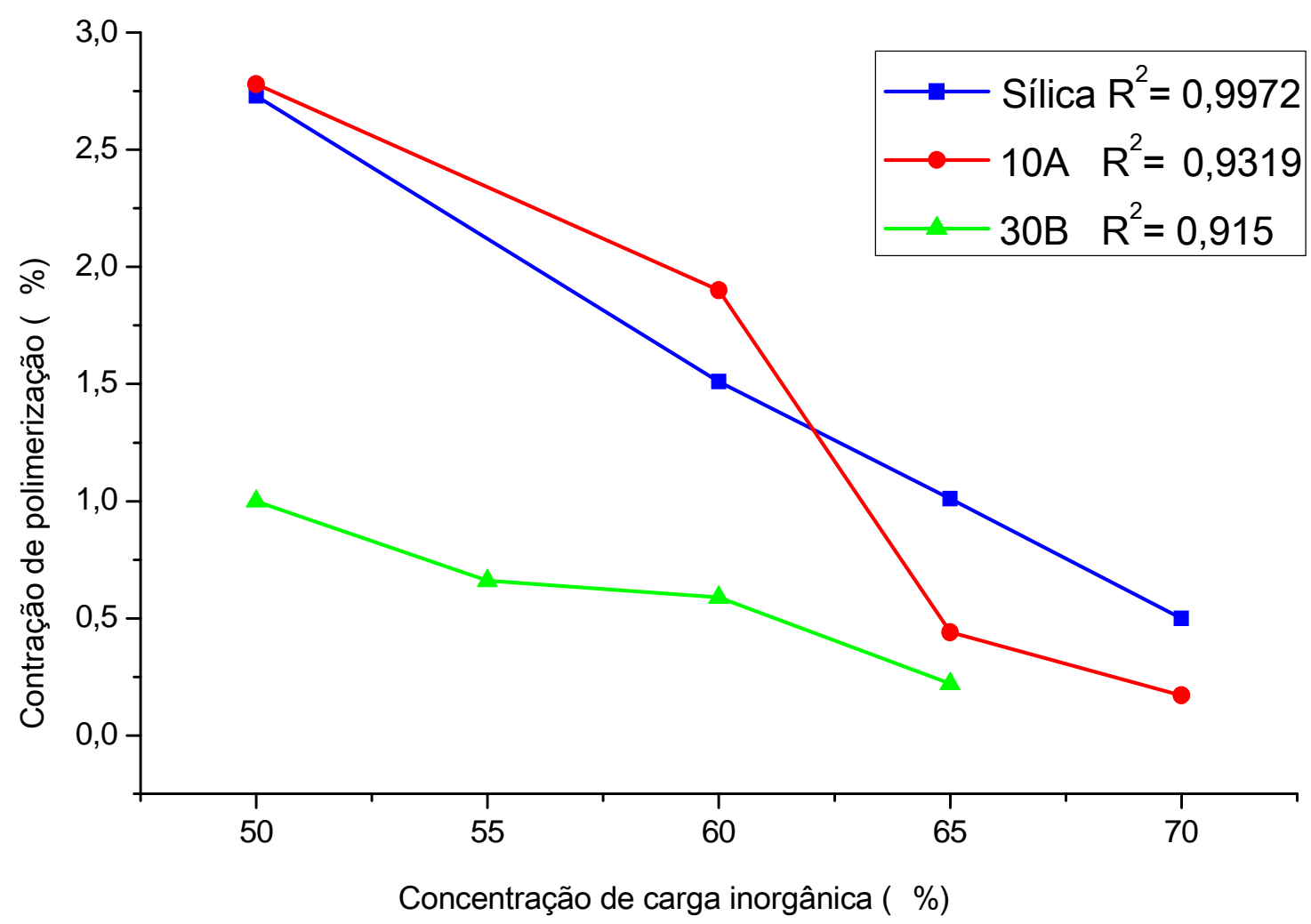

FIGURA 25: Comparação do desempenho de contração de polimerização em relação ao tipo e concentração das cargas inorgânicas: Sílica Aerosil OX-50, Cloisite $10 \mathrm{~A}^{\circledR}$ e Cloisite $30 \mathrm{~B}^{\circledR}$.

$\mathrm{Na}$ Figura 26 e 27, observa-se uma curva de contração de polimerização de cada Grupo de compósitos experimentais adicionados com Cloisite $10 \mathrm{~A}^{\circledR}$ e Cloisite $30 \mathrm{~B}^{\circledR}$, respectivamente. 


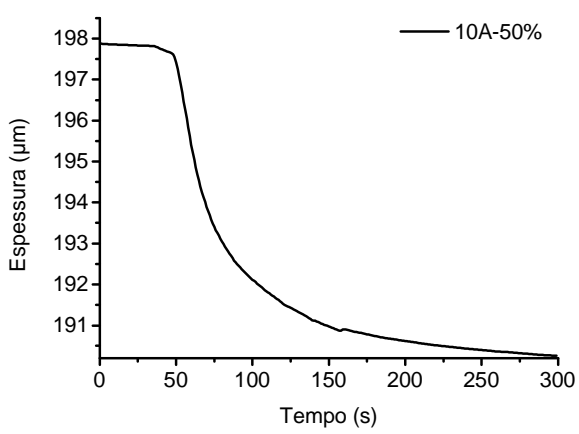

a)

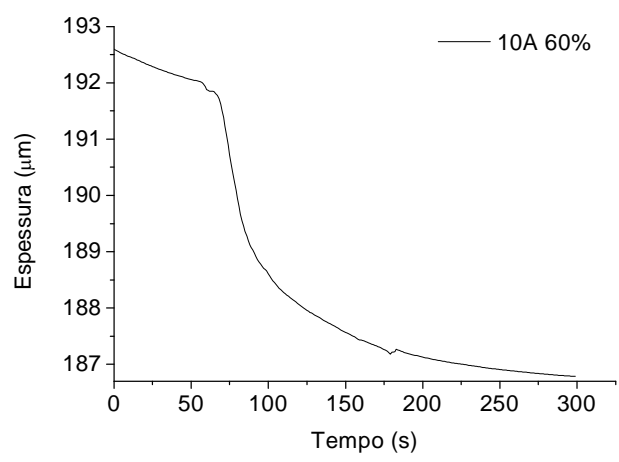

c)

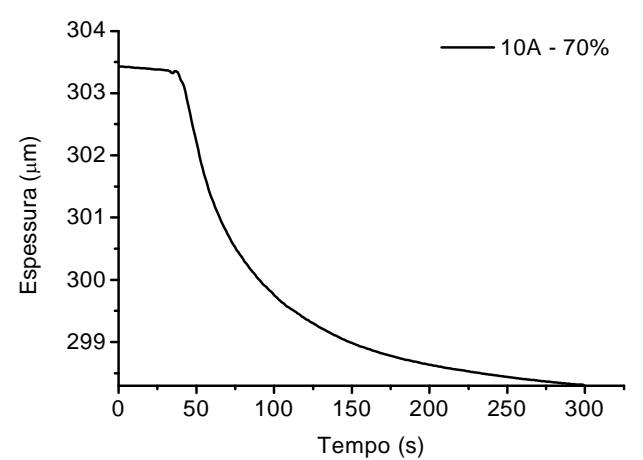

e)

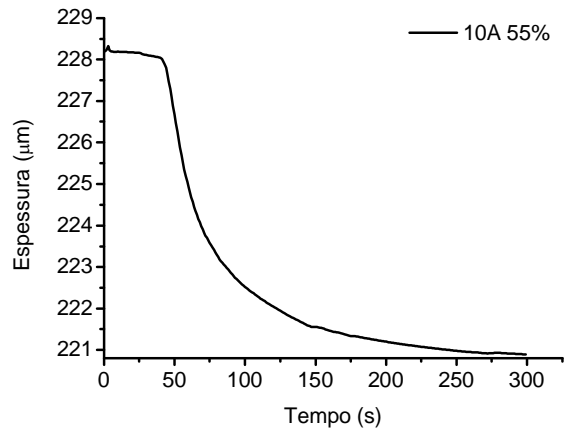

b)

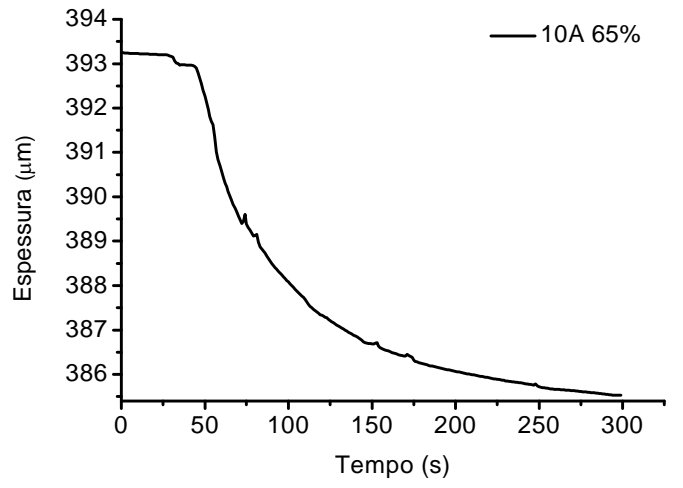

d)

FIGURA 26: Curvas de contração de polimerização registradas pela metodologia TMA. (a) Grupo1(50A). (b) Grupo 2(55A). (c) Grupo 3(60A). (d) Grupo 4(65A). (e) Grupo 5(70A).

Na Figura 27, ilustra-se cada curva de contração de polimerização de cada Grupo de compósitos experimentais adicionados com Cloisite $30 \mathrm{~B}^{\circledR}$. 


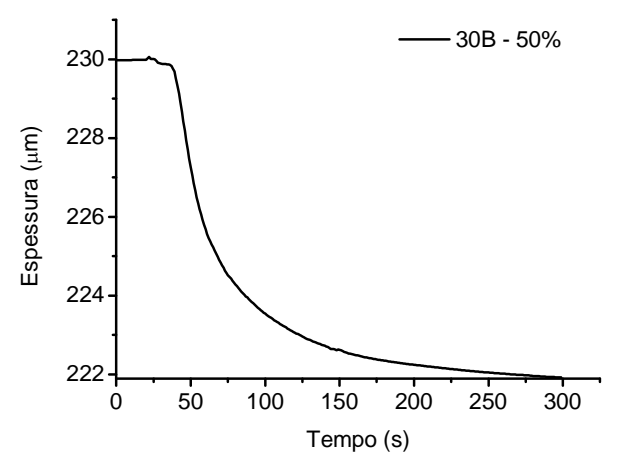

a)

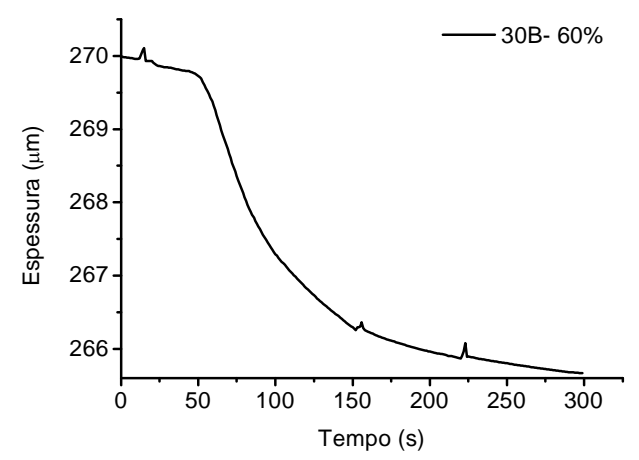

c)

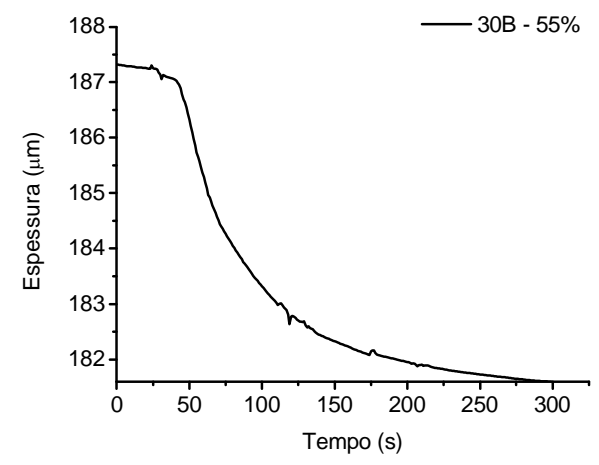

b)

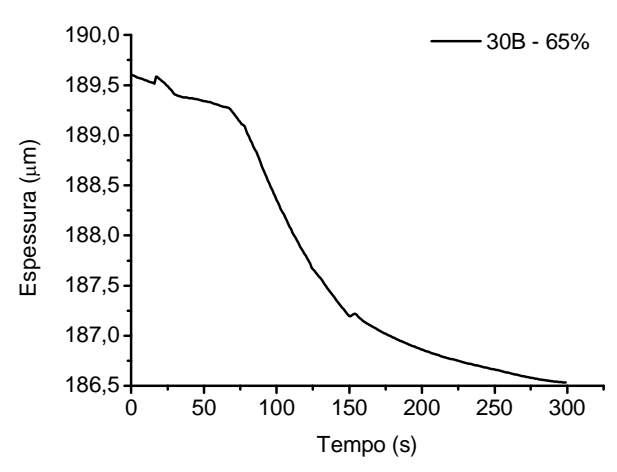

d)

FIGURA 27: Curvas de contração de polimerização registradas pela metodologia TMA. (a) Grupo 6(50B). (b) Grupo 7(55B). (c) Grupo 8(60B). (d) Grupo 9(65B).

De acordo com os resultados obtidos pode-se observar que, em todos os Grupos de compósitos experimentais, a contração de polimerização foi reduzida à medida que a concentração de carga inorgânica aumentou, comportamento esperado dos compósitos experimentais, pois quanto menor a concentração da matriz polimérica, menor será a contração de polimerização. Devido a isso pode-se atribuir precisão à análise do TMA, que demonstrou grande potencial para mensurações em escala micrométrica e deverá ser utilizado em futuras pesquisas, tanto para mensurar a contração de polimerização de compósitos experimentais, quanto para mensurar compósitos comerciais. Futuramente, essa metodologia poderá ser comparada com técnicas convencionais já existentes na literatura. 
Em relação ao desempenho dos compósitos experimentais adicionados com a Sílica Aerosil ${ }^{\circledR}$ OX-50 pode-se observar um comportamento típico de polímeros reforçados com partículas inertes e de preenchimento e uma forte correlação entre o aumento da concentração da carga inorgânica e a redução da contração de polimerização, visto que a contração reduziu linearmente $\left(R^{2}=0,9972\right)$.

Os compósitos experimentais adicionados com a nanopartícula Cloisite $10 \mathrm{~A}^{\circledR}$ apresentaram valores semelhantes na concentração de $50 \%$ de carga inorgânica, em relação aos compósitos adicionados com a Sílica Aerosil ${ }^{\circledR}$ OX-50. Entretanto, quando as concentrações de carga inorgânica aumentaram observou-se que os valores de contração permaneceram menores em todas as concentrações testadas. Observou-se também, uma grande redução da contração de polimerização entre 60 e $65 \%$ de concentração de carga inorgânica, revelando um tipo de interação matriz/carga inorgânica diferenciada $\left(R^{2}=0,9319\right)$. No entanto, quando a concentração de carga inorgânica atingiu 70\%, a contração foi ainda mais reduzida, apesar da proporção ter sido menor. O compósito que apresentou menor alteração dimensional dentre todos os Grupos testados, foi o Grupo 5 (70A), que apresentou $0,17 \%$ de contração de polimerização.

Os compósitos adicionados com a nanopartícula Cloisite $30 \mathrm{~B}^{\circledR}$ apresentaram um comportamento muito distinto em relação aos adicionados com a Silica Aerosil ${ }^{\circledR}$ OX-50 e um comportamento semelhante aos compósitos adicionados com a nanopartícula Cloisite $10 \mathrm{~A}^{\circledR}$, pois a maior redução da contração de polimerização foi observada entre 60 e $65 \%$ de concentração de carga inorgânica $\left(R^{2}=0,915\right)$, portanto em todas as concentrações testadas, foi o Grupo de compósitos experimentais que obteve os menores valores de alteração dimensional.

Os valores mais relevantes da contração de polimerização dos grupos adicionados com a nanopartícula Cloisite $10 \mathrm{~A}^{\circledR}$ e Cloisite $30 \mathrm{~B}^{\circledR}$, em relação aos adicionados com a Sílica Aerosil ${ }^{\circledR} \mathrm{OX}-50$, foram atribuídos à interação entre a matriz polimérica e as respectivas nanopartículas argilominerais.. Este fato pode ser relacionado com a interface entre a matriz polimérica e argila, que adquiriu propriedades particulares em função do aumento da superfície e com isso novas características foram obtidas. Segundo alguns autores, a habilidade de determinadas argilas em absorverem moléculas orgânicas faz com que suas 
lamelas se distanciem uma das outras ou se dispersem ao longo da matriz polimérica, desenvolvendo um volume adicional dentro do material. A hipótese dos autores é de que essa natureza expansiva poderia reduzir a magnitude da contração de polimerização e da tensão residual dos compósitos. (Kelly et al.,1994; Salahuddin e Sherata, 2001).

Outros autores afirmaram que a contração de polimerização de um sistema a base de BisGMA foi reduzida quando foram introduzidas nanopartículas argilominerais . O desenvolvimento de volume adicional livre dentro das galerias da argilas pode ter contribuído para o resultado (Discacciati e Oréfice, 2004). Pequenas quantidades dessas argilas podem melhorar as propriedades dos polímeros. Supõese que tal fato seja devido à sua geometria específica que tem forma de "prato fino" e a ocorrência de uma dispersão em nível molecular. Esses fatores fazem com que se tenha uma grande área superficial aumentando a interface entre partícula inorgânica e a matriz polimérica. (Fournaris et al.,2001).

A natureza polar da nanopartícula Cloisite $30 \mathrm{~B}^{\circledR}$, que possui a superfície modificada pelo Metil "tallow" bis-2-hidroxetil amônio quaternário (MT2EtOH), pode justificar seu melhor desempenho em relação a nanopartícula Cloisite $10 A^{\circledR}$ superfície modificada pelo Dimetil Di“tallow" hidrogenado de amônio quaternário $(2 \mathrm{MBHT})$, que possui uma natureza apolar. Por se tratar de uma matriz polimérica a base de BisGMA /TEGDMA que possui como característica ser uma matriz oxigenada, a afinidade química de uma nanopartícula polar pode ter sido determinante para o seu melhor desempenho.

Em relação à Análise Térmica Mecânica (TMA), Sakaguchi (et a.l, 2004) descreveu em um trabalho crítico a avaliação da contração de polimerização por quatro métodos, dentre eles a análise de TMA. Os autores afirmaram que sendo a técnica de TMA a que envolve amostras de menor tamanho entre as técnicas comparadas, os resultados são menos afetados por deformação ao longo da superfície (encolhimento), efeito de Poisson e compensação por deformação nas bordas. De fato a razão 3:1 entre os diâmetros da amostra e do sensor de TMA utilizados no presente trabalho, favorecem a anulação desses efeitos. A comparação das técnicas, segundo os autores, não relevou nenhuma técnica que verificasse efeito de pós cura das amostras para justificar a discrepância dos resultados. Os 
resultados do presente trabalho demonstraram que não houve pós cura das amostras, ou seja, o dispositivo de TMA propiciou a conversão máxima detectável por ensaio mecânico.

\subsection{Análise de Termogravimetia - (TGA)}

Os resultados da análise de estabilidade térmica, pela observação do perfil de decomposição das amostras, quando submetidas a um programa de aquecimento em atmosfera oxidativa estão descritos na Tabela 9:

TABELA 9: Resultados em porcentagem do resíduo (carga inorgânica) após decomposição das amostras pela análise do TGA.

Grupo

Grupo $1(50 A)$

Grupo 2 (55A)

Grupo 3 (60A)

Grupo 4 (65A)

Grupo 5 (70A)

Grupo 6 (50B)

Grupo 7 (55B)

Grupo 8 (60B)

Grupo 9 (65B)

Grupo 10 (50S)

Grupo 11 (55S)

Grupo 12 (60S)

Grupo 13 (70S)
Resíduo \% (carga inorgânica)
37,5

38,6

42,5

42,7

37,9

43,6

45,6

48,6

48,1

56,9

62,3

64,1 
A Figura 28, demonstra as curvas de decomposição térmica dos Grupos de compósitos experimentais adicionados com a nanopartícula Cloisite $10 \mathrm{~A}^{\circledR}$.

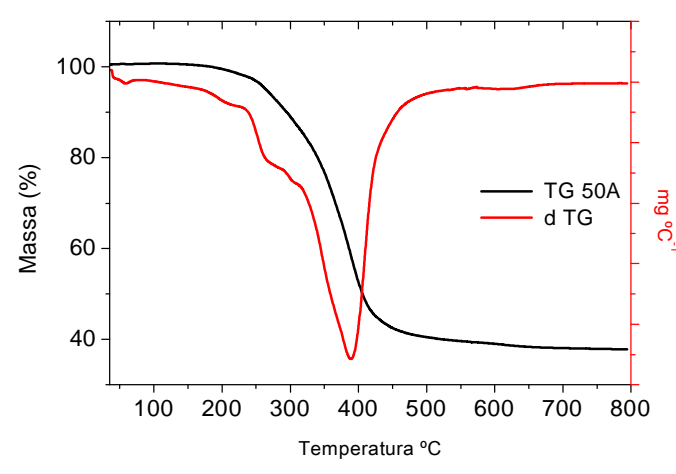

a)

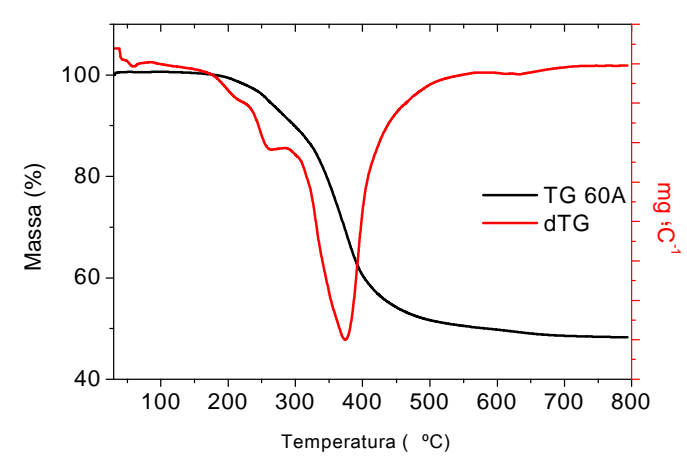

c)

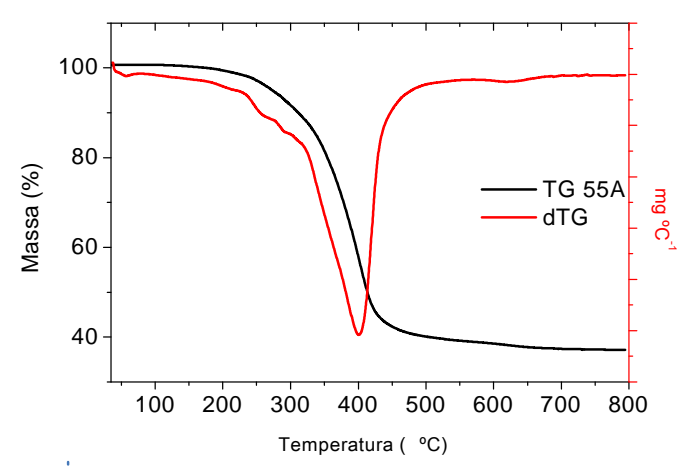

b)

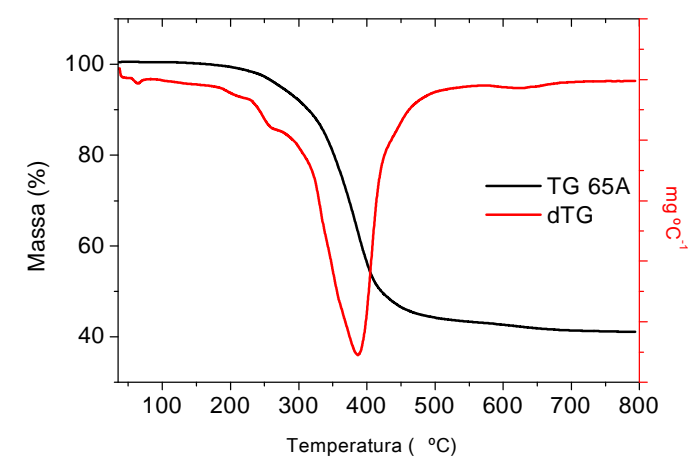

d)

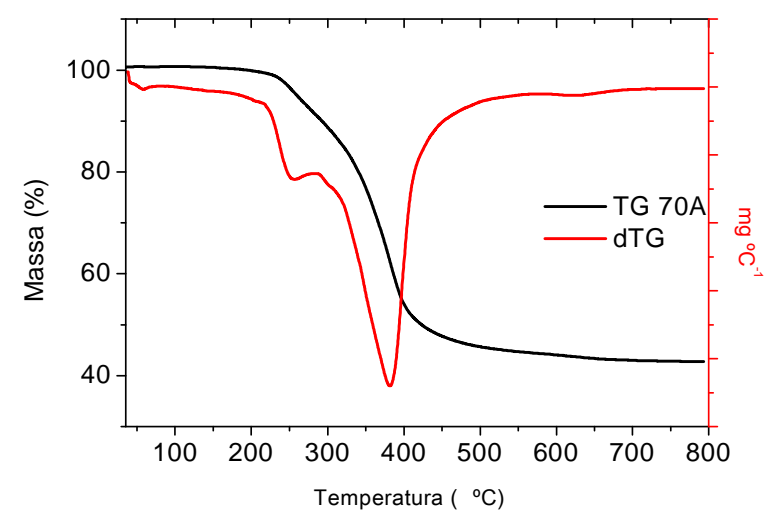

e)

FIGURA 28: Curvas referentes a decomposição térmica pela metodologia TGA. (a) Grupo 1(50A). (b) Grupo 2(55A). (c) Grupo 3(60A). (d) Grupo 4 (65A). (e) Grupo 5(70A). 
A Figura 29, demonstra as curvas de decomposição térmica dos Grupos de compósitos experimentais adicionados com a nanopartícula Cloisite $30 \mathrm{~B}^{\circledR}$.

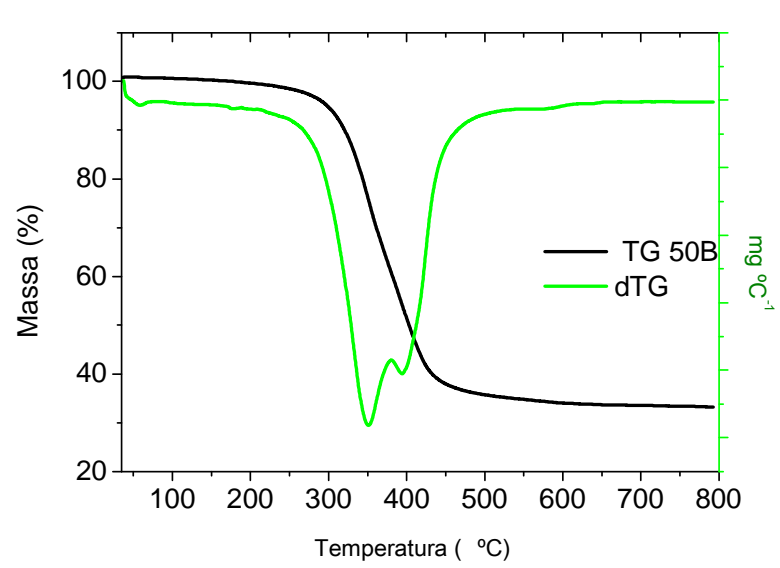

a)

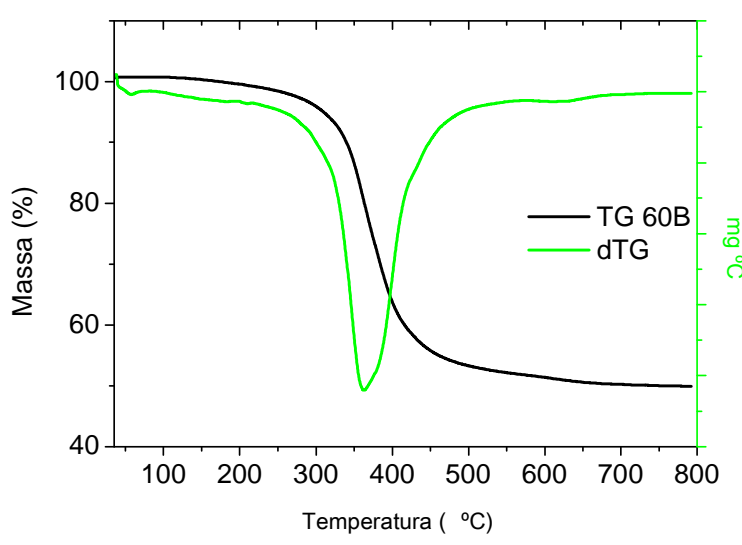

c)

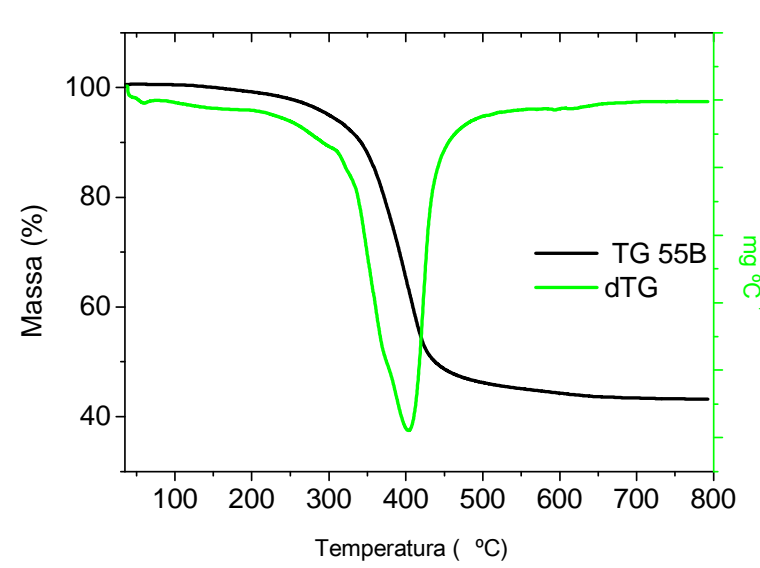

b)

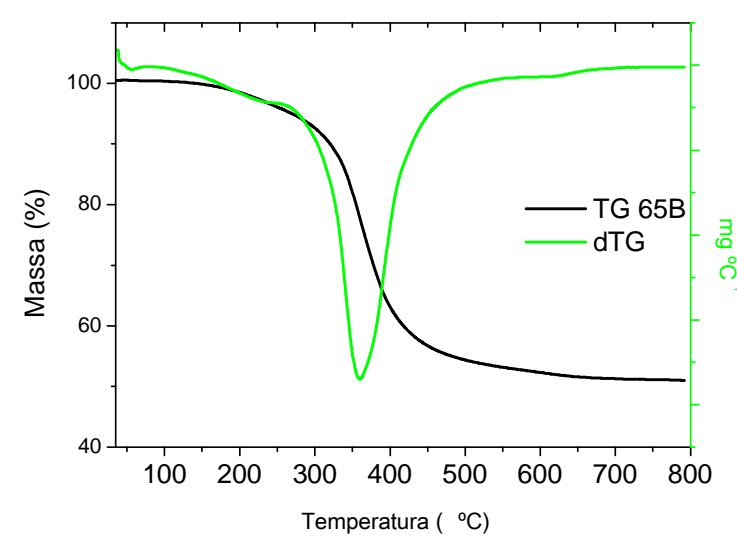

d)

FIGURA 29: Curvas referentes a decomposição térmica pela metodologia TGA. (a) Grupo 6(50B). (b) Grupo 7(55B). (c) Grupo 8(60B). (d) Grupo 9 (65B).

A Figura 30, mostra as curvas de decomposição térmica dos Grupos de compósitos experimentais adicionados com a Sílica Aerosil ${ }^{\circledR}$ OX-50. 


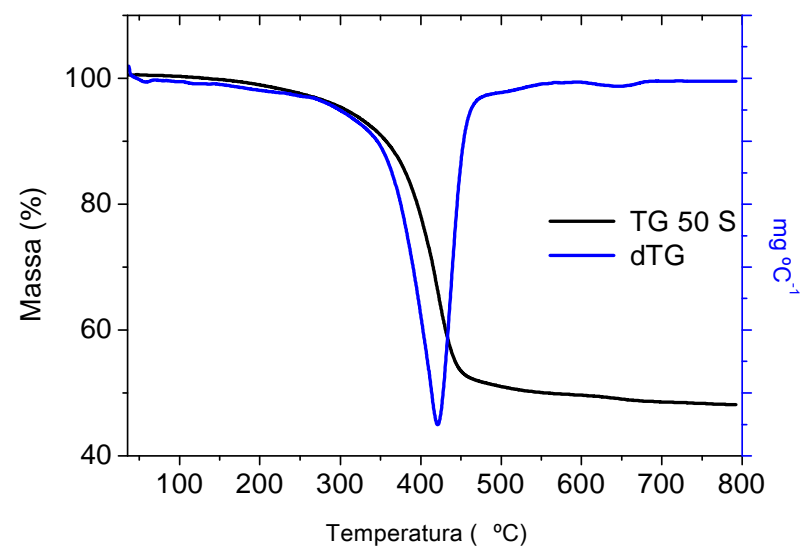

a)

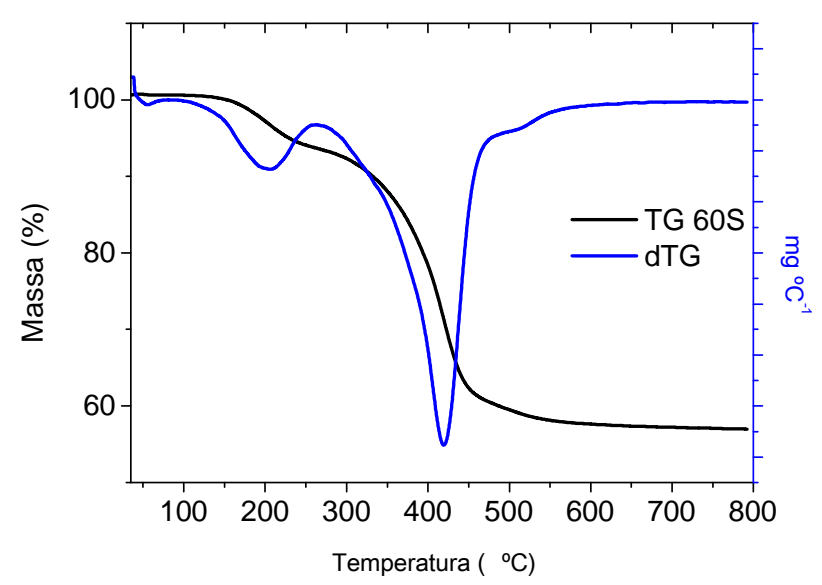

c)

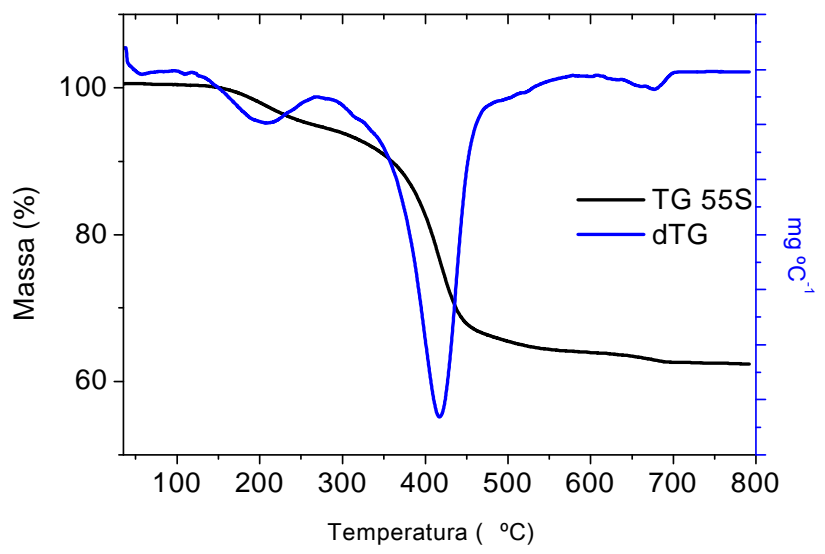

b)

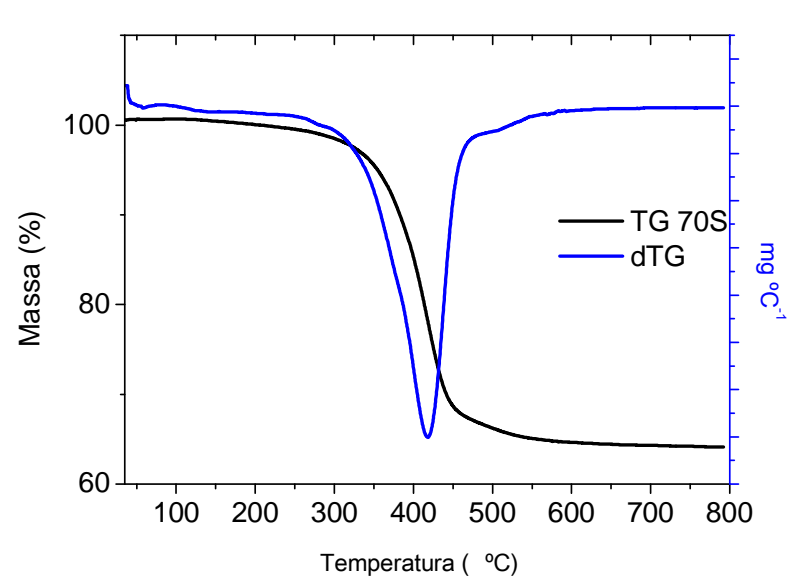

d)

FIGURA 30: Curvas referentes a decomposição térmica pela metodologia TGA. (a) Grupo 10(50S). (b) Grupo 11(60S). (c) Grupo 12(65S). (d) Grupo 13 (70S).

A perda da massa em atmosfera de nitrogênio, foi observada pelo aumento gradual da temperatura. Essa foi mensurada em todos os grupos de compósitos experimentais após a polimerização.

Observou-se nos grupos de compósitos experimentais adicionados com nanopartículas argilominerais Cloisite $10 \mathrm{~A}^{\circledR}$ e Cloisite $30 \mathrm{~B}^{\circledR}$ a perda de água inicial, anteriormente relatado por autores, que em um estudo afirmaram que em relação às 
nanopartículas argilominerais, há a maior perda de água quando a temperatura atingiu $93^{\circ} \mathrm{C}$ e essa perda foi relacionada a água superficial presente nas nanopartículas. Entretanto, quando a temperatura atingiu $273^{\circ} \mathrm{C}$, houve uma perda de água estrutural, ou seja, de entre as lamelas (espaço interlamelar) (Wang et al. 1994).

Em todos os Grupos de compósitos experimentais, incluindo os adicionados com sílica silanizada, observou-se que a perda de massa mais significativa ocorreu entre 200 e $400^{\circ} \mathrm{C}$, comportamento característico de perda de massa da referida matriz polimérica. A matriz polimérica, como dito anteriormente, foi composta por $50 \%$ de BisGMA (Metacrilato de glicidila do Bisfenol A) e 50\% TEGDMA (dimetacrilato de trietilenoglicol). O BisGMA possui um extenso comprimento da cadeia molecular e uma estrutura aromática no centro da molécula. Essas características são responsáveis pelos dois eventos de perda mais significantes.

Em um outro estudo realizado sob as mesmas condições da metodologia TGA desse trabalho, autores relataram o mecanismo de degradação de uma matriz polimérica a base de BisGMA/TEGDMA, na proporção 60:40 e observaram que o resíduo permaneceu constante com um rendimento de $9 \%$ em peso. Foram detectados nos produtos pirolisados de todas as amostras, ácido metacrilato e 2hidroxietil metacrilato no primeiro evento de perda $\left(124-271^{\circ} \mathrm{C}\right)$ e no segundo (331$388^{\circ} \mathrm{C}$ ). $\mathrm{O}$ ácido propiônico foi observado na fase final de degradação $\left(433-438^{\circ} \mathrm{C}\right)$. No co-polímero BisGMA/TEGDMA com maior grau de conversão, observou-se uma menor proporção de ácido metacrílico/fenol e uma maior proporção de ácido propiônico/fenol. Os autores descreveram o mecanismo de degradação da seguinte maneira: o ácido metacrílico foi produzido pela descompactação de cadeias poliméricas e pelo resíduo não polimerizado do BisGMA e dos monômeros do TEGDMA, semelhante a degradação de polimetacrilato de metila; o metacrilato de 2hidroxietila também foi produzido pelos monômeros do TEGDMA; o ácido metacrílico e o metacrilato de 2-hidroxietila que foram observados na fase inicial da pirólise e que diminuiram de quantidade com o aumento do grau de conversão, sugerem que os mesmos foram gerados a partir dos monômeros residuais de BisGMA / TEGDMA. Os dois principais tipos de reação radicalar de polimerização são conhecidos como "acoplamento" e "desproporcionamento" e os resultados 
indicaram que o ácido propiônico foi produzido a partir da extremidade das cadeias poliméricas, geradas pela reação de desproporcionamento. A quantidade de ácido propiônico aumentou com o grau de conversão e essa foi uma evidência adicional para co-polímeros a base de de BisGMA / TEGDMA. Por contraste, o fenol foi observado a 375-500 $\mathrm{C}$, na fase final da degradação térmica e a quantidade manteve-se constante, independentemente do grau de conversão. O comportamento de degradação térmica na fase inicial e secundária, foi afetado pelo grau de conversão dos co-polímeros, mas não na fase final. Esses resultados demonstram que o mecanismo de degradação térmica do BisGMA/TEGDMA foi denominado por "específica cisão final" que ocorreu durante a fase final de degradação térmica. $O$ grau de conversão do co-polímero BisGMA/TEGDMA, foi fortemente relacionado com a temperatura na intersecção das curvas das fases secundária e final, separadas a partir das curvas obtidas pela metodologia TGA (Teshima, 2004).

Em relação a sílica silanizada, autores observaram em um outro estudo a degradação térmica, sobre as mesmas condições desse trabalho, de compósitos experimentais adicionados com quatro diferentes tipos de sílica silanizada (Aerosil OX50, Aerosil 90, Aerosil 130, Aerosil 150 e Aerosil 300) em uma matriz polimérica a base de BisGMA/TEGDMA, na proporção 50:50 em peso. Foram observadas três fases de degradação. As duas primeiras fases foram relacionadas com a degradação da matriz polimérica pura e a terceira fase, foi relacionada com a condensação de silanóis superficiais da sílica. $O$ aparecimento de duas etapas de degradação térmica na matriz a base de BisGMA/TEGDMA foi atribuído a inomogeneidade na estrutura da rede, principalmente devido à formação de anéis primários durante a fotopolimerização. A primeira etapa de degradação (a baixas temperaturas) correspondeu a quebra da ligação dos anéis primários da rede polimérica e a segunda fase, correspondeu a quebra de ligação da rede principal. Em relação ao resíduo dos compósitos experimentais, os autores não observaram diferenças significativas entre perfis de decomposição térmica dos diferentes tipos de sílica silanizada. Os autores ainda ressaltaram que a terceira fase de decomposição térmica dos compósitos experimentais, foi devido a condensação de silanóis superficiais da sílica (Karabela e Sideridou, 2011). 
No resíduo remanescente dos Grupos de compósitos experimentais adicionados com nanopartículas argilominerais, pode-se observar nos resultados obtidos uma maior perda de massa dos grupos de compósitos experimentais adicionados com Cloisite $10 \mathrm{~A}^{\circledR}$, em relação aos adicionados com Cloisite $30 \mathrm{~B}^{\circledR}$. Isso se dá pela afinidade química apresentada entre a matriz polimérica e o tipo de surfactante da nanopartícula. A nanopartícula argilomineral Cloisite $10 A^{\circledR}$, se distingue da Cloisite $30 \mathrm{~B}^{\circledR}$ por sua apolaridade, dessa maneira apresentou uma menor afinidade química em relação a uma matriz polimérica oxigenada a base de BisGMA/TEGDMA. A nanopartícula Cloisite $30 \mathrm{~B}^{\circledR}$ devido a sua característica mais polar, apresentou uma afinidade química mais efetiva, podendo justificar os valores de resíduos mais elevado, pois tornou-se mais dificultoso degradar o compósito com afinidade química relativamente superior.

A nanopartícula Cloisite $10 A^{\circledR}$, além de sua natureza menos polar, possui um maior número de átomos de carbono em sua composição, o que também justificaria sua maior perda de massa em relação a Cloisite $30 \mathrm{~B}^{\circledR}$.

\subsection{Calorimetria Exploratória Diferencial - (DSC)}

Por meio dessa metodologia, conseguiu-se monitorar se as amostras previamente polimerizadas pelo TMA foram curadas e convertidas adequadamente. Isso foi possível comparando o comportamento de duas amostras do mesmo grupo, uma previamente polimerizada pelo TMA e a outra não polimerizada. Observou-se que o comportamento destas amostras foi muito distinto, pois as amostras não polimerizadas apresentaram uma reação exotérmica, ou seja, ocorreu uma polimerização pelo estímulo térmico. Em relação às amostras polimerizadas, observou-se um comportamento típico de degradação e fusão polimérica, decorrente das altas temperaturas que foram submetidas.

Nas figuras 31 a 39, observam-se uma das dez análises comparativas realizadas em cada um dos Grupos adicionados com a nano partícula argilomineral Cloisite $10 \mathrm{~A}^{\circledR}$, (Grupos 1(50A), 2(55A), 3(60A), $4(65 \mathrm{~A})$ e $5(70 \mathrm{~A})$ ), Cloisite 30B ${ }^{\circledR}$ (Grupo 6(50B), 7(55B), 8 (60B) e 9(65B)) e um grupo adicionado com a Sílica Aerosil ${ }^{\circledR}$ OX-50 (Grupo 10(50A)). Pela metodologia DSC, foi possível observar em 
todas as análises um fenômeno exotérmico nas amostras não polimerizadas (representadas pela linha "A" nas figuras). Esse evento inciou-se entre entre 120 e $150^{\circ} \mathrm{C}$. Não foi observado nenhum fenômeno exotérmico nas amostras previamente polimerizadas (representadas pela linha "B" nas figuras).

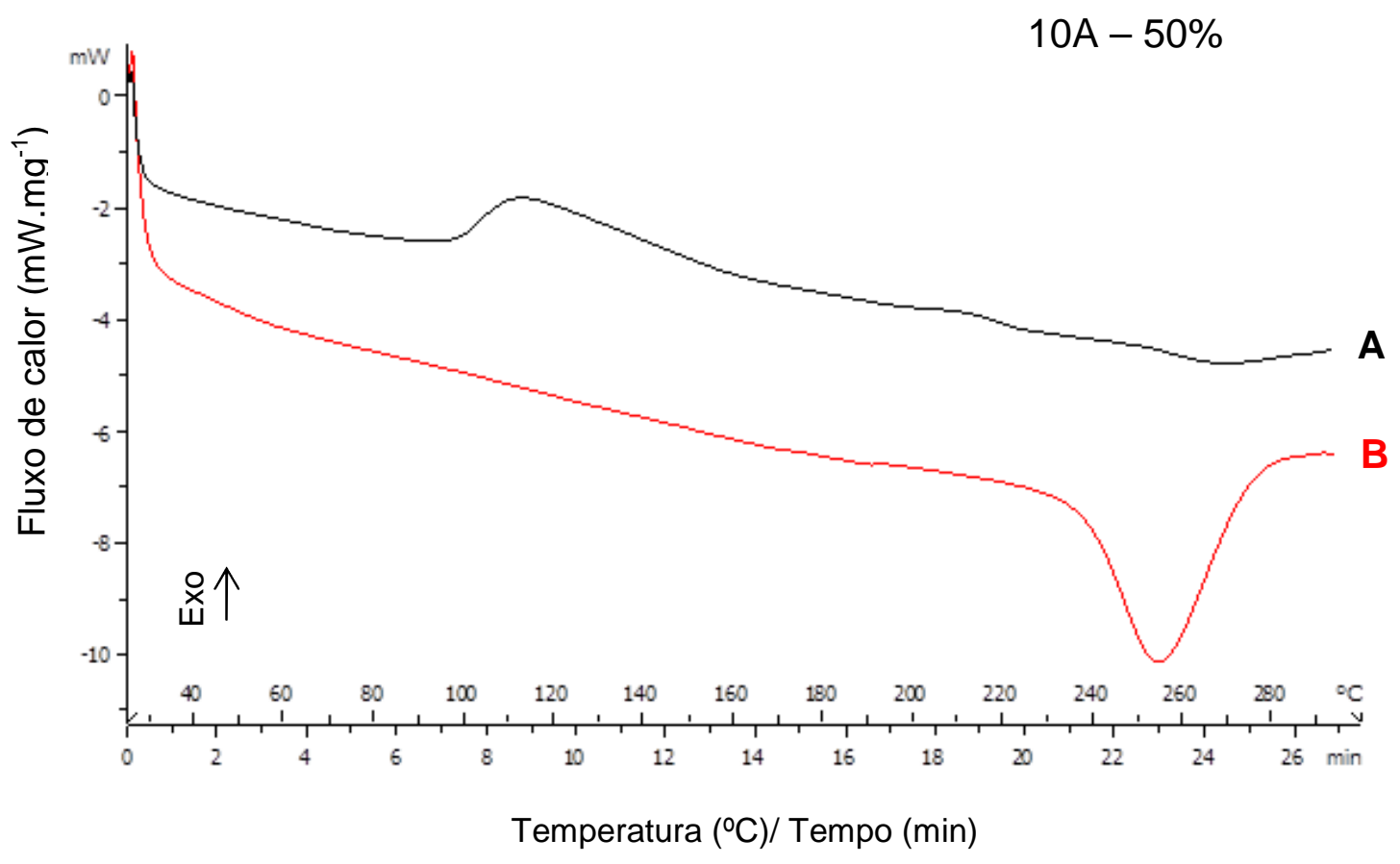

FIGURA 31: Comparação por meio da análise DSC de uma amostra não polimerizada $(A)$ e uma amostra previamente polimerizada pela metodologia TMA (B), do Grupo 1(50A).

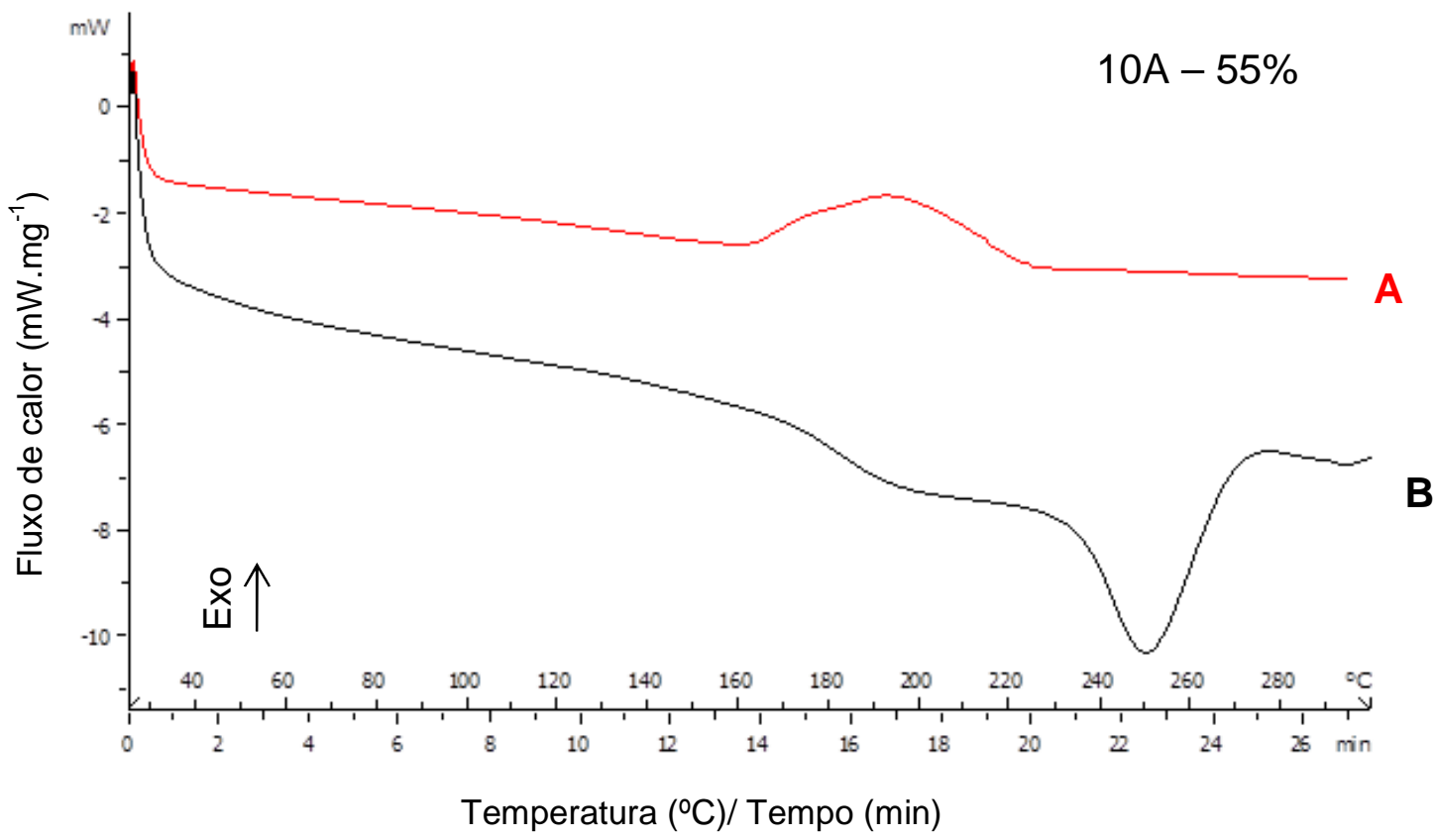


FIGURA 32: Comparação por meio da análise DSC de uma amostra não polimerizada $(A)$ e uma amostra previamente polimerizada pela metodologia TMA (B), do Grupo 2(55A).

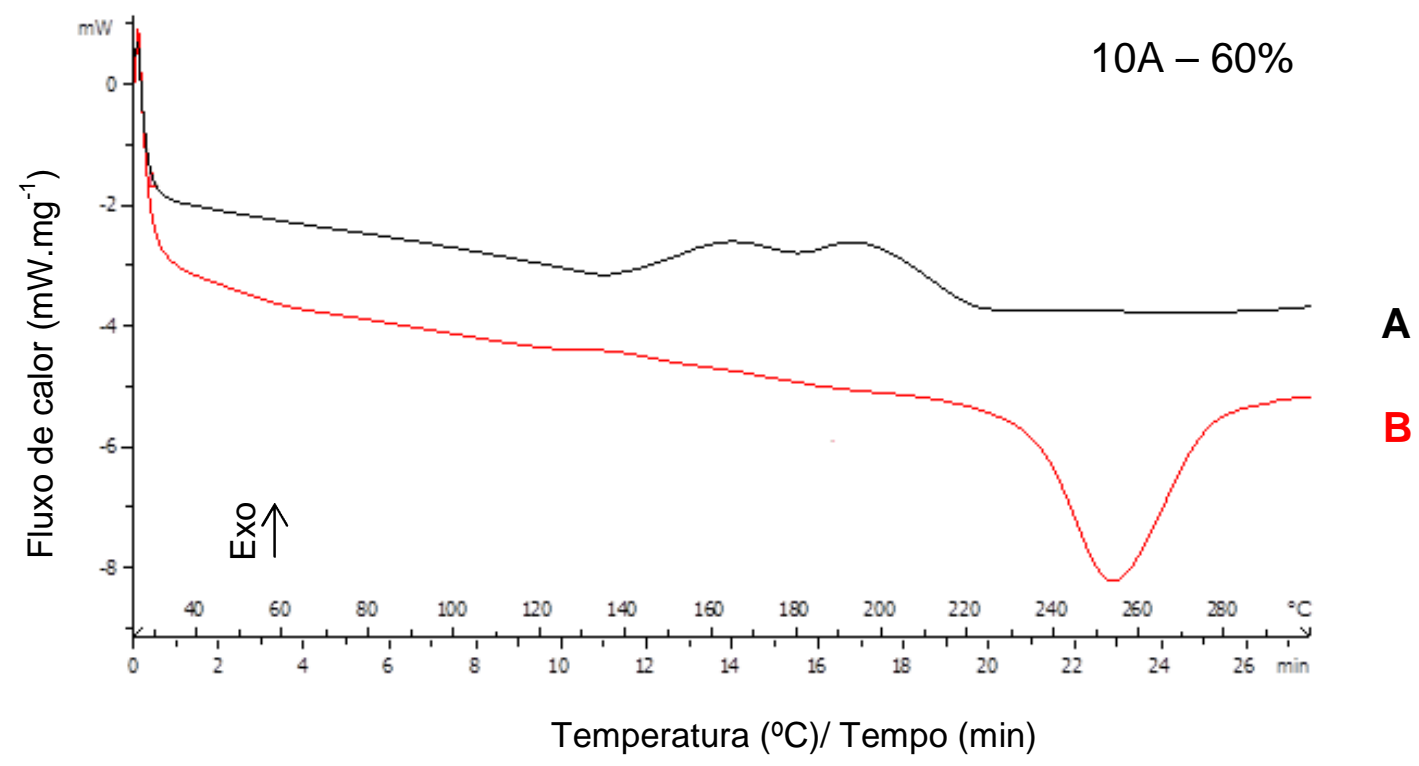

FIGURA 33: Comparação por meio da análise DSC de uma amostra não polimerizada da (A) e uma amostra previamente polimerizada pela metodologia TMA (B), do Grupo 3(60A).

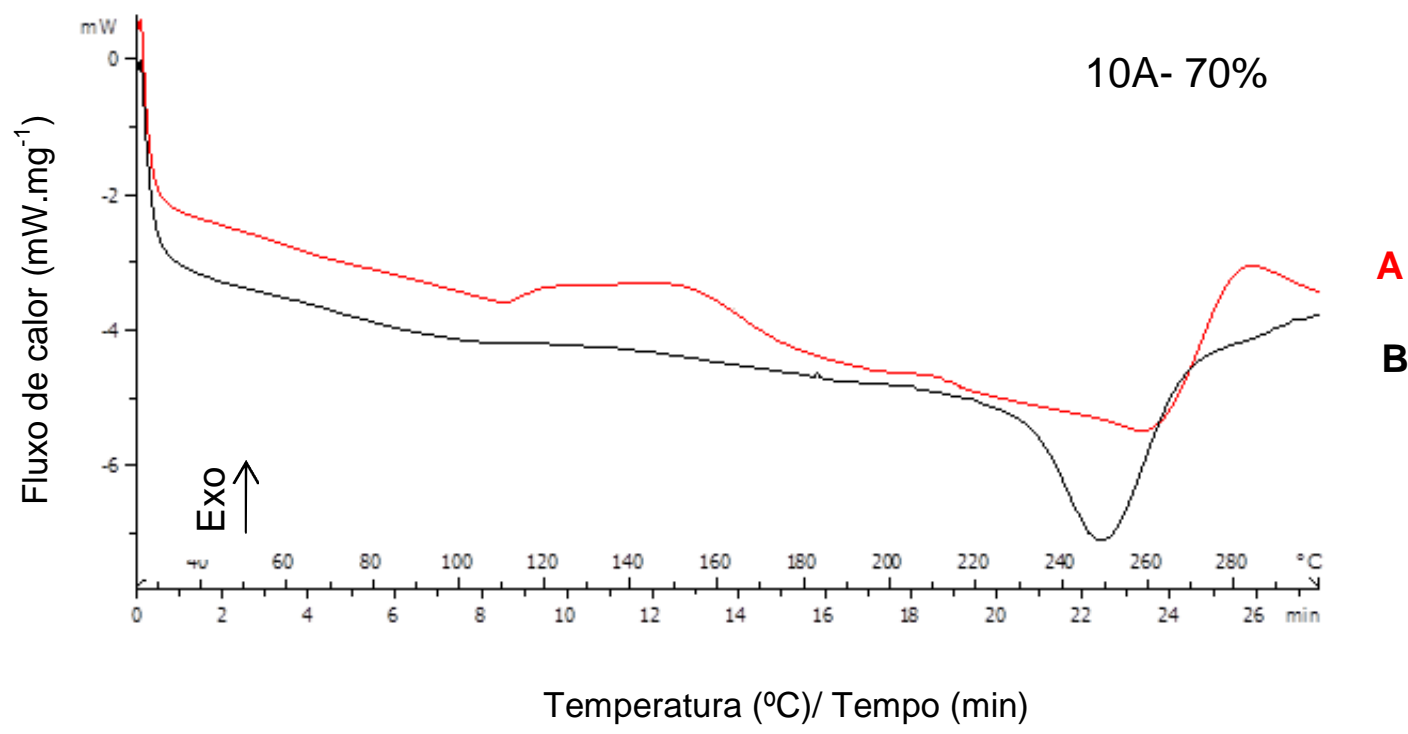

FIGURA 34: Comparação por meio da análise DSC de uma amostra não polimerizada (A) e uma amostra previamente polimerizada pela metodologia TMA (B), do Grupo 5(70A). 


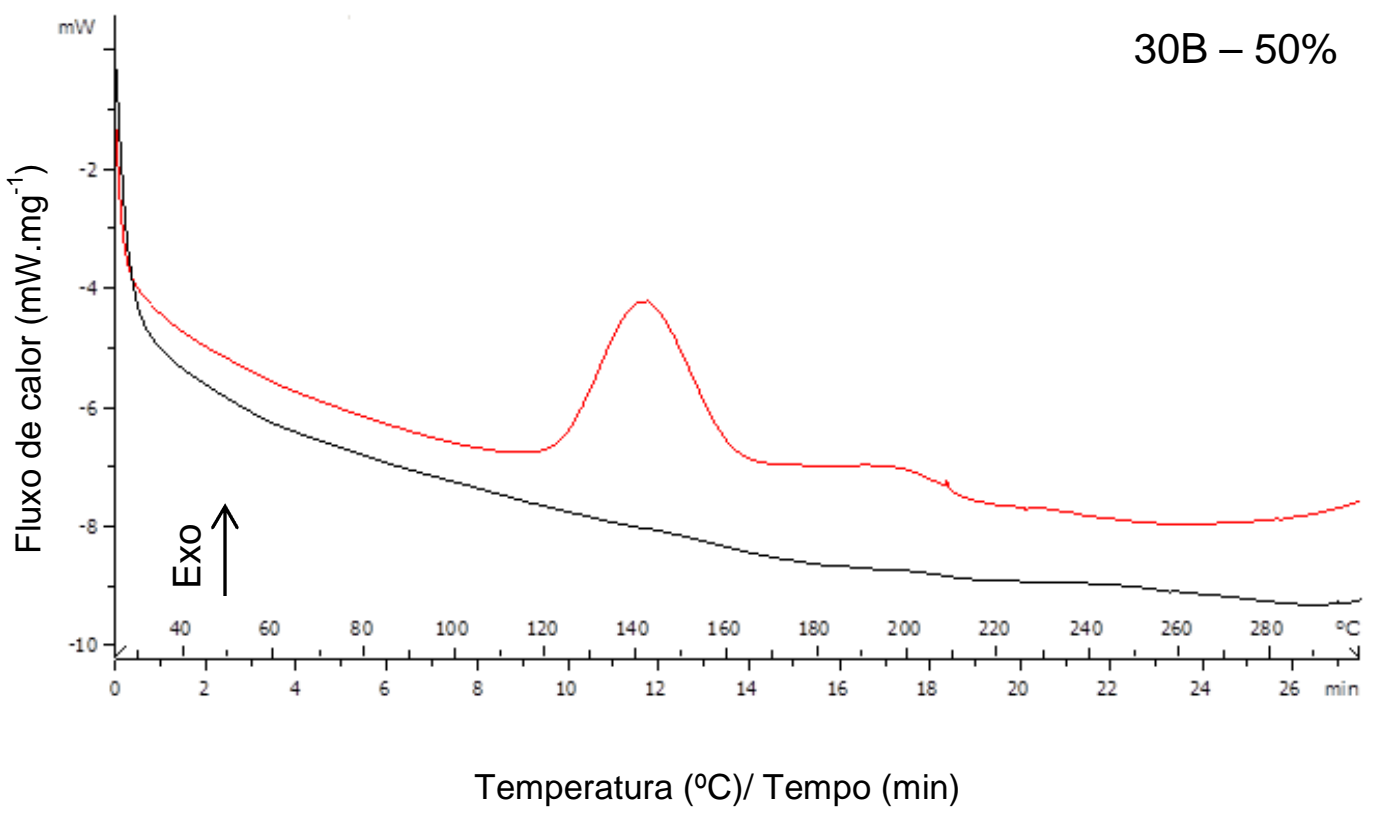

A

B

FIGURA 35: : Comparação por meio da análise DSC de uma amostra não polimerizada (A) e uma amostra previamente polimerizada pela metodologia TMA (B), do Grupo 6(50B).

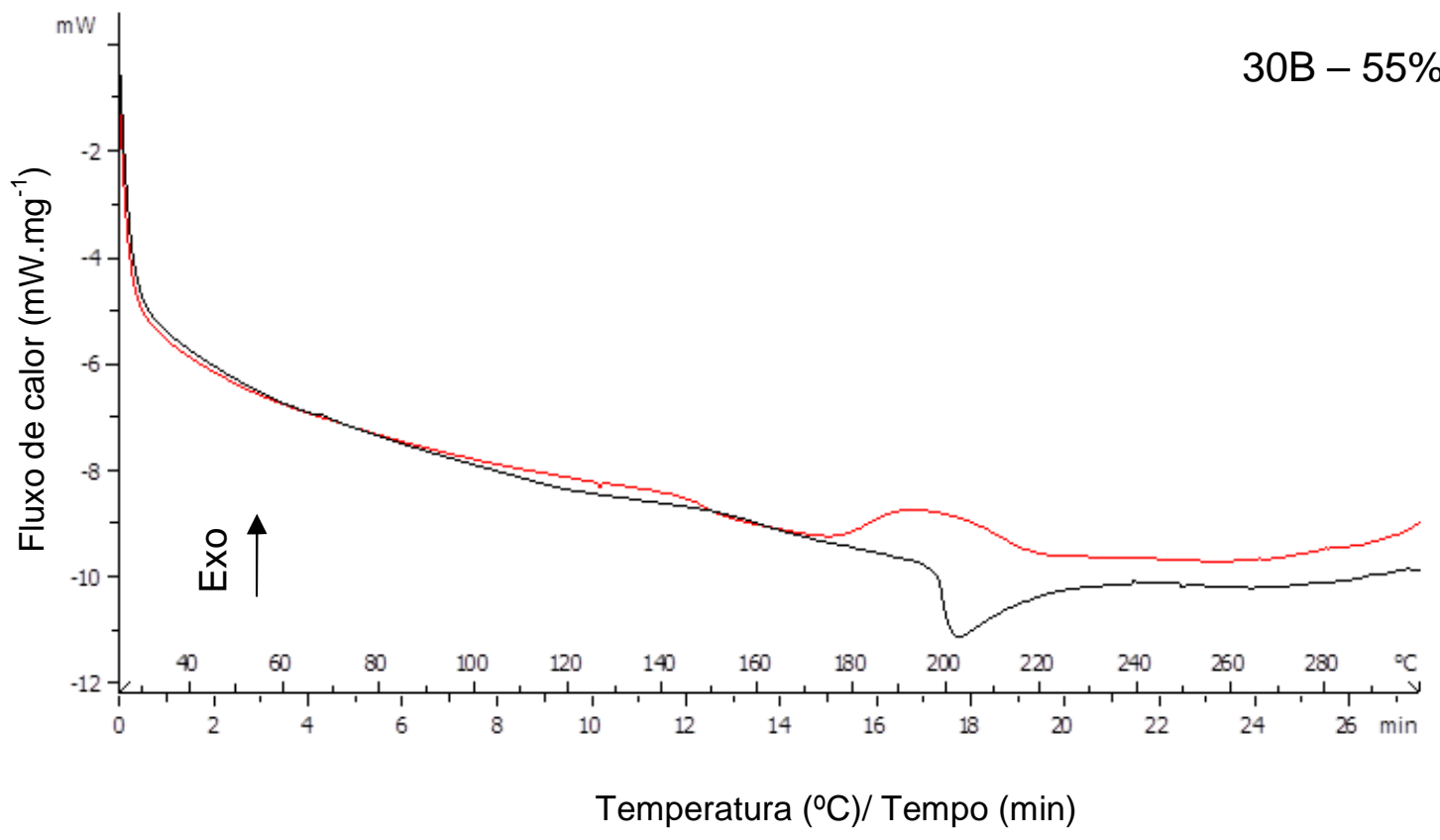

FIGURA 36: Comparação por meio da análise DSC de uma amostra não polimerizada $(A)$ e uma amostra previamente polimerizada pela metodologia TMA (B), do Grupo 7(55B). 


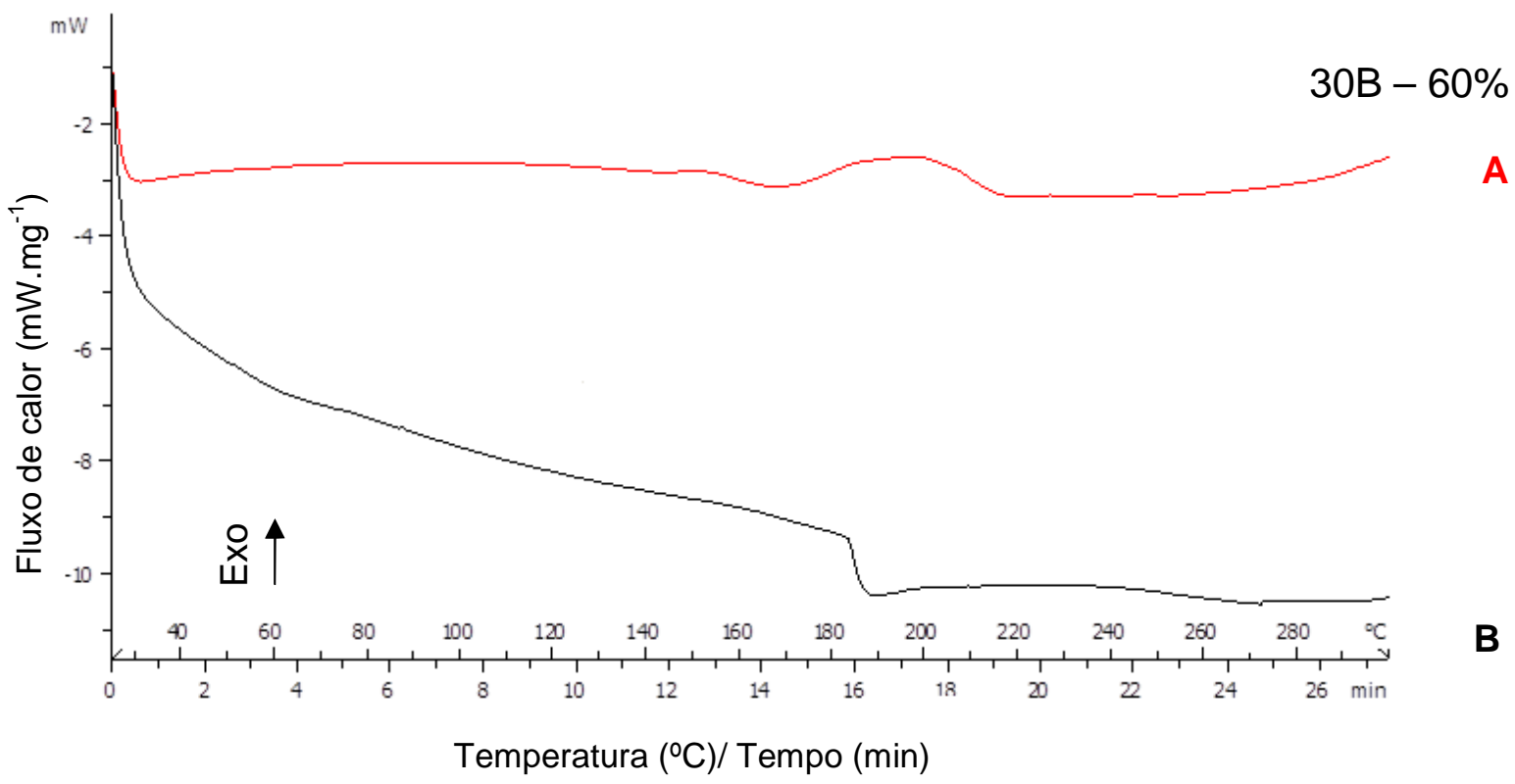

FIGURA 37: Comparação por meio da análise DSC de uma amostra não polimerizada $(A)$ e uma amostra previamente polimerizada pela metodologia TMA (B), do Grupo 8(60A).

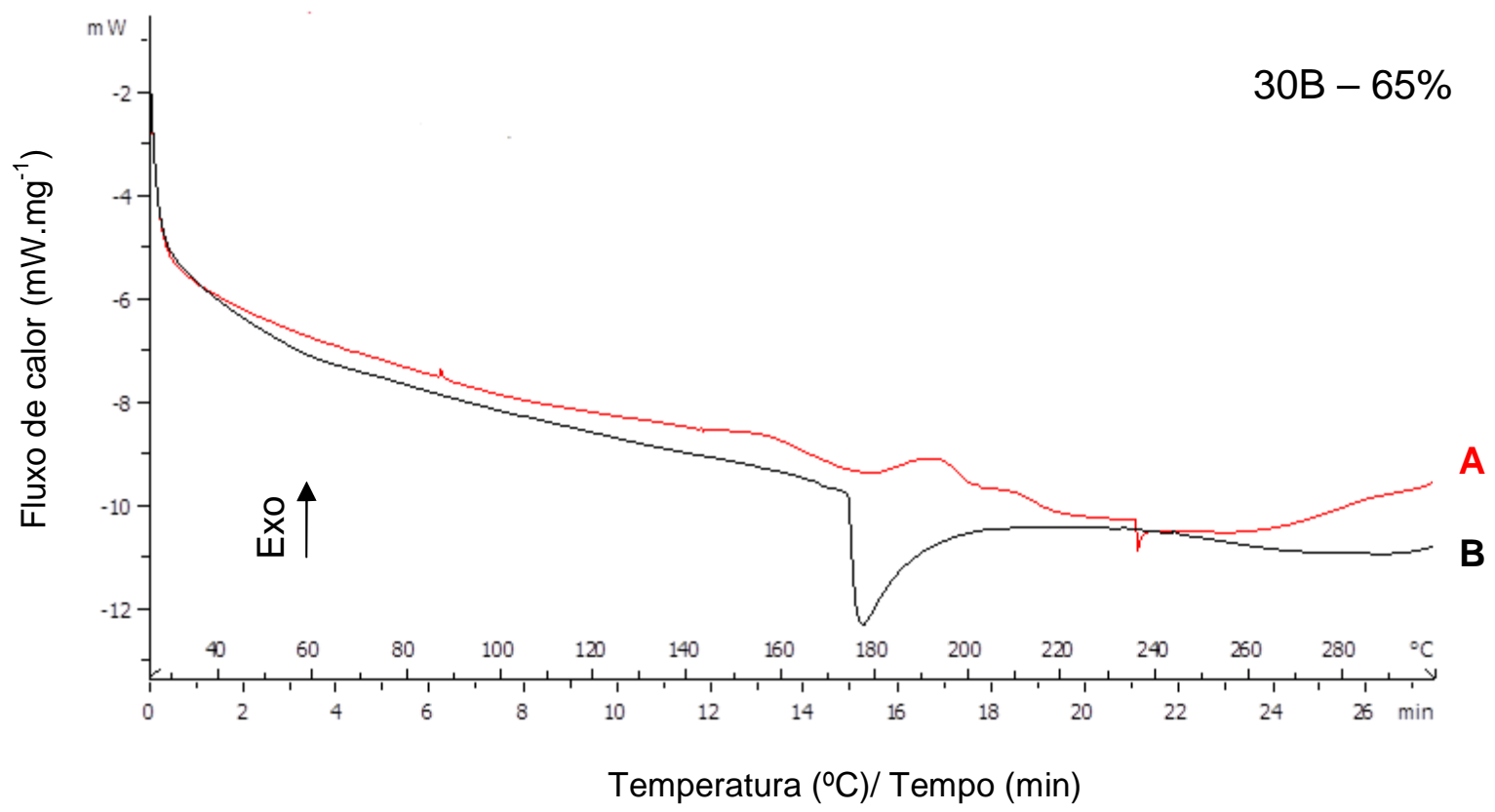

FIGURA 38: Comparação por meio da análise DSC de uma amostra não polimerizada $(A)$ e uma amostra previamente polimerizada pela metodologia TMA (B), do Grupo 9(65B). 


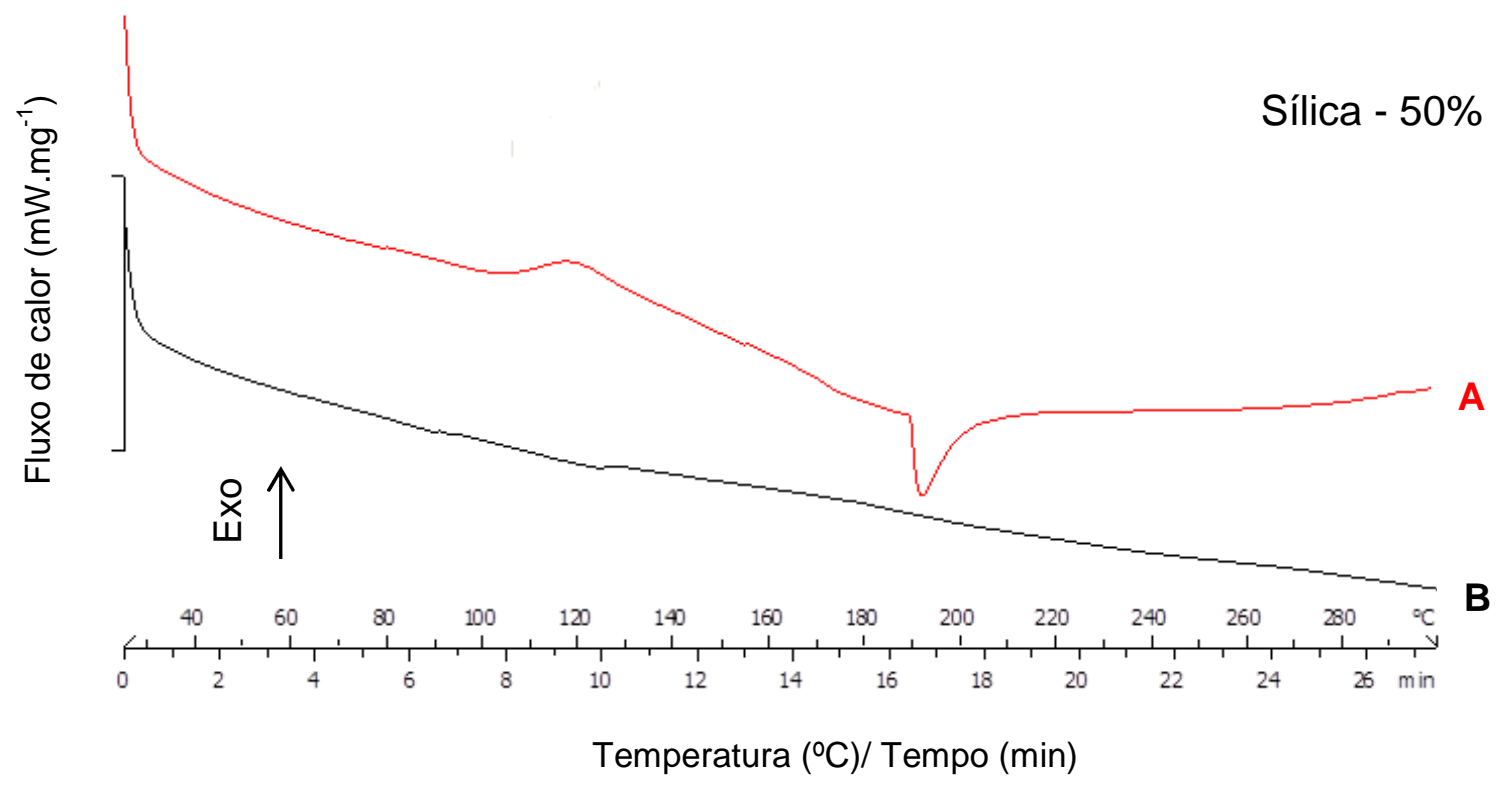

FIGURA 39: Comparação por meio da análise DSC de uma amostra não polimerizada (A) e uma amostra previamente polimerizada pela metodologia TMA (B), do Grupo 10(50S).

De acordo com os resultados obtidos, a metodologia DSC comprovou a eficácia da metodologia TMA na cura e conversão dos compósitos experimentais.

\subsection{Espectrografia no Infravermelho (FTIR)}

Incialmente, foram obtidas as espectrografias por infravermelho das nanopartículas argilominerais Cloisite $10 \mathrm{~A}^{\circledR}$ e Cloisite $30 \mathrm{~B}^{\circledR}$ puras, conforme demonstra a Figura 40. Posteriormente esses espectros foram camparados aos de seus respectivos Grupos de compósitos experimentais e dessa maneira, foi possível avaliar as alterações do conteúdo inorgânico em função da incorporação da matriz polimérica a base de BisGMA/TEGDMA. 


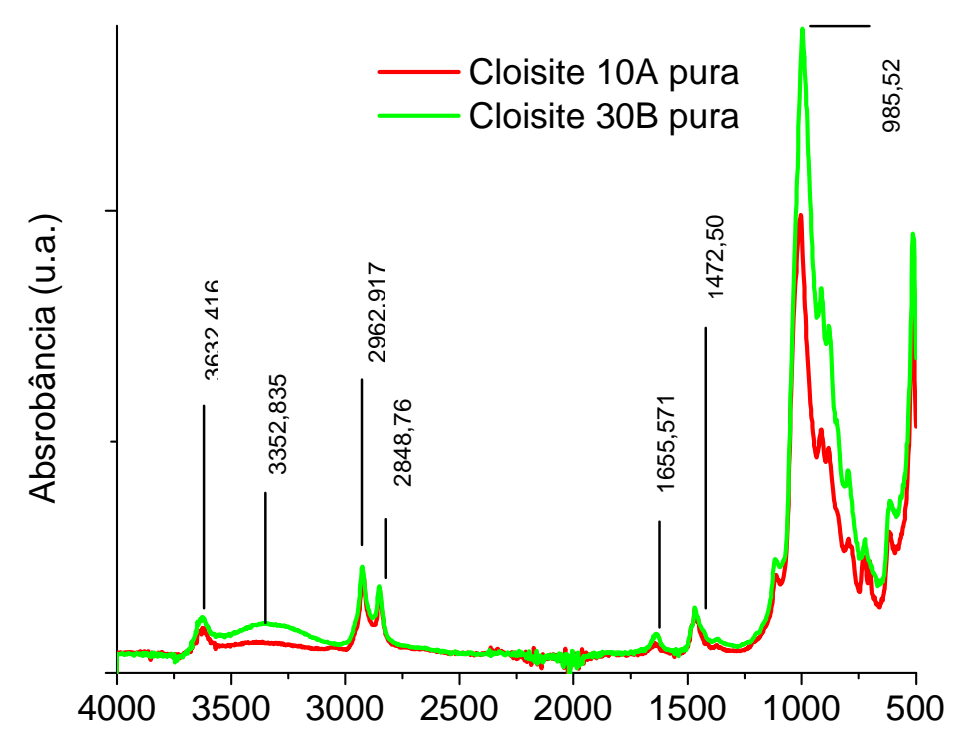

FIGURA 40: Espectrografia por infravermelho das nanopartículas argilominerais Cloisite $10 A^{\circledR}$ e $30 B^{\circledR}$ puras.

$\mathrm{Na}$ espectrografia por infravermelho das nanopartículas argilominerais Cloisite $10 A^{\circledR}$ e $30 B^{\circledR}$ puras, pode-se observar o pico $985 \mathrm{~cm}^{-1}$, referente às ligações Si-O característica dessa nanopartícula (estiramento do grupo Si-O-Si do silicato presente na argila). $\mathrm{O}$ pico $3632 \mathrm{~cm}^{-1}$ refere-se à presença estrutural de $\mathrm{H}_{2} \mathrm{O}$ ou hidroxilas quimicamente adsorvidas e os picos 3353 e $1655 \mathrm{~cm}^{-1}$, estão relacionados a presença de $\mathrm{H}_{2} \mathrm{O}$ livre. Os picos 2962 e $2848 \mathrm{~cm}^{-1}$, são referentes ao material orgânico presente nas nanopartículas (estiramento da ligação - $\mathrm{CH}$ do sal quaternário de amônio) e o pico $1472 \mathrm{~cm}^{-1}$, à deformação angular do grupo C-H e o estiramento da ligação N-H.

A carga inorgânica Cloisite $10 \mathrm{~A}^{\circledR}$ apresentou picos de menor absorbância em relação a Cloisite $30 \mathrm{~B}^{\circledR}$ e isso pode estar relacionado com a maior quantidade de átomos de carbono presentes na composição da nanopartícula argilomineral Cloisite $10 A^{\circledR}$.

Foi realizada também, a espectrografia da matriz polimérica a base de BisGMA e TEGDMA pura, ou seja, sem a adição de nenhum tipo de carga inorgânica, conforme demonstra a Figura 41. 


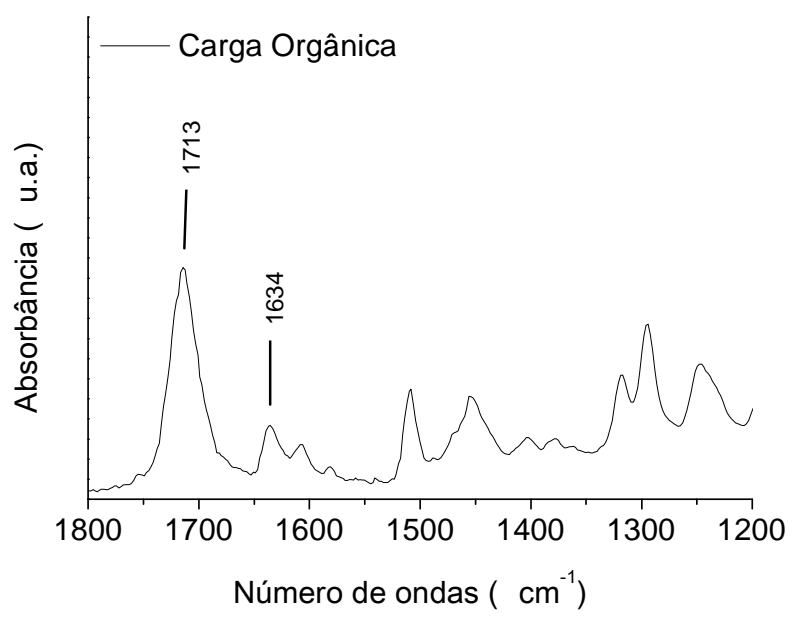

FIGURA 41: Espectrografia no infravermelho da matriz polimérica a base de BisGMA e TEGDMA, sem nenhum tipo de carga.

Ainda na Figura 41, observa-se o pico $1633 \mathrm{~cm}^{-1}$, referente ao estiramento $\mathrm{CH}$ do grupo carbonila $-\mathrm{C}=\mathrm{O}$ e o pico $1713 \mathrm{~cm}^{-1}$, referente a ligação $\mathrm{C}=\mathrm{C}$ e $-\mathrm{CH}$ da matriz.

Foram obtidos também as espectrografias dos Grupos de compósitos experimentais adicionados com a nanopartícula argilomineral Cloisite $10 \mathrm{~A}^{\circledR}$ e Cloisite $30 \mathrm{~B}^{\circledR}$, conforme demonstram as Figuras 42 e 43.

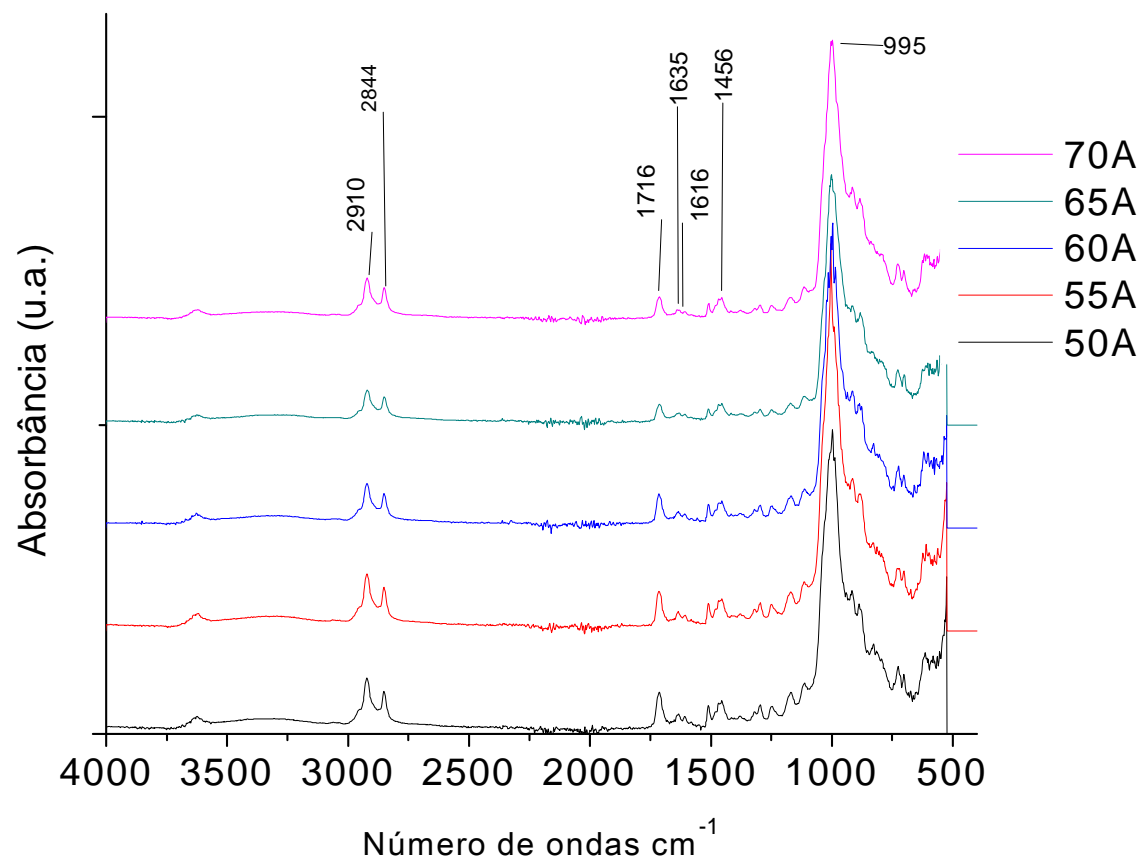

FIGURA 42: Espectrografia no infravermelho dos Grupos de compósitos experimentais adicionados com a nanopartícula argilomineral Cloisite $10 \mathrm{~A}^{\circledR}$. 


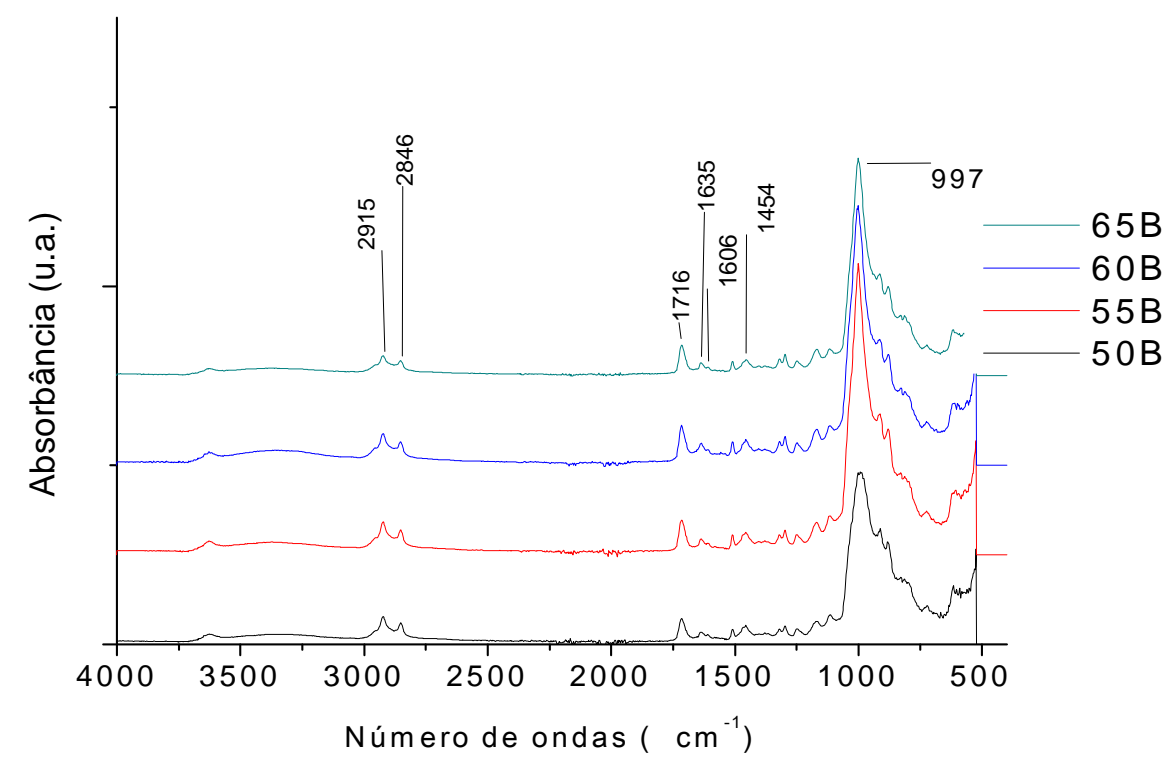

FIGURA 43: Espectrografia no infravermelho dos Grupos de compósitos experimentais adicionados com a nanopartícula argilomineral Cloisite $30 \mathrm{~B}^{\circledR}$.

Nas espectrografias dos Grupos de compósitos experimetais adicionados com Cloisite $10 \mathrm{~A}^{\circledR}$ e Cloisite $30 \mathrm{~B}^{\circledR}$, pode-se observar que os picos 2915 e $2844 \mathrm{~cm}^{-1}$, correspondem ao estiramento da ligação $-\mathrm{CH}$ do sal quaternário de amônio das nanopartículas argilominerais. O picos 1716 e $1635 \mathrm{~cm}^{-1}$, correspondem ao estiramento da ligação $-\mathrm{CH}$ do grupo carbonila $-\mathrm{C}=\mathrm{O}$ e a ligação $\mathrm{C}=\mathrm{C}$ e $-\mathrm{CH}$ da matriz polmérica presente nos compósitos experimentais. $O$ pico $1456 \mathrm{~cm}^{-1}$, corresponde a deformação angular do grupo $\mathrm{C}-\mathrm{H}$ e o estiramento da ligação N-H. O pico $995 \mathrm{~cm}^{-1}$, corresponde ao estiramento do grupo Si-O-Si do silicato presente na argila.

\subsection{Difração de Raio -X (DRX)}

Esta metodologia teve como objetivo analisar a distância interlamelar (espaçamento basal) da montmorilonita inserida na matriz polimérica a base de BisGMA /TEGDMA, dos compósitos experimentais adicionados com as nanopartículas argilominerais Cloisite $10 \mathrm{~A}^{\circledR}$ e Cloisite $30 \mathrm{~B}^{\circledR}$. 
Inicialmente, foram obtidos os difratogramas das nanopartículas puras e posteriormente, os difratogramas dos seus respectivos Grupos de compósitos experimentais. Dessa maneira, foi possível comparar a distância interlamelar inicial "d $\mathrm{d}_{001}$ " da nanopartícula pura, com a distância interlamelar "d" apresentada pelos compósitos experimentais. Por essa metodologia também foi possível avaliar o tipo de interação argila/polímero.

\subsubsection{Cloisite $10 \mathrm{~A}^{\circledR}$}

Na Figura 44, pode-se obervar o difratograma da nanopartícula argilomineral Cloisite $10 A^{\circledR}$ pura e a distância interlamelar inicial " $d_{001}$ ".

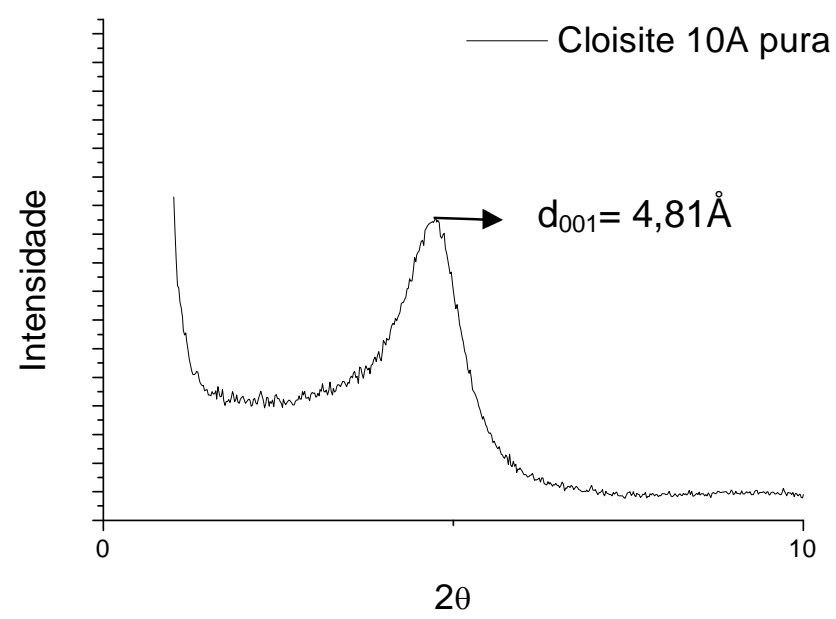

FIGURA 44: Difratograma da nanopartícula argilomineral Cloisite $10 \mathrm{~A}^{\boxplus}$ pura para obtenção do "d" inicial.

De acordo com o resultado da difração obtido, foi determinada a distância

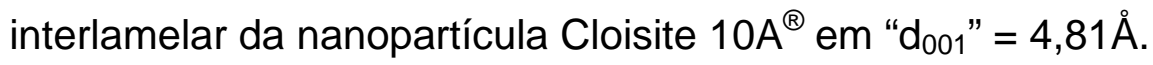

Em seguida foram obtidos os valores de "d" dos Grupos de compósitos experimentais adicionados com a referida nanopartícula. Os difratogramas dos Grupos 1(50A), 2(55A), 3 (60A), 4(65A) e 5(70A), estão demonstrados na Figura 45. 


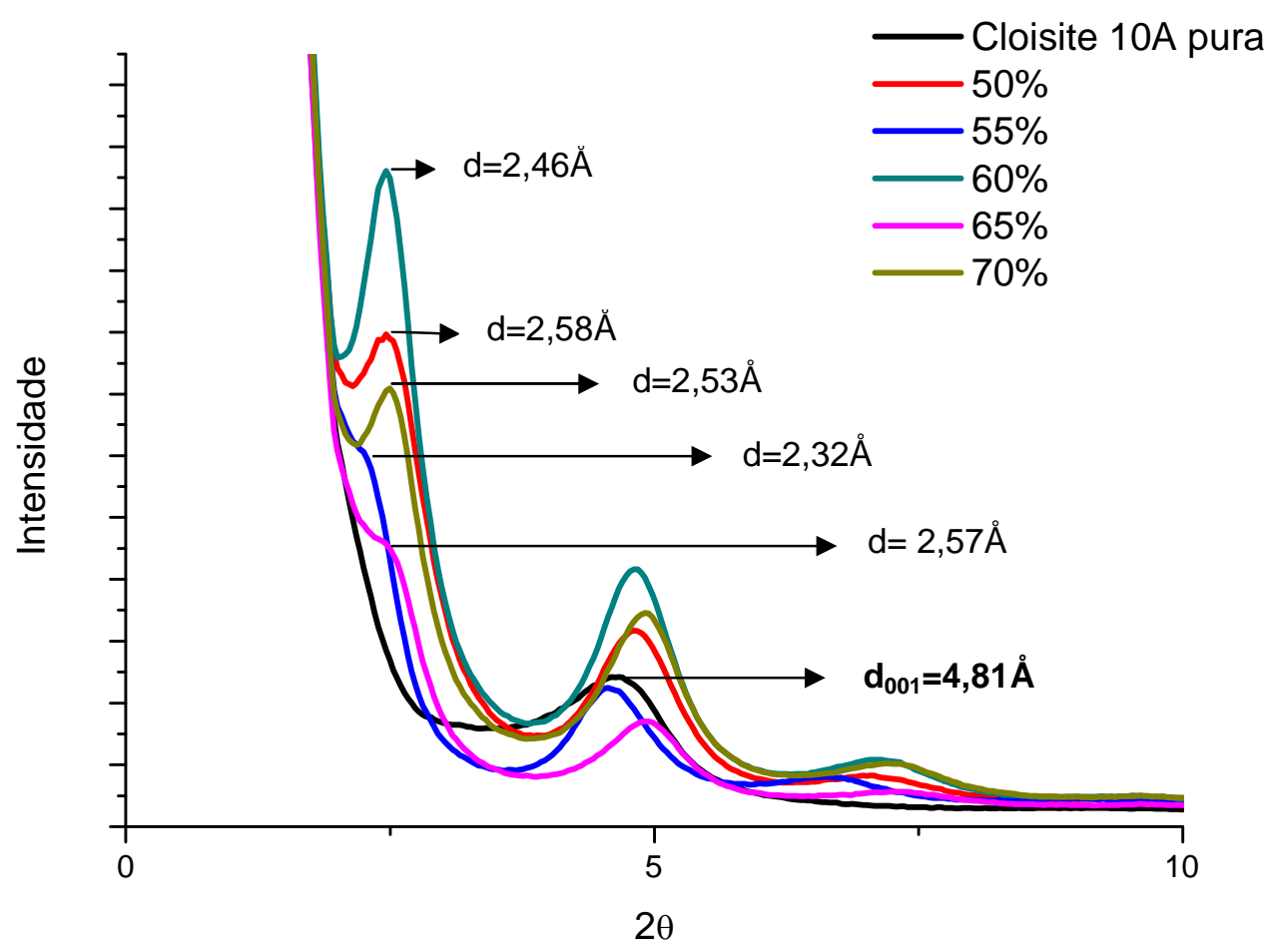

FIGURA 45: Difratograma dos Grupos de compósitos experimentais adicionados com a nanopartícula argilomineral Cloisite 10A ${ }^{\circledR}$. (Grupo 1(50A), 2(55A), $3(60 \mathrm{~A}), 4(65) \mathrm{A}$ e 5(70A)).

Observou-se pelos difratogramas dos Grupos de compósitos experimentais adicionados com a nanopartícula argilomineral Cloisite $10 \mathrm{~A}^{\circledR}$, que a intercalação da nanopartícula foi predominante em relação a matriz polimérica a base de BisGMA e TEGDMA. Foram realizados também os difratogramas de compósitos experimentais adicionados com quantidades inferiores da referida nanopartícula. As concentrações foram determinadas em: $0,5 \%, 1 \%, 2 \%, 10 \%, 15 \%$ e $20 \%$ de carga inorgânica, conforme demonstra a Figura 46. Dessa maneira, foi possível avaliar em quais concentrações ocorreram a esfoliação, a intercalação e a dispersão da nanopartícula, ou seja, o tipo de interação matriz polimérica/nanopartícula argilomineral Cloisite $10 \mathrm{~A}^{\circledR}$, de acordo com a concentração. 


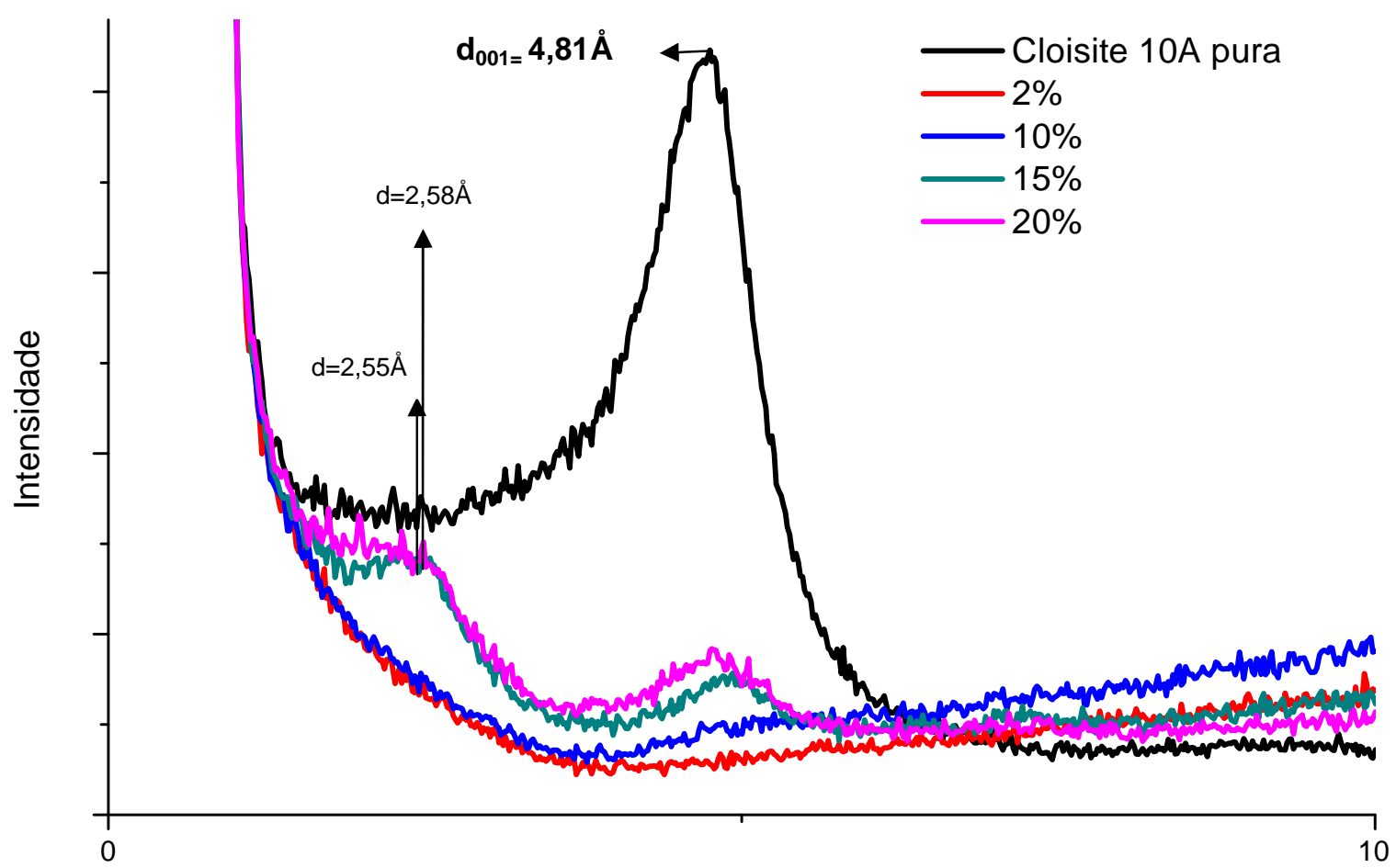

$2 \theta$

FIGURA 46: Difratograma dos compósitos experimentais de baixa concentração $(0,5 \%, 1 \%$, $2 \%$ e $10 \%$ ) adicionados com a nanopartícula argilomineral Cloisite $10 \mathrm{~A}^{\circledR}$.

$\mathrm{Na}$ tabela 10, observa-se a distância interlamelar "d" dos grupos de compósitos experimentais adicionados com a nanopartícula argilomineral Cloisite $10 A^{\circledR}$ e a comparação em relação ao "d 001 ". 
TABELA 10: Distância interlamelar "d" dos Grupos de compósitos experimentais adicionados com a nanopartícula Cloisite $10 \mathrm{~A}^{\circledR}$ e a comparação ao "d $\mathrm{d}_{001}$ ".

\begin{tabular}{|c|c|c|}
\hline Grupo & “d”" (Å) & $\neq “{ }^{\prime} d_{001} "=4,81 \AA$ \\
\hline $1(50 A)$ & 2,58 & 2,23 \\
\hline $2(55 A)$ & 2,32 & 2,49 \\
\hline $3(60 A)$ & 2,46 & 2,45 \\
\hline $4(65 A)$ & 2,57 & 2,24 \\
\hline 5 (70A) & 2,53 & 2,28 \\
\hline $0,5 \%$ & Esfoliado & - \\
\hline $1 \%$ & Esfoliado & - \\
\hline $2 \%$ & Esfoliado & - \\
\hline $10 \%$ & Esfoliado & - \\
\hline $15 \%$ & 2,58 & 2,23 \\
\hline $20 \%$ & 2,55 & 2,26 \\
\hline
\end{tabular}

\subsubsection{Cloisite $30 \mathrm{~B}^{\circledR}$}

Assim como realizado anteriormente com a nanopartícula Cloisite $10 \mathrm{~A}^{\circledR}$, iniciou-se a análise de DRX pela obtenção do difratograma da nanopartícula argilomineral Cloisite $30 \mathrm{~B}^{\circledR}$ pura. Dessa maneira foi possível obter o " $\mathrm{d}_{001}$ ", sendo correspondente a: "d $\mathrm{d}_{001}=4,95$, conforme demonstra a Figura 47. 


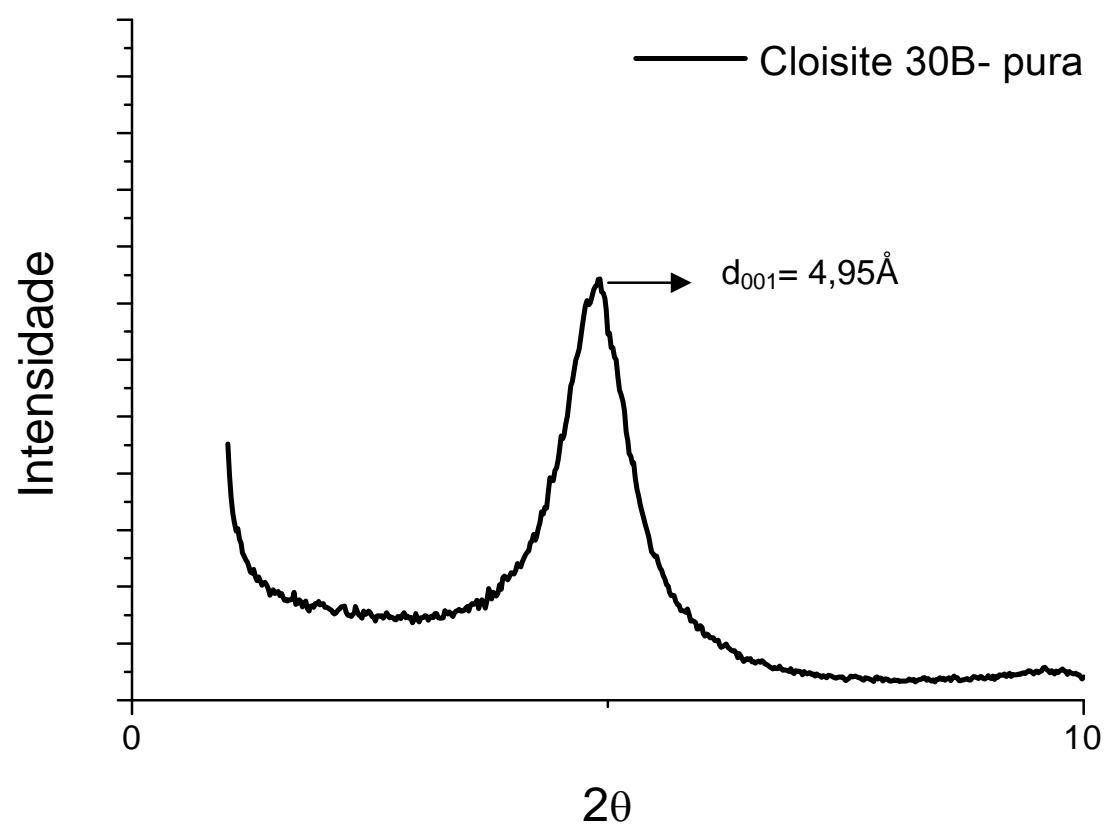

FIGURA 47: Difratograma da nanopartícula argilomineral Cloisite $30 \mathrm{~B}^{\circledR}$ pura para obtenção do "d $\mathrm{d}_{001}$ ".

De acordo com o resultado da difração obtido, foi determinada a distância interlamelar da nanopartícula Cloisite $30 \mathrm{~B}^{\circledR} \mathrm{em}$ " $\mathrm{d}_{001}$ " $=4,95 \AA$.

Em seguida foram obtidos os valores de "d" dos Grupos de compósitos experimentais adicionados com a referida nanopartícula. Os difratogramas dos Grupos 6(50B), 7(55B), 8 (60B) e 9(65B), estão demonstrados na Figura 48. 


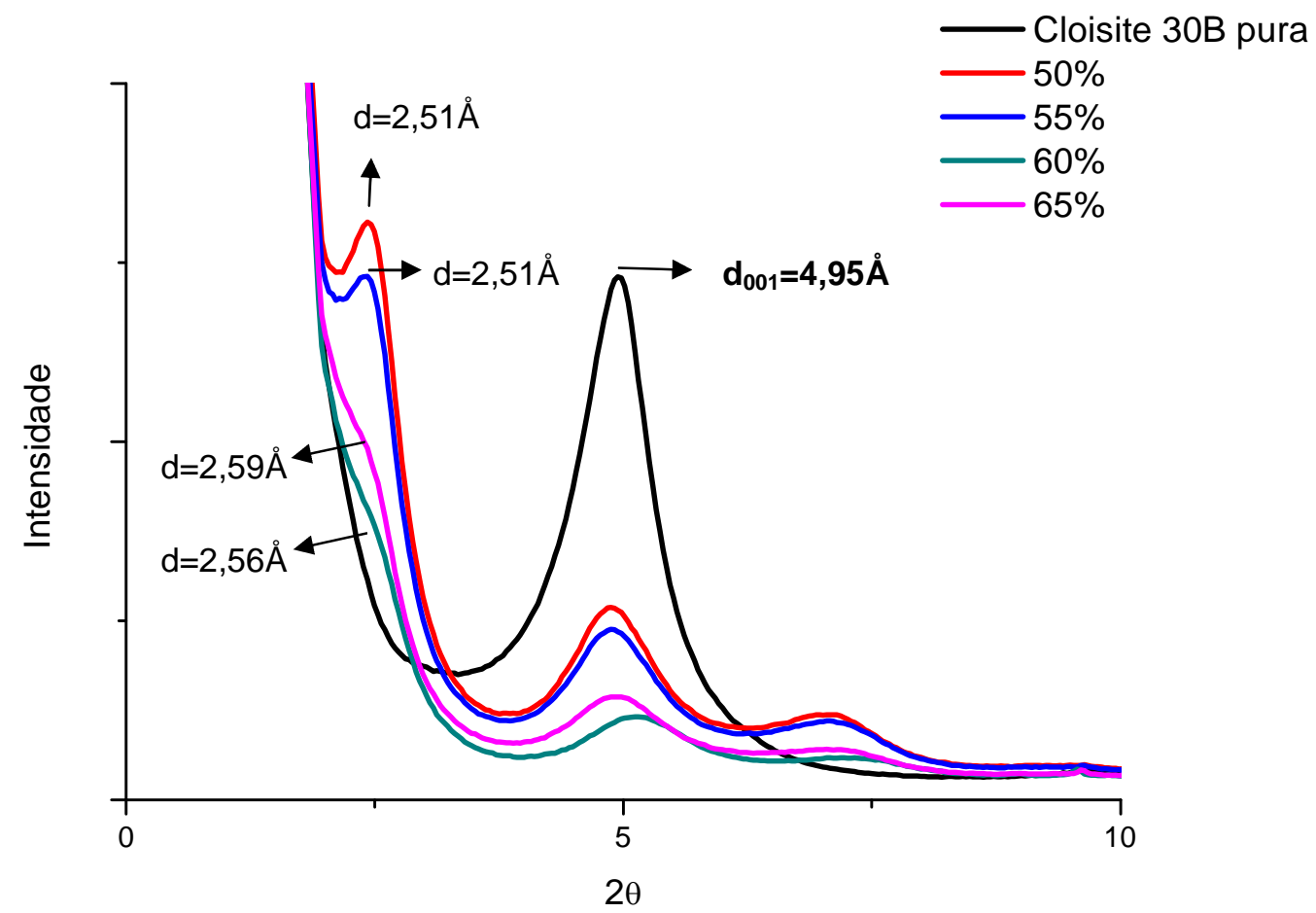

FIGURA 48: Difratograma dos Grupos de compósitos experimentais adicionados com a nanopartícula argilomineral Cloisite 30B ${ }^{\circledR}$. (Grupo 6(50B), 7(55B), 8 (60B), 9 (65B)).

Assim como observado anteriormente, os difratogramas dos Grupos de compósitos experimentais adicionados com a nanopartícula argilomineral Cloisite $30 \mathrm{~B}^{\circledR}$, apresentaram a intercalação da nanopartícula predominante em relação a matriz polimérica a base de BisGMA e TEGDMA. Foram realizados também os difratogramas de compósitos experimentais adicionados com quantidades inferiores da referida nanopartícula. As concentrações foram determinadas nas concentrações: 0,5\%,1\%,2\% e 10\% de carga inorgânica, conforme demonstra a Figura 48 . Dessa maneira, foi possível avaliar em quais concentrações ocorreram a esfoliação, a intercalação e a dispersão da nanopartícula, ou seja, o tipo de interação matriz polimérica/nanopartícula argilomineral Cloisite $30 \mathrm{~B}^{\circledR}$. 


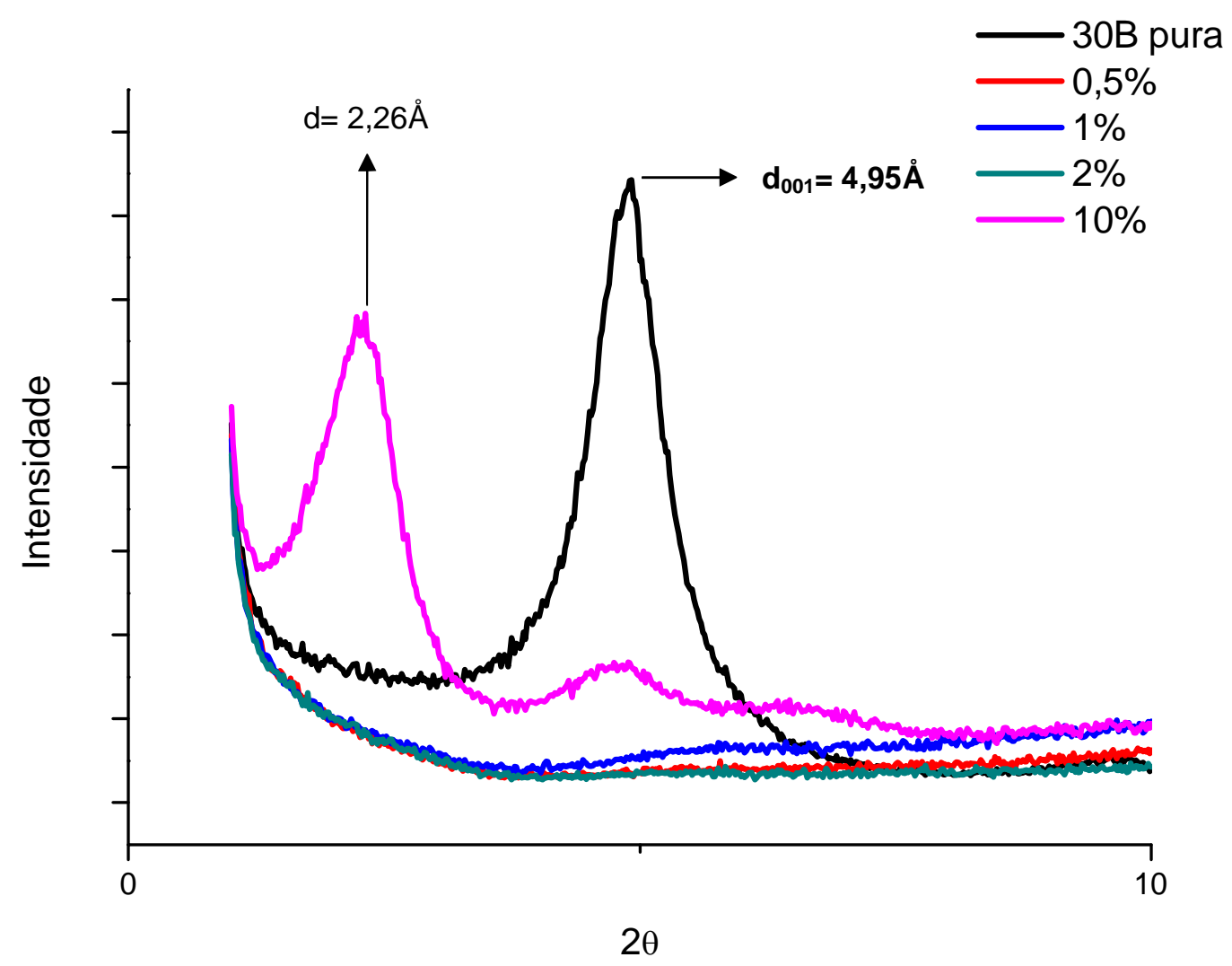

FIGURA 49: Difratograma dos grupos de compósitos experimentais de baixa concentração $(0,5 \%, 1 \%, 2 \%$ e $10 \%)$, adicionados com a nanopartícula argilomineral Cloisite $30 \mathrm{~B}^{\circledR}$.

$\mathrm{Na}$ tabela 11, pode-se observar a distância interlamelar "d" dos grupos de compósitos experimentais adicionados com a nanopartícula argilomineral Cloisite $30 \mathrm{~B}^{\circledR}$ e a comparação em relação ao " $\mathrm{d}_{001}$ ". 
TABELA 11:Distância interlamelar "d" dos Grupos de compósitos experimentais adicionados com a nanopartícula Cloisite $10 \mathrm{~A}^{\circledR}$ e a comparação ao " $\mathrm{d}_{001}$ ".

\begin{tabular}{lll}
\hline Grupo & "d" (Å) & $\neq$ "d $_{001}$ " $=4,95 \AA$ \\
\hline $6(50 \mathrm{~B})$ & 2,51 & 2,44 \\
$7(55 \mathrm{~B})$ & 2,51 & 2,44 \\
$8(60 \mathrm{~B})$ & 2,59 & 2,36 \\
$9(65 \mathrm{~B})$ & 2,56 & 2,39 \\
$0,5 \%$ & Esfoliado & - \\
$1 \%$ & Esfoliado & - \\
$2 \%$ & Esfoliado & - \\
$10 \%$ & 2,26 & 2,69 \\
\hline
\end{tabular}

De acordo com os resultados obtidos, nos Grupos de compósitos experimentais adicionados com as nanopartículas argilominerais Cloisite $10 \mathrm{~A}^{\circledR} \mathrm{e}$ Cloisite $30 \mathrm{~B}^{\circledR}$, observou-se que houve esfoliação nos compósitos experimentais adicionados com pequenas quantidades $(0,5 \% ; 1 \% ; 2 \%)$ para ambos os tipos de nanopartícula. Nos compósitos experimentais com 10\% de concentração de carga inorgânica, observou-se que houve esfoliação no compósito adicionado com Cloisite $10 \mathrm{~A}^{\circledR}$ e intercalação no compósito adicionado com Cloisite $30 \mathrm{~B}^{\circledR}$, (representado pelo "d"= 2,26). Nas concentrações de 15 e $20 \%$ observou-se a intercalação nos compósitos experimentais adicionados com a nanopartícula Cloisite $10 \mathrm{~A}^{\circledR}$.

Nos Grupos de compósitos experimentais com alta concentração de carga inorgânica, (Grupo 1(50A), 2 (55A), 3(60A), 4(65A), 5 (70A), 6 (50B), 7 (55B), 8 (60B) e 9 (65B)), observou-se que além da intercalação, houve dispersão das nanopartículas em relação a matriz polimérica.

Os Grupos de compósitos experimentais adicionados com a Sílica Aerosil ${ }^{\circledR}$ OX-50, não foram submetidos a análise de DRX pelo fato da sílica ser um material amorfo e não cristalino. 


\subsection{Micro Dureza -Knoop}

Os valores referentes a micro dureza dos compósitos experimentais, estão descritos na Tabela 12:

TABELA 12: Valores da micro dureza dos compósitos experimentais.

\begin{tabular}{lc}
\hline Grupo & Valor médio - Dureza Knoop \\
\hline Grupo $1(50 \mathrm{~A})$ & 12 \\
Grupo $2(55 \mathrm{~A})$ & 12 \\
Grupo $3(60 \mathrm{~A})$ & 13 \\
Grupo $4(65 \mathrm{~A})$ & 15 \\
Grupo $5(70 \mathrm{~A})$ & 18 \\
Grupo $6(50 \mathrm{~B})$ & 18 \\
Grupo $7(55 \mathrm{~B})$ & 19 \\
Grupo $8(60 \mathrm{~B})$ & 20 \\
Grupo 9 (65B) & $\mathbf{2 2}$ \\
Grupo $10(50 \mathrm{~S})$ & $\mathbf{1 1}$ \\
Grupo $11(60 \mathrm{~S})$ & $\mathbf{1 3}$ \\
Grupo $12(65 \mathrm{~S})$ & $\mathbf{1 5}$ \\
Grupo $13(70 \mathrm{~S})$ & $\mathbf{1 7}$ \\
\hline
\end{tabular}

Os tipos de carga inorgânica utilizadas nesse estudo, demonstraram influência na contração de polimerização e no comportamento mecânico dos compósitos experimentais e ambos estão relacionados ao tipo de interação entre matriz polimérica/carga inorgânica. A afinidade química entre a matriz polimérica a base de BisGMA/TEGDMA e a nanopartícula argilomineral Cloisite $30 \mathrm{~B}^{\circledR}$ de natureza polar (devido a superfície modificada pelo Metil "tallow" bis-2-hidroxetil amônio quaternário (MT2EtOH) durante o processo de organifilização), pode ter sido determinante, não só no melhor desempenho quanto a redução da contração de polimerização, como no desempenho mecânico. 
Os compósitos experimentais adicionados com a referida nanopartícula, apresentaram os valores de micro-dureza mais relevantes dentre todas as concentrações de carga inorgânica de todos os Grupos de compósitos experimentais analisados. Em relação aos compósitos experimentais adicionados com a nanopartícula argilomineral Cloisite $10 \mathrm{~A}^{\circledR}$ de natureza apolar, os valores de microdureza foram apenas um pouco elevados em relação aos compósitos adicionados com a Sílica OX-50.

A característica de reforço da argila é desempenhada quando são adicionadas ao polímero e deve-se às restrições da mobilidade das cadeias poliméricas. Devido a isso, a melhoria das propriedades dos nanocompósitos tais como resistência à tração e a flexão, compressão, fratura, impacto e do módulo de Young, têm sido relacionados com a dispersão da argila e as interações interfaciais polímero/argila (Barbosa, 2006; Kornmann, 1999). Os nanocompósitos se distinguem dos convencionais não pelo fato das partículas terem dimensões nanométricas, mas pelo fato de suas propriedades serem determinadas por essas dimensões. A argila simplesmente dispersa em uma matriz polimérica irá atuar como carga convencional, mas se a argila for esfoliada e intercalada na matriz polimérica durante o processamento, poderá atuar como um nanocompósito, promovendo características de reforço. Segundo alguns autores, a vantagem adicional é que essas propriedades já são obtidas com concentrações abaixo de $5 \%$ em massa (Yiu et al., 2006).

Em relação à sílica, o silano é necessário para promover uma adesão interfacial entre as partículas de preenchimento inorgânica e a matriz polimérica (Jones e .al. ,1996; Massouras et al., 2008; Garoushi et al., 2008; Yong Liu et al., 2009; Gonçalvez et al. 2010)

A dureza é uma das propriedades das resinas compostas mais investigadas desde que Ferracane (1985), observou uma correlação entre a Dureza Knoop e o grau de conversão dos compósitos. O autor obteve o grau de conversão pela metodologia FTIR de três compósitos sem carga inorgânica, em diferentes intervalos de tempo e com uma carga aplicada de $100 \mathrm{~g}$. A dureza apresentou uma forte correlação com o grau de conversão. 
Autores também observaram um forte correlação entre grau de conversão e microdureza Knoop, em um estudo que teve como objetivo avaliar a extensão mínima de cura necessária na base de uma restauração Classe II para suporte e selamento marginal, sob condições clínicas simuladas. Os autores utilizaram o compósito comercial Z250 (3M ESPE, St Paul, MN, EUA), e inseriram de forma incremental o compósito em cavidades de dentes molares naturais, preparados e expostos a diferentes densidades de luz de cura. As restaurações foram submetidas a 100 ciclos térmicos e 500 mil ciclos de fadiga de 18 a $85 \mathrm{~N}$, utilizando uma esfera de aço inoxidável. A integridade marginal foi avaliada visualmente e pelo teste de micro infiltração. O grau de conversão e a dureza Knoop, foram determinadas nas superfícies oclusais e gengivais. As propriedades mecânicas foram testadas em barras de resina composta. A densidade de energia teve um efeito significativo sobre as superfícies gengivais por análise visual, mas não por micro infiltração. A água teve um efeito significativo na dissolução da integridade marginal gengival em graus muito baixos de densidade de conversão e de energia $\left(4000 \mathrm{~mJ} / \mathrm{cm}^{2}\right)$, (Vanderwalle et al., 2004).

\section{$6.8 \mathrm{THI} / \mathrm{HD} / \mathrm{Cl}$}

Dentre as técnicas holográficas existentes, a Técnica de Interferometria Holográfica $(\mathrm{TIH})$, a Holografia Digital $(\mathrm{HD})$ e a Correlação de Imagem (Cl), foram selecionadas para mensurar o deslocamento molecular (ou deformação proveniente da contração de polimerização) durante a cura dos compósitos experimentais, por apresentarem inúmeras vantagens, dentre elas: excelente adaptação a esse estudo pela obtenção dos campos de deslocamentos de pequenas dimensões sem nenhum tipo de contato ou interferência; elevada resolução; processamento digital e fornecimento de dados pela fibra óptica que proporcionou compacidade, flexibilidade e versatilidade da técnica; informações de campo de toda a amostra em análise; obtenção precisa dos parâmetros das amostras, conforme exigido em uma técnica numérica.

As medições indiretas do comportamento dos compósitos experimentais durante a cura, foram obtidas a partir da mensuração do deslocamento molecular da 
superfície dos dentes artificiais e naturais utilizados como corpos de prova, dado que as medições realizadas diretamente na superfície dos compósitos experimentais, são inviáveis devido à descorrelação do "speckle".

\subsubsection{Dentes Artificiais}

O deslocamento total (ou contração de polimerização) sofrido pelos corpos de prova constituídos de dentes artificiais e compósitos experimentais de Cloisite $30 \mathrm{~B}^{\circledR}$ (Grupos 6 (50B), 7(55B) e 9(65B)) durante a cura, estão descritos na Tabela 13.

TABELA 13: Total do deslocamento pela metodologia $T H I / H D / C l$ dos corpos de prova de dentes artificiais adicionados com Closite $30 \mathrm{~B}^{\circledR}$. Grupos 6, 7 e 9.

\begin{tabular}{lc}
\hline Grupo & Total de deslocamento $(\boldsymbol{\mu m})$ \\
\hline Grupo 6 (50B) & 5,3 \\
Grupo 7 (55B) & 4,7 \\
Grupo 9 (65B) & 4,3 \\
\hline
\end{tabular}

Os resultados começaram a ser obtidos com o registro incial do "speckle", ou seja, antes do corpo de prova ser submetido a qualquer tipo de deformação. Após o registro inicial foi iniciado o processo de cura dos compósitos.

Logo após o início da ativação da luz, verificou-se que a fotopolimerização induziu a um aquecimento no dente artificial, o qual sofreu uma expansão térmica antes de sofrer a contração. O processo de cura durou 30 segundos, sendo registrado ainda valores após 30 segundos da desativação da luz, período que correspondeu ao arrefecimento e a reação de pós-cura dos compósitos experimentais. Os valores de deslocamento finais obtidos com os corpos de prova de dentes artificiais, englobaram os dois fenômenos: expansão (devido a dilatação térmica observada durante o processo de cura) e a contração de polimerização sofrida pelos corpos de prova. Dessa maneira os valores reais de contração dos compósitos experimentais foram alterados, invalidando a utilização de dentes artificiais de resina acrílica para esse tipo de análise. 
Os corpos de prova excitados pelo laser, foram filmados por uma câmera CCD e as franjas de correlação do speckle decorrentes do deslocamento, foram exibidas em tempo real no monitor. As Figuras 50, 51 e 52 demonstram as imagens captadas no início da fotopolimerização (a), onde foi possível observar as franjas que estão relacionadas ao deslocamento molecular (deformação) sofridos por cada corpo de prova testado. Em seguida, pode-se observar as imagens com uma escala de cores (b), onde as cores quentes indicam as regiões de maior deslocamento e as cores frias, as de menor deslocamento. Nas imagens captadas no término da análise (c), observa-se uma escala indicando os valores de deslocamento e por fim, pode-se observar um gráfico com os valores finais do deslocamento sofrido por cada grupo testado (d).

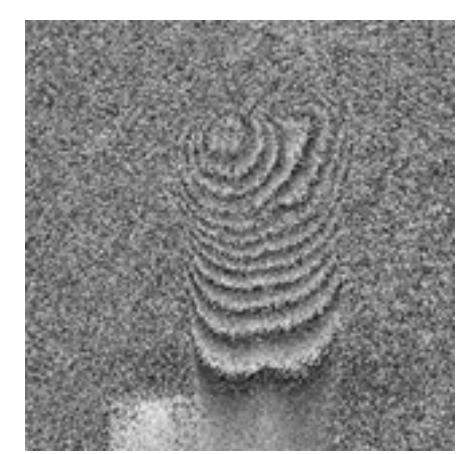

a)

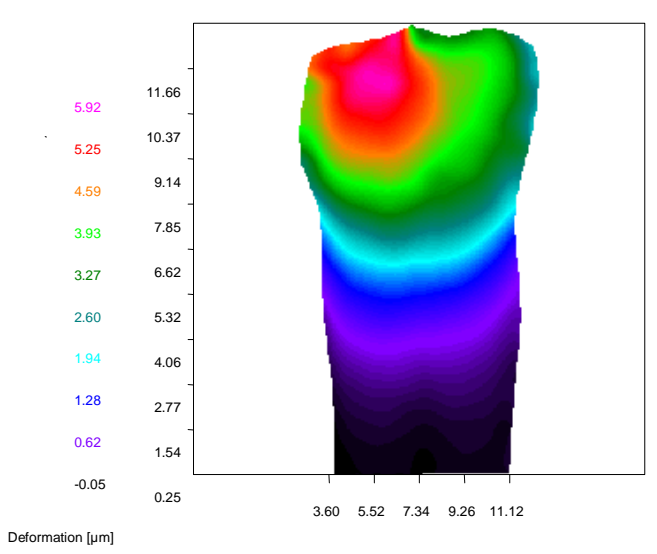

c)

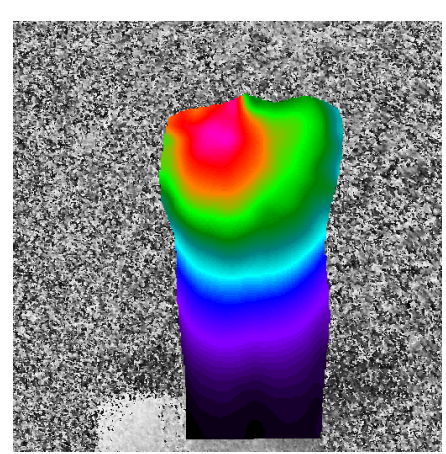

b)

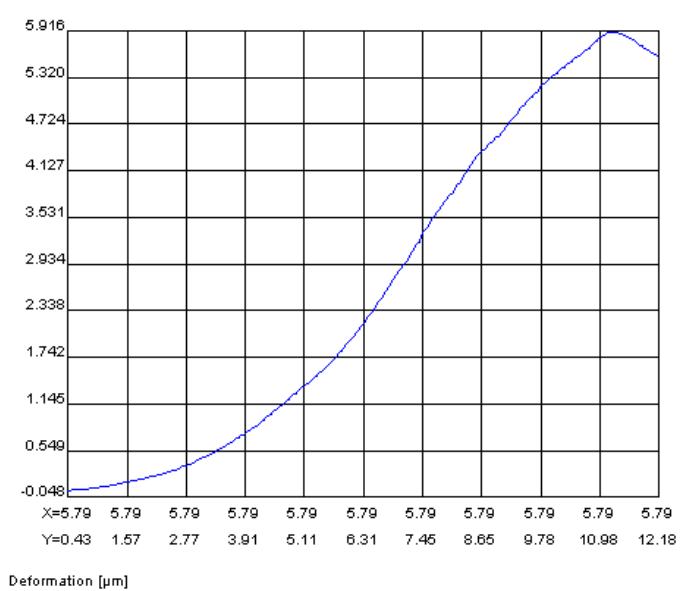

d)

FIGURA 50: (a) Imagem captada de uma amostra do Grupo 6 (50B), onde foi possível observar as "franjas" de deslocamento. (b) Escala de cores indicando as áreas de maior e menor deslocamento. (c) Imagem captada no término da análise, com uma escala indicando 
os valores finais de deslocamento. (d) Valores de deslocamento registrados na análise.

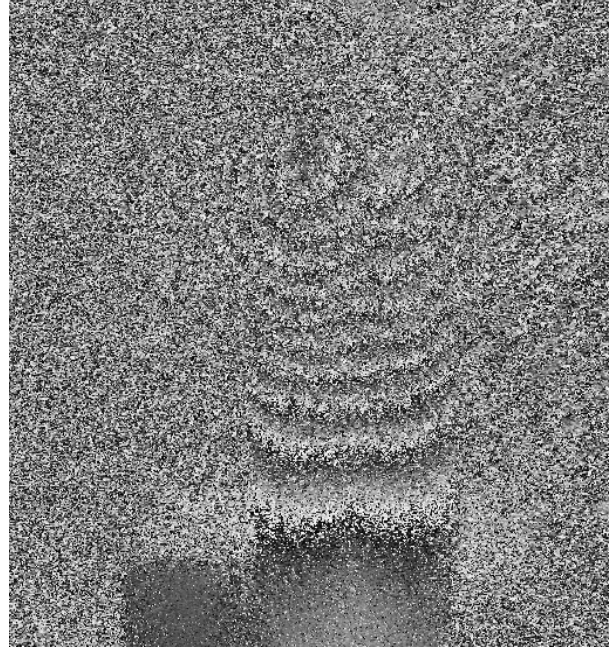

a)

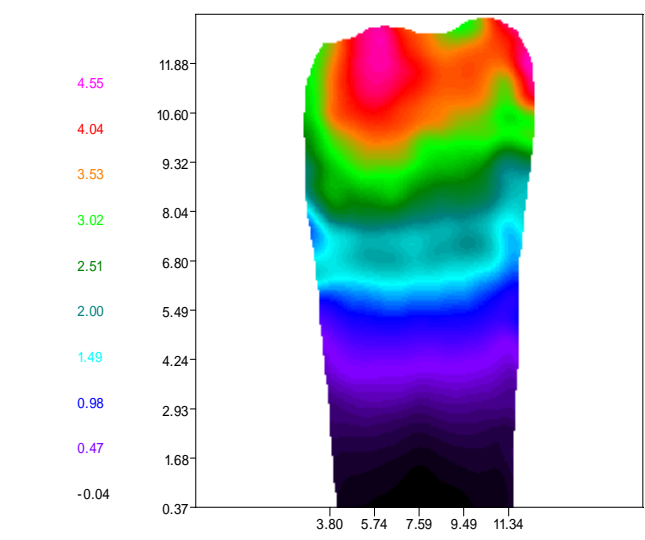

c)

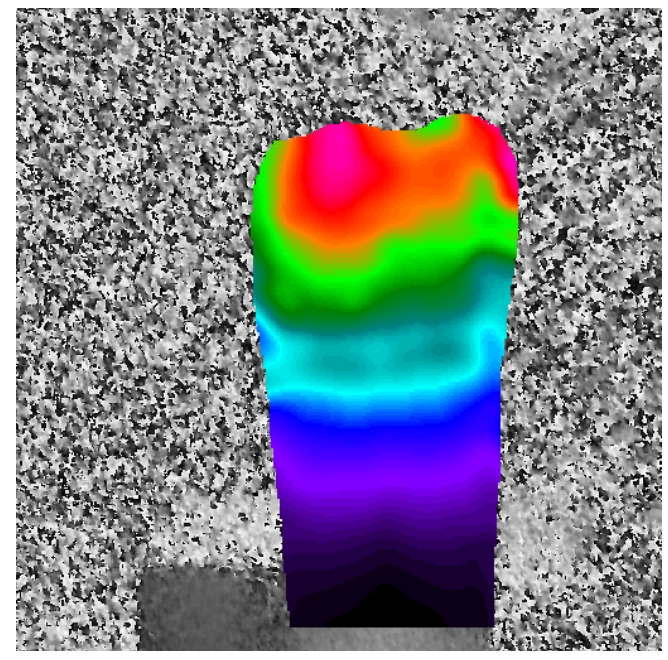

b)

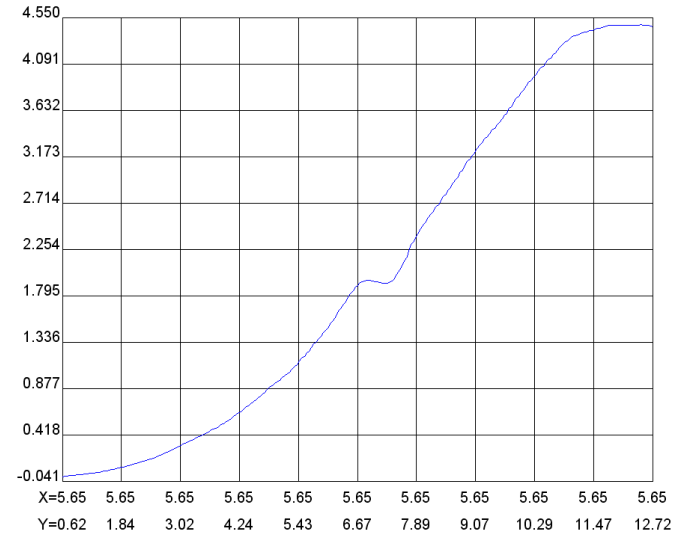

Deformation [Hm]

d)

FIGURA 51: Resultados de $\mathrm{THI} / \mathrm{HD} / \mathrm{Cl}$ em dentes artificiais: (a) Imagem captada de uma amostra do Grupo 7 (55B), onde foi possível observar as "franjas" de deslocamento. (b) Escala de cores indicando as áreas de maior e menor deslocamento. (c) Imagem captada no término da análise, com uma escala indicando os valores finais de deslocamento. (d) Valores de deslocamento registrados na análises. 


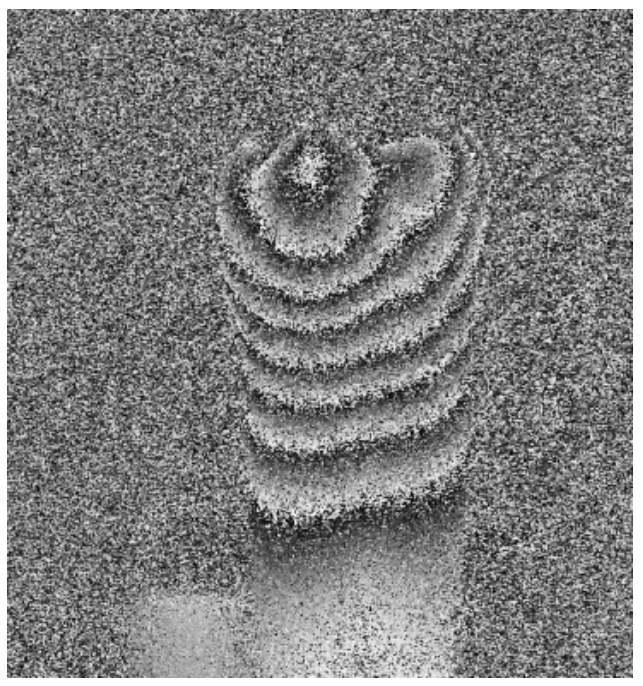

a)

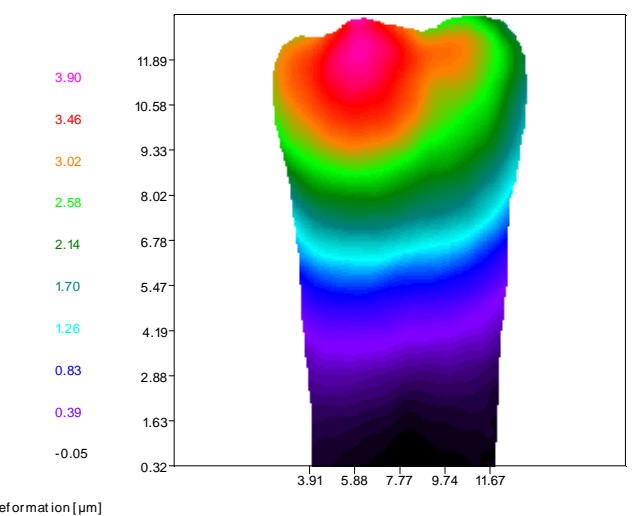

c) Deformation $[\mu \mathrm{m}]$

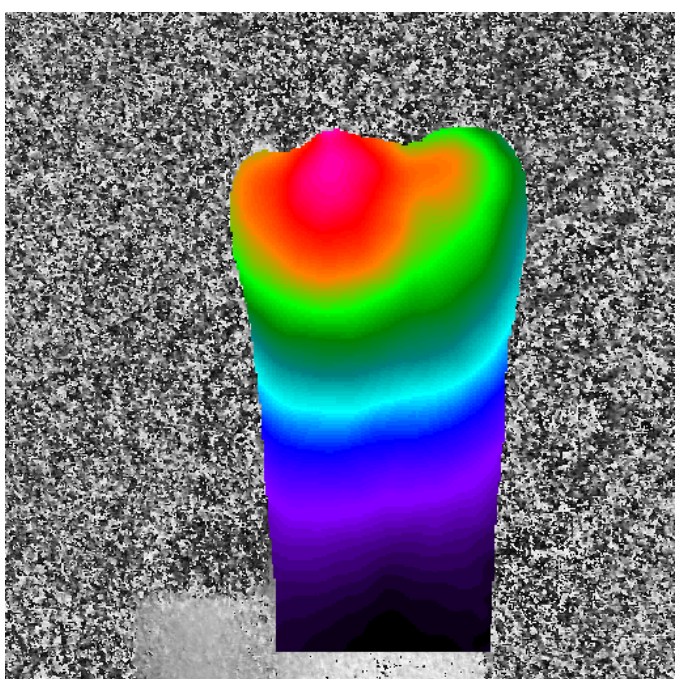

b)

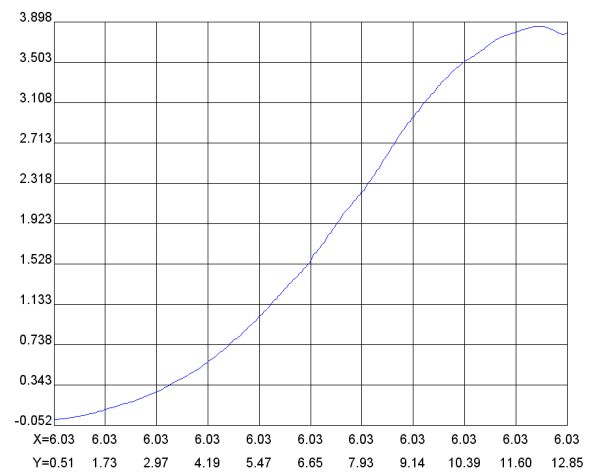

Deformation [um] d)

FIGURA 52: Resultados de $\mathrm{THI} / \mathrm{HD} / \mathrm{Cl}$ em dentes artificiais (a) Imagem captada de uma amostra do Grupo 9 (65B), onde foi possível observar as "franjas" de deslocamento. (b) Escala de cores indicando as áreas de maior e menor deslocamento. (c) Imagem captada no término da análise, com uma escala indicando os valores finais de deslocamento. (d) Valores de deslocamento registrados na análise.

De acordo com os resultados obtidos, foram realizadas análises de Termografia que mensurou a temperatura máxima atingida durante a fotopolimerização. Dessa maneira pode-se justificar a expansão térmica sofrida pelos dentes artificiais e a invalidação desse tipo de corpo de prova para a realização da metodologia $\mathrm{THI} / \mathrm{HD} / \mathrm{Cl}$. 


\subsubsection{Dentes Naturais}

Para a realização dessa metodologia, foram selecionados dentes naturais referentes aos primeiros pré-molares inferiores. Após o preparo cavitário e a fixação dos dentes naturais, foi iniciada a análise.

Os resultados começaram a ser obtidos com o registro inicial do "speckle", ou seja, antes do corpo de prova sofrer qualquer tipo de deformação. Posteriormente iniciou-se o processo de cura pela ativação da luz. O processo de cura durou 30 segundos, sendo registrados mais 30 segundos após a desativação da luz, período que correspondeu à reação de pós-cura dos compósitos experimentais. A análise foi encerrada pela obteção do "speckle" final, ou seja, após o corpo de prova sofrer as deformações decorrentes da contração de polimerização. Não foi observado em nenhum dos grupos testados o fenômeno de expanção ou dilatação térmica, somente o deslocamento correspondente à contração de polimerização.

Durante a análise, os corpos de prova foram filmados por uma câmera CCD e as franjas de correlação do "speckle" decorrentes do deslocamento, foram exibidas em tempo real no monitor.

As Figuras 53, 54, 55, 56 e 57 demonstram as imagens captadas no início da fotopolimerização (a), onde foi possível observar as franjas que estão relacionadas ao deslocamento molecular (deformação) sofridos por cada corpo de prova testado. Em seguida, pode-se observar as imagens com uma escala de cores (b), onde as cores quentes indicam as regiões de maior deslocamento e as cores frias, as de menor deslocamento. Nas imagens captadas no término da análise (c), observa-se uma escala indicando os valores de deslocamento. 


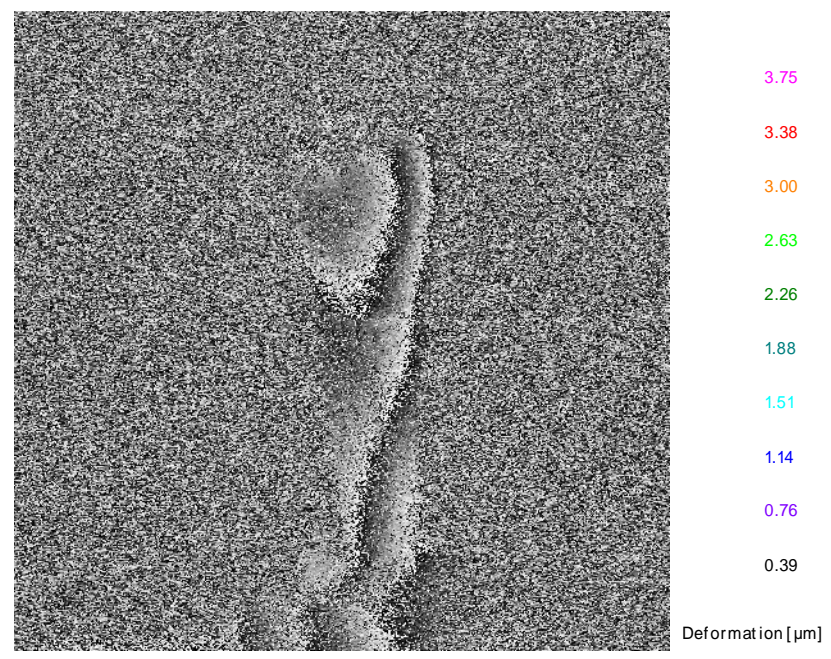

a)

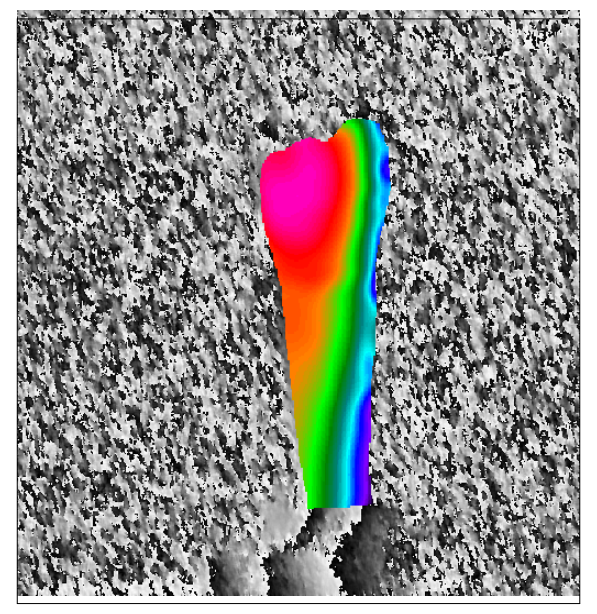

b)

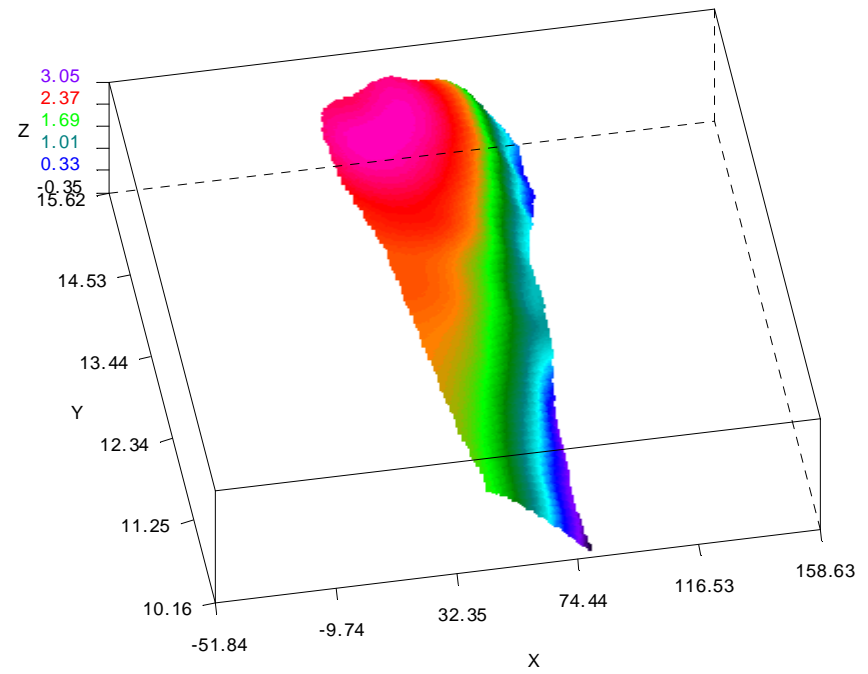

Deformation $[\mu \mathrm{m}]$

c)

FIGURA 53: Resultados de THI/HD/Cl em dentes naturais: (a) Imagem captada de uma amostra do Grupo 1 (50A), onde foi possível observar as "franjas" de deslocamento. (b) Escala de cores indicando as áreas de maior e menor deslocamento. (c) Imagem captada no término da análise com uma escala indicando os valores finais de deslocamento. 


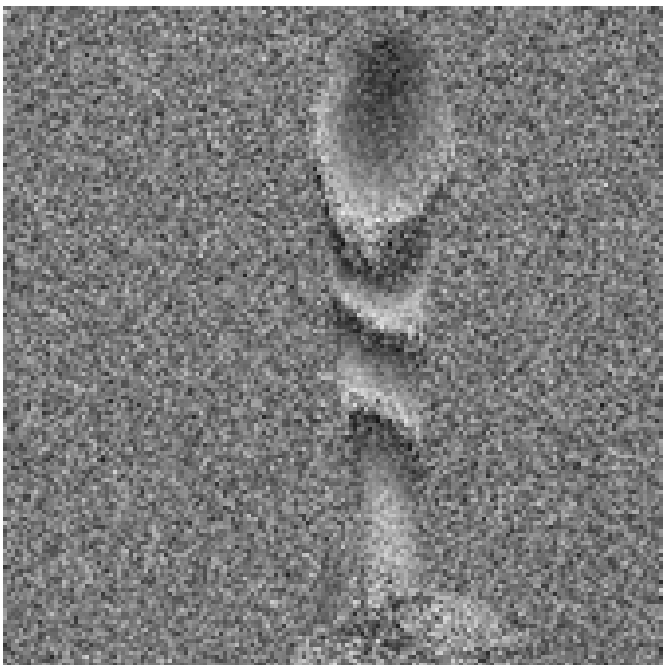

a)

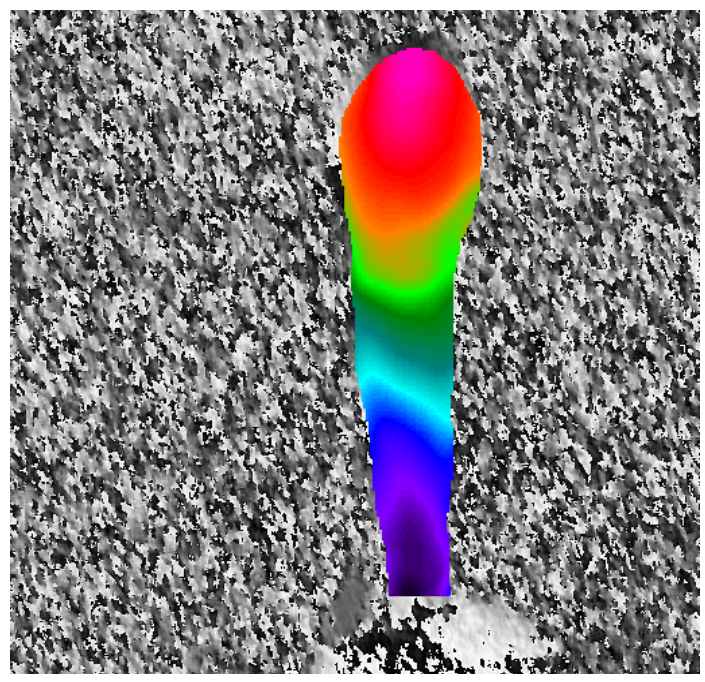

b)

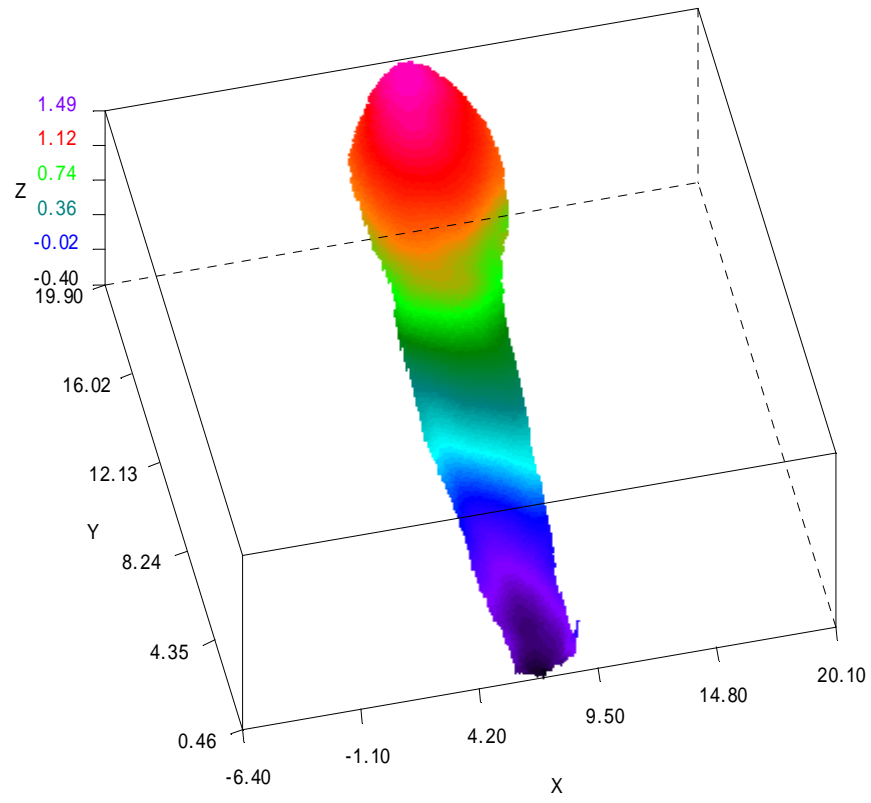

Deformation $[\mu \mathrm{m}]$

c)

FIGURA 54: Resultados de THI/HD/Cl em dentes naturais: (a) Imagem captada de uma amostra do Grupo 3 (60A), onde foi possível observar as "franjas" de deslocamento. (b) Escala de cores indicando as áreas de maior e menor deslocamento. (c) Imagem captada no término da análise, com uma escala indicando os valores finais de deslocamento. 


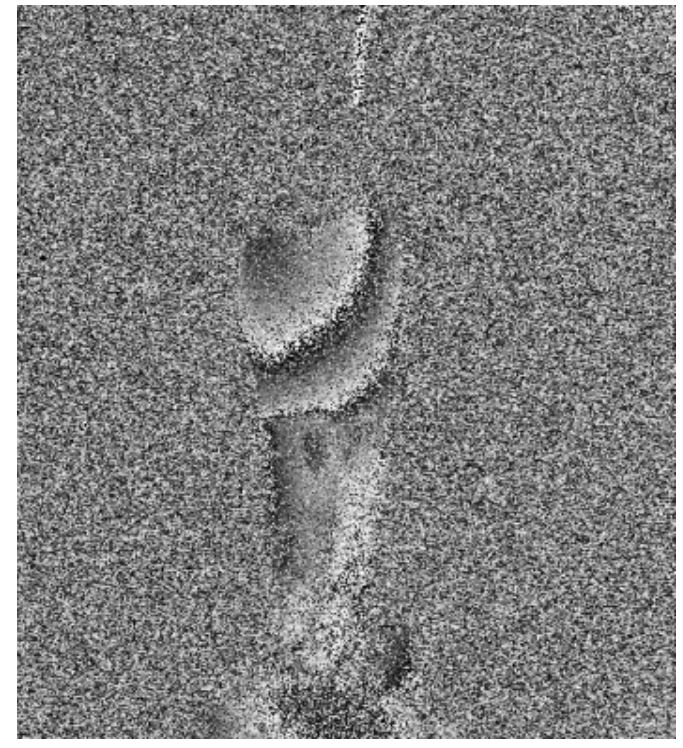

a)

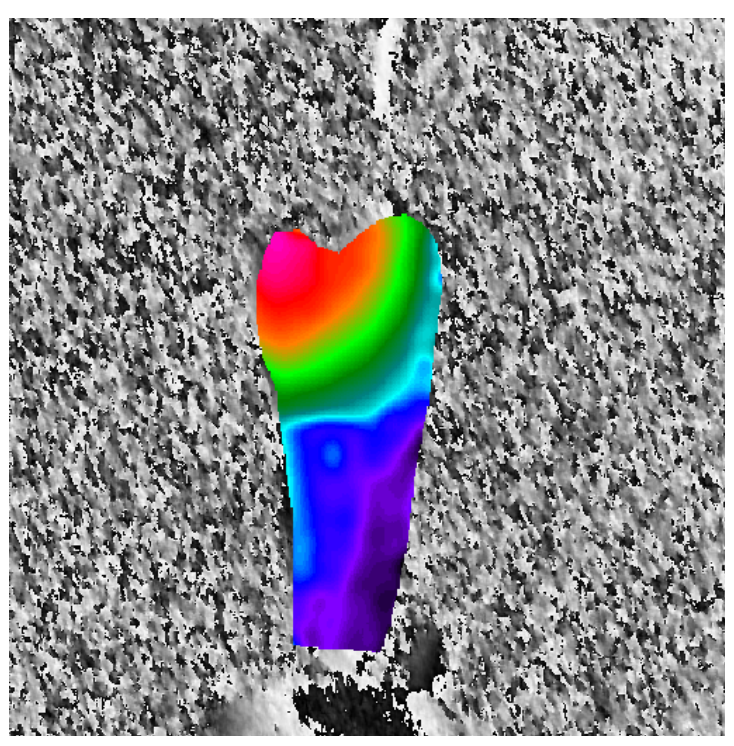

b)

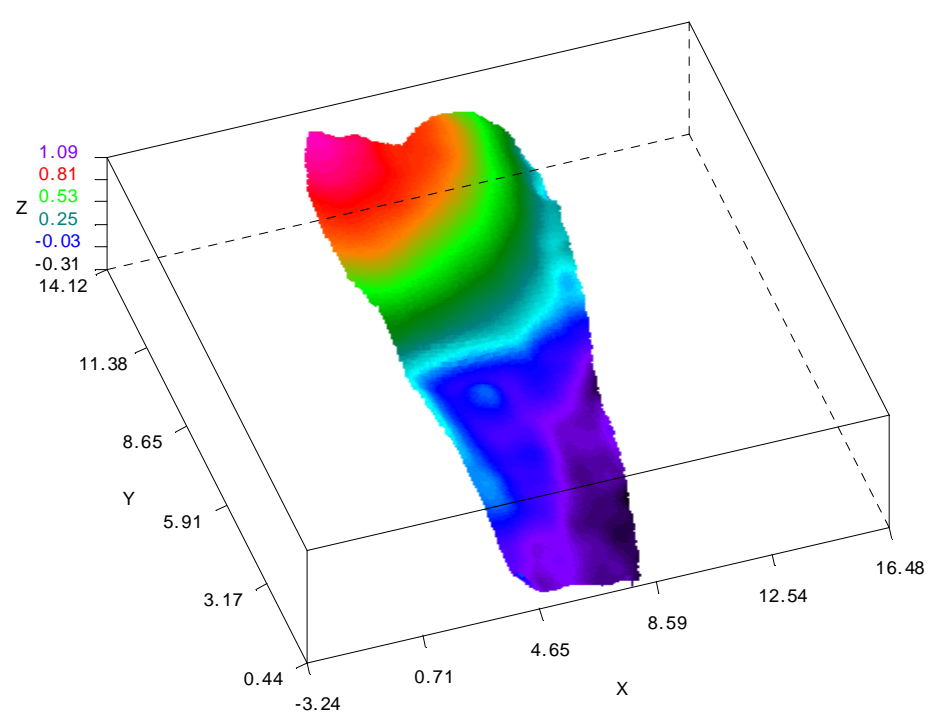

Deformation $[\mu \mathrm{m}]$

c)

FIGURA 55: Resultados de THI/HD/Cl em dentes naturais: (a) Imagem captada de uma amostra do Grupo 5 (70A), onde foi possível observar as "franjas" de deslocamento. (b) Escala de cores indicando as áreas de maior e menor deslocamento. (c) Imagem captada no término da análise, com uma escala indicando os valores finais de deslocamento. 


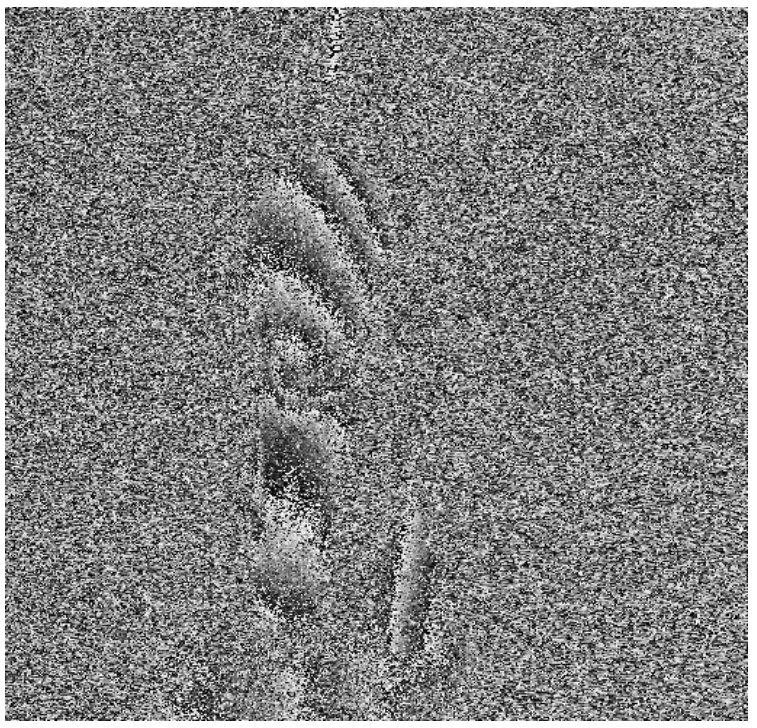

a)

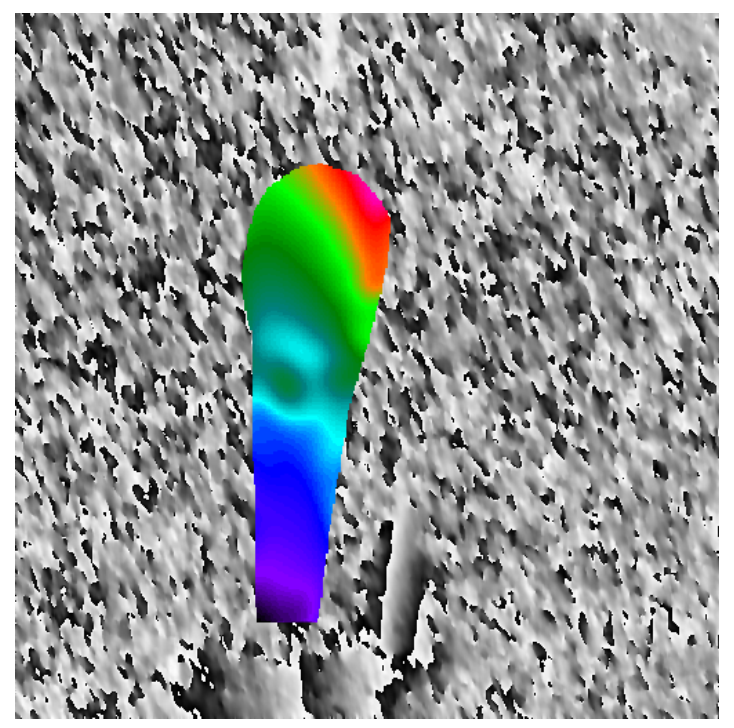

b)

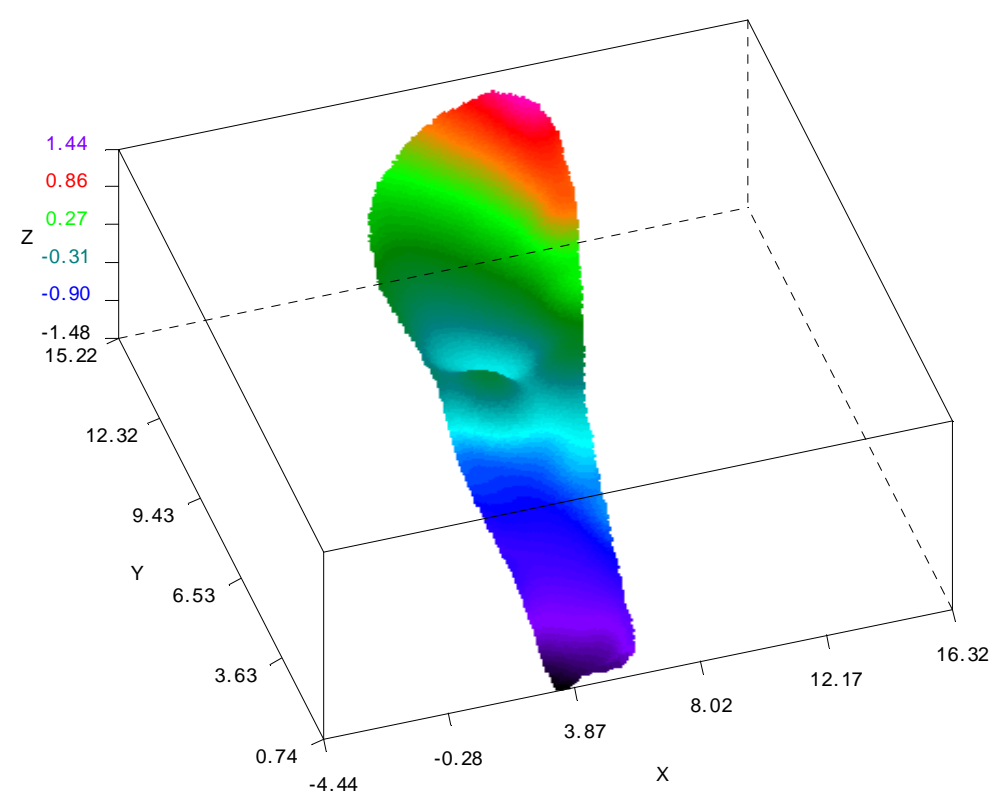

Deformation $[\mu \mathrm{m}]$

c)

FIGURA 56: Resultados de THI/HD/Cl em dentes naturais: (a) Imagem captada de uma amostra do Grupo 7 (55B), onde foi possível observar as "franjas" de deslocamento. (b) Escala de cores indicando as áreas de maior e menor deslocamento. (c) Imagem captada no término da análise, com uma escala indicando os valores finais de deslocamento. 


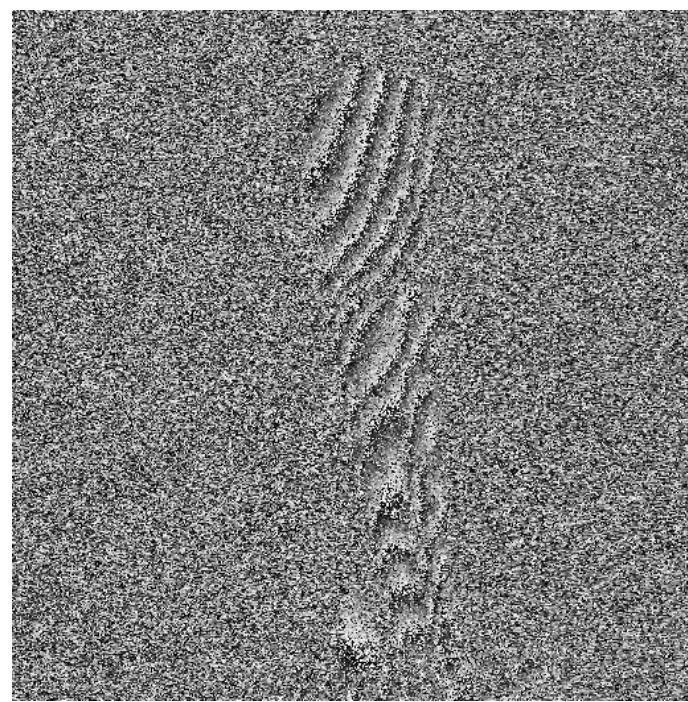

a)

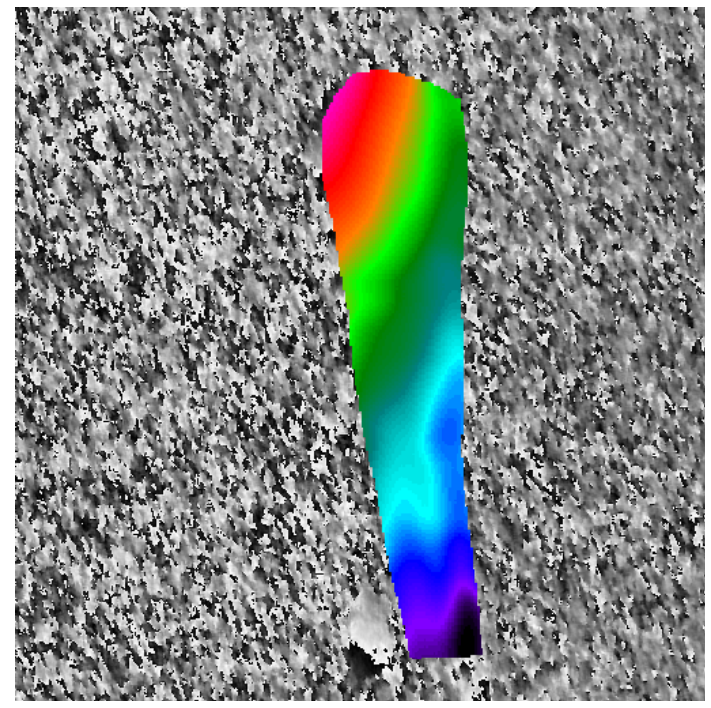

b)

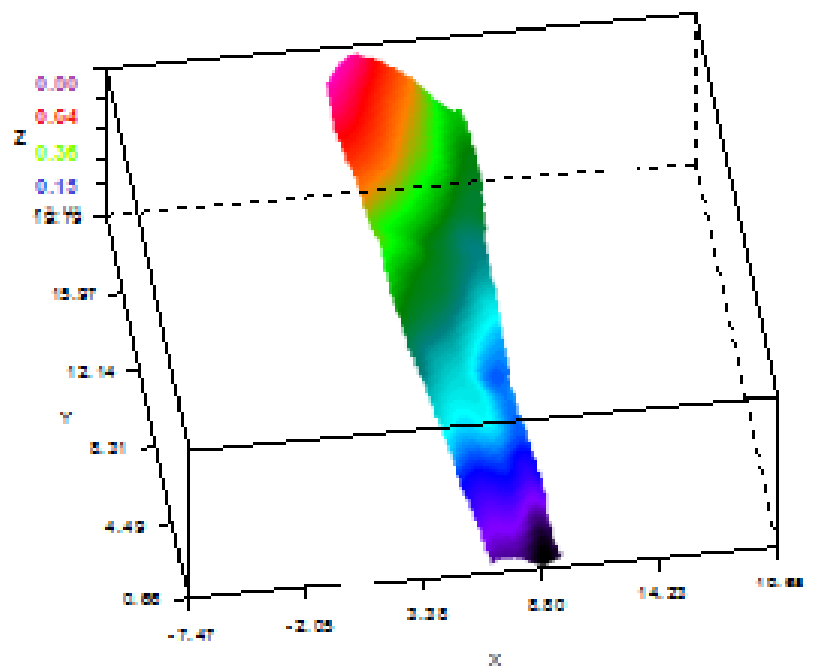

Def ormat ion[ $\mu \mathrm{m}]$

c)

FIGURA 57: Resultados de THI/HD/Cl em dentes naturais: (a) Imagem captada de uma amostra do Grupo 9 (65B), onde foi possível observar as "franjas" de deslocamento. (b) Escala de cores indicando as áreas de maior e menor deslocamento. (c) Imagem captada no término da análise, com uma escala indicando os valores finais de deslocamento. 
O deslocamento total (ou contração de polimerização) sofrido pelos corpos de prova constituídos de dentes naturais e compósitos experimentais dos Grupos 1(50A), 3(60A), 5(70A), 7(60B) e 9(65B), estão descritos na Tabela 14.

TABELA 14: Total do deslocamento pela metodologia $\mathrm{THI} / \mathrm{HD} / \mathrm{Cl}$ com corpos de prova de dentes naturais. Grupos 1(50A), 3(60A), 5(70A), 7(60B) e 9(65B).

\begin{tabular}{lc}
\hline Grupo & Total de deslocamento $(\mu \mathrm{m})$ \\
\hline Grupo 1(50A) & $\mathbf{3 , 7}$ \\
Grupo 3(60A) & $\mathbf{1 , 4}$ \\
Grupo 5(70A) & 0,9 \\
Grupo 7(55B) & $\mathbf{1 , 4}$ \\
Grupo 9(65B) & $\mathbf{0 , 8}$ \\
\hline
\end{tabular}

O processo de contração de polimerização de compósitos odontológicos, foi avaliado por autores por meio das técnicas ópticas ESPI, $\mathrm{HD}$ e $\mathrm{Cl}$ e posteriormente, foi realizado um estudo comparativo utilizando diferentes materiais compósitos, bem como um estudo numérico com simulação por elementos finitos. Nesse estudo, foram utilizados dentes humanos correspondentes aos primeiros pré-molares inferiores, primeiros molares inferiores e dentes artificiais de resina acrílica, correspondentes aos primeiros pré-molares inferiores. Foram realizados preparos cavitários do tipo Classe I e do tipo Classe II (MO) de Black, tendo uma profundidade de 2,5mm. A forma 3D dos dentes e dos preparos cavitários, foram obtidas por meio de um sistema de levantamento de forma (CEREC) e foram utilizadas na simulação por elementos finitos com código ANSYS. Os corpos de provas foram colocados em um dispositivo de HD e ESPI para a obtenção dos campos de deslocamentos e em seguida foram fotopolimerizados para que houvesse a indução da contração dos compósitos resinosos. Os dados experimentais obtidos, foram processados para a obtenção das deformações. As medições indiretas do comportamento dos compósitos foram obtidos a partir da deformação do dente, dado que a mensuração realizada diretamente na superfície dos compósitos, não seja possível pela 
modificação da rugosidade do material e devido a descorrelação do speckle. Os resultados obtidos demonstraram grande potencial dessas técnicas na mensuração indireta da contração de polimerização de compósitos odontológicos e ainda, segundo os autores, a técnica numérica/experimental deverá no futuro ser comparada com outras técnicas, como por exemplo, a dilatometria convencional ou interferométrica (Monteiro et al., 2011).

\subsection{Termografia}

\subsubsection{Dentes Artificiais}

Devido ao fenômeno de expansão observado na metodologia $\mathrm{TIH} / \mathrm{HD} / \mathrm{Cl}$ na mensuração da deformação dos corpos de prova de dentes artificiais, as análises foram repetidas sobre as mesmas condições para que fosse mensurada a temperatura durante a polimerização dos compósitos experimentais, pois esse fenômeno ocorria somente enquanto o fotopolimerizador estava acionado. A hipótese da dilatação térmica era evidente, dessa forma os corpos de prova foram submetidos ao teste da Termografia para que se pudesse observar as temperaturas exatas de todo o processo de cura.

$\mathrm{Na}$ Figura 58, pode-se observar o comportamento térmico dos corpos de prova de dentes artificiais preenchidos com compósitos experimentais dos Grupos 1(50A), 3(60A), 5(70A), 6(50B), 7(60B) e 9(65B). 


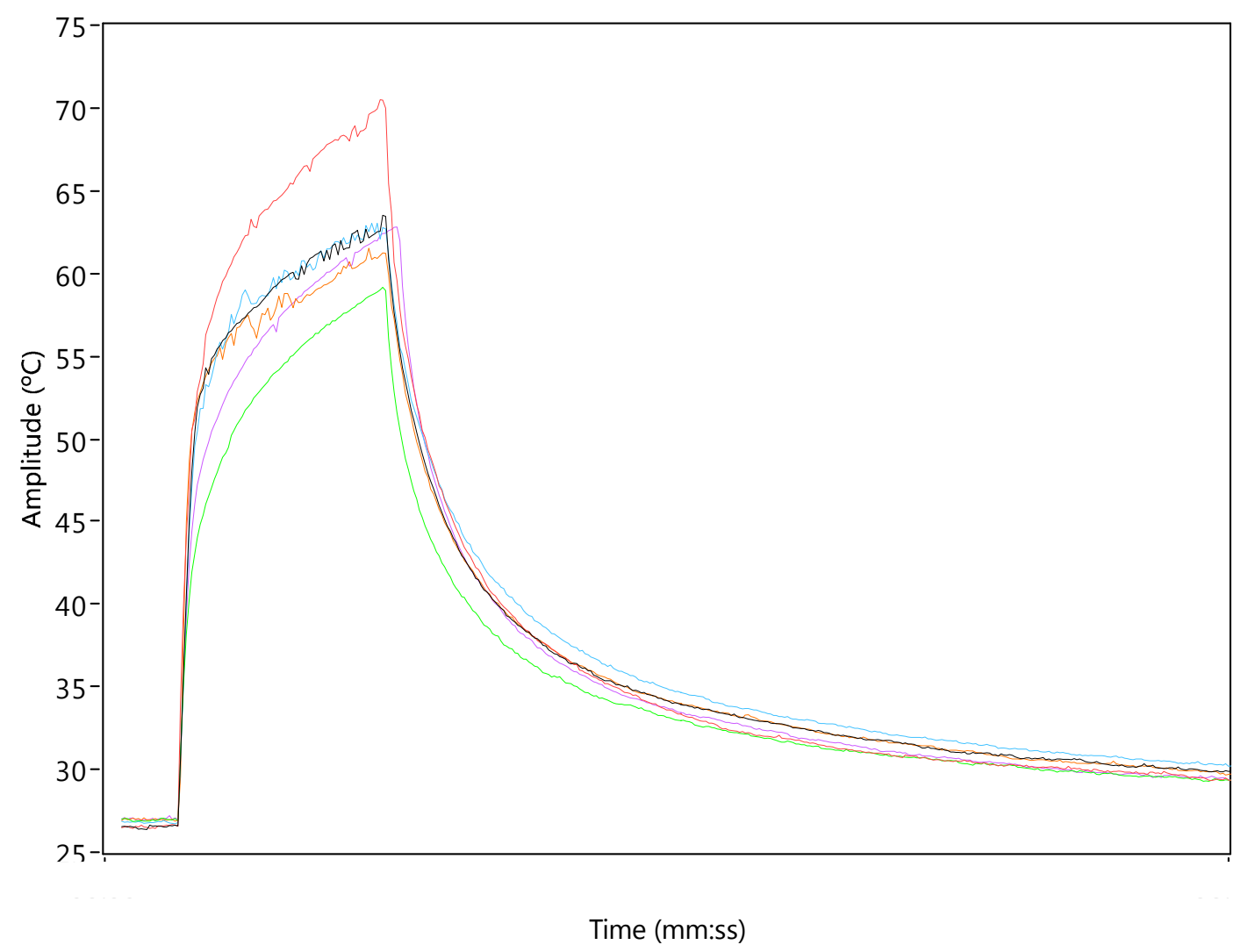

FIGURA 58: Resultados da Termografia dos Grupos 1(50A), 3(60A), 5(70A), 6(50B), 7(60B) e $9(65 B)$.

A ponta do fotopolimerizador foi posicionada e fixada em um suporte a $1 \mathrm{~mm}$ de distância da superfície oclusal do corpo de prova. Durante os 30 segundos iniciais, os corpos de prova não foram submetidos a nenhum tipo de estímulo, permanecendo em temperatura ambiente, por volta dos $26^{\circ} \mathrm{C}$. Após esse período, o fotopolimerizador foi acionado e foi observado um aumento expressivo da temperatura nos 10 primeiros segundos da fotopolimerização, permanecendo em elevação e atingindo a temperatura máxima aos 90 segundos de fotopolimerização, tempo em que a luz esteve ativada. Após a desativação da luz, foi observada uma queda expressiva da temperatura, que permaneceu diminuindo progressivamente até o fim da análise. O tempo total de cada análise foi de 2 minutos. Todos os corpos de prova de dentes artificiais apresentaram o mesmo comportamento térmico.

$\mathrm{Na}$ Tabela 15, pode-se observar a temperatura máxima atingida dos Grupos 1(50A), 3(60A), 5(70A), 6(50B), 7(60B) e 9(65B). 
TABELA 15: Resultados da Termografia do Grupos 1(50A), 3(60A), 5(70A), 6(50B), 7(60B) e $9(65 B)$.

Grupo Temperatura máxima atingida $\left({ }^{\circ} \mathrm{C}\right)$

Grupo $1(50 \mathrm{~A})$

Grupo $3(60 \mathrm{~A})$

Grupo $5(70 \mathrm{~A})$

Grupo 6 (50B)

Grupo 7 (55B)

Grupo 9 (65B)
64

71

59

63

61

63

Por meio da Termografia, justificaram-se os grandes deslocamentos observados na metodologia ESPI/HD/Cl para os corpos de prova de dentes artificiais. A expansão térmica sofrida por esse tipo de corpo de prova, invalidou os resultados finais do deslocamento molecular (contração de polimerização). Provavelmente a composição sintética desses dentes foi sujeita a reações químicas exotérmicas, liberando calor.

\subsubsection{Dentes Naturais}

Os corpos de prova de dentes naturais também foram submetidos a Termografia, com o objetivo de se observar se os mesmos sofreram algum tipo de alteração térmica. As análises foram realizadas nas mesmas condições dos corpos de prova de dentes artificiais. A ponta do fotopolimerizador foi posicionada e fixada em um suporte a $1 \mathrm{~mm}$ de distância da superfície oclusal do corpo de prova. Durante os 30 segundos iniciais, os corpos de prova não foram submetidos a nenhum tipo de estímulo, permanecendo na temperatura ambiente de $26^{\circ} \mathrm{C}$. Após esse período, $\mathrm{o}$ fotopolimerizador foi acionado e foi observado um aumento expressivo da temperatura nos 10 primeiros segundos do processo de cura, permanecendo em elevação e atingindo a temperatura máxima após 90 segundos, tempo em que a luz 
estava ativada. Após a desativação da luz foi observada uma queda expressiva da temperatura, que permaneceu diminuindo progressivamente até o fim da análise. $O$ tempo total de cada análise foi de 2 minutos.

O comportamento dos corpos de prova de dentes naturais preenchidos com compósitos experimentais dos Grupos 3(60A), 5(70A), 6(50B), 7(60B) e 9(65B), estão descritos na Figura 59.

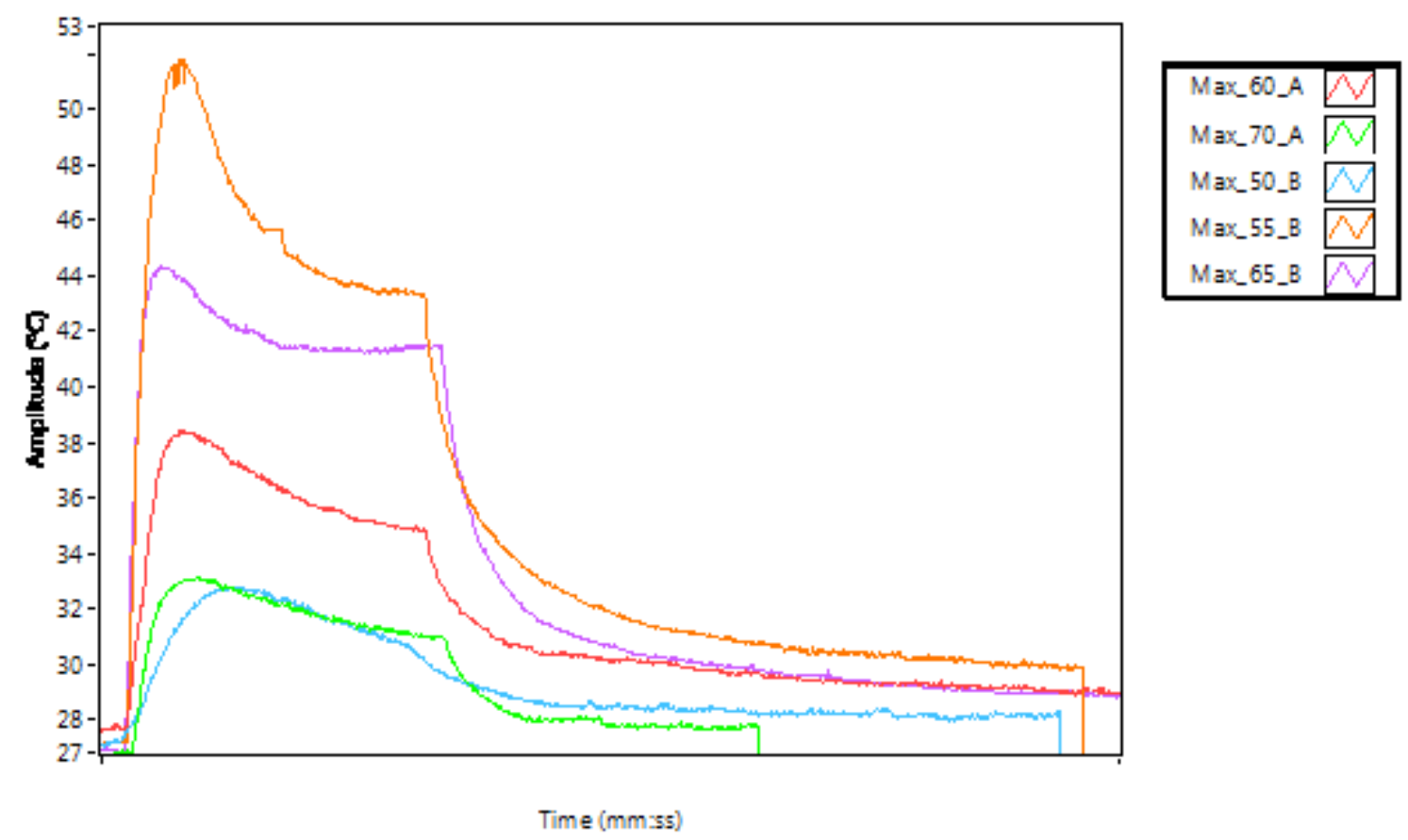

FIGURA 59: Resultado da Termografia realizada em dentes naturais. Grupos 3(60A), $5(70 \mathrm{~A}), 6(50 \mathrm{~B}), 7(60 \mathrm{~B})$ e $9(65 \mathrm{~B})$.

$\mathrm{Na}$ Tabela 16, pode-se observar a temperatura máxima atingida durante 0 processo de cura dos Grupos 1(50A), 3(60A), 5(70A), 6(50B), 7(60B) e 9(65B). 
TABELA 16: Resultados da Termografia com corpos de prova de dentes de naturais. Grupos 1(50A), 3(60A), 5(70A), 6(50B), 7(60B) e 9(65B).

\begin{tabular}{lc}
\hline Grupo & Temperatura máxima atingida $\left({ }^{\circ} \mathrm{C}\right)$ \\
\hline Grupo 1(50A) & 50 \\
Grupo 3(60A) & 38 \\
Grupo 5(70A) & 33 \\
Grupo 6(50B) & 54 \\
Grupo 7(55B) & 32 \\
Grupo 9(65B) & 44 \\
\hline
\end{tabular}

De acordo com os resultados obtidos, observou-se que os dentes naturais utilizados como corpo de prova pela metodologia $\mathrm{ESPI} / \mathrm{HD} / \mathrm{Cl}$, não sofreram alterações térmicas como os corpos de prova de dentes artificiais, o que justificou sua utilização e a validação de uma Técnica Holográfica para mensurar o deslocamento molecular durante a contração de polimerização.

Os resultados de temperatura máxima atingida demonstraram uma tendência de diminuição de temperatura com o aumento da quantidade de nanopartícula argilomineral na formulação empregada.

$\mathrm{Na}$ Figura 60, observam-se imagens extraídas dos vídeos da análise da Termografia do Grupo 1, sendo (A) a análise realizada com um corpo de prova de dente artificial e (B), com um corpo de prova de dente natural. Nos primeiros 30 segundos o fotopolimerizador não foi acionado e dessa forma não se observaram alterações térmicas. Com 35 segundos observaram-se as primeiras alterações térmicas devido a elevação da temperatura, com 90 segundos observou-se a máxima alteração térmica atingida e com 120 segundos, a arrefecimento da temperatura 30 segundos depois da desativação da luz. 

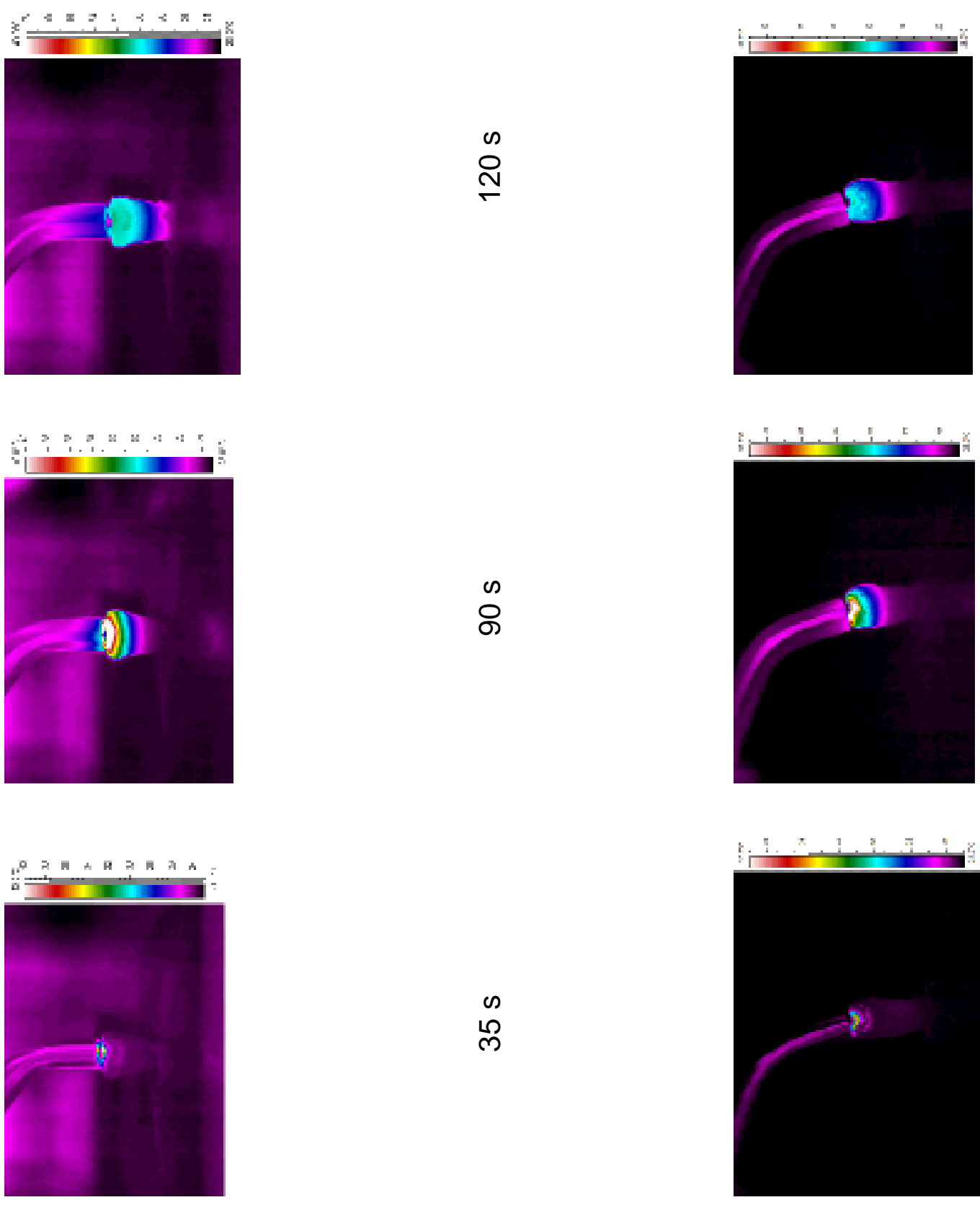

n
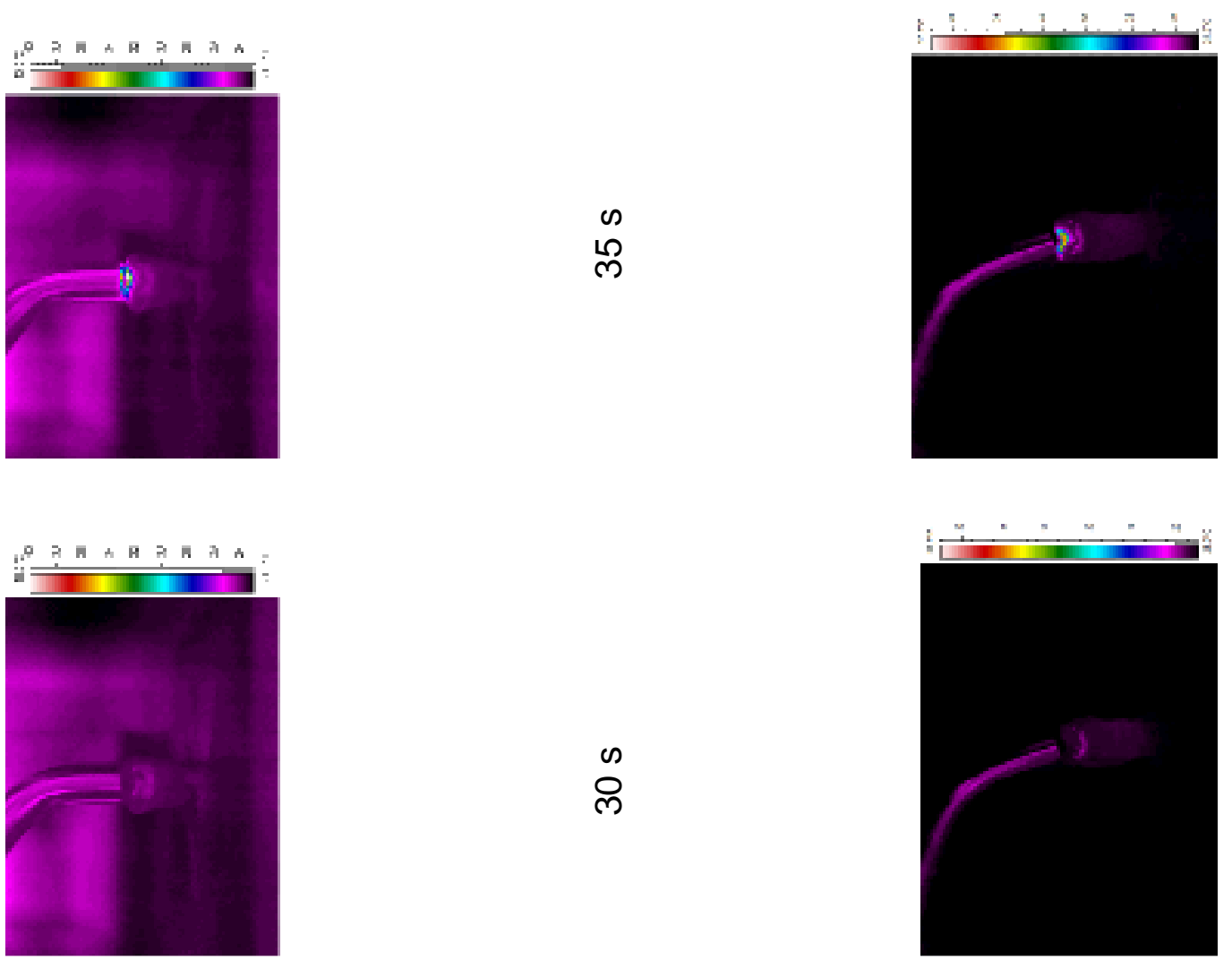

a)

n

b)

FIGURA 60: Imagens da análise de Termografia do Grupo 1. (a) Dente artificial e (b) natural. 


\section{CONCLUSÃO}

As nanopartículas argilominerais possuem uma característica de empilhamento ou de sobreposição quando inseridas em uma matriz polimérica a base de BisGMA/TEGMA. Esse comportamento sugere que houve uma organização lamelar pela formação de pilhas, de lamelas sobrepostas e espaços interlamelares.

As análises térmicas TMA e DSC provaram ser efetivas na caracterização e na mensuração da contração de polimerização dos compósitos experimentais analisados neste trabalho.

Pelas metodologias TMA e micro dureza Knoop concluiu-se que os Grupos adicionados com nanopartículas argilominerais obtiveram desempenho superior nas análises de contração de polimerização e micro dureza, em relação aos Grupos adicionados com a Sílica Aerosil OX-50 e que a afinidade química da nanopartícula argilomineral Cloisite $30 \mathrm{~B}^{\circledR}$ foi determinante para a obtenção dos resultados mais expressivos em relação à nanopartícula Cloisite $10 \mathrm{~A}^{\circledR}$, devido a sua natureza polar.

Pelas análises do TGA pode-se concluir que a afinidade química dos compósitos experimentais adicionados com a nanopartícula Cloisite $30 \mathrm{~B}^{\circledR}$ é a razão da presença de maior quantidade de resíduo após a degradação térmica, em relação aos compósitos experimentais adicionados com a nanopartícula Cloisite $10 A^{\circledast}$. Devido a essa característica considera-se de maior estabilidade o compósito com afinidade química relativamente superior .

A metodologia DRX provou que houve a formação de nanocompósitos por esfoliação nos Grupos de compósitos experimentais com as concentrações de 0,5; 1 e $2 \%$ de nanopartícula argilomineral Cloisite $10 \mathrm{~A}^{\circledR}$ e dos Grupos com as concentrações de 0,5;1; 2 e 10\% de nanopartícula Cloisite $30 \mathrm{~B}^{\circledR}$. Evidências da intercalação ocorreu nos compósitos com as concentrações 15 e $20 \%$ de nanopartícula Cloisite $10 \mathrm{~A}^{\circledR}$, e do compósito com $10 \%$ de nanopartícula Cloisite $30 \mathrm{~B}^{\circledR}$. Nos Grupos ocorreu também a intercalação das argilas em relação a matriz polimérica a base de BisGMA/TEGDMA, o que pode justificar a redução da contração de polimerização e os valores expressivos de micro dureza, em relação 
aos Grupos de compósitos experimentais adicionados com a Sílica Aerosii ${ }^{\circledR}$ OX-50.

Pela metodologia $\mathrm{TIH} / \mathrm{HD} / \mathrm{Cl}$, concluiu-se que o deslocamento molecular causado pela contração de polimerização dos compósitos pode ser mensurado com o uso de corpos de prova de dentes naturais. O uso de dentes artificiais tornou-se inviável para a realização das análises, devido a expansão térmica sofrida pelas amostras durante o processo de fotopolimerização, característica observada igualmente pela análise da Termografia. Por essa metodologia também evidencia-se que os menores valores de deslocamento apresentados pelos compósitos experimentais adicionados com a nanopartícula Cloisite $30 \mathrm{~B}^{\circledR}$ relacionam-se à afinidade química sendo mais efetiva em relação aos compósitos adicionados com a nanopartícula Cloisite $10 \mathrm{~A}^{\circledR}$. Por outro lado, a nanopartícula Cloisite $10 \mathrm{~A}^{\circledR}$ tende a apresentar menor variação na termografia.

Ambos os métodos de mensuração da contração de polimerização são eficientes e demonstraram dependência do caráter e da natureza da carga inorgânica adicionada à matriz polimérica. 


\section{PERSPECTIVAS FUTURAS}

As metodologias TMA e $\mathrm{TIH} / \mathrm{HD} / \mathrm{Cl}$ deverão ser comparadas com metodologias já descritas na literatura, devido ao potencial que apresentaram em mensurar com precisão a contração de polimerização de compósitos fotoativados.

As nanopartículas argilominerais poderão ser adicionadas em outros tipos de matrizes poliméricas de uso odontológico, para que assim novos nano compósitos sejam obtidos.

Além da Cloisite $10 \mathrm{~A}^{\circledR}$ e Cloisite $30 \mathrm{~B}^{\circledR}$, que possuem o espaçamento basal "d" em torno de $18 \AA \AA$, outros tipos de nanopartículas argilominerais poderão ser adicionadas a matrizes poliméricas de uso odontológico, como a Cloisite $20 \mathrm{~A}^{\circledR}$, que além de possuir um maior espaçamento basal "d" (por volta de $24 \AA$ ), possui duas cadeias alifáticas em seu surfactante, o que the confere um grande potencial para intercalação e formação de nano compósitos com baixos valores de contração de polimerização e alto valor tecnológico.

Ambas as técnicas devem ser intensamente exploradas para mensurar os efeitos na contração de polimerização em resinas odontológicas podendo ser aplicadas a outros materiais relacionados. 


\section{BIBLIOGRAFIA}

1. ALEXANDRE, M.; DUBOIS, P. Polymer-layered silicate nanocomposites: preparation, properties and uses of a new class of materials. Materials Science and Engineering, v. 28, p. 1-63, 2000.

2. AMORE, R.; PAGANI, C.; YOUSSEF, MN; ANAUATE NETTO, C; LEWGOY, HR. Polymerization shrinkage evaluation of three packable composite resins using a gas pycnometer. Pesquisa Brasileira Odontológica, v.17, p. 273-7, 2003.

3. ARAÚJO, R.M. Influência da intensidade de luz de fotopolimerizadores na infiltração marginal. $\boldsymbol{A P C D}$, v. 50, p.5, 1996.

4. ASMUSSEN, E. Clinical relevance of physical, chemical and bonding properties of composite resins. Operative Dentistry, v. 10, p. 61-73, 1985.

5. ATAI, M.; WATTS, D.C. A new kinetic model for the photopolymerization shrinkage-strain of dental composites and resin-monomers. Dental Materials, v. 22, p. 785-791, 2006.

6. AW, T.C.; NICHOLLS, J.I. Polymerization shrinkage of densely-filled resin composites. Operative Dentistry, v. 26, p. 498-504, 2001.

7. BARATIERI L.B. Estética - Restaurações Adesivas Diretas em Dentes Anteriores Fraturados. Santos Livraria Editora - Quintessence Books -São Paulo; 1995.

8. BARBOSA, R. Morfologia de Nanocompósitos de Polietileno e Poliamida. Polímeros: Ciência e Tecnologia, vol.16, oㅜ, p. 246-251, 2006.

9. BERGER, S.B.; PALIALOL, A.R.M.; CAVALLI, V.; GIANNINI, M. Characterization of water sorption, solubility and filler particles of light-cured composite resins. Brazilian Dental Journal [on line], v. 20, n.4, 2009. 
10. BERTINI, F.; CANETI, M.; AUDISIO, G.; FALQUI, L. Characterization and thermal degradation of polypropylene-montmorillonite nanocomposites. Polymer Degradation and Stability, v.91, p.600-605, 2006.

11. BHARADWAJ R, K. Modeling the barrier properties of polymer-layered silicate nanocomposites. Macromolecules, v. 34, p. 9189-9192, 2001.

12. BOUILLAGUET S, GAMBA J, FORCHELET J, KREJCI I, WATAHA JC. Dynamics of composite polymerization mediates the development of cuspal strain. Dental Materials, v.22, p. 896-902, 2006.

13. BOUSCHLICHER, M.R.; VARGAS, M.A.; BOYER, D.B. Effect of composite type, light intensity, configuration factor and laser polymerization on polymerization forces. Journal of American Dental Association, v.10, n.2, p.88-96, 1997.

14. BOWEN, R.L.; EICHMILLER, F.C.; MARJENHOFF, W.A. Glass-ceramic inserts anticipated for "megafilled" composite restorations. Journal of American Dental Association, v.122, p. 71-75, 1991.

15. BRAGA, R.R.; FERRACANE, J.L. Alternatives in polymerization contraction stress management. Critical Reviews in Oral Biology \& Medicine, v.15, p.176-84, 2004.

16. BRAGA, R.R.; HILTON, T.J. Contraction stress of flowable composite materials and their efficacy as stress-relieving layers. Journal of American Dental Association, v. 134, p. 721-728, 2003

17. BROZEIT, A.; BURKE, J.; HELMERS, H. Active phase stabilization in speckle pattern interferometry without additional optical components. Jounal of Optics, v.173, p. 95-100, 2000. 
18. BRUG, H. Interferometry in optics research group - an overview. Proceedings of SPIE, p.4101:413, 2000.

19. BURKE, J.; HELMERS, H. Performance of spatial vs. temporal phase shifting in ESPI. Proceedings of SPIE, v.374, p.188-199,1999.

20. BURTSCHER, P. Stability of radicals in cured composite materials. Dental Materials, v. 9, p. 218.221, 1993.

21. CALHEIROS, FC.; SADEK, F.T.; BRAGA, R.R.; CARDOSO, P.E. Polymerization contraction stress of low-shrinkage composites and its correlation with micro leakage in class $V$ restorations. Journal of Dentistry, v. 32, p. 407-12, 2004.

22. CALLISTER, J.R. Ciência e Engenharia de Materiais: Uma Introdução. 5edição. Rio de Janeiro: LCT, 2003.

23. CAMPOS, J.C.R.; CORREIA, A.; VAZ, M.A.P.; BRANCO, F.J.M.B. Holographic Stress Analysis in a Distal Extesion Removable Partial Denture. European Journal of Prosthodontics and Restorative Dentistry, v. 17, p. 111115, 2009.

24. CARVALHO, R.M., et al. A review of polymerization contraction: the influence of stress development versus stress relief. Operative Dentistry, v.21, p.17-24, 1996.

25. CHRISTENSEN, R.P.; et al. Resin Polymerization problems - are they caused by resin curing lights, resin formulations, or both? Compendium of Continuing Education in Dentistry, v.20, p.42-54, 1999.

26. CHUNG, K.H.; GREENER, E.H. Correlation between degree of conversion, filler concentration and mechanical porpierties of posterior composites resins. Journal of Oral Rehabilitation, v.17, p. 487-94, 1990. 
27. CHUNG, C.M.; KIM, J.G.; KIM, M.S. Development a new photocurable composite resin with reduced curing shrinkage. Dental Materials, v.18, p. 174-178, 2002.

28. CLOUD GL. Optical methods of engineering analysis. Cambridge University Press, p. 441-491, 1998.

29. CONDON, J. R., FERRACANE, J. L. Polymerization contraction stress of commercial composites. Journal of Dental Research, v. 77, Special Issue, p. 639, 1998.

30. CONDON, J.R.; FERRACANE, J.L. Assessing the effect of composite formulation on polymerization stress. Journal of American Dental Association, v.101, p.497-503, 2000.

31. CONDON, J.R.; FERRACANE, J.L. In vitro wear of composite with varied cure, filler level and filler treatment. Journal of Dental Research, v.76, p.1405-11, 1997.

32. DAVIDSON, C.L. Handling Of polymerization stresses in composite restorations. In: $\mathbf{2}^{\text {nd }}$ International Symposium, Italy, p. 22-25, 1998.

33. DAVIDSON, C. L., DAVIDSON-KABAN, S. S. Hadling of mechanical stresses in composite restorations. Dental Uptade, v. 25, 274-279, 2000.

34. DAVIDSON, C.L.; DE GEE, A.J. Relaxation of polymerization contraction stresses by flow in dental composites. Journal of Dental Research, v. 63, p. 146148, 1984.

35. DAVIDSON, C.L; DE GEE, A.J. Light-curing units, polymerization and clinical implications. The Journal of Adhesive Dentistry, v. 2, p. 167-73, 2000. 
36. DAVIDSON, C.L.; FEILZER, A.J. Polymerization shrinkage and polymerization shrinkage stress in polymer-based restoratives. Journal of Dentistry, v. 25, p. 435440, 1997.

37. DAUVILLER, B.S.; ARRNTS, M.P.; FEILZER, A.J. Developments in shrinkage control of adhesive restoratives. Journal of Esthetic and Restorative Dentistry, v. 12, p. 291-299, 2000.

38. DE GEE, A.J; DAVIDSON, C.L; SMITH, A. A modified dilatometer for continuous recording of volumetric polymerization shrinkage of composite restorative materials. Journal of Dentistry, v.9, p.36-42, 1981.

39. DE GEE, A.F.; FEILZER, A.J.; DAVIDSON, C.L. True linear polymerization shrinkage of unfiller resins and composites determined with a linometer. Dental Materials, v. 9, p.11-14, 1993.

40. DICKENS, S.; STANSBURY, J.; CHOI, K.; FLOYD, C. Photopolymerization kinectis of methacrylate dental resins. Macromolecules, v. 36, p. 6043-53, 2003.

41. DISCACCIATI, J. A. C., NEVES, A.D., ORÉFICE, R. L., PIMENTA, F. J. G. S., SANDER, H. H. Effect of ligth intensy and irradiation time on the polymerization process of a dental composite resin. Materials Research, v. 7, n. 2, p. 313-318, 2003.

42. DISCACCIATI, J. A. C., ORÉFICE, R. L. Processing structural evolution and properties of dental composites havig layared silicate nanoparticles. Proceedings of the Polymer Americas Regional Meeting, v. 1, p. 42-43, 2004.

43. DISCACCIATI, J. A. C. Síntese, evolução estrutural e propriedades de polímeros modificados por nanocomponentes minerais para aplicação odontológica. (Tese de doutorado), UFMG, 2005.

44. DURAN, N. Nanotecnologia: Introdução, Preparação e Caracterização de Nanomateriais e Exemplos de Aplicação. São Carlos: Artiber, 2006. 
45. EStRELA, C. Metodologia Científica- Ensino e Pesquisa em Odontologia. São Paulo, Artes Médicas, 2001.

46. FAN, L. P. Visible light - cured composites and activanting units. Journal of American Dental Association, v. 110, p. 100-103, 1985.

47. FERRACANE, J.L. Developing a more complete understanding of stresses produced in dental composites during the polymerization. Dental Materials; v. 21, p.36-42, 2005.

48. FEILZER, A.J. Curing contraction of composite and glass-ionomer cements. Journal of Prosthetic Dentistry, v.59, p.297-300, 1998.

49. FEILZER A.J.; DAUVILLIER, B.S. Effect of TEGDA/BisGMA ratio on stress development and viscoelastic properties of experimental two-paste composites. Journal of Dental Research, v. 82, p. 824-828, 2003.

50. FEILZER, A.J., DE GEE, A.J. DAVIDSON, C.L. Increased wall-to-wall curing contraction in thin bonded resin layers. Journal of Dental Research, v.68, p.48-50, 1989.

51. FEILZER, A.J.; DE GEE, A.J.; DAVIDSON, C.L. Setting stresses in composites for two different curing modes. Dental Materials, v. 9, p. 2-5, 1993.

52. FEILZER, A.J.; DE GEE, A.J.; DAVIDSON, C.L. Setting stresses in composite resin in relation to the configuration of the restoration. Journal of Dental Research, v.66, p. 1636-1639, 1987.

53. FEILZER, A.J.; DE GEE, A.J.; DAVIDSON, C.L. Quantitative determination os stress reduction by flow in composite restoration. Dental Materials, v.6, p. 167-171, 1990. 
54. FRANCO, E.B; LOPES L.G. Conceitos atuais na polimerização de sistemas restauradores resinosos. Biodonto, v. 2, p. 50-61, 2003.

55. FORNES, D.R.P. Crystallization Behavior of nylon 6 nanocomposite. Polymer, v.44, p. 3945-3961, 2003.

56. FOURNARIS, K. G., BOUKOS, N., PETRIDIS, D. Aqueous polymerization of protonated 4-vinylpyridine in montimorillonite. Applied Clay Science, v. 19, p. 77-88, 2001.

57. FU, X.A.; QUTUBUDDIN, S.A. Swelling Behavior of Organoclays in Styrene and Exfoliation in Nanocomposites Based on Ed-Functionalized Homopolymer and Block Copolymer. Macromolecules, v.38, p. 8414-8429, 2005.

58. FUSAYAMA, T. Posterior composite resin: a historic review. The Journal of Prosthetic Dentistry, v. 64, p. 534-538, 1990.

59. GILMAN, J.W. Flammability and thermal stability studies of polymers layeredsilicate clay nanocomposites. Applied Clay Sciense, v. 15, p.31-49, 1999.

60. GONÇALVEZ, F., AZEVEDO, C.L.N., FERRACANE J.L., BRAGA, R.R. BisGMA/TEGDMA ratio and filler content effects on shrinkage stress. Dental Materials, v. 27,p. 520-526, 2010.

61. GU, S.; REN, J., WANG, Q. Journal Applied Polymer Science, v.91, p.2427, 2004.

62. GUIMARÃES, T.R; MORALES, A.R.; PAIVA, L.B. Nano compósitos de propileno e montmorilonita: caracterização estrutural, morfológica e de opacidade. Anais Congresso Brasileiro de Engenharia e Ciência, v.17, 2006.

63. HALVORSON, R.H.; ERICKSON, R.L.; DAVIDSON, C.L. Energy dependente polymerization of resin-based composite. Dental Materials, v. 18, p. 463-469, 2002. 
64. HANSEN, E.K.; ASMUSSEN, E. Cavity preparation for restorative resins used with dentin adhesives. Scandinavian Journal of Dental Research, v. 93, p. 474479, 1985.

65. HECTH, E. Hecth Optics. Addison Wesley Publishing Co. 2a Edição, p.333$391,1987$.

66. HIRATA, R., MAZZETTO, A. H., YAO, E. Alternativas clínicas de sistemas de resinas compostas laboratoriais- quando e como usar. Jornal Brasileiro de Clínica \& estética em Odontologia, v.4, p. 13-21, 2003.

67. JACKSON, M.L. Soil Chemical Analysis Advanced Course. 2ª Edição, Madison Wis, 1985.

68. JOENATHAN, C.; et al. Speckle Interferometry with Temporal Phase Evaluation: Influence of Decorrelation, Speckle size and non-linearity of the Camera. Applied Optics, v. 38, p.1169-1178, 1999.

69. KARABELLA, M.M.; SIDERIDOU, I.D. Synthesis and study of properties of dental resin composites with different nanosilica particles size. Dental Materials, v. 27, p. 825-835, 2011.

70. KAPP, V.A. Otimização do desempenho metrológico do sistema de medição da estação holográfica. (Dissertação de mestrado). Universidade Federal de Santa Catarina, Florianópolis, 1998.

71. KELLY, P., AKELAH, A., QUTUBUDDIN, S., MOET, A. Reduction of residual stress in montmorillonite/epoxy compounds. Journal of Materials Science, v. 29, p. 2274-2280, 1994.

72. KEMP-SCHOLTE, C.M.; DAVIDSON, C.L. Complete marginal seal of Class V resin composite restorations affected by increased flexibility. Journal of Dental Research, v. 69, p. 1240-1243, 1990. 
73. KENJI, TAMURA, S.Y.; CHELO, S. P.; HIROHISA, Y. New age of polymer nanocomposites containing dispersed high-aspect-ratio silicate nanolayers. Chemestry of Materials, v. 20, p.2242-2246, 2008.

74. KICKELBICK, G. Concepts for the incorporation of inorganic building blocks into organic polymers on nanoscale. Progress in Polymer Science, v. 28, p.83-114, 2008.

75. KISHEN, A.; MURUKESHAN, V.M.; KRISHNAKUMAR, V.; ASUNDI, A. Analysis on the nature of thermally induced deformation in human dentine by electronic speckle pattern interferometry (ESPI). Journal of Dentistry, v. 29, p. 531537, 2009.

76. KINOMOTO, Y. Polymerization contraction stress of resin composite restorations in a model class I cavity configuration using photoelastic analysis. Journal of Esthetic and Restorative Dentistry, v. 12, p. 309-19, 2000.

77. KINOMOTO, Y.; TORII, M. Photoelastic analysis of polimeryzation contraction stress in resin composite restorations. Journal of Dentistry, v. 26, p. 165-171, 1998.

78. KLEVERLAAN, C.J.; FEILZER, A.J. Polymerization shrinkage and contraction stress of dental resin composites. Dental Materials, v. 21, p.11501157, 2005.

79. KOBAYASHI, A.S. Handbook on experimental mechanics. Society for Experimental Mechanics Inc. Prentice Hall, 1989.

80. KOLENOVIC, E.; OSTEN, W.; JUPTNER, W. Influence of unresolved speckles in interferometric phase measurements. Proceeding of SPIE, v. 41, p.104-112. 2000

81. KORNMANN, X. Synthesis and Characterization of Thermoset Clay Nanocomposites. Lulea Tekniska Universite, 1999. 
82. KOO, JH. Polymer Nanocomposites - Processing, Characterization and Applications. McGaw-Hill Professional, 2006, 1ํeição.

83. LANG, H.; RAMPADO, M.; MULLEJANS, R.; RAAB, W.H.M. Determination of the Dynamics of Restored Teeth by 3D Electronic Speckle Pattern Interferometry. Laser in Surgery and Medicine, v. 34, p. 300-309. 2004

84. LAMBRECHTS, P., BRAEM, M.; VANHERLE, G.; BUONOCORE. Evaluation of clinical performance for posterior composite resins and dentin adhesives. Operative Dentistry, v. 12, p. 53-78, 1987.

85. LOVELL, L.G.; NEWMAN, S.M; BOWMAN, C.N. The effects of light intensity, temperature and monomer composition on the polymerization behavior of dimethacrylate dental resins. Journal of Dental Research, v.78, p.1469-76, 1999.

86. LI, Y.; et al. Effect of filler content and size on properties of composites. Journal of Dental Research, v.64, n.12, p.1396-491, 1985.

87. LIU, L.Z.Q.; XIAOGUANG, Z. Studies on nylon-6-nanoclay nanocomposites by melt intercalation process. Journal of Applied Polymer Science, v. 71, p.11331138, 1990.

88. LU, H.; STANSBURY, J.W.; BOWMAN, C.N. Impact of curing protocol conversion and shrinkage stress. Journal of Dental Research, v. 84, p. 822-826, 2005.

89. LU, H.; STANSBURY, J.W.; BOWMAN, C.N. Towards the elucidation of shrinkage stress development and relaxion in dental composites. Dental Materials, v. 20, p. 979-986, 2004.

90. LUTZ, F.; KREJCI, I.; BARBAKOW, F. Quality and durabillity of marginal adaptation in bonded composite restorations. Dental Materials, Kansas, v. 7, n.2, pp. 107-113, 1991. 
91. MARCHINI, L., SANTOS, J. F. F., CUNHA, V. Polímeros de vidro, características e aplicações clínicas. Jornal Brasileiro de Clínica \& estética em Odontologia, v.4, n.19, p.38-41, 2000.

92. MARKARIAN, J. Wood-plastic composites: current trends in materials and processing. Plastics, Additives and Compounding, v. 7, p. 20-26, 2005.

93. MEHL, A.; HICKEL, R.; KUNZELMANN, K.H. Physical properties and gap formation of light-cured composites with and without soft start polymerization. Journal of Dentistry, v. 25, p. 321-330, 1997.

94. MERINSKA, D.; MALAC, Z.; POSPISIL, M.; WEISS, Z.; CHMIELOVA, M.; CAPKOVA, P.; SIMONIK, J. Comp Interf, v. 9, p. 529, 2002.

95. MICHAEL, A.P.D. Polymer-layered silicate nanocomposites: preparation, properties and uses of a new class of materials. Materials Science and Engineering, v. 28, p. 61-63, 2000.

96. MONTEIRO, J,; LOPES, H.M.; VAZ, M.A.P.; CAMPOS, L.M.P.; VASCONCELOS, M.R.; CAMPOS, J.C.R. Estudo do comportamento mecânico dos compósitos de restauro dentário utilizando técnicas ópticas. Anais do $4^{\circ}$ Congresso Nacional de Biomecânica- Coimbra, p. 131-135, 2011.

97. MURRAY, H.H. Traditional and new applications for kaolin, smectite and palyorskite: a general overview. Applied Clay Science, v. 17, p. 207-221, 2000.

98. NAGEL, R. Operation and diagnostic features of the VIP light. Compend Continuing Education Dental Supply, v. 25: S55-9, 1999.

99. NAVARRETE, N.; TORRES, F.; VERA-GRAZIANO, R. VILLAGRÁN-MUNIZ, $M$. The evolution of the longitudinal moculus during the photo-polymerizationof a BisGMA/TEGDMA resin by pulsed photoacoustic technique. The Journal of Physical Chemistry, v.125, p.749-751, 2005. 
100. OCHOA, N.A, et al. Contrast enhancement of electronic speckle pattern interferometry addition fringes. Applied Optics, v.36, n.13, 1997.

101. PAIVA, L.B, et. al. Organophilic clays: characteristics, preparation methods, intercalation compounds and characterization techniques. Cerâmica, v. 54, p. 213226, 2008.

102. PARK, S.H.; KREJCI, I.; LUTZ, F. Microhardness of resin composite polymerized by Plasma ARC or conventional visible light curing. Operative Dentistry, v. 27, p. 30-37, 2002.

103. PARK, J.H.; PARK, J.H.; JANA, S.C. Mechanism of exfoliation of nanoclay particles in epoxy-clay nanocomposites. Macromolecules, v.36, p. 2758-2768, 2003.

104. PEREIRA, R.A.; ARAÚJO, P.A.; CASTAÑEDA-ESPINOSA, J.C.; MONDELLI, R.F.L. Comparative analysis of the shrinkage stress of composite resins. Journal of Applied Oral Sciences, v.16, p. 30-34, 2008.

105. PEUTZFELD, T.A. Resins Composites in Dentistry: the monomer systems. European Journal of Oral Sciense, v.105, p. 97-116, 1997.

106. PUCKETT, A.D.; SMITH, R. Methods to measure the polymerization shrinkage of light-cured composites. Journal of Prosthetic Dentistry, v. 68, p. 56-8, 1992.

107. PURDELL-LEWIS, D.J.; GROENEVELD, A.; ARENDS, J. Hardness tests on sound enamel and artificially demineralized white spot lesions. Caries Research, v. 10, p. 201-215, 1976.

108. QIN, H.; ZHANG, S.; LIU, H.; XIE, S.; YANG, M.; SHEN, D. Polymer, v.46, p.3149, 2005.

109. RAY, S.; OKAMOTO, M. Polymer/Layered Silicate Nanocomposites: A Review from Preparation to Processing. Progress in Polymer Sciense, v.28, p.1539, 2003. 
110. REED, B.; DICKENS, B.; DICKENS, S.; PARRY, E. Volumetric contraction measured by a computer-controlled mercury dilatometer. Journal of Dental Research, vol. 75, p. 2184, 1996.

111. REES, J.S.; JACOBSEN, P.H. The polymerization shrinkage composite resins. Dental Materials, v. 5, p. 41-44, 1989.

112. ROBINSON, D.W.; REID, G.T. Interferogram Analysis. Ed. Institute of Physics Publishing, Bath, Great Britain,1993.

113. ROSIN, M.; URBAN, A.D.; GARTNER, C.; BERNHARDT, O.; SPLIETH, C.; MEYER, G. Polymerization shrinkage-strain and microleakage in dentin-bordered cavities of chemically and light cured restorative materials. Dental Materials, v. 18, p. 521-8, 2002.

114. RUEGGEBERG, F.A. Contemporry issues in photocuring. Compendium of Continuing Education in Denstitry, Suppl.25: S4-S15, 1999.

115. RUEGGEBERG, F.A. From vulcanite to vinyl, a history of resins in restorative dentistry. Journal of Prosthetic Dentistry, v. 87, p. 364-379, 2002.

116. RUEGGEBERG, F.A. Spectral irradiance of contemponary photo-curing units. Journal of Dental Research, v. 79, p.333, 2000.

117. RUEGGEBERG, F.A., JORDAN, D.M. Effect of light-tip distance on polymerization of resin composite. International Journal of Prosthodontic, v. 6. P. 364-370, 1993.

118. RUYTER, I.E.; NILNER, K.; MOLLER, B. Color Stability of dental composite resin materials for crown and bridge veneer. Dental Materials, v. 21, p. 246-251, 1987. 
119. RUYTER, I.E.; SVENDSEN, S.A. Remaining methacrylate groups in composite restorative materials. Acta Odontologica Scandinavica, v. 2, p. 75-82, 1978.

120. SAKAGUCHI, R.L.; BERG, H.X. Reduced light energy density decrease postgel contraction while maintaining degree of conversion in composites. Journal of Dentistry, v. 26, p. 695-700, 1998.

121. SAGAKUCHI, R.L. DOUGLAS, W.H. Strain gauge measurement of polymerization shrinkage. Journal of Dental Research, v. 68, p. 977, 1989.

122. SAKAGUCHI, R.L. DOUGLAS, W.H., PETERS, M.C.R.B. Curing light performance and polymerization of composite restorative materials. Journal of Dentistry, v. 20, p. 183-188, 1992.

123. SAKAGUCHI, R.L.; WILTBANK, B.D.; SHAH, N.C. Critical configuration analysis of four methods for measuring polymerization shrinkage strain of composites. Dental Materials, v. 20, p. 388-96, 2004.

124. SALAHUDIN, N.; SHEHATA, M. Polymerization-montmorillonite composites: preparation, characterization and properties. Polymer, v.42, n. 20, p. 8379-8385, 2001.

125. SANTOS, P.S. Ciência e Tecnologia de argilas. 2ª Edição, São Paulo, Editora Edgard Blucher, p.68-69, 1989.

126. SESSELMAN, M. Interferômetros robustos aplicados à medição de deslocamentos radiais em cilindros internos usando holografia eletrônica. (Tese de doutorado). Universidade Federal de Santa Catarina, 2000.

127. SIDERIDOU, I.C.; TSERKI, V.; PAPANASTASIOU, G. Effect of chemical on degree of conversion in light-cured dimethacrylate-based dental resins. Biomaterials, v. 23, p. 1819-1829, 2002. 
128. SOARES, L.E.S. Espectroscopia Raman no Infra Vermelho (IVP) e Microdureza Vickers no Estudo do Grau de Conversão de Resinas Compostas Polimerizadas com Laser de argónio e Lâmpada Halógena. (Dissertação de Mestrado). Universidade do Vale do Paraíba, 2002.

129. STANSBURY, J.W. Synthesis and evaluation of new monomers for double ring-opening polymerization. Journal of Dental Research, v. 71, p. 1408-1412, 1992.

130. StAnSBURY, J.W.; TRUJILlO-LEMON, M.; DING, X.; GE, J. Conversiondependent shrinkage stress and strain in dental resins and composites. Dental Materials, v. 21, p.56-67, 2005.

131. SUN-HONG, M., FERRACANE, J.L.; IN-BOG, L. Effect of shrinkage strain, modulus, and instrument compliance on polymerization shrinkage stress of lightcured composites during the initial curing stage. Dental Materials, v. 26, p. 10241033, 2010.

132. SUPRAKAS, S.R.M.O. Polymer/layered silicate nanocomposite: a review from preparation to processing. Progress in Polymer Science, v. 28, p.1539-1641, 2003.

133. TAYLOR, D.F.; et.al. Relationship between filler and matrix resin characteristics and properties of uncured composite pastes. Biomaterials, v.19, p. 197-204, 1998.

134. TRANCOSO, L.H,S. Sistema ativo de estabilização para medição com holografia eletrônica. (Tese de doutorado). Universidade Federal de Santa Catarina, Florianópolis, 1998.

135. TOUATI, N.; KACl, M.; AHOUARI, H.; BRUZAUD, S.; GROHENS, Y. The Effect of Gama Irradiation on the Structure an Properties of Poly(propylene)/Clay Nanocomposites. Macromolecular Materials Engineering, v.292, p. 1271-79, 2007. 
136. UNTERBRINK, G.L.; MUESSNER, R. Influence of light intensity on two restorative systems. Journal of Dentistry, v. 23, p. 183-189, 1995.

137. UTRACKI, L.A. Clay Containing Polymeric Nanocomposite. Smithers Rapra Technology, vol. 1. 2009.

138. VAIA, R.A.; JANDT, K.D.; KRAMER EJ. Kinetics of Polymer Melt Intercalation. Macromolecules, v.28, p.8080-8085, 1995.

139. VAN NORT, R. Introduction to Dental Materials. London, Mosby, p.89-104, 2005.

140. VANDEWALLE, K.S.; FERRACANE, J.L.; HILTON, T.J.; ERICKSON, R.L.; SAKAGUCHI, R.L. Effect of density on properties and marginal integrity of posterior resin composite restorations. Dental Materials, v. 20, p. 96-106, 2004.

141. VENHOVEN, B.A.; et al. Influence of filler parameters on the mechanical coherence of dental restorative composites. Biomaterials, v.17, p. 735-40, 1996.

142. VENHOVEN, B.A,; DE GEE, A.J.; DAVIDSON, C.L. Polymerization contraction and conversion of light-curing BisGMA-based methacryate resins. Biomaterials, v. 14, p. 871-5, 1993.

143. VERLUIS, A.; DOUGLAS, W.H.; CROSS, M.; SAKAGUCHI, R.L. Does an incremental filling technique reduce polymerization shrinkage stresses? Journal of Dental Research, v. 75, p. 871-878, 1996.

144. WANG, S. Biopolymer chitosan/montmorillonite nanocomposites: Preparation and characterization. Polymer Degradation Stability, v. 77, p.423, 2002.

145. WATTS, D.C.; CASH, A.J. Determination of polymerization shrinkage kinetics in visible-ligth cured materials: methods development. Dental Materials, v. 7, p. 2817, 1991. 
146. WATTS, D.C.; AL HIND, A. Intrinsic "soft-start" polymerization Shrinkagekinetics in an acrylate-based resin-composite. Dental Materials, v. 15, p. 39-45, 1999.

147. WeinMAMM, W.; THALACKER, C.; GUGGENBERGER, R. Siloranes in dental composites. Dental Materials, vol. 21, p, 68-74, 2005.

148. WILLEMAN, D.P. Desenvolvimento de uma roseta óptica para medição de tensões e deformações usando holografia electrónica. (Dissertação de mestrado). Universidade Federal de Santa Catarina, Florianópolis, 2002.

149. WILLEMS, G.; et al. Composite resins in the $21^{\text {st }}$ century. Quintessence Tnt, v.24, p. 641-58, 1993.

150. YIU, W.; ZHONG, Z. Polymer Nanocomposites. Cambrigde and New York: Woodhead Publishing Limited and CR Press, 2006.

151. ZANETTI, M.; COSTA, L. Polyamide 6/organoclay nanocomposites: effect of matrix molecular weight on structure and mechanical and thermal-mechanical properties. Polymer; v. 45, p. 4367-73, 2004.

152. ZHANG, Y.Q.; LEE, J.H.; RHEE, J.M.; RHEE, K.Y. Preparing PP/clay nanocomposites using a swelling agents. Composite Science and Technology, v. 64, p.1383-1388, 2004.

153. ZHOU, Y.; RANGARI, V.; MAHFUZ, H.; JEELANI, S.; MALLICK, P. Materials Science Engineering, v.402, p.109, 2005. 